University of Montana

ScholarWorks at University of Montana

Graduate Student Theses, Dissertations, \&

Professional Papers

1999

\title{
Men's experience of making the decision to have their first child: A phenomenological analysis
}

Andrew Peterson

The University of Montana

Follow this and additional works at: https://scholarworks.umt.edu/etd

Let us know how access to this document benefits you.

\section{Recommended Citation}

Peterson, Andrew, "Men's experience of making the decision to have their first child: A phenomenological analysis" (1999). Graduate Student Theses, Dissertations, \& Professional Papers. 10563.

https://scholarworks.umt.edu/etd/10563

This Dissertation is brought to you for free and open access by the Graduate School at ScholarWorks at University of Montana. It has been accepted for inclusion in Graduate Student Theses, Dissertations, \& Professional Papers by an authorized administrator of ScholarWorks at University of Montana. For more information, please contact

scholarworks@mso.umt.edu. 


\section{INFORMATION TO USERS}

This manuscript has been reproduced from the microfilm master. UMI films the text directly from the original or copy submitted. Thus, some thesis and dissertation copies are in typewriter face, while others may be from any type of computer printer.

The quality of this reproduction is dependent upon the quality of the copy submitted. Broken or indistinct print, colored or poor quality illustrations and photographs, print bleedthrough, substandard margins, and improper alignment can adversely affect reproduction.

In the unlikely event that the author did not send UMI a complete manuscript and there are missing pages, these will be noted. Also, if unauthorized copyright material had to be removed, a note will indicate the deletion.

Oversize materials (e.g., maps, drawings, charts) are reproduced by sectioning the original, beginning at the upper left-hand corner and continuing from left to right in equal sections with small overlaps. Each original is also photographed in one exposure and is included in reduced form at the back of the book.

Photographs included in the original manuscript have been reproduced xerographically in this copy. Higher quality $6^{n} \times 9^{n}$ black and white photographic prints are available for any photographs or illustrations appearing in this copy for an additional charge. Contact UMI directly to order.

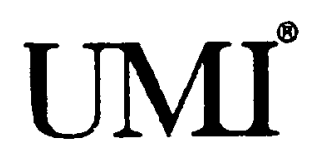

Bell \& Howell Information and Learning 300 North Zeeb Road, Ann Arbor, MI 48106-1346 USA 800-521-0600 
Reproduced with permission of the copyright owner. Further reproduction prohibited without permission. 


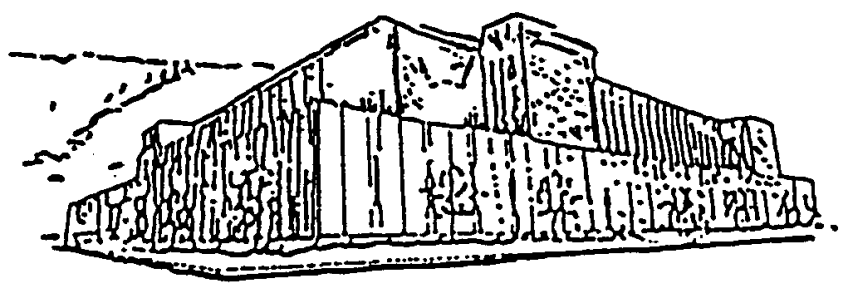

\section{Maureen and Mike \\ MANSFIELD LIBRARY}

The University of MONTANA

Permission is granted by the author to reproduce this material in its entirety, provided that this material is used for scholarly purposes and is properly cited in published works and reports.

** Please check "Yes" or "No" and provide signature **

Yes, I grant permission

No, I do not grant permission

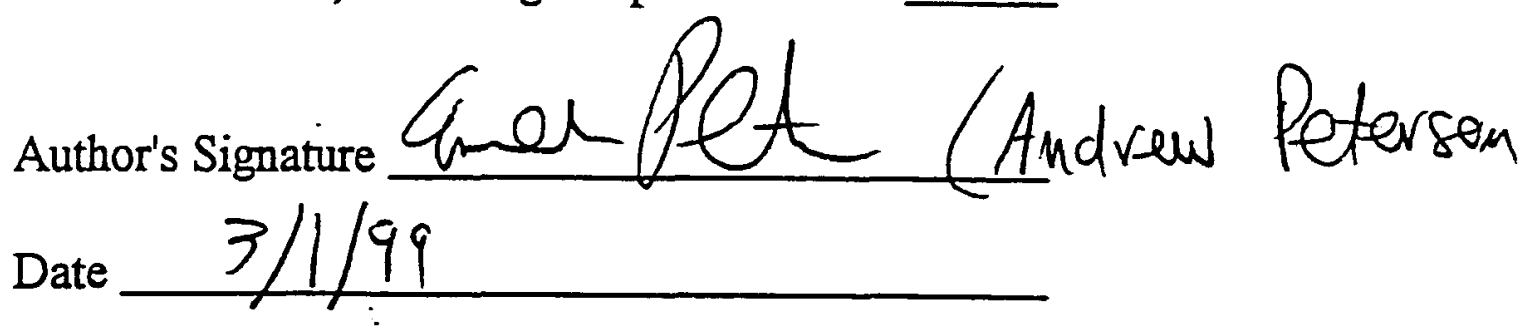

Any copying for commercial purposes or financial gain may be undertaken only with the author's explicit consent. 


\title{
MEN'S EXPERIENCE OF MAKING THE DECISION
}

TO HAVE THEIR FIRST CHILD:

\section{A PHENOMENOLOGICAL ANALYSIS}

\author{
by \\ Andrew Peterson \\ presented in partial fulfillment of the requirements \\ for the degree of \\ Doctor of Education \\ The University of Montana
}

1999

Approved by:

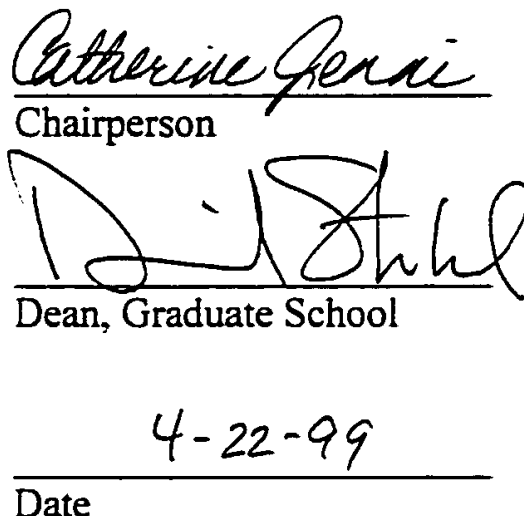


UMI Number: 9937462

Copyright 1999 by Peterson, Andrew L.

All rights reserved.

UMI Microform 9937462

Copyright 1999, by UMI Company. All rights reserved.

This microform edition is protected against unauthorized copying under Title 17, United States Code. 
Men's Experience of Making the Decision to Have Their First Child: A Phenomenological Analysis (412 pp.)

Director: Catherine Jenni $C g$

This dissertation presents the results of a qualitative analysis of men's experience of making the decision to have their first child. Using phenomenological research methods. this study draws directly upon descriptions of that experience as it was lived by six men who had recently made the decision to become fathers. Unstructured interviews were conducted to gain a spontaneous account of the experience. These interviews were analyzed using a process of phenomenological reduction in order to arrive at an essential description of the experience.

Through this analysis. this study sought to identify. the essential components of a man's experience of making the decision to have his first child. What meaning does a man assign to his decision to bring a child to life? What does the role of father mean to him? What motivates his decision to have a child and what factors cast it into doubt? What is the process by which he comes to some resolution of his ambivalent feelings?

The essential description that resulted from this analysis revealed a set of interlocking themes which manifested themselves within a dynamic. dialectical. self-modifying process. In this process men move from a logical analysis of comparing the cost and value of having a child toward an awareness of their inability to arrive at a rational understanding of the meaning of this decision. This in turn leads them to an awareness of the existential givens underlying the nature of the decision and finally to decision which abandons logical processes in favor of a leap of faith. 
Chapter One: Introduction

Chapter Two: Literature Review $\quad 8$

The Demographic Context 9

Motivation for Reproduction 11

The Development of the Wish for a Child 12

Socialization for Parenthood $\quad 17$

The Value and Cost of Children 19

Adult Development and Generativity 23

Making the Decision to Become a Father 25

The Decision Within the Couple 25

Are Reproductive Decisions Truly Decisions? $\quad 27$

The Experience of Making the Decision 30

The Transition to Fatherhood 32

Treatment and Clinical Issues $\quad 34$

Chapter Three: Method 37

Overview of the Phenomenological Method 37

Evaluation Criteria $\quad 42$

Rationale for a Phenomenological Approach $\quad 44$

Procedure $\quad 46$

Subject Selection $\quad 46$

Pilot Interviews $\quad 49$

Characteristics of the Sample 51

The Interviewer $\quad 52$

Data Collection: The Interviews 53

Data Analysis: A Description of Phenomenological Reduction 55

Chapter Four: Data Analysis and Results $\quad 59$

Level Five: Fundamental Description of Men's Experience of

Making the Decision to Have their First Child 70

Level Six: Essential Description of Men's Experience of

Making the Decision to Have their First Child 73

$\begin{array}{ll}\text { Chapter Five: Discussion } & 74\end{array}$

General Themes: Men's Experience in Deciding to Have their First Child 74

A Decision Ambivalently Made $\quad 75$

Accepting the Limitations of Personal Control $\quad 78$ 
Coming to Terms with the Permanence of Change 81

Embracing Change $\quad 85$

Coming into the Present Moment 88

Constructing a Paternal Identity 91

Separate and Together: Integrating Self and Marriage 94

The Decision as an On-Going Process 97

$\begin{array}{ll}\text { Summary } & 101\end{array}$

General Considerations and a Diaiogue with the Literature 103

Subjects and Samples 104

$\begin{array}{ll}\text { Gender } & 107\end{array}$

$\mathrm{I}$ and We $\quad 108$

Those Who Say No 109

Generativity 111

Stages of the Decision 113

Existential and Experiential Factors $\quad 117$

$\begin{array}{ll}\text { Chapter Six: Implications } & 119\end{array}$

Implications for Therapy 119

Individual Therapy with Men 120

Couples Therapy 126

Groups 127

Implications for Parent Educators and Reproductive Health Workers $\quad 128$

$\begin{array}{ll}\text { Need for Further Research } & 129\end{array}$

$\begin{array}{ll}\text { Chapter Seven: Summary and Conclusions } & 134\end{array}$

$\begin{array}{ll}\text { References } & 138\end{array}$

Appendix A: Frank: Data Analysis, Levels 1-4 148

Appendix B: Dylan: Data Analysis. Levels 1-4 198

Appendix C: Nathan: Data Analysis, Levels 1-4 243

Appendix D: Tobin: Data Analysis, Levels 1-4 286

Appendix E: Evan: Data Analysis, Levels 1-4 329

Appendix F: Abe: Data Analysis, Levels 1-4 358 


\section{Chapter One}

\section{Introduction}

We know too little about men's experience of family life.

For many years fathers have been seen essentially as peripheral players in family life whose role rarely extended beyond the function of provider. This perception has been slowly evolving in recent years. The rise of the men's movement is indicative of a gradual and somewhat awkward cultural movement toward an increased awareness of the fact that men's interior, emotional lives are more rich and complex than we have previously allowed. One aspect of this cultural evolution is that we are paying more attention to the vital role that fathers play in intimate family life.

Still, we are essentially in the dark with regard to some of the most basic questions about men's lived experience as potential and actual fathers. What meaning does a man give to his decision to assume the responsibility of fathering a child? What significance does he assign to the role of father? How does he experience the transition to fatherhood? And how does he live this role once he has decided to take it on?

Our difficulty answering these questions reflects the degree to which men's experience of family life is uncharted territory for psychological researchers. While research in this area has gradually begun to expand, we continue to be burdened by the reality that most research on reproductive decision-making, the transition to parenthood and childrearing practices has focused almost entirely on the reports of women.

We are not merely feeling our way in the dark with regard to questions about men's experience, we are operating on assumptions which are inhibiting our ability to see clearly the landscape of contemporary family life. Acting in the best interests of families 
requires re-thinking the role of father, looking freshly at men's experience in that role. challenging our assumptions about fatherhood with the actual descriptions of the experience which men give us.

Fein $(1978$, p. 328$)$ suggests that a consideration of men's experiences as parents "leads to reassessment of deeply held assumptions about the nature of family life." Similarly, Jessner, Weigert and Foy (1970. pp. 230-231) point out that the idea of fatherhood itself is "to a great extent still covered with the dust of stereotypes and convention." These stereotypes, they claim, contain several genuine elements of a man's experience in becoming a father, but they also present the father as "a slightly comical figure" in the drama of parenthood whose principal role has little effect on his interior life.

Making an argument which is an underlying premise of this research project. Cohen (1987, p. 73) claims that "men's lives may contain greater attachments to, and be more profoundly affected by, marriage and fatherhood than is usually assumed." Cohen writes that the men he studied experienced their lives being "remade" by their marital and parental roles, as "new responsibilities were incorporated into their lives. old activities took on different meanings, self-concepts and priorities were recast." He points out that many of these changes are not observable in men's outward behavior, "but were nonetheless very real consequences of becoming husbands and fathers".

A primary goal of this project is to render visible the inner transformation which men experience in making the decision to have a child. This is a more difficult task than it might at first seem. It is one which works against deeply entrenched assumptions about 
gender roles, assumptions which make it difficult even to ask the sorts of questions which this project poses. Gutmann (1975, p. 169), for instance, states:

We readily assume that parenthood stimulates powerful "maternal" instincts leading to unselfish nurturance in normal women; but we also tend to believe that the male response is less reliable, less instinctually based, and that men even have to be coaxed and coerced into accepting parental responsibilities. On examination, matters prove to be more complex.

This assumption is evident in the slightly puzzled reaction which the topic of this research initially draws. The fact that the question of men's experience in reproductive decision-making is one which few people have considered appears to conceal an underlying assumption that men have little or no role in reproductive decisions and that their feelings in this matter are of little consequence. This attitude corresponds, of course, to the equally outdated but still powerful notion that women bear primary responsibility both for making reproductive decisions and for the intimate care of young children.

Such assumptions do a disservice to the wide range of experience which both men and women have as parents. They become self-fulfilling prophecies as men who attempt to move beyond traditional gender roles in family life encounter little social support and are commonly confronted with negative stereotypes. Men look to the culture and find few if any images of other men who are actively involved in making reproductive decisions or even in the nurturing of children. The portraits of men as bumbling caretakers in films like "Mr. Mom" (Colomby, Shuler-Donner, \& Dragoti, 1983) and "Three Men and a Baby" (Cort, Field, \& Nimoy, 1987) do a disservice to men's efforts to occupy this role 
authentically. "The implications of many such films," write Lupton and Barclay (1997. p.69), "is that the spectacle of a grown man taking on the duties of caring for a child is amusing in its incongruity." For some, if not most men, the social awkwardness involved in crossing this role boundary amounts to an encouragement to remain silent. a reward for adhering to gender stereotypes. They are encouraged to suppress their awareness of their own experience. Yet as the research presented here demonstrates, when men are asked directly about their experience of making the decision to become a father, they have much to say.

My personal experience in making this decision has played a significant role in shaping both my perception of this issue and my motivation for exploring it further. I began this project not long after I gave birth to my own first child. I was acutely aware of the highly ambivalent feelings that I had experienced in attempting to decide whether or not I was capable of becoming a father. For me, making this decision was a highly conscious, intentional process. Having never assumed that I should or would have a child, I took little for granted. I interrogated my motivations for both having and not having a child. I struggled to make sense of what it meant to become a father, to comprehend the changes that such a decision would bring.

As I quickly discovered. these are somewhat delicate questions to bring up in polite conversation. Few people, it seem, are interested in entertaining the perfectly reasonable possibility that parenthood for some might be a negative experience. Many people gladly shared with me the positive aspects of their experience of becoming parents, but there were few with whom I could honestly express my fears and doubts, my reluctance to take on a responsibility whose significance I could barely comprehend. 
It puzzled me that I could not find my personal debate echoed anywhere in the culture. I was highly aware of the temptation simply to remain silent about my experience. But this struck me as a choice which could have significant implications. If. in making the decision to have a child it was necessary to repress our unresolved doubts. the impact on how I felt about and raised my child could potentially be profound. As I considered my choice to become a parent, I came to recognize that the ability to express my fears, my regret and even my grief about becoming a parent was an essential component in being able to become the sort of father to my child that I wished to be.

This research takes the stance that just as women's expression of economic and political power has been largely silenced in our culture. so has men's expression of their interior emotional lives. Because these gender role expectations are so deeply entrenched. efforts to give voice to men's experience of intimacy and connectedness in family life is as problematic in its way as has been feminism's struggle to give voice to women's need for social power. The cultural structures which mitigate against this awareness have come to seem natural, unassailable. We can barely recognize them for the social constructions that they are. Working against these assumptions requires an active. conscious effort.

In making the decision to become parents, partners face the collusion of both male and female gender role expectations. While in many ways men and women experience reproductive decision-making differently (Jessner, Weigert \& Foy, 1970), one aspect of our cultural attitude about children affects both men and women equally: we are surprisingly uneasy with the idea of thinking about having children as a choice. In part this surely reflects the fact that we have only recently had such a high degree of potential control over reproductive decisions. But it also reflects a larger cultural blind spot. We 
are biased toward babies. We are unlikely to consider the fact that couples may decide not to have children. We hesitate to examine the ambivalence that can easily accompany a couple's choice to make a change as unpredictable in its effects. as all-encompassing and irreversible as that of becoming parents. We are reluctant to acknowledge that some among us have little talent for raising children and no desire to do so. Certainly. once a couple has had a child we do not want to hear about any regrets they may experience.

This study describes one aspect of men's lived experience in family life-the decision to have a first child-by drawing directly upon descriptions of that experience as it is lived by men who have recently made the decision to become fathers. What are the essential aspects of the experience of making that decision? What meaning does a man assign to his decision to bring a child to life? What does the role of father mean to him? What motivates his decision to have a child and what factors cast it into doubt? What is the process by which he comes to some resolution of his feelings?

Questions such as these ask us to characterize the essential qualities of subjective experience. As such they require a research method which is capable of rigorously explicating the qualities of lived human experience as they appear in consciousness. The phenomenological approach is such a method. It is a methodology which differs in fundamental ways from quantitative psychological research in that it does not pretend to describe or measure an external, objective reality. Rather, it is a systematic manner of arriving at an understanding of the essential qualities of a particular experience as it is lived. It is a method well-suited for the questions raised by this project precisely because so very little is currently known about men's experience in most aspects of family life, 
but especially in making the decision to become a father-an essentially internal process. even when shared with a partner.

Prior to presenting the results of this study I will review of the available literature-much of it collateral in nature-which sheds light on men's experience in reproductive decision-making. Next I will present an overview of the phenomenological method, including a description of specific data gathering and analysis techniques. A presentation of the data analysis and results will follow, containing the central findings of the study. A detailed discussion of the central themes follows, which will include a dialogue with existing literature. A chapter on the implications of this data for clinical practice and for future research will then be presented. followed by a summary. Complete texts of interviews and their analysis are available in the appendices. 


\section{Chapter Two}

\section{Literature Review}

Until recently, men's experience in families has gone essentially unexplored in the psychological literature. Studies on family life have traditionally been based primarily upon the experience and reports of women. Our disinterest in men's experience within families has both reflected and reinforced cultural expectations about male gender roles. A shift in attitude is apparent, however, in recent developments in the literature. For instance, an increasingly robust body of research is growing up around issues related to men's transition to fatherhood (Berman \& Pedersen, 1987; Hangsleben, 1980; Lupton \& Barclay, 1997; and Nute, 1986) and on the effects that fathers have in the development of their children (Bronstein \& Cowan, 1988; Cath, Gurwitt \& Ross, 1982; Griswold, 1993; and Lamb, 1987). Still, men's experience in reproductive decision-making remains largely unexamined.

This chapter will review the literature which sheds light on the question of how men experience the decision to have their first child. Because the research rarely addresses this subject directly, it will often be necessary to examine studies which are not specifically about the experience of fathers-for instance, studies on reproductive motivation in general, on reproductive decision-making as it occurs within couples, or on voluntary childlessness. The research will be reviewed in four principal areas which will enhance our understanding of men's experience in reproductive decision-making: (a) motivation for reproduction, (b) the decision to become a father, (c) the transition to fatherhood, and (d) clinical and treatment issues for clients addressing reproductive decisions. Before exploring these topics, however, it will be useful to place this research 
into demographic context, as our current attitudes and assumptions about men's experience in becoming fathers are interwoven with these demographic realities.

\section{The Demographic Context}

Undeniably, the gender role climate in the United States has been transformed in recent years-demographically, politically, socially and psychologically. Eggebeen and Uhlenberg (1985, p. 252) describe a series of important demographic changes that took place between 1960 and 1980: the level of childbearing declined from a fertility rate of 3.8 to 1.8 , the median age at first marriage increased from 22.8 to 23.4 and the divorce rate increased $150 \%$. The result, they suggest, is that "at the same time that increased attention is being given to the role of fathering, it seems likely that men, on average, are spending less time in living arrangements where there is an opportunity to occupy the role of father."

During this same period, the advent of birth-control technology has profoundly affected both men and women's experience of making reproductive decisions. The fact that humans have liberated sexual intercourse from reproduction, suggests Barash (1978. p. 18), opens an interesting question: why reproduce at all? From a sociobiological perspective, he writes, "reproduction involves an enormous expenditure of time and effort, and, in fact, there is good evidence that the strain of reproduction causes a reduced lifespan in most animals."

While an attempt to answer this question would go far beyond the reach of this study, the implications of our being able to pose it go to the heart of the phenomenon being studied: reproduction has become a choice. The possibilities opened up by this radical shift include a transformation in the way we think about parenthood itself. With 
the increase in reproductive control, for instance, there has arisen a wider acceptable range of reproductive options for couples, including a somewhat greater acceptance of voluntary childlessness (Campbell, 1975). Such demographic changes in the family are directly tied to changes in the quality of family life. Entwisle and Doering (1981, p.1) for instance suggest that "choosing to have fewer children probably means that a family attaches a social premium to producing and nurturing each child." And as Veroff. Douvan and Kulka (1981, pp. 194-195), optimistically express it, the "recasting of parenthood as an act of choice rather than a combination of fate and biology" allows those who don't want to be parents to opt out of the role. Ideally, this could lead us to a state in which "those who become parents now more than ever before are people who actively want to be parents."

While the impact of birth control on women's lives has been extensively discussed. its implications for men's experience has remained largely unexplored. It is certainly true that most people do have children. Pohlman (1969) cites a number of studies supporting this assertion and Presser (1978, p. 159) cites census data indicating that 90 percent of $18-34$ year old women in the United States either expect to have or have had at least one child. Although Presser claims that these figures hold true for men as well, she offers no data to support this assertion.

While most studies which discuss the impact of our increased control over reproductive decision-making use only women as subjects, Griswold (1993, p. 230) paints a vivid portrait of how these changes and choices might affect men and fatherhood: As fatherhood becomes increasingly voluntary, the role of fatherhood and breadwinning in male identity will certainly decline. Men who would have 
once become fathers without question, who treated fatherhood as their fate, now face considerably less pressure to become such. A weighing of options is increasingly becoming the norm. Are children worth the time. effort, and money? Is the roller coaster of parenthood worth the ride? For some, it will surely be so, and in this new world of alternatives, these men. having considered the options, may become quintessential new fathers.

Others may look for masculine identity in their work, a childless marriage. a series of relationships, or their leisure.

It is not at all clear that this reconceptualization of fatherhood as a choice has become a salient factor in the minds of men. It is this question, this "weighing of options" which this project seeks to elucidate.

\section{Motivation for Reproduction}

Now more then ever, parenthood is a choice. Given this fact, understanding men's experience of making the decision to become a father first requires an exploration of the reasons that people in general want to have children. According to Pohlman (1969), these reasons may include "innate" factors (the so-called "maternal instinct"), conformity to social norms, role identity factors, relationship factors, or religious factors. Parents may want children for the vicarious experience it enables, or simply to bring change to their lives. "Children may be perceived." Pohlman writes, "as part of living a 'whole,' 'complete' life; one should taste as many of the possible experiences available, and parenthood is one of them" $(1969$, p. 78$)$. This section will review literature pertaining to motivations for reproduction in three areas: (a) the development of the wish for a child, 
(b) socialization for parenthood and the value of children, and (c) adult development and generativity.

\section{The Development of the Wish for a Child}

Much of the more detailed theorizing that has been done about motivations for parenthood has a speculative quality. The experience of real parents (and of non-parents) is far-removed from many of the theories which have been developed around this subject. This is especially true of the psychoanalytic papers from the Fifties and Sixties. which are highly theoretical in nature. Nonetheless, these papers have the virtue of being the only systematic effort to explicate the human desire to reproduce. In addition. they are unique in the degree to which they acknowledge the power of unconscious forces in reproductive decision-making.

Wyatt (1967) holds firmly that the desire to reproduce is more than a simple instinct. "Why does a woman want a child before she can possibly know what it will do to her?" he asks (p. 32). "Why does she. for very different reasons perhaps, want more children?" The cultural refusal to consider such questions, he suggests. provides a clue as to the potentially charged nature of issues underlying this question: "It's basic. people will assert, and at the same time shrug off the subject leaving the impression that this must be a curiously forbidding topic to think about" (p. 32). Wyatt debunks the idea that childbearing is an uncontrollable instinct by noting the simple fact that (at least in developed countries) "women, as a rule, stop having children long before their reproductive capacity has been spent" (p. 37). He conceptualizes the desire to have children as one which arises when the desire to give and receive love becomes too strong to be contained within the self. This gives rise to a narcissistic crisis which leads to the 
desire for a child as a love object. The desire to have children, he thus suggests, is an echo of the desire to give ourselves the love for which we hungered as children.

In an earlier paper, Jacobson (1950) outlines a more detailed theory of the development of reproductive desire in boys. She suggests a course of male development in which a boy sublimates his early identification with his mother (including his desire to have a child as she has) into an identification with his father through the resolution of the oedipal conflict. As part of this process a boy develops defenses against his envy of women's reproductive functions. And so, Jacobson claims, in a psychologically healthy adult male, the desire for a child is based on both his love for his partner and his identification with his father. But that desire also contains deeper neurotic longings. Pregnancy gives rise to fears of death and a corresponding wish for omnipotence through immortality. These impulses activate a man's frustrated reproductive wishes. "It is the actual birth of the child," Jacobson writes (p. 145) "which enables him. if he is normal, gradually to eliminate disturbing infantile and narcissistic elements and to transform his fantasies into healthy paternal love relationships to his children."

Benedek $(1959,1960)$, bases her theory of reproductive drives directly on biological processes. She sees the motivation to have children as arising out of internal (and largely unconscious) drive conflicts. She claims that all children form internalized images of a "good mother" and a "bad mother" and that the tension between these polarities is reflected in either the wish for pregnancy or a hostile defensiveness against it. This conflict is resolved (again unconsciously) through a process in which "the dominant tendency of childhood-the need to be fed and taken care of-is replaced by the adult woman's physiological and emotional ability to give, to succour, to be a mother" 
(1960, p. 10). While these formulations are specifically about women, Benedek also asks (p. 12) "if there exists in man a primary, biological tendency towards becoming and being a father, a provider." She answers this question affirmatively, arguing that boys go through the same early pattern of identification with their mother as do girls (which gives rise to a primary drive to have children), but that it is resolved differently with the boy's identification with his father, (which gives rise to his secondary reproductive drive). In a later paper (1970), Benedek stresses even more forcefully her view that fatherhood for a man is identified with the role of provider and that fulfilling this role plays a primary function in a man's adult development.

In a review of the psychoanalytic literature on the subject of reproductive motivation. Ross (1975) compiles a detailed description of the stages boys move through in the development of a paternal identity. His description both integrates and expands the work of other theorists. In its early stages, Ross sees a boy's developmental process as one which parallels the development of maternal desire in girls. However, with "the ascendancy of phallic strivings, castration anxiety, and the consolidation of an intrusive male gender identity," boys begin to identify with "a giving, productive father rather than a starkly aggressive rival" (pp. 811-812). This transition allows a boy to engage in "experiments with caretaking and cognitive exploration of reproduction under the mentorship of a 'good father' who neutralizes oedipal rivalries and provides a model of manly care during middle childhood" (p. 812).

While psychoanalytic theories of reproductive motivation are quite fascinating, they are difficult to connect to the lived experience of men as they actually make reproductive decisions. On the other hand, several studies have used survey instruments 
and interviews in an attempt to isolate the conscious factors which influence reproductive motivations. Based on a survey of 200 undergraduate students (a sample which included both men and women), Rabin and Greene (1968, pp. 39-40) identified four categories of responses to open-ended questions about why people want to have children. The motivations they identified include:

1) Altruistic: an affection for children and the need to express nurturance.

2) Fatalistic: the belief that parenthood is the preordained order of things.

3) Narcissistic: the expectation that the child will "reflect glory" on the parent and will prove his or her physical or psychological adequacy

4) Instrumental: the child is seen as a means to an end who will play a role in meeting specific parental goals.

These categories appear to reflect some combination of the subjects' own feelings and their beliefs about social expectations regarding childbearing.

Based on a set of interviews with 82 women, Flapan (1969) conceptualized the question of reproductive desire in terms of motivational factors which encourage or inhibit the desire for children. He identifies thirteen factors which are "motivational considerations pertaining to childbearing," most of which could be extrapolated to men as well as to women (p. 417): social expectations, childbearing among peers, identity implications of childbearing and motherhood, identification with a fantasized child, childhood memories and identification with one's own mother, childbearing anticipations and expected relationship with one's children, marital context of childbearing, relationships with one's own parents, age and years of childlessness, expected fertility, 
pregnancy anticipation, childbirth anticipation. and fantasies pertaining to the newborn infant.

In a 1973 review of the literature pertaining to the antecedents to conception. Miller follows a similar model as Flapan in identifying "procreational motivations" which influence reproductive behavior in women either positively or negatively. Miller conceptualizes these motivational factors as elements which "enter the ego independently, as derivatives of a number of different desires and needs" (p. 172) and which then must be integrated. Recognizing that ambivalence can be a significant element in the experience of making reproductive decisions, Miller states that this integration "may or may not take the form of a dominant wish (or decision) for or against having a child." It is likely, he suggests. that "there is a complex mixture of feelings and wishes, each of which asserts itself with a different intensity in different contexts, thereby creating a varying procreational profile across time" (pp. 172-173).

To date there has been no study which is specifically designed to explore men's reproductive motivations. However, Marsiglio (1991) has noted in a theoretical paper that "males" personal interpretations of procreative experiences appear to have changed significantly in recent years" (p. 268). He suggests the need for a conceptual framework which adequately addresses two key aspects in the development of men's reproductive motivations: procreative consciousness and procreative responsibility. In his theory, men's procreative consciousness is comprised of "phenomenological experiences related to their fecundity/fertility" (p. 269). Men's procreative responsibility on the other hand is tied specifically to their role identity as partner in a relationship and as father to a child. Men's procreative responsibility consists of "beliefs, attitudes, preferences, and behaviors 
related to their expectations and involvement in contraception (and fertilization technologies), pregnancy resolution, childbearing, and child-care activities" (p. 269). Because Marsiglio's focus is theoretical, he does not attempt to describe the specific characteristics of procreative consciousness and procreative responsibility in the population. But these concepts will serve as useful guideposts as we examine the ways in which men experience the decision to have children.

\section{Socialization for Parenthood}

Another important factor which influences the motivation for having children is the existence of social norms and expectations regarding parenthood. While social influence factors are inadequate in and of themselves to explain men's subjective experience in making reproductive decisions, they inevitably play a role in shaping that experience.

Ory (1978) holds that the decision to have children is based on two factors: social norms and structural influences (by which she is referring to sociodemographic and psychosocial factors). Her study found that "the existence of family size norms...was clearly supported" and demonstrated "the widespread application and perception of social sanctions prescribing the two-to-three child family as ideal and proscribing the childless, one-child or large family as undesirable" (p. 537). She also points out, however, that the presence of these norms was not sufficient to pressure non-parents into having children. She concludes that "whereas the normative model is most appropriate for explaining general childbearing expectations, the structural decision-making model seems best suited for explaining specific fertility outcomes within a normatively prescribed range" (p. 538). 
A particularly rich source of analyses of the social pressures on individuals and couples to procreate can be found in the literature on voluntary childlessness. While this material cannot inform us directly about what it means to make the decision to have a child, it shines an indirect light on that decision by illustrating the cultural norms which are inevitably operating within individual decisions. Veevers, for instance (1973). identifies six "social meanings" that are attached to the idea of parenthood by our culture. Parenthood is: a moral or religious obligation; a civic responsibility; an instinctive. natural state; proof of sexual competence for one's gender; the meaning of marriage: and a sign of normal mental health. Any or all of these beliefs may play a role in an individual's decision either to have a child or to remain childless.

For the most part. analyses of social pressures to reproduce have focused exclusively on women. In a study of childless married couples. Seccombe (1991) suggests that "the omission of males [in previous studies on voluntary childlessness] is due largely to the presumption that females make the initial decision to forgo parenthood and are more committed to that decision than are males" (p. 192). Interestingly, her study showed that women in childless couples did not in fact hold more pronatalistic attitudes than did men. "These men rate the importance of having children higher than women do, and they are also more apt to want to become parents themselves" (p. 200).

Chafetz (1978, p. 197) suggests that it is men's social and psychological role identification which leads to the lack of a specific focus on fathers in the literature. Fatherhood, she states "is a very minor part of the total masculine role constellation; it ranks relatively low on the list of priorities a male is likely to have, and the father is not strongly sanctioned socially for playing this role either well or poorly" The result. she 
claims, is that "males are under little...direct social pressure to become parents, except as it is exerted through their wives." While there undoubtedly exists a significant difference between socialization for parenthood between men and women. Chafetz's claims are highly arguable and are not supported empirically. They reflect a long-standing bias in the literature which is only recently beginning to change as men's lives and role identities become increasingly valid subjects for study. In fact. men's lives are profoundly transformed by their entrance into parenthood (Cohen, 1987).

\section{The Value and Cost of Children}

Economic models have had a significant influence in current thinking about motivations for reproduction. Such models (which reflect in many ways the socialization factors described in the previous section), frame reproductive decisions as choices which are made on the basis of the perceived value and costs to parents of having (or of not having) children. Because such models tend to assume a high degree of conscious intention in the decision-making process, they inevitably raise questions with regard to the degree of ambivalence and to the degree of consciousness with which such decisions are made. This is a subject which will be touched upon briefly here but will be discussed in more detail later. Various authors have categorized the gains and losses associated with parenthood in different ways. In this section. these schema will be reviewed in order to provide a framework for understanding how such calculations may be operative in men's experience of making reproductive decisions.

With regard to the value of children, Hoffman and Hoffman (1973, p. 19) lament the lack of data "on why certain values are important, why children seem to satisfy them, which of the values are salient at certain times, which actually motivate the parents to 
have a child." But in spite of this difficulty they identify (p. 46-47) nine basic values which they believe children represent for parents:

1. Adult status and social identity.

2. Expansion of self, tie to larger entity, "immortality."

3. Morality: religion; altruism; good for the group. norms regarding sexuality, impulsivity, virtue.

4. Primary group ties, affiliation.

5. Stimulation, novelty, fun.

6. Creativity, accomplishment, competence.

7. Power, influence, effectance.

8. Social comparison, competition.

9. Economic utility.

While not identifying specific costs associated with having children, Hoffman and Hoffman suggest that understanding motivations for reproduction involves assessing five factors as predictors: the value of children (as listed above), alternate sources of those values, costs, barriers, and facilitators.

Fawcett (1978) suggests that the decision to have a first child takes place within a "motivational context" which can be measured through the "parents' expectations about the values and costs of children" (p. 244). Fawcett suggests that this motivational context -which can either be facilitative or constraining-is comprised of situational. sociocultural and psychological factors. He lists the positive values associated with having children as: emotional benefits, economic benefits, self-enrichment and development. identification with children and family cohesiveness and continuity. He lists the negative values 
associated with having children as: emotional costs, economic costs. restrictions or opportunity costs, physical demands, and family costs. He sees the most influential positive motivations for having a first child involving such factors as "adulthood. parenthood, virility or femininity, fecundability, fulfillment of the marriage. and the establishment of a 'family'" (pp. 261-262). On the other hand, he suggests that negative motivations affect the timing rather than the actual occurrence of the first birth. "The most powerful negative motivations, prior to the birth of the first child, are those connected with restrictions on freedom and opportunity costs," he states, although "for a substantial minority, anticipated emotional costs are also important" (p. 262).

In a study comparing childless couples, couples who were delaying parenthood. and current parents Bram (1974) argues that "analysis of the motivation to have or not to have children in terms of the perceived values and costs of children is "a useful way of understanding the distinctions between the three groups" (p. 77). She found a consensus between all couples (including those who had chosen to remain childless) on six values related to parenthood: affiliation. achievement. stimulation, novelty, and power/influence. All couples also agreed on three costs of having children: overpopulation, interference with the wife's education, and loss of freedom in the marriage. Childless couples additionally stressed several costs which parents and parents-to-be did not: psychological, achievement, affiliative and lifestyle. Husbands in particular added two additional costs: financial and responsibility. Non-childless couples emphasized one particular value for parenthood which childless couples did not: expansion of the self. Finally-and interestingly-only current parents stressed the values of adult status and identity, and social comparison. 
Pohiman (1969) identifies a number of costs of having children including: the costs to the marital relationship; anxiety, conflict, separation and grief: mess. noise. confusion and congestion; time, commitment and hard work: and health and appearance. He describes four factors which could theoretically be used in performing a sort of cost/benefit analysis in the decision:

1. Perceived advantages of a child's presence.

2. Perceived disadvantages of a child's presence.

3. Perceived advantages of the child's absence in terms of other competing possibilities.

4. Perceived disadvantages of a child's absence.

The conscious desire to have children, Pohlman states, "can be thought of as some sort of compromise of such factors as these" (p. 189). But. as he also points out. unconscious factors complicate this equation enormously. And as Lieberman and Kastelowitz (1986, p. 26) suggest, "the persistence of unplanned and unwanted pregnancies, especially given the present day availability of contraceptive technology, is indicative of how unconscious some people's decision to become parents may be."

Taking issue with both the normative model and the rational choice (or economic) model for explaining reproductive decisions, Friedman, Hechter, and Kanazawa (1994) propose instead a two-staged model which is based on the theory that the motivation to become parents is driven by the desire to reduce uncertainty (regarding life course and role identity) and on the desire to enhance marital solidarity. They argue (p. 384) that "the value of children derives from their capacity to reduce uncertainty for individual women and to enhance marital solidarity for couples." Myers (1997) however, found little 
empirical support for these hypotheses. Using data from a 12-year study of "Marital Instability over the Life Course" (Booth, Johnson, White. \& Edwards, 1991). Myers found that "couples are less likely to have children when the stability of their marriages is less certain, they have fewer common ties, they are married longer. they are less socially and geographically mobile, and they are less traditional in their gender roles" (p. 1285). It does not appear, he states (p. 1287), "that one theory of fertility is adequate by itself. Because decisions regarding childbearing are so dynamic, single-minded theories (e.g. economic, marital uncertainty) may not capture the complexity involved."

\section{Adult Development and Generativity}

Generativity has been the dominant concept underlying contemporary theories regarding the role that parenthood plays in adult development. As such. it could reasonably be expected that issues surrounding dependency needs would comprise a significant component of men's experience of making the decision to become parents.

Erikson wrote in his outline of the seventh stage of his theory of human development (generativity vs. stagnation) that "mature man needs to be needed" (1950. pp. 266-267). Erikson grounded his view of healthy adult development on this concept, which he defined fundamentally in terms of biological procreation. While acknowledging that generativity can in some cases take other forms-such as productivity and creativityhe believed that these alternatives "cannot replace it." According to Erikson, when adults fail to achieve generativity "regression to an obsessive need for pseudo-intimacy takes place, often with a pervading sense of stagnation and personal impoverishment" (p. 267). The motivation for children, according to his view, involves both dependency needs and the desire for personal fulfillment. 
McAdams, Hart and Maruna (1998) take a more expansive and systematic view of generativity, which is not so rigidly tied to the specific act of procreation. They describe a model of generativity which has both individual and social components. On one hand generativity is an inner drive and a need which stems from two sources: a desire for symbolic immortality and the "need to be needed." On the other hand. generativity is "strongly determined by cultural demand" (p. 10). These two forces combine to create a concern for the next generation which (ideally reinforced by a sense of general faith in the worthwhileness of human existence) leads to a commitment which may lead to generative action-"creating, maintaining, or offering that which has been created or maintained to a community" (p. 8).

McAdams, Hart and Maruna (1998) suggest that the idea of generativity is interwoven with a cultural sense of time:

In that generativity refers to the creation (generation) of new forms that will outlive the self, generativity points to the future. In that generativity also refers to the maintenance, preservation, and passing on of that which has been valued in a given social context, it points to the past. (p. 15) Although they are not specifically addressing the question of generativity, Jessner, Weigert and Foy (1970) arrive at a similar description of the individual's sense of time when on the verge of parenthood. On one hand, the commitment to parenthood "implies a decision for lifetime" (p. 212), on the other hand, that choice creates a sense of nostalgia and loss of past infantile dependency needs and a vague awareness that "a perfect fulfillment of this yearning would mean individual death" (p. 213). 
Unlike so much of the literature around reproductive decision-making. research on generativity is comparatively free of gender bias. The "need to be needed"-if it truly exists as a universal need-is one which applies equally to both men and women. At the same time the literature in this area reflects a pro-natal bias which subtly pathologizes voluntary childlessness and has the potential for minimizing the importance of the costs of parenthood and the implications of ambivalence in reproductive decision-making.

\section{Making the Decision to Become a Father}

While the literature provides us with clues as to both the internal psychological motivations and the external social pressures to have children, it offers us little insight regarding the question which the current project seeks to address: how do men actually experience making the decision to have children? As Marciano (1979) argues, fertility decisions in general are much more strongly influenced by male preference than has been previously acknowledged. Yet we have little understanding of just what that male influence is. This section examines research pertaining to the conceptual framework with which we talk about reproductive decisions, beginning with studies which look at the decision process as it occurs within couples and following with studies which ask whether concepts such as intention and wantedness can be usefully applied to such decisions, whether logical processes are adequate for explaining reproductive decisions, indeed, whether they should be thought of as decisions at all.

\section{The Decision Within the Couple}

While researchers have seldom focused directly on men's experience in making reproductive decisions, several studies have examined how couples decide (or fail to decide) to have children. Relationship factors are of course central to men's decision 
process and so these studies provide important information about this aspect of men's experience.

Perhaps the most comprehensive description of the process by which couples make reproductive decisions comes out of Cowan and Cowan's (1992) longitudinal study "When Partners Become Parents." Cowan and Cowan identify four pattems of reproductive decision-making in couples: planners, acceptance-of-fate couples. ambivalent couples, and yes-no couples (in which there is a strong, unresolved conflict between each member on the subject of children). Cowan and Cowan demonstrate that (relatively speaking) marital satisfaction is positively correlated with a higher degree of active planning about reproductive decisions. Making an argument with important implications for clinicians working with couples and families, they write that "much of what happens after the birth of a baby is shaped by what is happening in couples' lives before the baby comes along. And one of the most important things that happens in the prebaby period is the way the couple goes about deciding whether to become parents in the first place" (p. 32).

Daniels and Weingarten (1980) look not only at how but at when couples decide to become parents. They identify five attitudes that couples have regarding the timing of parenthood: natural (it will happen when it happens), brief wait (a two to three year period for the couple to be together without family responsibilities), programmatic postponement (putting off parenthood until specific personal and professional goals have been met), mixed script (in which partners disagree over timing), and an unformed scenario. They see the factors which influence this decision as being shaped by larger developmental issues. "The decision to become a parent," they write, "is set in motion not 
with the first pregnancy, or with the first conversation about when to have a baby. but in a person's first thoughts and fantasies about having children of one's own" (p. 12).

In her 1974 comparison of parents, parents-to-be and voluntarily childless couples, Bram outlines the components of the decision process which couples in her study went through in making their decisions. Like Daniels and Weingarten. she describes the process as being first defined by the pre-existing attitudes of each member of the couple toward children. It is subsequently shaped by the occurrence (or nonoccurrence) of discussions early in the marriage about the decision (or by unspoken assumptions within the marriage about the decision), which determines whether the couple will have children right away. will not have children at all, will delay having children, or will fail to make a decision. Other factors which Bram sees as influencing the way a couple makes and acts on their decisions include the reasons for delaying (if this is applicable), the comparative contribution of each spouse to the decision, the method and regularity of birth control and the desired family size.

\section{Are Reproductive Decisions Trulv Decisions?}

Several authors have questioned whether reproductive decisions are in fact decisions at all. Smith (1973), suggests that we cannot even say within any certainty to what extent reproductive decisions are "real decisions that strategically affect fecundity or essentially epiphenomenal pseudo-decisions of little real consequence." His list of unanswered questions regarding such decisions illustrates the limitations of our understanding in this area:

What are the units of decision, and how do they come to bear upon fertility-relevant behavior? Do marital partners decide upon a wanted 
family size? Or on an acceptable range? Or rather on the acceptability or desirability of a next pregnancy now? Are family decisions made in a short-run time perspective. like "incrementalist" government policy, or do some parents make their plans in a longer time perspective? Which parents? Who makes the decisions, with what degree of real or assumed consensus? What alternatives are weighed. and what considerations are seen as relevant? (1973, pp. 9-10)

Smith emphasizes that "close phenomenological inquiry followed up longitudinally is needed to throw further light on these questions" $(1973$, p. 10) and suggests that in the absence of such studies "we may be ducking the problem of whether from an insider's perspective...there is any kind of decision process going on at all" (1978, pp. 266-267).

Several studies have attempted to categorize the quality of intentionally with which couples plan the birth of their first child (Entwisle and Doering. 1981; Poffenberger and Poffenberger.1952). But such schema do not stand up well under scrutiny, because of the difficulty of defining with any precision the very terms used to describe them. As Pohlman (1969. p. 191) states, defining the word "wanted" with regard to reproductive decisions is "exceedingly complex and perhaps impossible." He points out that while two parents might both want their children, "the feelings of one might be much more ambivalent while the feelings of the other were closer to wholehearted enthusiasm" (p. 39). Many people, he suggests, "may never make any clear-cut decision one way or another" (p.192).

This terminological ambiguity will be very significant in interpreting of the results of the present study. The words we use to describe reproductive decisions-wanted 
versus unwanted children, planned versus accidental pregnancies-reflects unspoken assumptions about parenthood. Our language contains within it a desire for certainty, a need to believe that decisions are made or not made in ways which can be clearly described. But this clarity does not necessarily exist in the lived experience of those who are actually in the process of making reproductive decisions. As Pohlman argues (1969. p. 191), there exists "a very intricate ambivalence" which "is present for almost all parents, as they think about any given conception."

The difficulty of arriving at a clear understanding of the process by which reproductive decisions are made is evident in a series of studies by Miller (1973. 1974, 1978), who attempts to develop not only more rigorous definitions of intendedness and wantedness but also quantitative scales with which these qualities might be measured. Noting that "psychological terms in this area have been adopted from those of demography, which "tend not to be related to how individual people actually think and feel" (1978, p. 210), Miller acknowledges the "surprising lack of differentiation. clarity, and precision in the concepts we use to describe and understand the subjective states and the overt behaviors involved in the decision making, planning, and adaptive responses associated with conception and birth" (1978, p. 209).

Miller's work indicates that "wantedness" and "intendedness" are not absolute quantities in reproductive decisions. He suggests that there is an implicit ambivalence inherent in many if not most reproductive decisions:

In general conception and childbearing seems to be such a fundamental aspect of being human, affecting so many fundamental psychological issues, that most people have a mixture of feelings about it, including both 
positive and negative elements. As a result, whether they are striving to avoid or to achieve conceptions, it is inevitable that some feelings and wishes will oppose the primary thrust of their conceptive efforts. in whichever directions those may be made. (1973, p. 171)

These results are echoed in Gerzi and Berman's (1981) study which noted that even in subjects who defined their pregnancies as wanted and planned. this "conscious wish was frequently accompanied by conscious or unconscious resistance and fear" (p. 264). Miller speaks of this ambivalent intent as subintention, "the assumed mental state of people who do not fully intend an action but rather pursue it inconsistently, make a decision about it by default, or expose themselves knowingly to an increased chance of its happening" (1978. p. 214). His research indicates that a degree of ambivalence may be the norm in the process of making reproductive decisions.

\section{The Experience Of Making The Decision}

Is the decision to have a child a logical process in which one weighs the costs and benefits of having a child and comes to a rational decision? Or is it an unconscious and ambivalent process which is inherently irrational, even mysterious in its workings? A satisfactory description of the decision-making process will probably require an acknowledgement of both of these aspects.

Few researchers have attempted to explicate or explore the subjective experience of those who are actually involved in the process of making reproductive decisions. Lupton and Barclay (1997) performed a series of phenomenologically oriented interviews with men just prior to and at regular intervals after the birth of their first child. While their focus is more on the transition to fatherhood than on the decision to become a 
parent, and while they indicate that most men in their study did not perceive the decision to enter parenthood as a true choice, nonetheless many of the themes described in their pre-birth interview overlap with considerations pertinent to the decision process itself. These include: the responsibility arising out of a child's long-term dependence. the effort to construct a role identity based on comparison with one's own father. the difficulty of imagining what being a father will mean, concerns about the impact a child will have on the marital relationship, and apprehension and ambivalence about one's own ability to be a good enough father. These are all themes which might arise as part of men's experience in making the decision to have their first child.

Jessner, Weigert and Foy (1970) also emphasize the importance of subjective factors in understanding men's fears around parenthood. A description of expectant fatherhood, they write, "must fall back upon experiential components such as hope. appropriation, and responsibility. The meaning of fatherhood is grafted upon the procreative act. There is a sense in which fatherliness crystallizes in a decision and a responsibility recognized and accepted" (p. 239).

Lieberman and Kastelowitz (1986) emphasize both the experiential and the existential components inherent in the decision to become a parent, suggesting that the decision is a "boundary situation" which "involves increased contact with the nonrational, ineffable. trans-logical, uncontrollable mystery of existence" (p. 12). This encounter "highlights those aspects of existence which cannot be altered or controlled, and remind us of our smallness and vulnerability" (p. 12). They identify three ways in which the decision to become a parent confronts couples with existential limitations. Partners must face the limited time that they have in which to make a decision. They may 
discover through infertility or miscarriages that they are not in control of the decision. And finally, "the fact of time's irreversibility will be brought home by the nature of this decision's irreversibility" (p. 13).

\section{The Transition to Fatherhood}

While the question of how men adapt to the role as father after having made the decision to have a child is not properly the subject of this study, the literature on this subject merits some discussion because this is an area in the literature in which research focuses specifically on the experience of men and also because the way in which a man makes this transition will inevitably reflect his attitude toward becoming a father during his decision-making process. Past reviews of the literature on the transition to fatherhood (Berman and Pedersen, 1987; Hangsleben, 1980; Nute, 1986) have focused on issues such as readiness for parenthood, parental involvement and parenting style. This section will review those studies which shed some light onto the decision-making process.

Is the transition to fatherhood a crisis in a man's life? To the degree that this is so it is reasonable to assume that the anxiety created by becoming a father reflects to some degree the ambivalence inherent in the decision-making process. The literature on the transition to fatherhood has been highly influenced by the crisis model as defined by LeMasters (1957) and Hobbs (1968). In this tradition, a series of studies have focused on the anxieties which arise in men as a result of becoming a father, several of which describe a correlation between a man's readiness for parenthood prior to the birth of his child and his subsequent level of ambivalence and anxiety after the birth (Clinton and Kelber, 1993; May, 1982; Obrzut, 1976). Other authors focus on the timing of fatherhood as a key component of a man's facility in forming a paternal identity. Nydegger (1973) 
finds that late-timing fathers were more settled in their paternal role. while early-timing fathers were more uneasy. Cooney, Pedersen. Indelicato. and Palkovitz (1993) find that late-timing fathers are more likely to have planned their entrance to parenthood and so are also more likely to have rehearsed their paternal role. Fein $(1976,1978)$ challenges the crisis model while simultaneously confirming the correlation between the anxiety of new parenthood and preparedness for the role of father. He observed that effective postpartum adjustment in fathers is correlated with the development of some kind of coherent role identity - no matter what form that role identity took.

Daniels and Weingarten (1988) expand the concept of timing to include not simply the fact of becoming a father but the internal "click" that signals the formation of a coherent identity. They report (p. 37) that "men become fathers at different times of the life cycle, not only literally but experientially. That is, as a central, fully realized developmental experience, fatherhood 'clicked' at different times for different fathers, and at a time distinct from the timing of the birth of their first child."

The common thread in all of these studies appears to be the formation of a paternal identity as a key factor which affects both a man's decision to become a father and his transition to fatherhood. Herzog (1982) asserts that the formation of paternal identity occurs in the context of a man's pre-existing "conceptual road map" that he has created for his life. "A man experiences his wife's pregnancy largely in terms of his underlying views of his own life" (p. 301). This simple statement has important implications for both future research and clinical practice. A man's pre-existing perception of the role of father plays a defining role in shaping whether or not he chooses to have children, how he makes that decision, and the sort of father he will eventually be. 


\section{Treatment and Clinical Issues}

Given the universality of the experience, the paucity of clinical materials relating to counseling men (or women. or couples) who are making reproductive decisions is disheartening. Several books (Bombardieri, 1981; Whelan, 1975) were once available for a general audience which directly addressed the question of how to decide whether or not to have children. While both of these books are currently out of print. they remain highly valuable in guiding both individuals and clinicians through the decision-making process.

What little exists in the professional literature on this subject deals primarily with decision-making programs for groups of women or with couples (Daniluk \& Herman. 1983; Kimball \& McCabe, 1981). There does exist. however. a small treatment literature focused on facilitating men's transition to fatherhood. Cronenwett and Kunst-Wilson (1981) present a scheme for understanding men's transition to fatherhood which see the transition as occurring within a social support system model. They emphasize the lack of socialization, support and education that men receive for the role of father and the need for active father role models, increased comfort in men for expressing nurturing aspects of themselves, and compatibility of a man`s fathering values with those of friends and colleagues in order to lessen role ambiguity and increase social support. Each of these aspects could be easily adapted to a program aimed at men who are still in the process of making the decision about whether or not to become a father.

Levant (1988) outlines a parent education program for fathers which argues that parent education has traditionally ignored fathers. Stating that "men do not easily seek support or freely express their feelings" (p. 263), Levant describes a program which is geared toward "men's traditional learning styles": 
When men first walk into the room, hardware is immediately in evidence in the form of video equipment, which may provide a sense of familiarity. in terms of their traditional relationship to machines. Furthermore. they are told that we will teach them to be better fathers in a manner comfortable to them, in much the same ways they might have learned to play a sport. such as football or tennis. (p. 267)

Though based on arguable assumptions about male gender roles. this program acknowledges the difficulty of drawing men into programs such as these. recognizing and responding to the specific needs of men rather than attempting to draw them into programs which have been designed primarily for women.

Shecket (1995) and Klein (1985) both present models for support groups for fathers after the birth of their first child. "The array of feelings that accompany the arrival of a new baby can be a common reaction to change," Klein states (p. 264), "yet many men fail to verbalize their anxieties and concerns." He describes the goal of these groups as being primarily support and secondarily education, with the underlying premise that "not only the fathers who are assisted during this time. but also their families, including spouse and child, will fare better during the adjustment period and beyond than they would without such group support" (p. 265). Shecket describes similar concerns regarding the lack of support that men in his hospital-based support groups had received in the transition to fatherhood: "None of the fathers... had ever had the opportunity to talk honestly with other men about what it was like for them to be fathers" (p. 141). (Notably, this program also emphasizes the importance of a pre-conception class for couples on the decision to have a child.) C. P. Cowan (1988) describes a support group for couples going 
through the transition to parenthood. with a particular emphasis on the value of this program for new fathers. In an interesting counterpoint to Shecket and Klein`s perception that men are rarely able to discuss their feelings about becoming fathers. Cowan states that "it is clear that men are quite comfortable thinking about and working on family issues. Although they often expressed more initial skepticism than their wives did about the need for the intervention...most fathers in our study eventually become vocal supporters of the couples groups" (p. 295).

Lieberman and Kastelowitz (1986) suggest that "attempts to increase the planfulness of the family formation process will need to focus as much on the existential meaning of giving birth as much as on sex education" (p. 26). Achieving this increased awareness of the complex realities involved in the experience of making the decision to have a child is a difficult task-especially prior to the decision. And those who seek assistance in doing so will find few resources available. A fundamental goal of this research project is to provide clinicians in a variety of areas with practical information about men's experience in making reproductive decisions. As can be seen from this review, much of what is currently available on this subject is speculative or reflects on men's experience in a tangential manner. The following chapter will explore how the phenomenological method can be used to capture more directly the essential themes and structures of men's experience in making reproductive decisions. 


\section{Chapter Three}

\section{Method}

\section{Overview of the Phenomenological Method}

This project seeks to describe men's experience of making the decision to have their child using principles of the phenomenological research method as outlined by Giorgi (1985b), Polkinghome (1989), and Kruger (1981), among others. (The concepts in this chapter have also been influenced in a global way by methodological statements presented in phenomenological studies by Cudmore (1997) and especially by Jenni (1990)). The phenomenological method applies a rigorous analytical procedure to naïve descriptions of lived experience, with the goal of arriving at a descriptive statement which characterizes the essential structure of that experience as it appears in consciousness.

The phenomenological approach represents a significant shift in focus from the methods of traditional quantitative psychological research, which are rooted in the positivistic assumptions of the natural sciences. Those methods have been developed to measure the characteristics of an external physical reality and as such they have been and continue to be highly useful for increasing our understanding of psychological phenomenon as they are manifested in external behaviors. But, as Giorgi argues (1985a, p. 1), in traditional psychological research "many important aspects of [psychological] phenomena as lived and experienced were either overlooked or severely distorted because the methods of the natural sciences were invented primarily to deal with phenomena of nature and not experienced phenomena." 
Phenomenological research does not seek to replace or even to question the relevance or value of traditional psychological research. Rather it seeks to broaden the discussion by making possible the study of psychological phenomenon which cannot be adequately measured or described by traditional methods. In addition, by embracing aspects of human experience which could not be included in past research. phenomenological methods bring additional depth to what has been discovered through traditional research methods.

Like any research method, quantitative psychological research contains certain limiting assumptions. These require the researcher to assume a detached position with regard to his or her subjects, to create necessarily simplified definitions of specific behaviors and to impose pre-determined hypotheses on the significance and structure of those behaviors. By imposing these assumptions the researcher gains the ability to make authoritative statements about the behavior being studied, to assert causality or to make predictions. But the cost of being able to make such assertions is that their applicability to lived experience is greatly reduced. The subject's lived experience-a rich source of information about the phenomenon being studied-is lost in the process.

While the question of how descriptions of behavior which are generated by traditional methods relate to the actual subjective experience of those being studied is worth considering, the difficulty involved in addressing this question calls to our attention a central limitation of positivistic methods: by rendering phenomenon measurable, they impose an artificial separation between experience and behavior. Positivistic psychological research methods are simply not designed to capture the full scope of human experience. 
Phenomenological research addresses these concerns, Polkinghorne states (1989. p. 43), in taking the stance that "human behavior is an expression of meaningful experience rather than a mechanically learned response to stimuli." Phenomenology operates at what he calls "the intersection of the person and the world" (p. 51$)$. It is a method which seeks to not to measure external reality but rather to understand human experience and the ways in which humans render experience meaningful. As Giorgi describes it (1986, p.6), phenomenology "is concerned with phenomena in the strict sense: that is, how things and events are for the consciousness that beholds them and not how they are in themselves." This aspect of human psychology-which is especially important in clinical practice-cannot be well understood when we limit our area of study to observable behaviors.

While the goal of traditional psychological research is to arrive at verifiable claims about the nature of reality, phenomenology does not make such claims. It does not describe reality objectively but rather describes subjective human experience through an analysis which seeks to understand the essential structures of a given phenomenon as it appears in consciousness. Thus, no claims are made about abstract principles which govern a behavior or phenomena. As a result, rather than requiring the researcher to develop hypotheses and to construct theories about reality, it asks that the researcher examine and reflect upon a description of a given experience.

In this description of the goals of phenomenological research the limitations of the method can also be seen. As will be discussed shortly, familiar quantitative criteria of reliability and validity must be re-conceptualized when using this method. Phenomenological research is not easily replicated. It cannot make statistically defensible 
claims about generalizability. Finally, because it is a method which is fundamentally defined by intersubjective processes between the researcher and his or her subjects. it makes no claims to scientific objectivity.

From the perspective of traditional research, these limitations might seem untenable. However, just as the limitations of quantitative research arise inevitably out of the specific goals of the method. so the limitations of phenomenological research arise out of the goals it sets. In choosing what aspects of a phenomenon we wish to understand. we facilitate certain understandings while curtailing others. In the present study, a choice has been made to focus not on statistical characteristics of men who make the decision to have their first child, but rather to arrive at an understanding of that experience as it appears in consciousness.

The manner in which the phenomenological researcher attempts to understand experience is through the analysis of naive descriptions of those experiences as they are lived by human subjects. These descriptions are generally either written or oral. In order to achieve a sufficiently rich variety of descriptive data about the subject, phenomenological research generally uses at least three subjects. Sample size is not determined by principles governing generalizability, as it is in quantitative studies. Rather, the standard used is one of "saturation." The researcher considers the subject to be fully-enough described at the point when continued interviews cease to contribute substantially new or different aspects of the experience.

Because it is rooted in the analysis of naïve descriptions, phenomenological research inevitably makes use of the engaged, subjective experience of the researcher. Prior to conducting interviews, the researcher conducts a review of the relevant 
psychological literature on the subject in order to establish what is known. believed and assumed about the subject. In addition, the researcher interrogates him or herself with regard to assumptions and attitudes held on the subject. There is no assumption that the researcher is objective or unbiased with regard to the subject. Rather. the phenomenological approach takes researcher bias as a given and seeks to address the issue by engaging in a process through which both existing knowledge of a phenomenon and pre-existing prejudice on the part of the researcher are brought into awareness. Once conscious, the researcher "brackets" these assumptions to the best of his or her ability, setting aside assumptions in order to perceive as clearly as possible the characteristics of the subjective descriptions which are gathered.

This process of bracketing assumptions and biases is ongoing, beginning in the interviews and continuing through the data analysis and presentation. This is inevitably an imperfect process which the researcher seeks to address through several measures. First and foremost, data is presented in its entirety, so that every step of the analysis is open to scrutiny. In addition, this research has taken place within the context of an ongoing workshop in which a group of students involved in phenomenological research projects share their data and discuss issues related to all aspects of the research, including the definition of the question to be asked, subject selection, and data analysis. This group support is important both as a check against the researcher's biases and blind spots, and also as a mechanism which assists the researcher to see the data as fully as possible.

The phenomenological method begins with open-ended interviews in which subjects are asked to describe their experience of a particular phenomenon. Subjects are encouraged to describe all relevant aspects of their experience as they arise in their 
awareness during the interview. These interviews are then transcribed and analyzed through a process of phenomenological reduction which begins with the researcher "sitting with" the data and allowing its constituent components to present themselves. (The specific steps of this process are described in detail below). The researcher sets aside his or her expectations and allows the elements that compose the experience to define themselves as they are. The researcher then moves through a process of analysis which begins with the subject's concrete language and moves through a process of distillation toward an increasingly abstract reduction of the essential structures of the experience itself as it appears in consciousness.

\section{Evaluation Criteria}

Because phenomenological research does not result in assertions which can be statistically tested and experimentally replicated. the evaluation criteria used in quantitative research-as they are commonly defined-are not adequate for this research method. Because the findings of qualitative research are descriptive, concepts such as reliability and validity must be re-conceptualized. There is a debate among qualitative researchers as to whether terms which have their roots in positivistic methods are appropriate at all in qualitative research (Creswell, 1998).

Creswell (1998, p. 201) in reviewing current thinking on standards of quality and verification in qualitative research, advises the use of the term "verification" rather than validity, pointing out that verification is "a distinct strength of qualitative research in that the account made through extensive time spent in the field, the detailed thick description, and the closeness to participants in the study all add to the value of a study." He lists eight methodological procedures which serve as verification procedures (pp. 201-203): 
1. Prolonged engagement and persistent observation in the field.

2. Triangulation (corroborative use of multiple methods. sources and theories).

3. Peer review or debriefing.

4. Negative case analysis (refining hypothesis in view of disconfirming evidence).

5. Clarifying researcher bias.

6. Member checks (soliciting informants' views of the credibility of the findings).

7. Rich, thick description.

8. External audits.

Creswell recommends that at least two of these procedures be used in any given study. With regard to issues of validity in phenomenological research. Polkinghorne (1989, p. 57) states that the underlying question is this: "Does the general structural description provide an accurate portrait of the common features and structural connections that are manifest in the examples collected?" He elaborates five questions which serve to address this question:

1. Did the interviewer influence the contents of the subjects' descriptions in such a way that the descriptions do not truly reflect the subjects' actual experience?

2. Is the transcription accurate, and does it convey the meaning of the oral presentation in the interview? 
3. In the analysis of the transcriptions. were there conclusions other than those offered by the researcher that could have been derived? Has the researcher identified these alternatives and demonstrated why they are less probable than the one decided on?

4. Is it possible to go from the general structural description to the transcriptions and to account for the specific contents and connections in the original examples of the experience?

5. Is the structural description situation-specific, or does it hold in general for the experience in other situations?

Regarding validity in phenomenological research, $\operatorname{Kruger}(1981$, p. 131) states that the criterion

is not whether another researcher (or a judge) would use exactly the same words or arrive at an identical description of the data. Rather validity is indicated by whether such differences in wording may be intersubjectively understood to reflect an identical meaning or indicate similar essential themes to those which emerged from the data as explicated by the original researcher.

As these statements indicate. phenomenological research has developed a set of evaluation criteria through which research practices and results can be rigorously interrogated.

\section{Rationale for a Phenomenological Approach}

What makes the phenomenological approach an appropriate method for understanding men's experience in deciding to have their first child? One way of 
answering this question is to examine the limitations inherent in the existing quantitative research. For instance, in reviewing the available literature on motivations for wanting conception, Pohlman (1969) points out that most research on the subject is done from a demographic perspective which has a limited ability to capture the psychological components of the experience. The phenomenological approach directly addresses this problem.

But a more fundamental rationale for using a phenomenological approach concerns the nature of the experience being studied. Because many psychological phenomenon exist primarily within the experience of individuals, they are difficult if not impossible to observe and measure directly. The phenomenological method is particularly well suited for studying such concerns. Another area for which phenomenological methods are appropriate are those which have been little studied and are not well understood. In such a case, a phenomenological study can serve the dual purpose of explicating the experience in and of itself and also of suggesting directions in which quantitative studies might proceed. Finally, phenomenological studies have the virtue of approaching a subject of inquiry with pre-conceived assumptions bracketed. For this reason, it is a valuable tool for exploring subjects in which are thinking is currently dominated by untested assumptions.

The question of men's experience of making the decision to have their first child clearly falls into each of these categories. It is a deeply interior experience which is not easily measured through surveys or direct observation. It has been little studied and is not well understood. And what little understanding of the phenomenon we do have is heavily influenced by cultural assumptions. This project attempts to transcend these limitations 
by following Cohen's distinction (1987, p. 60) between "men's reports of their behaviors as husbands and fathers and their stated role attachments. their emotional involvements in. and the self-images they derived from. their family roles."

Finally, qualitative methods are particularly useful in clinical settings as they provide the sorts of clues about client's interior experience which quantitative methods cannot access. As Nelson and Poulin (1997, pp. 170-171) write in comparing the usefulness of the two approaches with regard to counseling research:

Quantitative inquiry can demonstrate how theories of personality, treatment, and training apply in a probabilistic sense. Qualitative inquiry can provide understanding about the experienced meanings of individual and family development, leaming phenomena, social problems, and process and outcome in counseling and training.

If it is a goal of a research project-as it is of this one-to provide clinicians with information that will be directly applicable to their practice. then the phenomenological method is a very effective means of reaching that end. It is a specific goal of this project to increase our understanding of men's psychological experience in general and specifically with regard to reproductive decision-making.

\section{Procedure}

\section{$\underline{\text { Subject Selection }}$}

The purpose of the phenomenological method. Giorgi writes (1985a, p. 1), "is to do justice to the lived aspects of human phenomena, and to do so, one first has to know how someone actually experienced what has been lived." As a result, subject selection in phenomenological research presents different demands on sample size and populations 
than does quantitative research. The purpose of phenomenological research. Polkinghorne states $(1989$, p. 48$)$ is

...to describe the structure of an experience. not to describe the characteristics of a group who have had the experience. Rather than seeking to describe the mean and standard deviation of a group as it relates to the experience, the phenomenological concern is with the nature of the experience itself.

Thus the point of subject selection is not to obtain statistical generalization but "to obtain richly varied descriptions" (p. 48).

Subject selection for this project was guided by criteria defined by Polkinghorne's (1989, p. 47) suggestion that there are two fundamental requirements for subject selection in phenomenological research. The first is that the subject "has had the experience that is the topic of the research." The second is that the subject "has the capacity to provide full and sensitive descriptions of the experience under examination." Kruger (1981, p. 125) adds a third criteria which is that subjects "should preferably be naïve with respect to psychological theory" in order to "increase the probability of their verbalizing the data of their awareness without undue interference from implicit philosophies of various schools of psychological thought."

Finally, while the number of subjects used in phenomenological research varies widely across different studies (Polkinghorne, 1989), at a minimum three subjects are necessary in order provide a sufficiently rich and complex variation of the experience being studied. The specific number of subjects is less important than that the researcher arrive at a point at which the combined descriptions capture the experience in a 
"saturated" way-that is, when further interviews cease to add significant new information about the experience. For this project, six interviews were conducted.

Subject selection was also guided by the outcome of several pilot interviews which led to a decision to interview only men for whom parenthood was a conscious. considered decision, men who had at some point in their lives experienced some degree of ambivalence about whether or not to have children. (The results of these pilot interviews and their implications are described below.) The pregnancy had to be the man's first child and it had to have been planned. In order to insure that subjects have made a full commitment to that decision. men were interviewed after their partners had become pregnant. Subjects were not used after the birth of their first child in order to ensure that the focus was on the decision to become a father rather than the transition to fatherhood and also because of the possibility that the experience of fatherhood itself and the reality of the newborn child would play back onto and affect men's memory of their experience of making the decision.

Subjects were recruited through announcements posted at obstetrician's offices and birthing classes, and through informal, word-of-mouth referrals. Interviews were tape-recorded and ranged in time from 45 to 90 minutes. Those who participated were actively engaged in thinking about their expectant fatherhood. Although they were interested in the project and were generally eager to describe their experience. there was for some subjects an small degree of initial confusion as to what they should focus on. Most commented on the fact that they were unaccustomed to talking about their feelings and experiences in such depth because they had little opportunity to do so. All seemed to enjoy talking about the subject once they settled in to it. 


\section{Pilot Interviews}

Prior to beginning this research, two pilot interviews were conducted. The first was conducted on the researcher himself by an experienced phenomenological interviewer, the second was with an expectant first-time father in his mid-thirties. Both interviews were conducted with the goal of illuminating the phenomenon in a preliminary way; the interview with the researcher also sought to reveal any presuppositions which he held about the meaning of the phenomenon.

These interviews suggested to the researcher the possible existence of two poles in men's experience of making the decision to have children. On one extreme is the prospective father who has experienced substantial doubt about taking on this responsibility and who as a result experiences that decision as an extended and rather difficult process. For this father, the choice about whether or not to have children is experienced as a conscious conflict which must be resolved. On the other extreme is the prospective father who has never experienced this choice as a conflict. This father has known all his life that he wanted to have children and the experience of making this choice has primarily to do with matters such as timing and career.

Pilot interviews and subsequent discussion suggested that men in this latter category may not experience the choice to have a child as a "decision" in the full sense of the word. These men conveyed a sense of inevitability about their choice, with little weighing of options. If these men engaged in a decision process, it had possibly taken place at a much earlier age or possibly unconsciously. At any rate, the experience being sought was not accessible to consciousness and they could not provide a description of it for the researcher. 
After conducting these pilot interviews a decision was made to exclude from the study those men who experienced the decision to have their first child in this latter manner. The reason for this exclusion was that they did not meet one of the fundamental criteria for subject selection in phenomenological research: the ability to provide a description of the phenomenon. Subjects for this project thus include only those men who experienced making this decision in a conscious, elaborated way. These are the only men who can provide a full description of the phenomenon.

The implications of this decision merit some discussion as it is. in a sense. a finding of the study whose significance is unclear. It raises questions, both quantitative and qualitative, about the implications of this study. A first, basic question pertains to the proportion of men who experience the decision to have a child in a conflicted way versus those who do not fundamentally experience it as a decision. A second question concerns the characteristics of those who fall into either group. In the course of recruiting subjects, the researcher found no suitable way to screen for the characteristic of conscious decision-making prior to conducting an interview. Some men who initially suggested that they were unambivalent in their decision process proved during an interview to have experienced an active, ambivalent, and highly conscious decision process. Conversely, some men who claimed to have gone through an ambivalent decision process proved unable to articulate that process in an interview (such interviews were not included in the analysis). A third question would speculate on whether at the deepest level these are in fact different experiences. That is to say, is this finding a factor of the experience itself or is it a factor of some aspect of the man's expressive style? It is possible that the underlying experience itself is the same for both groups, but the distinction encountered 
was their ability to access and articulate that experience? A final area of speculation concerns men's experience in making decisions across the wider range of reproductive experience. What, for instance, is a man's experience in adjusting to and making decisions about accidental pregnancies? What are the characteristics of the decision to have abortions? What about those who decide to remain childless? These are all questions which merit further study and which would shed valuable light on the findings presented here.

\section{Characteristics of the Sample}

As suggested above, little is known in general about the characteristics of men as they relate to reproductive decision-making. It was hypothesized, prior to the beginning of this study, that men who fit the selection criterion of having made a conscious decision to have their first child would likely be "late-timing" fathers. In fact, subjects' ages ranged from 20 to 44 years old at the time of the interview. In the analysis of the interviews the experience of the youngest subjects combined easily with those of the older subjects. (This is not meant to suggest that experience does not vary by age. but simply to illustrate that a man can experience and articulate a conscious decision process at any age.) All of the subjects were married, none had been divorced. For all of them this was their first child. although one had recently begun step-parenting two children.

At the point when subjects were interviewed the progress of the pregnancy ranged from a recent conception that was only eight weeks along to several subjects who were at or near their due date. Several subjects had experienced fertility problems in the process of attempting to conceive. One had experienced a miscarriage. 
Subjects were all white, but class and education levels varied widely. Three subjects held graduate degrees, two had attended college. one had not gone beyond high school. Similarly, subjects made up a wide occupational range: a maintenance worker. a carpenter, a social worker, a store clerk, a medical technician and a university professor.

\section{The Interviewer}

As described in the introduction, the phenomenological method acknowledges and engages the subjective experience of the researcher. As such. the characteristics of the researcher-as they relate to the phenomenon being studied-play an inevitable role in shaping and defining the research.

The researcher for this project is himself a recent father who had a one year old son at the time these interviews were conducted. He is a third year graduate student in a counseling program who served an internship which focused on parent education and in which he facilitated a fathers support group. He came to this subject with a pre-existing interest in the experience being studied which arose out of his particular personal and professional experience. Prior to conducting these interviews. he immersed himself in the available psychological literature on fathers and on reproductive decision-making.

Although the researcher made a conscious and continuous effort to bracket his personal experience and knowledge as he conducted these interviews and analyzed the resultant data, his recent involvement with the phenomenon being studied was inevitably a subtle factor which influenced the entire process. He observed that a certain sense of camaraderie seemed to be an integral aspect of the very act of sitting down to discuss this experience with another expectant father. Such a conversation constitutes an unusual experience for a man and he sought out a common bond with the interviewer which gave 
him permission to move deeper into his description of the experience. He wanted to know that he was understood and the researcher commonly provided him with this reassurance. While the researcher does not believe that this pre-existing perspective biased the results in any significant way-in fact, in some instances he had the uncomfortable experience of having to let go of his assumptions as they were disconfirmed by the data-he acknowledges the importance of their presence in the research.

\section{Data Collection: The Interviews}

The goal of phenomenological interviewing is to obtain complete and deeply expressive descriptions of an experience. As a result, the interview process is unstructured and informal, with the researcher following the movement of the subjeci's consciousness. The interviewer in phenomenological research does not attempt to draw out specific information, but rather to facilitate the subject's ability to provide a rich description of their experience. This process is described in detail by Polkinghorne:

The interview seeks descriptions of the experience itself without the subject's interpretation or theoretical explanations. To keep the focus on non-theoretical descriptions of the experience, the interviewer takes care to remain open to the presence of new and unexpected constituents in the description and does not shape the questions as tests of ready-made categories or schemes of interpretation. Rather than seeking general opinions, the interview focuses on specific situations and action sequences that are instances of the theme under investigation so that the essence or structure of the theme will emerge and show itself. When the statements of 
an interviewee are ambiguous, it is the task of the interviewer to seek clarification. (1989, p. 49)

While the researcher makes every effort not to guide the subjects. he or she is not naïve about what is known in the existing psychological literature relating to the experience. This knowledge informs the subject selection process. the definition of the question to be asked and suggests directions for exploration and expansion within the interview.

Possible subjects were contacted by telephone prior to each interview at which point they were given basic information about the research and asked if they were interested in participating. (Some subjects were screened out at this point if they clearly didn't meet the criteria-such as those who had experienced an unplanned pregnancy.) Interviews were conducted at a place of the man's choosing-two at the subject's home, four at their place of work. Prior to the beginning of each interview, subjects were provided with information regarding the agreement they were entering into in participating in this research, including confidentiality, transcriptions and use of the data, and their right to withdraw. Each was informed that the interview would be transcribed and that all identifying information (names, place of work, etc.) would be changed or removed. Each had an opportunity to ask questions regarding procedures. use of the data, etc. before signing an informed consent form agreeing to these terms. Each received a copy of this form.

The formal interview begin with the researcher reading each subject the following statement: 
I know that you have recently made the decision to have your first child. I would like you tell me about the experience of making that decision.

Subjects were encouraged to respond to this question in any way they pleased. with minimal intervention from the researcher. Some expressed some initial confusion about where to focus but each quickly engaged in his version of the narrative of the process.

After the interview was completed, it was transcribed verbatim. in its entirety. Subjects were provided with copies of the transcript and were asked to review it for any inaccuracies or for any information which might reveal their identity. No such changes were requested by subjects.

\section{Data Analysis: A Description of Phenomenological Reduction}

Various authors have outlined the specific steps that are used in the analysis of phenomenological research data (Giorgi. 1985b: Kruger. 1981; Polkinghorne. 1989). each describing those steps in slightly different terms. The process as it is described here will draw on all of these accounts. The process of analysis takes place in six steps, as described below.

Level One This stage involves the transcription and multiple readings of each interview in order to get what Kruger (1981, p. 128) calls "an intuitive holistic grasp of the data."

Level Two At this stage, the researcher re-reads each interview allowing "meaning units" to emerge from the data. The researcher examines the data looking for shifts in focus and/or meaning in it. Giorgi (1985b, p. 11) defines these meaning units as "spontaneously perceived discriminations within the subject's description arrived at when the researcher assumes a psychological attitude toward the concrete description." 
At this point, the researcher retains the language of the subject as it occurs. The researcher operates using what Giorgi terms a "disciplined spontaneity" (p. 14). "whereby one first discovers the relevant meaning unit. or its category. and only later. based upon a subsequent analysis, explicates its actual full import."

Level Three At this stage, the researcher examines the meaning units identified in each interview in order to eliminate those which are not essential to the experience being described. For this project, each meaning unit was interrogated by asking the following question: "What does this reveal about this man's experience of deciding to have his first child?" Those meaning units which did not bear on this experience were discarded. At this stage, the sequence of interview material were re-arranged into a narrative format in order to bring similar topics together.

Level Four Here, the researcher transforms the meaning units discovered in each interview from language of the subject into language which expresses its psychological meaning with regard to the experience. This process is necessary, Giorgi writes (1985b, pp. 17-18), "because the descriptions by the naïve subjects express in a cryptic way multiple realities, and we want to elucidate the psychological aspects in a depth appropriate for the understanding of the events." Giorgi refers to the process by which this is done as "reflection and imaginative variation" (1985b, p. 18). In the first part of this process, the researcher reflects on the meaning of the subject's statements in order to ascertain their psychological meaning. As Polkinghome describes it (1989, p. 55), this transformation is accomplished by asking two questions: "What is truly being described in the meaning unit? and What is absolutely essential to understand the psychological dynamic operating here?" "Imaginative variation" refers to the process of testing the 
transformed language by possible variations in order to identify incorrect or imprecise formulations. "The point of free variation." Polkinghorne elaborates (1989. p. 55). "is to imaginatively stretch the proposed transformation to the edges until it no longer describes the experience underlying the subject's naïve description." The movement at this stage is toward an increased level of abstraction, away from a focus on the specific situation or content in the interview.

Up until this point, each stage of the analysis is performed on individual interview transcripts. For the final two steps, all six interviews are combined.

Level Five In this stage, the researcher looks at the data arrived at in level four for all six interviews in order to arrive at a "situated" description of the structure of the experience which is common to all six subjects. Those aspects of the experience which were shared by all six subjects were combined into a single description: those which were not common across subjects were discarded. This synthesis, Polkinghorne states (1989, p. 56), "involves an intuitive 'grasping' of the essential psychological elements that incorporate the redescribed psychological meanings, and it is thus different from an inductive or simple generalization procedure." At this stage, however, the description remains situated within the specific aspects of the subjects' experience. As some orienting content remains, it is not yet an "essential" description.

Level Six In this final stage, the researcher further reduces this combined description of the experience by eliminating those situated aspects of the description in order to arrive at an essential description of the experience. This "general structural description," Polkinghorne states (1989, p. 55), "leaves out the particulars of the specific situation reported in the protocol. Instead, it centers on those aspects of the experience 
included in the protocol that are transsituational." This Level Six description is the central finding of a phenomenological study, which reveals the deep structures of a phenomenon as it appears in consciousness. 


\section{Chapter Four}

\section{Data Analysis and Results}

This chapter will describe the data analysis process as it was performed on each interview, using sample text from one interview to illustrate the process. The complete text for all interviews and the analysis on Level One through Level Four is available in appendices $A$ through $F$ of this report. Analysis on Level Five (the Fundamental Description of men's experience of making the decision to have their first child) and on Level Six (the Essential Description of men's experience of making the decision to have their first child) will be presented in this chapter.

The examples presented below should provide the reader with a good sense of the overall analytical process which was performed on the data for this project. However this summary cannot begin to convey the full range of rich thematic material that is contained within the interviews themselves. In order to appreciate the depth and range of the experience which is summarized here and to be able to assess the validity of the phenomenological reduction performed in Level Five and Level Six, the reader is encouraged to explore the full texts of the interviews.

The analysis proceeded in a similar pattern for all interviews. After transcribing all of the interviews from audiotape, the researcher analyzed each separately, beginning with Level One (the transcript itself) through Level Four. Because an essential aspect of the analysis process involves a thorough immersion in the themes within each interview, analysis was completed through Level Four on each individual interview before proceeding to the next stage, at which interview data was combined. 
Men's experience in making the decision to have their first child is rich and complex. It draws from many areas of a man's current and past life and it is often marked by contradictory elements. Because of this complexity, the researcher did not assume that the constituent elements of the experience would necessarily be easily or immediately apparent. Prior to beginning the analysis he read through each interview a minimum of three times, during which time he "sat with" the experience as it was described in an effort to allow the subjective experiences to define themselves for him as much as possible.

On the following reading, the researcher marked in the interview each point at which the subject's consciousness appeared to make a shift or transition. These divisions in the text. which are indicated by slash marks. represent the researcher's determination of meaning units in the text. The division of the text in this manner is not an exact science. One could easily dispute the precise division of individual meaning units. However, as the analysis proceeds to increasing levels of abstractions. these fine distinctions fall out and become less significant. The purpose of this initial division of the text is not so much to identify subtle distinctions in meaning as it is to allow for a transformation of the data which will render it more tractable.

Once meaning units in the text have been identified, the researcher advances to Level Two in which the subject's speech is re-stated in a manner which is generally more concise than the original but which retains most of the subject's original language. Frequently the exact language used by the subject is retained in quotes. The re-statements developed in Level Two are numbered consecutively through the interview and are placed side by side next to the subject's original statements. An example of this stage of 
the analysis follows. (This is an excerpt from Dylan's interview which can be found in Appendix B.) Level One is the interview transcript on the left hand side of the page;

Level Two is the composed of the numbered meaning units on the right hand side: 
Interview Text

Yeah, that sounds great. That sounds really important.

/But you know, it's always a tossing it's a juggling game. from the time you decide you want to get pregnant to the day you find out you are, it's a constant juggle. Especially for me. /One day I was all for it, the next day I was, you know, "no, no, we can't do this, we're too young." you know. /And then, probably right around the time that we decided this is it for sure, no turning back, I decided that, you know, I was done listening to everyone, you know. /One day I get the readings of "yeah. you'll be a great dad, you'll be great parents," the next day everyone told us "you "re too young for that, you"re too young," you know, "don't have a baby yet, you're going to ruin your life." /One day I decided to quit listening to everybody. And I decided to make up my own mind. /And I actually feel sorry for the people that said that I was going to ruin my life by having a child. /It's been hard - the mood swings, the staying up with her at three in the morning watching her throw up, but I mean, thus far I have more joys than complaints. She's just now starting to get her belly. It's kind of cute - she sees me looking, I'm in trouble. /But you know, I feel sorry for them, they're going to miss all this stuff and then one of these days they're going to wake up and roll out of bed and they're going to be single or with their wife going to realize it's too late or they should have done this, you know, a long time ago.

So you feel really strong in your decision. It sounds like that point where you just decided to stop
76. From the time $S$. and his wife decided to get pregnant to the day the found out they were. it's been "a juggling game" for him.

77. S. went back and forth in his feelings about having a child. "One day I was all for it. the next day I was, you know. 'no. no. we can't do this, we're too young."'

78. At the point when $\mathrm{S}$. and his wife decided that they were going to have a child for sure-"no turning back"-S. decided that "I was done listening to everyone."

79. S. got mixed messages from others about the decision to have a child. One day he was told that he'd be a great dad. the next day he was told that he was too young and was going to ruin his life.

80. One day S. decided to quit listening to everybody: "I decided to make up my own mind."

81. S. feels sorry for those who warned him against having a baby.

82. The pregnancy has been hard, but $S$. has "more joys than complaints." He's excited by the changes in his wife's body.

83. S. feels sorry for those who warned him against having a baby. $\mathrm{He}$ believes that they're going to miss what he is now experiencing, that they'll wake up one day and realize it's too late. 


\section{listening to everybody and decide for yourself...was a big moment.}

Y Yeah. it was actually. I was at work when I did it. Some lady had come in that, she had a baby. And we were just sitting there kind of talking back and forth. And I don't remember exactly what it was that she had said, something about she used to listen to everyone and she was, you know, an older lady, and she said that her biggest regret was that she' $d$ waited so long to have a baby because she was scared of what people would think and this and that. Then you know she said that if she could give advice to anybody, it'd be. if you want to have a baby, have it when you think you can handle it. not when you think your friends can handle it. And that was kind of the big snap in it all.
84. S. had an experience at work which caused him to stop listening to others about the decision to have a child. He was talking to an older woman who told him that her biggest regret was having waited too long to have a baby because of the fear of what other people would think. Her advice to S. was that "if you want to have a baby, have it when you think you can handle it. not when your friends think you can handle it." 
The themes which arise in this excerpt from Dylan's interview involve a fairly representative sample of the sorts of issues which were involved in his decision process. including his ambivalence about his readiness to become a father. the importance of the influence of other parents in helping him come to trust his own abilities. the choice to trust in his own ability to make the decision. and his excited reaction to the pregnancy itself. In discussing his experience of making the decision. Dylan draws connections between the influence of others and the resolution of his own internal ambivalence. As he speaks he interweaves these and other themes. This was not at all an uncommon process in these interviews, as the issues involved in the experience were integrally related to one another.

After breaking the transcript into meaning units in Level Two, the researcher proceeded to Level Three, which involves the shaping of meaning units into a narrative. In constructing this narrative. the language of the meaning units in Level Two was left essentially intact-changes were mostly of a syntactical nature and were made primarily to facilitate the flow of the subject's story. Much of the subject's original language remains at this level in the form of direct quotes. The description remains situated in the subject's concrete experience.

In the process of shaping the data into a narrative format, the researcher subjects the data to two additional transformations at Level Three. First, each meaning unit is interrogated with regard to its relevance to the experience being studied. The researcher examined each meaning unit, asking what if anything it revealed about the experience of making the decision to have a first child. If the meaning unit did not reveal anything about this experience-this occurred very rarely-it was discarded. Some statements were 
repeated. This redundancy was observed and retained-sometimes in the form of repetition, sometimes in the form of emphatic re-statements. The second transformation at Level Three occurred in the re-arranging of meaning units to reflect what the researcher perceived as a reasonable representation of the data. both chronologically and thematically. In this re-organization, the researcher took the first steps toward explicitly identifying the larger themes present in the subject's description of his experience.

Examples from Dylan's Level Three analysis is presented below (it appears in its entirety in Appendix B). While this text corresponds roughly to the excerpt from Dylan's interview presented above, it should be noted that the analysis of the data at Level Three resulted in a significant re-arranging of the data, in which statements were re-organized thematically. As a result. it is not possible to compare precisely across these two levels. Statements are included in this Level Three excerpt which were taken from different portions of the interview and so do not appear in the excerpt previously presented in Levels One and Two. 


\section{Level 3 (excerpts)}

From the time he and his wife decided to get pregnant to the day the found out they were, S. has gone back and forth in his feelings about it. "One day I was all for it. the next day I was, you know, 'no, no, we can't do this. we're too young."' It's been "a juggling game" for him. But now that he and his wife have made the decision. he acknowledges that "it's too late to turn around and go back." (...)

S. spent time at his job talking to other women about their decision to have children. This was a big factor in his decision process. He asked these women what they thought about having children and how their babies had affected their lives. They all told him that they'd worried too much about what their friends thought about the decision. They said to "forget what everyone says, if this is what you want, do it." Some of the women he talked to about having a child said that having a baby had split up their marriage. But none of them regretted it. They said that "before they were pregnant they couldn't imagine life with a baby and now that they had one they couldn't imagine life without it."

S. had one experience in particular which caused him to stop listening to others about the decision to have a child. He was talking to an older woman who came into the store who told him that her biggest regret was having waited too long to have a baby because of the fear of what other people would think. Her advice was that "if you want to have a baby, have it when you think you can handle it, not when your friends think you can handle it." In making the decision to have a child, S. believes that men should "forget what people say, they're not the ones living with it, you are."

One day S. decided to quite listening to everybody: "I decided to make up my own mind." At the point when he and his wife decided that they were going to have a child for sure-"no turning back"-he decided that "I was done listening to everyone. Now: he says that he feels sorry for those who warned him against having a baby. He believes that they're going to miss what he is now experiencing, that they'll wake up one day and realize it's too late. 
Level Four is the final level of analysis prior to the combining of interviews. Here the researcher deliberately imposed for the first time his own psychological understandings on the subjective data presented in the interview. At this stage the narrative of this experience was transformed through abstraction. presented in language which reflects the researcher's psychological understanding of the subject's experience of making the decision to have his first child. This involved a further level of reorganization according to an increasingly abstract thematic understanding of the data. Certain key phrases-those which seem to articulate essential aspects of the experiencewere left in the subject's original language. The description at this level remained situated in many of the specific aspects of the man's experience. but the language of the description moved toward a level of abstraction which would allow the specific components of his experience to be compared with those of other subjects. When themes were expressed implicitly or obliquely, the researcher at this point expressed them more explicitly.

On the following page is an excerpt from the Level Four analysis of Dylan's interview which corresponds-again, roughly-to the excerpts previously presented: 


\section{Level 4 (excerpt)}

As he has gone through the process of deciding to have a child. S. has been powerfully affected by what others have told him about becoming a parent. This has been both a positive and a negative influence on him. Some have encouraged him to have a child and others have wamed him against it. The most important conversations he had were with other women about their experience of making the decision. The advice they gave was that he should follow his own heart rather than worrying about what others thought. They also suggested to him that even if having a child damaged his marriage. he would not regret the decision.

Through these conversations, S. reached a point at which he could put aside his concerns about what other people thought and make the decision for himself. $\mathrm{He}$ recognized that if he didn't decide to have a child now he would go through his life wondering whether he should have done it. He did not want to feel this regret. It was at this point that he was able to go ahead and make the decision. 
At Level Five all six interviews were combined to create a statement which reflected the fundamental aspects of a man's experience of deciding to have his first child. The process through which this synthesis was achieved involved a process of imaginative variation in which the thematic elements in each interview were sifted and compared as the researcher arrived at a determination as to which themes were common across all interviews and which were not. This process is similar in many ways to the abstraction which occurs in Level Four. The researcher examined the full range of themes as they are expressed in all interviews to determine which is were essential components of the experience and which were variants. This process once again involved examining both implicit and explicit themes, bringing out more clearly in the text those which were implicit. (At this stage, certain themes presented themselves as unique to individual subjects. The significance of these variants will be explored in the discussion of the data which follows in the next chapter.) The researcher then transformed the data into a unified statement which reflected those elements of the experience which were common across all subjects. The Fundamental Description of men's experience in making the decision to have their first child follows. 


\section{Level 5}

\section{Fundamental Description of Men's Experience of Making the Decision to have Their First Child}

In contemplating the possibility of becoming a parent $\mathrm{S}$. is transfixed by the permanence of the connection that will be created when he chooses to have a child. He is both drawn to and intimidated by the power of that bond. attracted to the joy it might bring but also acutely aware that the emotional investment he makes in a child-even before it is born-will expose him to the possibility of pain and loss. In making this decision, S. has a vivid. concrete awareness of what he stands to lose. The benefits. on the other hand. are mostly abstract to him. He finds he cannot directly measure one against the other.

S. thus arrives ambivalently at the decision to have his first child. He holds off ms:king the choice because it causes him stress, forcing him to move outside of his habitual ways of being. bringing to consciousness aspects of his personality which he is unaccustomed to acknowledging. He struggles to balance his felt need to serve as provider for his family with a more vaguely felt desire to maintain an intimate presence in his future child's life. While he feels reasonably confident about his ability to support and provide for a child. the larger meaning of creating a life is ineffable. even magical to him. Because he cannot know with certainty what effect it will have on him. he must acknowledge his limitations and accept that in many ways the outcome will be governed by forces beyond his control. As a result. in choosing to have a child $\mathrm{S}$. embraces a paradox. In his effort to make the decision rationally. he seeks certainty and control; but he finds the very nature of the decision requires that he relinquish the control he seeks.

S.'s decision thus entails a leap of faith. He feels the need to abandon logic, to follow instead an impulse in his heart. He re-frames his question in order to render it answerable. Instead of asking whether the benefits of having a child outweigh the costs. he asks himself whether or not this is an experience he desires. in and of itself. In so doing. he transforms a process which he perceives as irrational into one which has a transcendent significance. In relinquishing his own need for personal control. he trusts in the larger forces which govern the universe. He moves from a view of the world which has been defined by his sense of separateness and personal power. to one which is defined by generosity, interconnection. and trust.

As he makes this decision. S. enters a process of constructing a positive image of his future child and of himself as a father. His memory of his own childhood-which he instinctively projects onto his imagined child-retains a profound influence. $\mathrm{He}$ accomplishes the difficult task of learning to see beyond the boundaries of that experience in large part by looking at the experience of other parents and children. What he sees is equivocal, but the positive impressions he forms have a powerful effect in counter-balancing his own negative expectations. He seeks and finds confirming evidence that both childhood and parenthood can be positive experiences. 
By creating an image of himself as father to a child, the previously abstract benefits of parenthood become more real to $\mathrm{S}$. He begins to trust that he can be a good enough father, that he has something to offer a child. He has a pre-existing notion of what an ideal father should be. one which he has constructed largely by examining the strengths and weaknesses of his own parents. He looks back at the model his father has provided, deciding which qualities to emulate and which to reject. He takes an inventory of his personal strengths and weaknesses to see how he measures up against his own constructed standard. He acknowledges his flaws but pays increasing attention to his strengths.

As $\mathrm{S}$. integrates his understanding of his past with his concerns about the future. he brings himself fully into the present moment. He feels that he is coming to see himself and his world more realistically. He clears away his pre-existing expectations about himself and the world, about children and parenthood. He discovers that he has already changed and grown-more than he had realized. This recognition gives him the courage to move forward.

Every aspect of this decision is informed by the quality of affection and communication within S.'s relationship with his wife. He knows that the decision must be made within this relationship and as he speaks about it he cannot always separate his own attitudes from those he holds together with his wife. He frequently speaks not of "I" but of "we." In making the decision, he integrates his individual identity into the relationship more fully than he has in the past. This is a source of both strain and comfort for him. On one hand. he feels a loss of personal control, on the other he is greatly relieved at not being alone in bearing this responsibility. His trust in his wife's nurturing abilities and in the stability of their union are essential to his being able to decide to have a child.

S. does not experience the decision to have a child as an event which occurs in a single moment. Rather it is a dialectical process in which he moves back and forth between two conflicting poles-his desire for independence and his need for connection. his desire for control and the need for trust. his fear of loss and his longing for the positive transformation which he hopes a child will bring. The point at which he is able to decide to have a child occurs when his awareness of the potentially positive aspects of that experience is strong enough that he can tolerate without undue anxiety his awareness of the losses that the choice may bring. His ambivalence does not come to an end at this point. Rather, he becomes capable of holding within his consciousness the conflicting aspects of his experience.

With the conception and the developing pregnancy the child's existence becomes more real to $S$. and his commitment to the decision solidifies. The impending reality of the birth puts his past concerns in a new context. He comes to see these feelings as challenges which he can overcome and through which he will grow. He looks forward to the birth with excitement and anticipation. 
At the final level of analysis. Level Six, the researcher steps back from the description arrived at in Level Five in an effort to arrive at a description of the essential. invariant structure of that experience as it appears in consciousness. This final statement was arrived at through a process of reduction, which transformed the data from a still subjective. still somewhat situated description of the experience, to a generalized description of the phenomenon as it occurred across a variety of specific circumstances. The description at this level no longer possesses an entirely intuitive relationship with the descriptions previously arrived at. The subjects might not describe their experience in this way-they might not even recognize themselves in it. Rather, the description is a statement of the researcher's perception of the abstract and invariant structure of the experience. Level Six, the Essential Description of men's experience of making the decision to have their first child, follows. 


\section{Level 6}

\section{Essential Description of Men's Experience of Making the Decision to have Their First Child}

In making the decision to have his first child, a man moves through a dialectical process of personal transformation as he seeks a satisfactory way to contain within himself his contradictory desires for independence and interconnection. for security and change, for self-control and trust. The movement between these poles is activated by and draws energy from his ambivalence. The inner conflict he experiences impels him toward resolution.

The decision process is recursive and self-modifying. The very fact of engaging with this question causes a man to examine himself and his world in a new light. As a result, his sense of potentiality becomes less constricted. He is partially drawn out of his image of himself as a separate, self-controlling being and increasingly drawn into a deeper awareness of his dependence and inter-relatedness with others.

In the process of making this decision a man creates an interior image of himself as father to a child. In creating this image he is pulled both backward into memory and forward into an imagined future. The commitment implicit in the permanence of a physical connection with a child anchors him in time, heightening his sense of vulnerability to pain and loss. His awareness of the expansiveness of genetic time heightens his awareness of the limits of his own existence. 


\section{Chapter Five}

\section{Discussion}

\section{Generai Themes: Men's Experience in Deciding to Have their First Child}

Yeah, it, it...I was pretty close to that point where the ambivalence felt...or the negative aspect of the ambivalence was waning somewhat and I was feeling definitely more positive about the idea. And then it really does feel like at some point I had to just philosophically throw up my hands and say what the hell, let's go ahead and do this. (Tobin)

The analysis presented in Levels Five and Six contains a narrative account of the essential themes of a man's experience of deciding to have his first child. This account is composed of a series of overlapping and interwoven themes. In order to facilitate discussion of these themes across subjects in this chapter, they will be separated into eight categories: (a) a decision ambivalently made. (b) accepting the limitations of personal control, (c) coming to terms with the permanence of change, (d) embracing change, (e) coming into the present moment, ( $\mathrm{f}$ constructing a paternal identity, (g) separate and together: integrating self and marriage, and (h) the decision as an on-going process.

It should be emphasized that these distinctions are artificial. Although it is necessary to break the decision process into a set of discrete themes. the experience as such cannot truly be broken down into each of its component elements. As will become evident, each of these themes contains aspects of the others. Although the component aspects of this experience can be identified and named, they are truly part of a gestalt. The whole is greater than the sum of the parts. 


\section{A Decision Ambivalently Made}

I don't know if there was any point like, one day I woke up saying. okay. I'm ready. I don't think it was anything like that, it was like... when we first started trying I guess it was like, well, if it happens... I've got nine months to get ready. (Evan)

Although he wishes he could do so, a man cannot make the decision to have his first child unambivalently. He approaches the question using the tools with which he is familiar: logical reasoning. He seeks to understand whether or not it makes sense to have a child. He attempts to perform a sort of cost/benefit analysis. to measure the pros and cons of the decision. But what he discovers. as Tobin describes it. is that "the negatives seemed verry concrete... and the positives seemed somewhat more abstract." He is trying to compare across fundamentally different categories and as a result. his efforts to make the decision logically lead him to an internal sense of stalemate.

The decision causes a man stress. He agonizes about it and avoids discussing it, although he knows that he cannot responsibly avoid it. The decision is compelling to him. He finds himself pulled toward it. The irritant of his ambivalence mobilizes a certain energy within him. The intensity of his ambivalence sometimes rises to a level of felt distress. It demands some sort of resolution. Although his ambivalence will continue in some form through to the pregnancy, it is at its most intense in the early stages of the decision process.

The resolution of this ambivalence will be defined not by the development of a clear rationale for making the decision one way or the other, but rather by the man's increased ability to hold both the positive and negative aspects of the experience 
simultaneously in his mind. He achieves this resolution through a process (which varies in its specifics from man to man), in which he lets go of his efforts to make the decision rationally and arrives instead at an attitude of sufficient trust in the emotional. nonrational or spiritual aspects of his experience. This transformation makes it possible for him to re-frame his basic question. He no longer asks himself if his life will be better or worse if he has a child. He asks instead whether or not he wants the experience of having and raising a child, in and of itself.

Tobin begins the process with an intense ambivalence, which is heightened by his inability to weigh the costs and the benefits of his options. His resolution to this dilemma is to embrace the emotional aspects of the decision.

...I still have ambivalence about it, but...yeah, I think that there was at some point kind of a, oh. well, I'm not, I've done all the thinking I can do about it. I'm not coming to anything that feels like a logical conclusion, or that, you know, that I've got this balance beam that's weighed way down on this side toward the positive, you know. So, I'm not going to be able to make a rational decision. Leslie wants to have a child. And I feel very positive it would be a positive experience. And you know, once I started feeling more like she was fairly positive-[ think it was a little bit of a bootstrapping process for both of us.

Tobin characterizes his decision to have a child as "the most irrational decision I've made in my life."

Abe is perhaps on the other end of the spectrum with regard to the sense of ambivalence. His feelings about having children had once been extremely negative but 
they switched quite abruptly to a positive outlook. While he had previously felt a "distant nagging that it just wouldn't work." his hesitation was overcome by an experience which he describes as having a revelatory quality. "Somewhere deep inside of me." he says. "all of a sudden I could see myself with a child."

In between these two extremes lies a fairly wide range of experience with regard to the development of a man's initial ambivalence. Frank's ambivalence was not so much about the child itself as about the conditions of the relationship in which he would have that child. Could he truly trust another person enough to have a child with them? Evan and Dylan both describe moving dramatically back and forth in their immediate feelings about the decision. Evan describes his feelings as "scared...confused. just the normal thing. Am I ready, am I not ready? Is this the time, isn't this the time?" Dylan describes his experience of ambivalence as a "juggling game." He says that one day he was " all for it. the next day I was, you know, 'no, no, we can't do this. we're too young.' you know." He hopes that his hesitations are typical:

...can I handle this? Am I physically and emotionally strong enough to handle all this? Guys have this macho front, and I don't care who the guy is. they all have these wonders, they all have this and that. And I think any father who's planned it out, I'm hoping once again, has these worries. you know, can I handle this. can I handle that?

Dylan moves through his ambivalence with a continuing questioning of God for giving him this pregnancy: "Man, did You know what You were doing?" He says that he's "kind of crossing my fingers hoping God has a plan of what He's doing in all of this." He seeks and finds evidence in the details of his life that God "knows what He's doing." 
Nathan also sees his ambivalence as being mediated through his faith and trust in the guidance of God. His entire decision was defined in terms of a discussion with God through prayer. His reluctance to have a child was personal but he came to feel that God wanted something different for him:

...as I prayed about it, and as I had the feeling internally that it. whether. you know the proper thing to do was to have another baby now as opposed to wait. And I kept thinking, you know, I want to hold off on this thing here. So I did, I prayed about it several times, I said "now are You sure about this?" because I, I, you know, am willing to do what I need to do, because that's a big, big jump.

Nathan moves into an position in which he can embrace the experience of having a child by understanding that "I have the strength of my Heavenly Father and of my wife and her wisdom. And we're a team. All three of us are a team in raising these children. And if we 're working together, it's going to work." Nathan expresses in an explicit form the sort of resolution which all of these men sought and found in their decision process. Before they can arrive at a decision, they first have to find a way to contain their internal doubts within some sort of transcendent belief system.

\section{Accepting the Limitations of Personal Control}

Because like I said, I like to be in control. And part of the way you grow is to allow somebody else to be in control. To learn how to follow. (Nathan)

The decision to have a child requires men to relinquish to some degree their sense of personal control over their own life. As they describe it, this demand has a paradoxical quality. On one hand they are assuming a tremendous responsibility. On the other, they 
cannot describe or even comprehend what the nature of this responsibility will be. Implicitly or explicitly, they ask themselves how they can be assured that they are capable of assuming this responsibility when the decision itself forces them to accept the limits of their own control.

While all men express concern about the issue of personal control in the decision to become a parent, for some it is expressed rather subtly while for others it is a matter of central concern. The degree of power this theme holds for each man relates not to the decision itself but to his pre-existing experience and personality traits. If a man has a need for a high degree of control prior to the decision, this becomes a significant conflict for him during the decision. A man who has less need for personal control finds that this issue, while still present, is less central.

Implicit in the notion of letting go of personal control is the necessity of being able to trust in forces outside of the self. This necessary dependence presents a dilemma which each man resolves in his own way. For some this simply means accepting that making the decision will alter their lives in ways which they cannot know beforehand and which are perhaps entirely ineffable. For others this trust is expressed in the form of an explicit faith in a deity, trust in the marriage or in one's own inherent capabilities. Sometimes it is simply a matter of blind faith and hope-a trust not in any person or object or force, but in life itself. All of these attitudes have in common that they are means of moving beyond the need for control and accepting that one's life will in some ways be controlled by forces beyond oneself. 
Frank and Nathan describe the need for control most explicitly as a defining factor of the decision. Frank describes his need for control before making the decision this way:

So that I said... if I have a child I want every single duck in a row. So I want to make sure that I've got my education finished, I've got a job that's in perfect shape, I have a house that is almost paid for so that I don "t have to worry about that.

He comes to feel however, that this was "sort of a crazy way to think." At some point. he says, he realized " that giving up control may be the best thing for me to continue to grow." Nathan describes a similar need for personal control. And like Frank, he believes that relinquishing this need is a part of his process of spiritual growth.

Other men's need for personal control takes a more subtle form. Often it is reflected in statements in which they relinquish their need to comprehend the meaning and outcome of their decision. Tobin's struggle for personal control is reflected in the way he accepts his inability to make a rational decision. Abe's struggle for control is observable within the abandonment of his staunch, long-held attitude that he would not have children. Dylan's and Evan's struggles are reflected in their concerns about being able to support and provide for a child and their decision to have that child even without feeling fully "ready."

Both Nathan and Dylan turn over his sense of personal control to God. "You know," Dylan says, "I think this is more faith than it is anything." Although Tobin's experience is not explicitly religious, it has a spiritual quality. He describes his decision as a "leap of faith." Interestingly, several men are able to relinquish their sense of 
personal control by invoking their own self-confidence. Evan describes how he knows "in the back of my head that yeah, I'm going to be a good father regardless when it happens." It seems paradoxical at first glance to describe this self-confidence as a quality which transcends the self. but he describes it as a force which is in certain ways outside of and beyond himself. Similarly, Abe says: "I have an over-blown sense of self-confidence." He describes this feeling as "something inside of myself that just. it calmed me. it was soothing. I realized that anything I did would work out well." Although he labels it selfconfidence, this is a quality which goes beyond the self. It is a faith in the transcendent qualities and abilities of the self which Abe attributes directly to God: "I realized that it was through the greater power of God, you know. Or of even just my wife and mine love. That I'd become a better, kinder, gentler, maybe wiser person."

\section{Coming to Terms with the Permanence of Change}

And this is...a creature, a child that can't function without me and my wife being there pretty much constantly. I've never had any-l've never had any situation in my life like that before. It's a little bit fear of the unknown in a sense. It's, I've never had a responsibility of that magnitude where someone was that dependent on me. (Tobin)

In making the decision to have a child, a man is transfixed by the permanence of the implications of his actions. In contemplating his potential child, he extends his imagination over the entire length of the child's life. He is acutely aware that its permanence makes this decision fundamentally different than any other he has previously made. He struggles to find a way to comprehend the meaning of the permanent and dependent relationship which he contemplates creating. In so doing he develops a 
heightened awareness of the limitations and potential losses which this decision may bring. In deciding to create a life he becomes conscious of his own place in time. He has arrived at a point in his life at which he can begin to measure out his future in terms of the development of his future child.

Although the men in this study rarely refer directly to an awareness of their own mortality, an awareness of the limits of time is implicit in many of the other limitations and losses which they struggle to accept as they make this decision. These losses-of personal freedom, intimacy in their marriage, the possibility of losing contact with their future child-arise out of the permanent change in the man's condition. There is no turning back once this decision has been made.

The specific felt losses and limitations vary from subject to subject, but all men describe a sense of awe at the permanence of the connection they will have with a child. And all in turn struggle to come to terms with their anticipated regret about the losses which parenthood will bring. Tobin, for instance. in the quote at the beginning of this section, describes explicitly the awe which all men seem to feel about the permanent quality of the dependent relationship he will have with his future child. And this sense of awe also contains within it "this feeling of I'm going to lose my freedom to kind of do whatever I want to do, you know, when I want to do it." This fear of options being foreclosed with the birth of a child comes up frequently. Evan, for instance, repeatedly expresses his fear that the security needs of his family after the birth of a child will prevent him from being able to change jobs. In addition, the decision for him brought up memories of an old girlfriend for whom he had some lingering romantic feelings. To him, having a child means accepting the final loss of this relationship. 
For the most part, when a man contemplates the nature of this relationship he expresses some degree of anxiety. Abe, however. describes the permanence of the connection as being part of the appeal of having a child:

And one of the things that appealed to me about having kids after thinking of it from my father's point of view, was that, you know, those kids that you have or that kid that you have, is never going to not be a part of you. it's never going to be a part of your life that you lose.... It's always. forever going to be a good thing about your life, you know. There are people I know with kids that have gone to jail, kids that have stolen from them and kids that have really made their lives miserable. But they love them unconditionally just the same.

Abe is unique in having arrived at the point of articulating positive feelings about the permanence of the dependent relationship with his child. But in common with other subjects that permanence also contains a quality of awe which moves him toward an awareness of limitation and loss. The "good thing" that this permanent connection represents also contains within it the possibility of being made miserable.

For Frank, the decision is defined by the fact that he will have to trust his wife more deeply than he previously knew how. "When we have a baby," he says, "I'm done. I am fully committed and I have to fully trust at that point." Trusting in this way means facing his "biggest fear," the possibility that he could one day lose access to his child: More than anything it becomes a matter of just trusting that...trying to trust my wife, being able to fully trust her. She's not going to freak out. She's not going to just up and leave. She's not just some flake. She's not 
just going to have kids and then all of a sudden go to Jamaica. You know, all these scenarios that potentially run through my mind that have to do with this potential fear of...I'm going to have a kid but I'm not going to have a kid.

Dylan describes similar anxieties:

So you know, I mean even if it doesn't work out between me and my wife. I'll most assuredly go out of my way to see the child part of it. Because I want to be a big part in my child's life, regardless. Like I said, another thing I worried about, is am I going to be a big part of my child's life? And I certainly want to be that part of his life, you know, I want to be his dad, I don't want to come over one day and see, you know, my eight year old son calling her new husband or boyfriend "dad," because it would just tear me apart. So I'm going to make sure - and I swore this before I even met my wife, you know - I'm going to make my way to see my child. That child is going to know who his dad is, one way or the other.

The thought of conceiving a child then having it be harmed or facing its death is another frequently described fear. But it is one which is most often expressed (perhaps because these interviews took place during the pregnancy) after some acceptance of the loss has been arrived at. Nathan says that "even if the child were to have a medical deficiency problem, I would know that things will still work out." Abe describes the process of having a child as one that has made him grow "in ways you know, that if this child is stillborn I've still learned so much from it." Dylan describes a similar acceptance: "If she came home hemorrhaging and lost the baby it"d be hard, you know really hard, but I 
mean, I'd eventually realize you know, even though it's a problem for us. perhaps you know there was a problem with the baby, the baby wasn't going to be normal. her body aborted it." Tobin is alone among the men in having had to come to an acceptance of these issues through facing the actual loss of a pregnancy:

And I was really surprised at my own reaction to it. I would have thought that it would have felt like. okay, the freedom and the absence of responsibility is still [laughs] potentially there.... Yeah. I think it. again. it almost...helped guide me in more trusting that I'd made the right decision. the sort of disappointment that I felt, the loss.

The awareness that he is exposing himself to the possibility of loss is an essential element of a man's experience as he goes through the process of making this decision. And as he moves toward an increasing commitment to his decision, his awareness of that potential loss becomes a sort of glue which binds him emotionally to his future child.

\section{Embracing Change}

...I know that there are things that change in your, in your...there's some intangible, sort of ineffable things that happen when you have a child. that people describe to me or try to describe to me about how you feel about that child, that I'm aware are probably going to be there for me. Yet I can't really feel those exactly right now. (Tobin)

As a man arrives at a conscious decision to have a child he chooses to embrace the changes that this decision will bring. He knows that he will be transformed by this decision in ways he cannot yet fully comprehend. Because he cannot understand the 
nature of these changes in advance, the decision causes him anxiety. He is moving into an unknown territory. He has no map for this terrain. Walking through it is an act of faith.

Change is thus both a cause and effect of a man's decision to have a child. Before being able to embrace the change that this decision will bring, a man must already have gone through a process of transformation. This transformation has two inter-related components. First, he moves away from his emphasis on his own personal control and toward a greater sense of generosity and unselfish love. Second. he moves away from his view of himself as an isolated individual and toward a view of himself as someone who is interconnected and interdependent with his family and his community. As Abe puts it, "you come to a point where the roads cross and you have to decide to become one, to give up that individuality, you know."

Change is a fundamental aspect of a man's experience in making this decision. Frank, for instance, describes how he "had to go through that...transformation" in order to arrive at the point at which he could decide to have a child. Dylan describes a feeling a more expansive sense of his own priorities, one which is characterized by an interconnected sense of responsibility: "my priorities also became my wife, my child, and you know, our house, which I call 'our little world." He discovered through the positive outcome of anger management classes that he was capable of transforming himself. Evan describes the changes he experiences in terms of the threshold of his own internal sense of readiness:

Well, everyone says you're never ready to have kids, usually. Like financially ready, you're never ready. There's no way you'll ever be ready financially. But then there's a point also when you're just plain not not 
ready, meaning, where can we pinch from to have money to provide for this little one.... There's a point where you're really really not ready and when you're just not ready.

The change Evan is describing is subtle. It is perceptual in nature. It is characterized not by external financial realities but by a quality of opening oneself to experience. It is not the world which changes, he is saying, but one's perception of the world. You never feel truly "ready." But you choose to open yourself to that change anyway.

In recognizing that he can change-that he has already changed-a man experiences a feeling of hope and a greater sense of faith in himself which allows him to move forward into further change. Still, he struggles to understand the nature of the changes he is choosing in deciding to have a child. Frank describes part of his motivation to have children as realizing that "there's something that [other parents are] experiencing that I haven't experienced yet. And I will never be able to experience it unless I - or. my wife and I decide to have kids." But men find it very difficult to articulate just what that "something" is, as can be seen in Tobin's effort to describe what he will experience in becoming a father:

You know I, beyond just...you know I suspect I'll feel kind of a feeling of love that is...tangibly for me, if not very easily expressed. different than other kinds of love I've felt. But beyond that, you know, it's...I'm guessing, you know?

The uncertainty inherent in the nature of this change causes men to question themselves and their ability to adapt. As Nathan poses the question: "Can I overcome the, the uh, trained response, and be the father. Instead of the commander, be the father. And that has 
been the big area of debate in my heart when I made the decision." Such debates will continue, expressed in the form of doubts and worries about the decision. But making the decision indicates that while he retains feelings of doubts, a man has chosen to embrace whatever experiences that decision brings.

\section{Coming into the Present Moment}

And uh, you know once I again looked at myself in the now as opposed to in the past-you know I'd always believed that I am what made me what I am. You know, and all my past is there. And I came to a different decision that I am no longer what I was that made me what I am now. (Abe) In making the decision to have a child, a man arrives at a deep awareness of himself in the here and now. In working through his ambivalent feelings (to do with loss. permanence, trust, dependence. etc.), he re-examines both his own past (particularly his view of how his own mother and father parented him) and his assumptions about the sort of person he will be in the future. He integrates his beliefs about the past and his expectations about the future into a synthesis which he perceives as an authentic awareness of his own capabilities in the present moment.

As he makes this decision, a man inevitably looks back to his own childhood. He examines his own childhood experience, projecting that experience forward and asking whether it is an experience he wishes to pass on. If his own experience was positive, he wonders how he can pass that experience on. If it was negative, he contemplates how he can have a child without re-creating that experience. He wonders whether or not it is inevitable that his child's experience will replicate his own. 
While men find positive aspects about their own childhood experience. they also express a desire to change at least some aspects of that experience. Of the subjects interviewed for this study, only Evan described a childhood which was fundamentally positive. The rest had to wrestle with significant negative experiences: divorce. loss of a parent, death of a sibling, intergenerational conflicts. The past weighs heavily on a man as he contemplates the future. Nathan, for instance. describes painful fights with his parents which he hopes to avoid repeating with his own children. Believing that "I"m highly likely to have a child with the same amount of stubbormness that I have." he speaks of "trying to figure out a more effective means to channel the talents of the child than the one that was used with me."

In order to make this decision. a man must overcome the belief that his past experiences will determine his future as a father. In order to accomplish this he engages in a process of social comparison. He begins looking more closely at other parents and children in the world around him, attempting as he does so to put aside his preconceptions. He pays attention to his reactions to other parents and children. Through this process, he revises his assumptions about parenthood. The benefits of having a childwhich had previously been somewhat abstract-begin to assume a more concrete form in his imagination. As he allows himself to look honestly at the experience of other parents and children, he becomes more receptive to the positive aspects of both childhood and parenthood.

Although the transformation is the same, each man experiences it in his own way. Frank describes how he looked at other parents and found himself envying "this circle that they had, whether it was a spiritual circle or a whole person circle, whatever it might 
be, that it came round and sort of fully developed itself when these folks had experienced parenthood." Similarly, Tobin both observes and converses with other parents to arrive at "the recognition that maybe it's not such a terrible thing to have a couple of children. And maybe it could be a really positive thing." For both Dylan and Abe. the decision is heavily influenced by certain key conversations with others who had recently become parents. For Evan, the process of coming to see himself as a potential parent involves observing himself playing with neighbor children. Similarly, Nathan is able to observe himself as a step-parent to his wife's children.

As he comes into the here and now of the decision, a man shifts his focus of attention. He sets aside the social pressures which he perceives are being placed on him either to have or not to have a child. He listens to himself. Dylan describes this transformation as a realization that happened in a single moment:

And then, probably right around the time that we decided this is it for sure, no turning back, I decided that, you know. I was done listening to everyone, you know. One day I get the readings of "yeah, you'll be a great dad, you'll be great parents," the next day everyone told us "you're too young for that, you're too young," you know, "don't have a baby yet, you're going to ruin your life." One day I decided to quit listening to everybody. And I decided to make up my own mind.

Evan describes his shift in a more understated way, but it has a similar quality: "It was...Am I really ready? And the more, the more I thought about it, it's like... well, yeah, I am ready." Tobin describes how his "selective attention" to the negative aspects of parenthood began to shift toward an increasing attention to the positive: "Yeah, it was 
just opening up to the idea that it could, for me that it could be a positive experience. You know, that there wasn't, I think the main thing to making the leap may have been to say. it's not irresponsible to have a child, or one or two children." And for Abe the shift involved his separating his assumptions about the world from his present reality: "I started to look at myself now-as opposed to looking at myself in the past." he says. "And uh, what I felt was out there really wasn't any longer. I lived in a different world."

\section{Constructing a Paternal Identity}

And you know, it's one of my thriving goals, I want to be the best father I can be, I want to be there. And I wasn't sure about myself. I didn't know if. if you know I was cut out to be a dad. I didn"t know if I, you know, a lot of, can I be a dad, you know, can I hold my temper? When my son falls on his bike when he's first learming to ride, you know, can I be there for him or am I going to be stuck at work? (Dylan)

Before he can make the decision to become a parent, a man must construct a positive image of himself as father to his future child. In so doing, he becomes aware of his pre-existing attitudes and ideals about what it means to be a good father. Those attitudes vary greatly from man to man. Some, like Evan, possess a great sense of confidence in their ability to be a good father. Others, like Dylan, have many doubts and questions. But regardless of the ideals and expectations that he starts with, a man must arrive at an attitude of trust in his ability to be a good enough father. He must construct for himself a positive paternal identity.

A man carries in his mind an image (it may be unspoken or even unconscious) of what it means to be a good father. Although that image is built up from many experiences 
and beliefs, no influence is greater than the model provided by a man's own father. In making this decision. a man scrutinizes his father's strengths and weaknesses as they relate to his vision of what a good father should be. Simultaneously he examines his own strengths and weaknesses. He seeks a way to resolve the tensions between his ideal vision and the reality of his own imperfect personality.

A man's image of himself as a father is in no way limited to the traditional view of his role as provider. Certainly, he feels and expresses concerns about his ability to be an adequate provider for their children. He feels a sense of responsibility in this regard which assumes without question. For some men this role is central to their paternal identity. As Nathan puts it, "to me. being able to be financially responsible is a big issue where families are concerned." But for others it is less salient.

More pressing than concerns about providing are a man's feelings about his ability to maintain an intimate, emotional presence in his child's life. This is a central component of his definition of his role as father. Being a good father to Nathan means "to be able to meet the emotional needs of all of my children." Abe expresses a similar feeling: "I don't want to be the disciplinarian-slash-breadwinner, you know, while my wife was the caregiver and you know, needs giver." Frank's definition of fatherhood also centers around the importance he attaches to his sustained presence in his child's life: "And you know it's just the most important job that a person's ever going to do and I want to be fully engaged with it." His goal in making the decision included trying "to make sure that I could just be a dad. As much as possible, just be a dad. And try to not have to, you know, work extra days and potentially...the time of having a child should be I think a time of cutting back from work rather than taking more on." 
Some men actively question themselves as to whether they will be able to live up to their own standards regarding fatherhood. Nathan asks himself directly: "would I be a good father?" Tobin speaks of the weaknesses in his own personality-such as his difficulty with organization-and looks to his wife's strengths to balance those weaknesses. Abe expresses no concerns in the present but he relates how he has overcome in the recent past his fears that he might behave harshly toward a child.

Evan was less concerned than other subjects about his ability to be a good father. His worries in this regard focused more on issues relating to his career and his role as provider. (This seemed to relate to the fact that he described himself more than anyone else as having had a happy childhood.) But at the same time, as he looks back at his own childhood he wishes that he had had more intimacy with his parents. more ability to talk with them about things that mattered to him. He describes the process through which he compares himself with his own father as he constructs his own paternal identity: "and that's kind of where I picture myself as being a father, doing the stuff that I did with my father and then trying to go a step above that." Dylan, who had a much less positive experience as a child, expresses a somewhat similar desire to transcend his own experience: "That's just always been a thing for me. I've always wanted to make life better for a child."

As he makes the decision to become a father, a man struggles to come to terms with the discrepancies he feels between his vision of what he should be as a father and his sense of his own hesitation and limitations. His sense of the awesome nature of the responsibility involved in this decision weighs heavily on him in this regard. In making 
the decision, he forgives himself in advance for his imperfections. As Nathan puts it. " you recognize that nobody, nobody starts out being a perfect father. Or a perfect parent."

\section{Separate and Together: Integrating Self and Marriage}

...at some point I was able to trust that - trust the fact that I could trust

somebody else and develop that relationship and then have kids enter into our lives, you know, in sort of a normal way. But it was through a. quite a process. (Frank)

As he makes the decision to have his first child a man becomes aware that he is binding himself permanently not only to his future child but also to his partner. Because this decision cannot be separated from his relationship, the process of deciding activates whatever anxieties he still has about his ability to trust her. Throughout the decision process he feels the balance shifting between his sense of himself as an individual and his sense of himself as a partner in a relationship. By the time he makes the decision. his needs and desires and those of his partner are so tightly interwoven that he frequently finds it difficult to separate his own thoughts and beliefs from those of his partner. When he describes the decision. he often speaks not of "I" but of "we."

Frank identifies explicitly the way in which he and his wife merged identities in the process of making this decision:

Then we got to the point where we were able to, um, to take a good look at where we were at and what we were doing and whether or not having children was something we wanted. It was less of an "[" decision and more of a "we" decision at that point. 
A similar process occurs for all subjects. Abe, for instance. describes how he reached the point where "this is starting to feel right for me. in and of myself. But I'm part of a unit now." Similarly, Tobin describes how the decision was "very mutual." adding that "it feels impossible for me to really separate at what point it was a more internal process of me deciding yes this is okay, and both my wife and I deciding yes this is okay."

The decision process has a quality which Tobin describes as "bootstrapping." in which both partners in some sense talk each other into it. Dylan describes how he and his wife "scared each other, knowing that we were both serious about what we were talking about." Neither partner can make this decision alone, but in their union they discover an unexpected source of strength. They find that their strengths together are more than the sum of the parts.

This does not mean, however, that a man an his partner are equally committed to the decision at the point at which it is made. Tobin, for instance, says that "I really think that the decision, the mutual decision to have a child, somewhat, well, it proceeded my deciding at some internal level, yes this is okay." A similar process takes place for Frank, who describes being only fifty percent committed to the decision at the time he and his wife started trying to conceive. Evan also describes how he made the decision to have a child before he was entirely prepared inside himself, out of his need to keep peace in his home: "I was doing it more for her, when we were trying. [pause] Because I wasn't sure that this is the time. I didn't think it was going to happen this fast."

A man's interdependence with his partner in making this decision is a two-sided coin. On one hand it causes him anxiety. He is unfamiliar with making decisions in this way. He edges up to the decision through a series of intermittent and somewhat hesitant 
discussions. Inside himself, he faces stressful questions about whether or not he trusts his partner enough to have a child with her. In making this decision he must find the ability to trust her more deeply than he has before. At the same time, however, the interdependent nature of the decision is a source of comfort. His lingering doubts about his own ability to be a father make him aware of how much he will depend on her strengths in raising a child. He is relieved not to have to bear the entire burden of this decision alone.

For some men the issue of trust in the relationship is central to the decision. For Frank, issues of trust presented a major impediment to his ability to make the decision. For others, issues of trust had a more subtle quality. Often it was reflected in fears about the changes that came with pregnancy and with new children. Men ask: is our relationship strong enough to handle this? In attempting to gain the benefits of having a child, will I risk losing what I value in my relationship with my wife?

At the point when he is able to make the decision to have a child. notwithstanding his continuing internal ambivalence, a man makes a commitment to trust fully in his partner. As Abe puts it, "we shifted into a different relationship, where we were a lot more on equal footing." It is a decision arrived at mutually, as Nathan describes: "We acknowledged that it was the right thing to do at the right time. And that we would make it through, there would be trials but we would do fine. We would make it through. And even with problems between the two of us." This strengthened sense of trust in the relationship-which reflects aspects of many other themes already discussed-makes the decision possible. 


\section{The Decision as an On-Going Process}

Sometimes we have moments of sheer panic. And I have moments of sheer terror. Because I...just tell myself that oh, my, what have I gotten into? (Nathan)

A man's decision to have his first child is not an event which takes place in a single moment. It is a process which precedes his relationship with his wife and continues to evolve throughout the pregnancy. As Tobin describes it. "there wasn't any epiphany where it was suddenly like I see where, I fully understand now that I want to have a child and I have no doubts." Instead, the hesitation and anxiety which a man experiences prior to making the commitment to have a child continues in some form after he has made the decision.

The strength and quality of a man's continuing doubts after the child has been conceived vary from person to person. But they are always present in some form. In making the decision he does not conquer his doubts but instead finds a way to live with them. For some (like Nathan, quoted above), continuing doubts are expressed in moments of abrupt panic. Tobin says: "I still struggle with the idea. I still wake up at night thinking, oh my god." But for others, ongoing doubts are more subtly expressed. For Dylan there is a certain hesitation in the way he is aware of the pregnancy. He has committed to the decision but he hasn't yet had to assume the full responsibility. He nervously confesses that he is trying to "appreciate not having the baby yet $-I$ mean we're still not harnessed down." He acknowledges his continuing fears but says that "I choose to put my faith in God right now." Abe expresses this continuing ambivalence in a more abstract manner: 
Anybody who says that they're not afraid is probably a little bit too rigid. you know, to open up and share with a child. I mean. you know I think that the best lesson you could ever learn. and it took my father thirty years to tell me, was that you are afraid and that you are doubtful and that you aren't the Rock of Gibraltar. And that sometimes it is on a wing and a prayer.

He accepts the existence of his doubts calmly. For him they are a natural part of the experience.

Thus the point at which a man is able to make an explicit commitment within his relationship to having his first child is not identical to the point at which he feels fully committed to the decision within himself. His feelings continue to evolve. Tobin acknowledges what all men subtly suggest, that to some extent he expects that his ambivalent feelings will always be there.

I think I'm enough of a-I know myself well enough to realize that I'm always going to have some of those doubts. And I expect I'll probably continue to have some real doubts about this whole, the whole...fatherhood package.

Frank expresses a similar dynamic in his description of his level of commitment at the point when he agreed to start trying to conceive a child with his wife:

...if you took maybe a decision that was, that you might make that you're fully invested in - I think maybe I was about fifty percent invested. At the first point of saying yeah let's go ahead and try it. And uh, fifty percent 
unsure. So I was sort of moving from maybe being 10-90 to at least 50-50. And saying okay, let's go ahead and do it.

He goes on to describe how his investment in the decision continued to increase as he and his wife encountered difficulties conceiving, until he arrived at a point of feeling ninety percent committed.

A couple's efforts to conceive and the developing pregnancy itself both have a powerful influence on a man's sense of inner commitment to the decision. Frank describes this as an "evolving process that's made me become more and more committed to wanting to have a child." This increasing commitment to the decision brings with it a further development of a man's understanding of himself. For Evan. this shift in consciousness was directly related to his being able to experience the baby through his own senses.

I guess I really didn't realize how ready I was until I went with Alice on Friday to the first appointment. We're sitting there, we're talking to the midwife and stuff and she's checking everything out and says. just with her exam and talking with us she figured that everything was going really great and all that, and then when we had the ultrasound done I could see the little baby. Then when I heard the heartbeat...I melted. I was like. there's no way l'd ever pass this up.

As Abe expresses it, the very nature of how he thinks about being a father has shifted:

"...you stop worrying about how am I going to take care of this baby and you start thinking about how well can I do for this child, you know. And it's become a constructive challenge instead of a debilitating, crippling fear." Anxiety is transformed into a sense of 
challenge and, as Tobin puts it, adventure: "And now it-you know, I'm really looking forward to it. I mean, it feels like it's going to be something of an adventure. And I'm starting to think of it more that way, without forcing myself to think of it that way."

Tobin's comment represents what might be described as the final step in the process of a man's making the decision to have his first child. With an ongoing sense of ambivalence and an awareness of how little he can comprehend the transformation that is coming in his life, he develops through the pregnancy a sense of commitment which enables him to arrive at a state of excited anticipation about the birth. "I mean we were so much ready." Frank says. "we were ready forever." Nathan says in spite of the difficulties he and his wife experience, "we have the peace and solitude of spirit to know that it's going to work out fine." Dylan describes how, when talking thinking about becoming a father "I just kind of get smiley and...you know, it's just one of those things, I can"t believe this happened to me." As Evan describes the shift that took place in his feelings when he first heard the baby's heartbeat: "I don't know anybody that would want to pass this up. It was just like you, why were you so put off about this when it makes you feel so good?" And Abe feels the transformation in himself with unbridled enthusiasm: "But you know, the love that's growing is just amazing. I mean, it's so good for me, it makes me feel like a different person. Everyday. Everyday. Yeah. I enjoy it. I can't wait."

In making the decision to have his first child a man does not eliminate his doubts. He still has fears and possibly some regrets. But he willingly embraces the transformation to come. 


\section{$\underline{\text { Summary }}$}

As was noted in the introduction and as can be seen throughout the interviews. the division of a man's experience into the discrete themes described above has an artificial quality. In even the briefest excerpts from the interviews, it is impossible to speak of one aspect of the experience without invoking others. For instance, because the ambivalent quality of the decision continues throughout the entire process. these theme affects all the others. Similarly, the quality of a man's relationship with his partner is so deeply interwoven with the decision that its presence can be detected in every other theme. A similar argument could be made for each of these themes. Because in truth they are part of a single fabric of a man's experience.

Going back to look at each interview individually, it becomes evident that for most men one or several of these themes was more powerful than the rest and so functioned as the lens through which every other theme was defined. For Frank, the defining theme was his concem with the stability of his relationship as it affected the possibility that he might one day be separated from his child. For Nathan. his religious beliefs (which were a defining factor in his sense of personal control) played a central role in every other aspect of the decision. For Abe it seemed that the transformation in his life which was brought about by seeing himself in the present moment was a key component of every other aspect of the decision. While this emphasis in individual interviews in no way negates the common elements that each shares with the others, it is an interesting characteristic of the experience for at least some men.

Finally, it is important to note that each subject described one or more issues which was central to the decision for him but which was not encountered across subjects 
and so was not included as part of the combined description of the experience. While these issues did not appear to be essential to the experience they were important for those who described them and can reasonably be assumed to be important for some proportion of men in general.

Some of these issues arose in some but not all of the interviews. For example. concern about what effect a child would have on a man's relationship with his wife (which is reflected in the theme of coming to terms with the permanence of the change). was expressed by some but not all subjects. Experience of or fears about infertility played a role in the later experience of Frank, Dylan and Abe. Pregnancy difficulties that were not related to infertility played a role in the experience of Nathan and Tobin. Thoughts of the possibility of adopting were expressed by Tobin and Frank.

In addition, a number of themes arose which were more or less unique to individual subjects. Frank. for instance. was the only subject who had actively considered having a child on his own outside of a relationship. At twenty years old. Dylan was the youngest subject and thus had the unique concern about whether he was mature enough yet to become a father. Nathan was alone amongst subjects in having had some fathering experience as a result of the fact that his wife had two children from a previous marriage. As a result, his decision process contained an element of comparison that the others did not. Tobin was the only subject who struggled with concerns about over-population. In addition, his awareness of social and family pressure to have children was little echoed by other subjects. Evan's memories about his old girlfriend seemed more or less unique to his experience, reflecting a concern not so much about having a child itself but about 
what having a child would indicate about his commitment to his wife. Finally, Abe was the only subject who explicitly raised the subject of dependency needs.

Each of these outlying themes, while unique in itself. also affected the shared elements of the experience. Many were connected to one or more of the specific themes described above. All represent aspects of this experience, which, while not essential and defining, represent an important part of the experience for at least some men.

\section{General Considerations and a Dialogue with the Literature}

The experience described in this study is both unique and universal. From a developmental perspective, having a child is an unparalleled process in a man's life. He will make few if any decisions which will be comparable in impact to this one. At the same time, many elements of this experience appear to overlap with and echo the process by which men and women both experience other important decisions and life transitions. This section will examine some of the specific factors which affect the results presented here and, when appropriate, will connect these questions back to the literature reviewed earlier.

It must be acknowledged at this point that the focus of the research presented here makes for an imperfect fit with existing studies and theories. As a result, some areas of the specific research discussed previously will not be discussed here. Psychoanalytic theories on the motivation for reproduction, for instance, provide an interesting perspective on the experience described, but the interviews themselves shed little light on those theories. Research on the transition to fatherhood is similar in nature. It provides a useful context for looking at this data but does not provide a significant point of comparison with the data itself. As a result. the discussion which follows will be driven 
by the findings of this study. When those findings confirm or conflict with the existing research, appropriate points of comparisons will be discussed.

\section{Subiects and Samples}

As discussed in the chapter on methodology, the selection criteria developed for this study had a significant effect on the quality of the experience being described by these men. The men interviewed for this study experienced the decision to have a child as a conscious and intentional process. There are other men-several of whom were interviewed during this project-whose decision to have a first child has the quality of a forgone conclusion. These men express little overt sense of doubt or ambivalence about the choice. As they describe it, it does not appear to be a decision in the true sense of the word. They do not consider the possibility of saying no.

What is the relationship between these two groups of men? This is an important question, about which this project can only hypothesize. One interesting point of comparison is available from Lupton and Barclay's (1997, p. 119) longitudinal interviews with sixteen first-time Australian fathers. Lupton and Barclay report that fatherhood for the men in their study was not seen as a "choice." Rather "they described it as an inevitable and logical step for them in their relationships with their partners and part of their own development as an adult man." Echoing a sentiment reported by several of the men who were screened out for this research, the subjects for Lupton and Barclay's study "claimed they always imagined that one day they would become fathers. and that the only uncertainty was when this would happen rather than if it would occur." Interestingly, in spite of the seeming inevitability of the decision, Lupton and Barclay report a significant amount of anxiety and apprehension in their subjects about the process of becoming a 
father. In fact. many of the themes identified in the present study over-lap with themes identified by Lupton and Barclay's subjects.

In attempting to assess this issue it is useful to keep in mind Miller's (1973. 1974. 1978) descriptions of the inherent complexity of both the experience of making the decision to have a child and of the terms we use to discuss that decision. Miller states (1973, p. 161) that while there exists a "close relationship between conceptive decisions. either for avoiding or achieving conception, and other major, life-cycle decisions which occur when beginning one's sexual career, when planning to get married, when deciding about one's work career, etc." there are also "many psychological considerations which influence conceptive decisions, considerations which often result in some ambivalence and inner uncertainty as to what course to follow." We do not have the language, much less psychological instruments which are adequate for capturing the richness of the experience as described by the subjects in this study.

Nonetheless, it is the researcher's impression that the differences between these two groups may be useful explored using Marsiglio's (1991) concepts of procreative consciousness and procreative responsibility. Men who do not experience the decision to have a first child as a conscious decision may well possess a high degree of procreative responsibility, but their procreative consciousness, their "phenomenological experiences related to their fecundity/fertility" (p. 269) appeared not to be very accessible. It was the impression of the researcher that this latter group of men were not able to articulate. because they did not have conscious access to, the more ambivalent aspects of the experience described by the subjects used in this study. What doubts and worries they did experience focused not around whether or not to have a child but instead on whether it 
was the right time to have the child which they were certain they would one day have. The decision had already been made and they were not able to access or articulate the process through which they had arrived at their choice.

Pohlman's (1969) statement that all conceptions involve some level of ambivalence seems important here. Pohlman argues that some people find it very difficult to acknowledge and articulate that ambivalence. The researcher suspects that this factor is at play in the phenomenon being described. especially in light of the cultural pressures concerning gender roles and reproductive decisions that were discussed in the introduction. For instance, if the sentiments of Chafetz (1978.p. 197) that fatherhood is "a very minor part of the total masculine role constellation," is one which is culturallyreinforced (as the researcher believes it is), it is reasonable to assume that men might inhibit the full and complex expression of their feelings about that role. Similarly. the pro-natal sentiment which dominates the cultural discussion about parenthood makes it difficult for anyone-male or female-to express ambivalent about becoming a parent.

Thus it does not seem unreasonable to wonder whether the experience described in this study exists but is inhibited in those men who do not describe going through the same process. The data presented here lead the researcher to agree with Marciano's (1979) argument that fertility decisions are more powerfully affected by male influence than we have previously imagined. However the possibility must also be acknowledged that the experience described in this study is a fundamentally different experience from that described by this other group of men. The data do not allow us to answer this question. 
Finally, it is important to keep in mind the cultural context in which this research has been performed. The premise on which this project is based-that men's emotional experience in reproductive decision-making is not acceptable in the cultural conversation-requires that the researcher look for this experience in those men who in certain respects appear not to be representative or typical. The very nature and goal of this research (as described in the introduction), concems the effort to bring to the surface voices which our culture has effectively silenced. The fact such men have been used to describe the experience should not be seen as a distortion of this experience. Rather they are a vehicle through which we can begin to understand what may be unstated and repressed in many others.

\section{Gender}

The question of how women experience making the decision to have their first child is worth exploring. However, for several reasons this study chose to focus exclusively on men. First, as has been discussed at length. men's experience in family life has been inadequately addressed in previous studies. Second, this research is driven in part by a belief that men's emotional experience in general is poorly understood and deserves greater attention. Third, it is the assumption of the researcher that gender role socialization leads to very different attitudes about and experiences of reproductive decisions. It seems likely that women would respond to the question posed by this project differently than would men.

With these assumptions taken into consideration, the results presented here give rise to several questions with regard to reproductive decision-making and gender. Because this research does not allow for any comparisons across gender, we cannot 
assess whether the division encountered in men also exists in women-between those who experience becoming a parent as a conscious decision and those for whom having a child was an assumption which precludes any conscious decision-making process. The qualities of this distinction are worth exploring. both within and across gender. Finally. for women who experience a conscious decision-making process like the one described here, it would be highly informative to study that experience and to compare it to the results presented here. A comparative study of this nature would allow us to begin to understand which aspects of this experience are gender-specific and which are universal.

\section{I and We}

The issue of how the decision to become a parent is experienced differently by men and women leads us to yet another question: to what extent can a man's decision to have his first child be considered truly his own decision? As has been discussed in this chapter, a man's experience of making this decision is deeply embedded in his experience of his relationship. He cannot always separate his own individual decision process from that which takes place within his relationship. He experiences, to a greater or lesser degree. a merging of his personal identity into that of the relationship.

What is the influence of this merging of identities on the decision process? To what extent is influence or pressure within the relationship a factor in a man's decision? Does he give in to such pressure or resist it? And what effect does such pressure-if it exists-have on the way a man experiences the decision? These are questions which cannot be addressed well without doing comparative studies similar to this one, studies which would need to pose somewhat different questions. 
The literature which discusses the decision-making process tends to look at the process primarily as it occurs within couples (Cowan \& Cowan, 1992: Daniels and Weingarten, 1980). It is difficult to move from descriptions of the conjoint decision process to the individual experiences which comprise it. While some of the categories Cowan and Cowan (1992) have developed to describe reproductive decision-making within relationships (planners, acceptance of fate couples, etc.) can be applied to the experiences described here, this does little to illuminate the link between individual and conjoint decision-making experiences.

The ways in which a man merges his individual identity into his relationship has profound implications for many of the themes discussed above: change. control, identity. etc. It is a defining feature of his decision to have a child, a choice which is activated through physical union and which will create a permanent physical link between a man and a woman. The degree to which a couple feels themselves together or apart in making this decision is an important factor which deserves further study but which cannot be well addressed by this study.

\section{Those Who Sav No}

While the subjects interviewed for this study all expressed some degree of ambivalence about whether or not to have a child, by definition of the selection criteria all answered this question in the same way. There are pragmatic reasons for studying men who decided for rather than against having children. First and foremost. in deciding to have a child a definable commitment has been made which can at least potentially be examined and described. In remaining childless a man also makes a choice, which is subject to much of the same motivational uncertainty that we have encountered in the 
decision to become a parent. But that decision is much more difficult to define operationally than is the decision to become a parent.

For research purposes, the decision to have a child has the virtue of being a clearly identifiable and essentially irreversible choice. It isolates a moment of commitment in a man's life. The same cannot be said with assurance of the decision to remain childless. A man who professes a desire to remain childless-so long as he does not reinforce that decision with a vasectomy-can easily change his mind if he so chooses. A man who has decided to become a parent does not have this liberty. This is not meant to suggest a lack of commitment in voluntarily childless men. but rather to point out a qualitative difference between their experience and that of first-time fathers.

These factors dictated the choice of subjects for this study. But it also presents the study with certain limitations. We cannot say with any assurance in what ways the description of a man's experience of deciding to have a child resembles the experience of deciding not to have a child. Undoubtedly the factors involved in both decisions overlap. But are there fundamentally different characteristics of a man's decision to remain childless? Research by Bram (1974) suggests that while most of the salient factors in measuring the value and cost of children are similar for childless and non-childless couples, there are several important differences. Childless couples placed additional emphasis on costs relating to psychological, lifestyle, achievement and affiliative factors. Non-childless couples placed additional emphasis on factors to do with expansion of self, adult status and identity, and social comparison.

The subjects in this study felt an awareness of both the costs perceived by childless couples and the values perceived by the non-childless couples in Bram's study. 
But this study describes these factors as being in flux. They are part of a process in which the costs become less salient while the benefits become more so. An important finding of this study is that the decision making process itself changes men's perceptions of both the value and cost of children. Although the data presented here do not permit such a comparison. it might be hypothesized that the childless couples move through a similar process but in a different direction. A study of childless men's experience in deciding to have a vasectomy could shed a great deal of light on this question.

\section{Generativity}

Erikson's declaration that "mature man needs to be needed" (1950, pp. 266-267) has been a central foundation of contemporary beliefs about generativity in adult development. As widely-accepted as this notion has become. one could have reasonably expected it to be a central aspect of the accounts described here of men's experience in deciding to become parents. However, this was not the case. While one subject (Abe) expressed such a sentiment directly, none of the other subjects described their anticipation about the pleasure they would take in caring for a child in this way. Quite to the contrary, it was the very fact that they felt little necessity which made the decision difficult for most of these men.

Erikson's suggestion that a choice not to procreate would have negative consequences for these men (and the implication that they are in some sense denying their dependency needs in these interviews) cannot be effectively evaluated here. For those men who described a long-standing desire to have a child (Evan and Frank), it is reasonable to assume that this desire contains some degree of dependency needs. But for those men for whom the decision was perceived as entirely optional (Tobin, Dylan, 
Nathan), there was no explicit evidence of such feelings. They did however express a secondary motivation which Erikson described for having children: a desire for the personal growth and fulfillment that would come from the experience of having a child. While it is one aspect of generativity, this desire is separate and apart from dependency needs. Even when it was strongly felt, this desire had an optional quality. It was not a need.

One aspect of the generativity literature which this study strongly confirms is the relationship of generative acts to an individual's sense of his or her place in time. The descriptions of McAdams, Hart and Maruna (1998) and of Jessner, Weigert and Foy (1970) regarding the ways in which the generation of new forms leads us to refer back to past traditions while simultaneously looking forward beyond our own deaths was a fundamental aspect of the experience of making the decision to become a parent. The men in this study all expressed a heightened awareness of the their own place in time which resulted from the process of making this decision.

Finally, the question of the role of dependency needs in reproductive decisionmaking is one which would be well worth comparing across gender. As McAdams. Hart and Maruna (1998) point out, dependency needs are powerfully affected by socialization factors. Since girls are more forcefully socialized toward the role of mother than boys are toward the role of father, it seems intuitive that women might experience the need to be needed more than men. At the very least. it seems reasonable to assume that the effect of gender role socialization would have a significant effect on the experience of such needs. 


\section{Stages of the Decision}

In their review of the psychological literature on decision-making. Janis and Mann (1977) acknowledge that human decisions are not governed solely by rational processes. They call attention to the existence of ambivalence in decision-making. conceptualizing that ambivalence primarily in terms of logical processes which are blocked due to a lack of information. "People are sometimes keenly aware." they state (p. 10), "of a low-level sense of uncertainty and concern that some crucial bits of information not yet available might make them regret whatever choice they make."

In acknowledging the non-rational elements in decision-making. Janis and Mann focus primarily on the cognitive processes through which humans attempt to weigh the costs and benefits of a given decision: their ability to process information relevant to the decision and the ways in which they resolve the conflicts inherent in all decision processes. Decisional conflicts, they suggest, create stress which affects the decisionmaker's ability to process information about the decision and is simultaneously affected by the decision maker's degree of investment in the outcome of the decision.

This study conceptualizes ambivalence in a fundamentally different manner. Ambivalence in making reproductive decisions is not so much a function of unavailable information (although it is partly that) as it is the result of confronting the existential givens of life. It is by definition a process which moves beyond logical cognitive processes to an experience which is less easily mapped.

It is not the purpose of this project to formulate a theoretical model of reproductive decision-making. However, because counseling around issues of reproductive decisions is one of the important clinical applications of this study (which 
will be discussed in the following chapter) it is worth exploring some of the qualities of decision-making in general in order to begin to develop a framework within which to position our understanding of men's experience in making the decision to have their first child. In this discussion, attention will be paid to both the rational and non-rational components of the decision-making experience. As has been described above. neither is sufficient on its own to describe men's experience in deciding to become parents. Cognitive processes are instrumental in shaping the initial stages of the decision. but the decision itself is a leap of faith.

Janis and Mann (1977, p. 137) identify four types of considerations that enter into decision processes in general:

1. utilitarian gains and losses for self.

2. utilitarian gains and losses for significant others.

3. self-approval or disapproval.

4. approval or disapproval from significant others.

Hoffman and Hoffman (1973). Fawcett (1978) and Pohlman (1969) all use similar models in their attempt to identify the specific individual and interpersonal. utilitarian and non-utilitarian factors which are at play in the decision to have a child. Applying this analysis to reproductive decision-making provides us with what might be thought of as an economic model (a cost/benefit analysis) for such decisions. Certainly aspects of this model are evident in the data presented here. In fact, some of the men interviewed for this study (Dylan most explicitly) went through a process which is almost identical to that described by the authors listed above, identifying the costs and benefits, utilitarian and non-utilitarian, for having a child. 
In addition. Janis and Mann (1977, p. 172) have suggested that humans go through a typical series of stages in the process of making decisions, as listed below:

1. appraising the challenge.

2. surveying alternatives.

3. weighing alternatives.

4. deliberating about commitment.

5. adhering despite negative feedback.

Again, this schema clearly bears some resemblance to aspects of the experience described in this study. Bram's (1974) outline of the components that affect reproductive decisionmaking is an even more better match with these interviews, as it represents decisionmaking stages specifically as they relate to reproductive choices.

The data presented here lend themselves to a similar hypothetical stage model for the process which men go through in making the decision to become a father. This model is an intuitive description on the part of the researcher of overlapping stages which appear to operate in men's decision process:

1. Pre-decision state: a man's pre-existing attitudes about children.

2. Contemplation: a man considers the implications of the decision without fully assuming the responsibility of making it.

3. The dialogue within the relationship: he talks through the decision with his partner (this may or may not take the form of a "stage"-it may be operative throughout the entire process). 
4. Deciding: after attempting to balance the costs and benefits of the decision, he re-frames his choice as experiential choice rather than a logical decision.

5. The leap: in the face of uncertainty and ambivalence. he decides.

6. On-going resolution: his commitment to the decision increases. in spite of some degree of continuing ambivalence.

It is important to emphasize that these stages represent simply a quasi-chronological restatement of the thematic material presented above and that this formulation is a representation of the experience, not the experience itself. The purpose of re-stating the experience in this manner is to expand the ways in which these themes can be understood and to facilitate comparison with stage models of decision-making.

While helpful as conceptual tools. such models only take us so far in understanding men's lived experience of making this decision. The results of this study confirm Smith's (1978) suggestion that rational or even semi-rational decision-making models may simply be inadequate for describing the process of making reproductive decisions. In particular, what is missing from economic decision-making models is an adequate understanding of the stage which I have called "the leap."

This leap-which is expressed in different ways for different men-is at the heart of the experience of making the decision to become a parent. It can be thought of as the point at which the rational decision-making process breaks down. A significant finding of this research is that at some point during a man's attempt to make this decision. he discovers that logical processes are inadequate for the choice he has to make. The decision becomes possible not through a rational consideration of costs and benefits but 
through a re-framing of the question itself: a man asks not whether the benefits outweigh the costs but instead whether this is an experience he desires. At this point. the decision itself is transformed.

\section{Existential and Experiential Factors}

Although we speak of reproductive decisions as if they were discrete and clearly definable events, in fact it is often stated in the literature that we are uncertain whether or not reproductive decisions are in fact consciously-made decisions (Bram. 1974; Lieberman and Kastelowitz, 1986; Smith. 1973), that very language we use to describe these processes is inadequate (Miller, 1973. 1974, 1978: Pohlman. 1969), and that both the decision to have a child and the outcome of that decision are so complex that it is difficult if not impossible for prospective parents to comprehend the implications of the choice they are making (Entwisle and Doering, 1981: Jessner. Weigert and Foy, 1970).

Our inability to define this dimension of the decision in terms of externally measurable attitudes or behaviors confirms Lieberman and Kastelowitz's (1986) assertion that a consciousness of reproductive decisions is interwoven with an awareness of the existential givens of life, the four "ultimate concerns" which Yalom (1980) claims give rise to existential anxiety: death, freedom, isolation, and meaninglessness. In making the decision to have a child, a man is faced with each of these. In choosing to create a life he grounds himself in time and becomes more of aware of his own mortality. Because it shines a bright light on a man's ultimate freedom, the decision engenders anxiety about the responsibility inherent in that freedom. Because of the permanence of the connections the decision creates, it forces him to become aware of both his own isolation and his own inter-relations with others. And as he peers into the incomprehensible mystery of the 
decision to assume responsibility for a life not yet created, he struggles to understand the meaning to this act. The implications of this awareness for clinical practice will be explored in greater depth in the following chapter.

It is in existential and experiential factors that the results of this study move beyond the existing literature and shed a light on men's experience of deciding to have a child which cannot be found elsewhere. The themes described in the Essential Description of men's experience of making the decision to have their first child transcend the measurable qualities discussed in the literature, toward an experiential process which is defined by existential givens and which cannot be easily reduced to categorical descriptions. For instance, the self-modifying aspect of this process (the way in which entering into the decision alters a man's perception of himself and of the decision) cannot adequately be reduced to a theme in the decision process, yet it is a defining aspect of the process as it is experienced.

The decision as it is described by men involves a synthesis of all the thematic elements of the experience. Those themes have been artificially separated here for the purpose of this discussion. But in truth this decision is experienced as a dialectical process in which a man moves back and forth between contradictory desires. toward a resolution which is defined not by an economic determination of costs versus benefits but rather by an expansion of the self, an increased ability to contain within himself those contradictory needs and desires. The implications of this process for clinical practice will be explored in the following chapter. 


\section{Chapter Six}

\section{Implications}

Because men's experience within family life has been ignored for so long. the vital importance of that experience for both men's identity and for the healthy functioning of families has often been obscured. For those in the helping professions who seek to assist men in their efforts to become more present in both relationships and their families. understanding this experience is crucial. It is also very important for those who seek to improve the functioning of families generally. While the research presented here provides us with a window into men's experience specifically with regard to reproductive decisionmaking, that experience has relevance over the entire course of a man's life. It is the researcher's hope that this research will find a wide range of applications. across the lifespan, across treatment modalities and across settings. This chapter will explore the some of the implications of this data for those who work in the helping professions. It will conclude with a discussion of the need for future research.

\section{Implications for Therapy}

The interviews contained in this report are not far removed from the sorts of descriptions which men might deliver in therapy about their experiences with regard to reproductive decisions. But it must also be noted that this data may also represent experiences which men choose to keep concealed. The researcher's experience in obtaining these interviews suggests that men are unaccustomed to talking about their feelings around issues such as these. When asked to describe this experience, men tended at first to be somewhat confused by the very nature of the question. For the most part they had not had many opportunities to talk about these experiences, especially with other 
men. As a result, they are unaccustomed to being asked about their experience and they may hold an expectation that their feelings and experiences will not be considered valid subjects for discussion. Therapists must thus be sensitive to the possibility that men are experiencing more complex emotions with regard to reproductive issues than they are expressing. Because as these interviews demonstrate. the experience of making reproductive decisions is a rich and vital part of men's lives. It is a formative experience which needs to be taken into account when we are engaged in therapy not only with men but also with their families.

\section{Individual Therapy with Men}

The most specific clinical application of this research involves working with men who are struggling with question of whether or not to have a child. Although this is unlikely to be a common presenting problem, a discussion of an approach to this situation will serve as a foundation for exploring a variety of other clinical applications. In addition, the themes and therapeutic dynamics discussed here are in no way limited to clients who are currently engaged in making reproductive decisions. Rather. these are all tasks which have relevance in all stages of a man's life.

As was discussed in the previous chapter, men's reproductive decision-making process contains both economic and existential components. Both aspects of decisionmaking play a role in the therapeutic process and both will be explored here in turn. Regardless of which aspect of the decision process is being discussed, the therapeutic goal will be the same, mirroring Yalom's (1980, p. 329) description of the purpose of counseling around decision-making in general: "to bring the patient to the point where he or she can make a free choice." 
As has already been described, the initial stages of man's experience of making reproductive decisions are dominated by his effort to make the decision through the logical processes with which he is most familiar. He attempts to measure the costs and benefits of the decision and come up with a rational answer based on this effort. While this research demonstrates that this is only one aspect of the process. it is a significant component which will have an influence on the outcome of the decision.

This study revealed several specific factors which impede men's ability to move through this cost/benefit analysis constructively with regard to their decision to have a child. To begin with, men are heavily influenced by assumptions and expectations which are based on past experience. They scan for information which confirms their current view of parenthood, whatever it may be. As a result. when they begin wrestling with the decision they are not fully capable of perceiving their own potential as fathers. These factors mitigate against a constructive decision-making process.

A central goal in counseling men making this decision thus must be to assist them in arriving at a more realistic view of themselves and their capabilities in the present moment. While the men in this study were all able to arrive at such a point on their own, counseling could facilitate this process, helping men to make decisions which are more firmly grounded and which cause them less anxiety.

Janis and Mann (1977) describe a process of counseling which is aimed at improving the quality of decision making in general and which can readily be applied to this aspect of the decision to have a child. The goals of this form of treatment consists of four general types of interventions:

1. Decision counseling to foster vigilant problem solving. 
2. A systematic balance sheet procedure to stimulate more thorough examination of the pros and cons of each alternative course of action.

3. Outcome psychodrama to enhance vigilance and induce awareness of preconscious anticipations.

4. Emotional inoculation procedures to increase tolerance for the stresses of post-decisional setbacks.

Some of the subjects in this study found their way intuitively to certain of these techniques. Dylan, for instance, describes a balance sheet approach that he and his wife used together in making their decision: "If we're having this big conflict of what to do. we'll each take a piece of paper, draw a line down the middle and list the pros and cons of everything. And then you know, we combine them, and we mix out all the other ones and we compare them."

In addition, the men in this study commonly spoke in a sort of language which seemed aimed at providing them with a degree of "emotional inoculation" against future stress and anxiety related to the decision. Tobin was particularly conscious of this process in himself, using the psychological term "cognitive dissonance" to describe the ways in which he felt himself adjusting his current attitude to match the decision he had already made.

Outcome psychodrama is one technique which men are not likely to use on their own in the process of making this decision. Given the quality of mystery that the decision has, it could be particularly helpful when working with men in making this decision. As Entwisle and Doering (1981) and Lieberman and Kastelowitz (1986) have suggested, the difficulty of imagining parenthood can leave parents ill-prepared for the transition which 
comes after the birth of a child. In this regard, psychodrama might be constructively combined with appropriate educational materials to enable a man to base his decision on a realistic assessment of the practical significance of the decision he is making.

The purpose of these techniques is to assist a man as he moves through the initial stages of this decision process, grounding that process in a realistic view of himself and his world. An accurate assessment of his situation provides a man with a solid base as he moves beyond the cognitive aspects of the decision and toward facing the inevitable existential leap.

It is at this point that the rational and irrational aspects of the decision process meet up. Logical processes lay the groundwork for the decision. But as Yalom states (1980, p. 332), conscious approaches to working with decision-making are limited in their usefulness "because so much of a decision dilemma exists at a subterranean level and is impervious to a rational approach."

As has been described previously, in making the decision to have his first child a man moves outside the realm of logical cognitive processes. As he reaches the limits of his ability to comprehend the meaning and implications of this decision. he finds himself drawn into a heightened awareness of ultimate concerns. In fact. as Yalom (1980, p. 319) suggests, decisions in and of themselves draw one into an awareness of the basic conditions of existence:

Decision, especially an irreversible decision, is a boundary situation in the same way that awareness of "my death" is a boundary situation. Both act as a catalyst to shift one from the everyday attitude to the "ontological" attitude-that is, to a mode of being in which one is mindful of being. 
This mindfulness of being-which is evident in all of the subjects interviewed for this study-causes a man stress, but it also presents a therapeutic opening.

Yalom argues that the process of decision-making itself evokes a mindfulness of ultimate concerns. In addition the specific content of the clinical themes which arise in discussing reproductive decisions is also likely to evoke such concerns. Those themes should mirror-to a greater or lesser extent-the themes discussed in the previous chapter. (Although they are derived from interviews with men who have chosen to have a child. the issues would likely be similar for men who ultimately decide to remain childless.) Restated slightly, they include:

1. Ambivalence about the choice.

2. Acknowledging the limits of personal control.

3. Acknowledging the life change that having a child will mean.

4. Embracing change.

5. Living in the present.

6. Constructing a paternal identity.

7. Balancing individual needs and the demands of the relationship.

8. Living with the decision as an on-going process

Each of these themes touches on the fundamental conditions of human existence and the choices we make in the face of these conditions. Thus, both the process and the content of the decision evoke ultimate concerns. As a result, this is a point in a man's life in which he is uncharacteristically exposed to and aware of the fundamental conditions of his existence. 
The development of appropriate therapeutic interventions and treatment goals must begin with a sensitivity to this awareness. The therapist must work within the context of this heightened awareness toward the goal of enabling clients to arrive consciously at constructive choices. Yalom (1980, pp. 332-333) outlines three steps which he believes therapists must follow in working with the "subterranean" aspects of decision making:

The therapist must first help the patient become aware of the inevitability and the omnipresence of the decision. The therapist helps the patient "frame" or gain perspective upon a particular decision. and then assists in laying bare the deeper implications (the "meaning") of that decision. Finally, through the leverage of insight the therapist attempts to awaken the dormant will.

In working toward this goal, therapists must tolerate the anxiety that this ambivalence creates. They must allow the expression and co-existence of emotions on both sides of the decision. They must assume a stance which is capable of tolerating the risks of change, one which can facilitate the deep imagining of divergent future paths. Therapists must ground themselves in the present moment with the client as a tool for exploring the effect of both past influences and the imagined future.

Most importantly, therapists must develop a stance which can contain the process of the client's decision but which does not seek to shape or influence it. As has been discussed, our beliefs about children and parenthood are heavily influenced by cultural assumptions and stereotypes. They are also deeply held. As a result, this is a subject which has a high likelihood of activating the therapist's countertransference. In working 
with issues of reproductive decision-making, it is thus imperative that the therapist take an inventory of his or her personal assumptions and beliefs about the meaning of parenthocd. The therapist's role is to allow the client's self to express itself as fully and as honestly as possible so that the decision can be made as consciously and as responsibly as possible. The task of the therapist is to assist clients in preparing for whatever decision they make and to walk beside them as they make it. But in the deepest sense. the client must still make the decision in isolation.

While this description of the underlying nature of decisional concerns is articulated from an existential perspective, the goals of treatment described here are broadly conceived and are not bound to any specific therapeutic theory or technique. Rather, the interventions are contained within the therapist's stance. which must embrace a deep acceptance and empathy for the ambivalence inherent in the decision as well as a tolerance of the option of childlessness. This is a complex task which requires of the therapist not so much a set of techniques as a way of being.

\section{Couples Therapy}

The themes and interventions discussed above are also highly relevant to therapy with couples. While the research presented here does not address the lived dynamics of interactions between men and women in making reproductive decisions. it is instructive about men's experience within that dynamic and so could be effectively used to enhance understanding and communication in couples. Because the question of whether or not (or when) to have children is a fundamental and irreversible choice which couples must make together, it is one which is likely to cause conflict and which may be a part of what leads a couples to therapy. Even if it is not a presenting issue, the ways in which a couple 
negotiates this decision within their relationship will reflect and reveal the communication patterns and the power dynamics that exist between them.

The issue of reproductive decision-making within relationships is especially important in light of Cowan and Cowan's (1992) suggestion that a couple's parental attitude after the birth of the baby is partly shaped by the style in which they decide to become parents. Therapists working with couples who have not yet made firm decisions about having children have the opportunity to make this process more conscious, to open up room for the expression of doubts and ambivalence, and to enhance communication within the couple. In this regard, a discussion of reproductive decision-making would be very valuable in pre-marital couples counseling. which would be likely to have a positive impact on family functioning in the future.

\section{Groups}

The usefulness of discussing reproductive decision-making processes in groups for men at all phases of life is clearly indicated by this research. In addition to offering benefits of efficiency, men's groups encourage an awareness of the universality of men's emotional experiences. This awareness is particularly valuable with regard to reproductive decisions, as the experience of making such decisions require a man to become aware of an aspect of his self-his interior, emotional life-which cultural stereotypes often suggest are inappropriate for him to express. The opportunity to express his feelings about this issue (and to see those feelings reflected by others) in a safe, supportive environment is a valuable way in which men can arrive at an adaptive resolution of the conflicting feelings inherent in making reproductive decisions. 
It has been the researcher's experience that recruiting for men's groups is in general a difficult task. As a result, the most practical approach to developing groups which will serve the needs of men engaged in making reproductive decisions (especially in smaller communities), might involve group facilitators bringing these issues into existing group formats rather than developing new groups aimed at this highly specific population. For instance. prospective fathers might be effectively integrated into general purpose fathers' groups or into support groups for expectant fathers. Such groups could be modeled on existing programs which provide support for new fathers in making the transition to parenthood (Klein. 1985: Shecket. 1995). The potential disadvantages of such mixed groups (less cohesion due to mixed themes) would be countered by the opportunity it would present for non-fathers to assess the meanings of parenthood more realistically, and for current fathers to express and work through any lingering ambivalent feelings they may have about the choices they have made.

\section{Implications for Parent Educators and Reproductive Health Care Workers}

In an ideal world. parent education would begin long before a couple decides to become parents. Programs aimed at assisting couples in making the decision to have a child are unfortunately rare. One such program, called "Baby Maybe" is briefly described by Shecket (1995, p. 138) as being designed

to assist men and women with their decision to parent or to remain child-

free. At the "Baby Maybe" classes men and women openly discuss their fears, their ambivalence, and their expectations about parenting. They leave with more information, and a more realistic sense of what it might be like for them to be a parent. 
A program like this one-one which holds no assumptions about whether or not a couple will or should have children together-is unfortunately rare in our culture.

Other areas in which this data could be used for supportive educational purposes include birthing and parent education courses for new and expectant parents. and in adoption and infertile counseling. While decision-making factors have not traditionally been a part of birthing preparation classes, this research provides a window into the subjective experience of men which could prove helpful to those teaching such classes. Those who work with couples considering adoption can make use of this data in both understanding men's experience in desiring a child and in helping both the man and the couple clarify their commitment to the decision which Johnston (1992) suggests is a vital part of the adoption experience. Further, reproductive health care workers-especially those engaged in pregnancy options counseling-can use this data to become more attuned to the experiences of men in making reproductive decisions and thus facilitate more engagement and more satisfactory outcomes.

\section{Need for Further Research}

As was discussed in the review of the literature. there exists a broad need for more and better research on the experience of fathers in family life. While the recent expansion of research on fathers and fatherhood is heartening, the need for more and better research on fathers and fatherhood remains a commonly repeated complaint (Berman \& Pedersen, 1987; Entwisle \& Doering, 1988; Marciano, 1979; Seccombe, 1991). Further analysis of men's relationship to reproductive issues is warranted, Marsiglio states (1991, p. 269), because "males' relationship to the reproductive realm affects family systems, father- 
child relations, males" psychosocial well-being, and the organization of gender relations in contemporary American society." Similarly Fein (1978, pp. 333-334) describes the need for research concerning the ways boys and men learn how and what it means to be a parent. Questions concerning boys' and men's preparations for parenthood cover a wide spectrum. from the fantasies boys have about having babies and being parents. to the lessons taught by society through its agents (family, school, media. church) about what it means to be a man and a father.

The research presented here is an attempt to address some of these questions. But as has already been seen, the insight this study provides into men's experience of making the decision to have a child also generates many new questions. Answering these questions will require further research. This section will summarize the unresolved issues that have been raised here in the hope that this may provide possible directions for future research.

First and foremost, this study points to the importance of understanding the full range of the process through which men become parents. from men's pre-existing attitudes toward children and parenthood, to the quality of their relationships. through the variety of reproductive decisions that they will make in their life-from birth control practices to decision-making about both planned and unplanned pregnancies. Most of the current research on fathers and fatherhood starts from an assumption of parenthood. This is an assumption which rules out an important aspect of men's lived experience-the possibility of not becoming a parent.

Because the focus of most current research starts after the decision to become a father has already been made, it leaves us with an incomplete picture of the meaning of 
fatherhood in a man`s life. In particular. this focus makes it much harder to acknowledge the negative aspects of parenthood-the ambivalent feelings, the losses that may ensue, the regret and even the grief that a man may feel in making the decision to become a parent. This study demonstrates the power of such feelings in the decision-making process. The researcher believes that these feelings must carry over in some form into the experience of parenthood. Research which focuses on the entire range of the process of making reproductive decisions will be better equipped to acknowledge and explore such issues.

Several specific research questions concern the experiences of men who make parallel reproductive decisions to the one explored here. What is the experience of childless men who elect to obtain a vasectomy? What is the experience of men who. when faced with an unplanned pregnancy, decide with their partners either to have a child or to obtain an abortion? An understanding of such experiences. when placed next to the descriptions provided in this study, would be greatly illuminating as to the full range of men's reproductive attitudes and experience.

These questions in turn give rise to several important contextual questions. An important quantitative question concerns the proportion of men who experience different categories of pregnancies. What proportion of men experience accidental versus planned pregnancies? What proportion of men who experience accidental pregnancies desire abortions? What proportion of men who define a pregnancy as planned experience the sort of conscious decision-making process which has been described in this study?

The categories of decision-making styles described by Cowan and Cowan (1992) and Daniels and Weingarten (1980) might prove to be useful constructs in beginning to answer such questions. The data presented here fit nicely into previously described 
categories of decision-making patterns within couples. It would be reasonable to take as a starting point the supposition that men's decision process would mirror Cowan and Cowan's categories (planners, acceptance of fate, and ambivalent) and those proposed by Daniels and Weingarten relating to timing (natural. brief wait. programmatic postponement, unformed scenario).

Some pieces of this information could be derived from demographic data. But some would require a more sensitive survey which obtained measures of men's inner experience, their intention toward pregnancy and the degree to which they want to have the child of both intended and accidental pregnancies. While it involves moving away from the meaning of the lived experience of reproductive decision-making-which has been the focus of this study-studies which shed light on these questions would provide us with valuable baseline data. With such data we could begin to place the variety of men's experience into demographic context.

Quantifying (or even simply defining) terms related to the intendedness and wantedness of a child is a complex and difficult task (Miller, 1973, 1974. 1978; Pohlman. 1969). Miller's initial work in developing instruments and scales with which to measure both the intendedness and wantedness of a conception does not appear to have been pursued by others. Further work in this area-particularly in applying such scales to demographic surveys-would be highly useful in providing a context for the data presented in this study.

Finally, to be fully contextualized the research presented in this study requires comparisons that go beyond the selected subject group. Specifically, there has as yet been no comparable phenomenological study of women's experience of making the decision to 
have their first child. Such a study would surely present a different set of difficulties and dilemmas than were faced in this project. Those difficulties would be enlightening in and of themselves when compared to this study. A related question concerns the dynamics between partners in the process of making reproductive decisions. A phenomenological study which examined the experience of both partners would be quite illuminating. both as a comparison across gender and as a window into the role played in this process by factors such as communication processes and power dynamics within couples. The results presented here indicate that these are-as would be expected-an important part of the decision process. But because the focus of this study is limited to men, we can only acknowledge the importance of such factors. Additional research is required to understand these processes in depth.

In summary, the need for further research on men's reproductive decision-making is both global and specific. In many ways, we are working in the dark with regard to most aspects of this experience. We continue to be bound too heavily by assumptions which have been drawn from methods and subjects which may not apply. A commitment to further research on men's experience in reproductive decision-making will both enhance our knowledge of the range of human experience in general and will enable us to begin to see through the cultural assumptions which have prevented us from being fully aware of the richness and depth of the experiences which have been described in this study. 


\section{Chapter Seven}

\section{Summary and Conclusions}

There remains much that we do not know about men's experience within marriage and family life. The research presented here clearly demonstrates that despite cultural stereotypes which characterize men as being disengaged from reproductive decisionmaking, those men who consciously choose to have children are profoundly emotionally involved in that decision. The decision to have a child marks a momentous transformation in a man's life. It is a decision to which he accords great importance.

Men are increasingly aware of the ways in which they have been defined-and have defined themselves-as peripheral players in family life. They are also alert to pressures placed on them to participate more actively in the care of their children. This awareness has placed men at a crossroads with regard to how they perceive and inhabit the role of father. They are struggling to understand the meaning of their experience, but they are doing so in a sort of cultural vacuum. They do not find their experience reflected anywhere in the culture. In trying to move beyond traditional roles. men thus experience a double bind: they are being encouraged to assume more direct responsibility in the creation and care of their children, but they receive extremely little social support when they attempt to do so.

Feminism has gone a great distance toward re-shaping our views on family life, opening possibilities for women to expand into the more socially-powerful positions traditionally occupied by men. But while we have become much more comfortable with the idea of women occupying traditionally male roles, we are less comfortable when men attempt to make a reciprocal transformation, letting go of a piece of their traditional role 
as provider in order to assume greater responsibility in the care and nurture of their children. As Cohen (1987, p. 72) describes it:

Men's notions of appropriate familial role behaviors are produced and then reinforced or challenged by a culture that is still less than wholehearted in embracing the idea of family-oriented men. Thus, subtle yet powerful pressures from peers, kin, or coworkers could restrain men from developing deeper levels of involvement or restrict them from fully expressing the role attachments they currently possess (Lein. 1979). This normative or cultural constraint may even limit men's social-psychological involvement in their families in a similar way that structural constraints restrict men's opportunities.

The implications of this conflict are tremendously important. We are currently at a point in our culture at which it is possible to make great changes in the way we work together as men and women to have and to raise our children. The status of men in families plays an important role in the problems faced by modem American families. Resolving these problems will require that we look beyond our current assumptions about male gender roles and begin to see more clearly men's actual lived experience. We need to begin allowing men's interior voices more fully into the cultural conversation so that men's efforts to grow beyond the limiting confines of traditionally assigned gender roles is met with mirroring voices and images in the larger culture.

This study has been an attempt to facilitate this process by looking directly at the subjective experience of men who have committed themselves to having children after having had an initial period of doubt about whether or not they wanted to do so. The 
results of this study demonstrate the effectiveness of the phenomenological method as a means of understanding men's lived experience in family life. Using the phenomenological method, the researcher interviewed six men to gain a spontaneous and unstructured account of their experience of making the decision to have their first child. These interviews were transcribed and analyzed using a process of phenomenological reduction in order to arrive at an essential description of this experience.

The description that resulted from this analysis revealed a set of interlocking themes which manifested themselves within a dynamic. dialectical, self-modifying process. In this process men move from a logical analysis comparing the cost and value of having a child toward an awareness of their inability to arrive at a rational understanding of the meaning of this decision. This in turn leads them to an awareness of the existential givens underlying the nature of the decision and finally to decision which abandons logical processes in favor of a leap of faith.

This process was characterized by a set of interlocking themes. A man's decision to have his first child is ambivalently made. It is a stressful experience in which he discovers that he cannot resolve his doubts and fears through a logical process of analyzing the costs and benefits and must instead accept that he cannot fully comprehend the outcome of the decision-he must trust in forces that are beyond his control. As a result of this process he is forced to accept the limitations of his own personal control. Having a child has a magical, unknowable quality to him and so requires him to develop a sense of faith, trust or hope. In making the decision, comes to terms with the permanence of having a child. The irreversibility of the decision forces him into a heightened awareness of the possibility of loss. He must embrace the idea of change at a 
deep level. While he must change himself in order to be able to make the decision. in making the decision he chooses to change himself further. He moves from selfishness toward generosity, from individuality toward a greater sense of interconnection.

When he makes the decision to have a child, a man comes fully into an awareness of himself in the present moment. He accomplishes this through an integration of his view of his own childhood with his imagination of himself as a father in the future. Through examining these influences and looking carefully at other parents and children. he re-focuses himself, sees himself and the world more clearly as they are in the present. Before he can commit to the decision to have a child, a man must construct for himself a constructive image of himself as a father. He does this through comparing his internal idea of what a good father is against his experience with his own father and an inventory of his personal strengths and weaknesses. The entire process of making this decision is informed by the quality of his relationship with his partner. In order to make the decision he must arrive at an attitude of trust and faith in her. The decision takes place within the relationship and is inseparable from it. Finally, the entire process of making this decision is an on-going dynamic in which a man's initial ambivalence is never fully resolved. However, his doubts and fears are transformed by the decision itself and by the fact of the pregnancy. By the time he has passed through this process, he looks forward to the birth of his child with excitement. 


\section{References}

Barash, D. P. (1978). Human reproduction: A sociobiologic perspective. In W. B. Miller, \& L. F. Newman (Eds.), The first child and family formation (pp. 15-23). Chapel Hill, NC: University of North Carolina.

Benedek, T. (1959). Parenthood as a developmental phase: A contribution to the libido theory. Journal of the American Psychoanalytic Association 7. 389-417.

Benedek, T. (1960). The organization of the reproductive drive. The International Journal of Psvchoanalysis 41(1), 1-15.

Benedek, T. (1970). Fatherhood and providing. In E. J. Anthony. \& T. Benedek (Eds.), Parenthood: Its psychology and psychopathology (pp. 167-183). Boston: Little. Brown and Company.

Berman, P. W., \& Pedersen, F. A. (1987). Research on men’s transitions to parenthood: An integrative discussion. In P. W. Berman, \& F. A. Pedersen (Eds.), Men`s transitions to parenthood: Longitudinal studies of early family experience (pp. 217-242). Hillsdale, NJ: Lawrence Erlbaum Associates.

Bombardieri, M. (1981). The baby decision: How to make the most important choice of vour life. New York: Rawson. Wade.

Booth, A., Johnson, D. R., White. L. K., \& Edwards, J. N. (1991). Marital instability over the life course: Methodological report and code book for three wave panel studv. University of Nebraska Bureau of Sociological Research.

Bram, S. (1974). To have or have not: A social psychologicai .udy of voluntarily childless couples, parents-to-be, and parents. Unpublished doctoral dissertation, University of Michigan, Ann Arbor. 
Bronstein, P., \& Cowan, C. P. (Eds.). (1988). Fatherhood todav: Men's changing role in the family. New York: John Wiley \& Sons.

Campbell, A. (1975. May). The American way of mating: Marriage si. children only maybe. Psychology Today $37-43$.

Cath, S. H., Gurwitt, A. R., \& Ross, J.M. (Eds.). (1982). Father and child: Developmental and clinical perspectives. Boston: Little. Brown \& Company.

Chafetz, J. S. (1978). Masculine feminine or human? Itasca. IL: F.E. Peacock.

Clinton, J. F., \& Kelber, S. T. (1993). Stress and coping in fathers of newborns: Comparisons of planned versus unplanned pregnancy. International Journal of Nursing Studies $30(5), 437-443$.

Cohen, T. F (1987). Remaking men: Men`s experiences becoming and being husbands and fathers and their implications for reconceptualizing men's lives. Journal of Family Issues 8(1), 57-77.

Colomby, H.. Loring, L., \& Shuler-Dooner, L. (Producers). \& Dragoti. S. (Director). (1983). Mr. Mom [Film].

Cooney, T. M., Pedersen. F. A., Indelicato, S., \& Palkovitz. R. (1993). Timing of fatherhood: Is "on-time" optimal? Joumal of Marriage and the Family 55. 205-215.

Cort. R. W., \& Field, T. (Producers), \& Nimoy, L. (Director). (1987). Three men and a baby [Film].

Cowan, C. P. (1988). Working with men becoming fathers: The impact of a couples group intervention. In P. Bronstein, \& C. P. Cowan (Eds.), Fatherhood today: Men's changing role in the family (pp.276-298). New York: John Wiley \& Sons. 
Cowan, C. P., \& Cowan, P. A. (1992). When partners become parents: The big life change for couples. New York: Basic Books.

Creswell, J. W. (1998). Qualitative inquirv and research design. Thousand Oaks. CA: Sage Publications.

Cronenwett, L. R., \& Kunst-Wilson, W. (1981). Stress, social support, and the transition to fatherhood. Nursing Research 30(4), 196-201.

Cudmore, L. G. (1997). The transition to motherhood: A phenomenological study of women's experiences as first time mothers. Unpublished doctoral dissertation. University of Ottawa, Ottawa, Canada.

Daniels. P., \& Weingarten, K. (1980). Sooner or later: The timing of parenthood in adult lives. New York: W.W. Norton.

Daniels. P., \& Weingarten, K. (1988). The fatherhood click: The timing of parenthood in men's lives. In P. Bronstein, \& C. P. Cowan (Eds.), Fatherhood todav: Men's changing role in the family (pp. 36-52). New York: John Wiley \& Sons.

Daniluk, J. C., \& Herman, A. (1983). Children: Yes or no, a decision-making program for women. Personnel and Guidance Journal. 62(4), 240-243.

Eggebeen, D., \& Uhlenberg, P. (1985). Changes in the organization of men's lives: 1960-1980. Family Relations 34. 251-257.

Entwisle, D. R., \& Doering, S. G. (1981). The first birth: A family turning point. Baltimore: Johns Hopkins University Press.

Erikson, E. (1950). Childhood and society. New York: W.W. Norton. 
Fawcett, J. T. (1978). The value and cost of the first child. In W. B. Miller. \& L. F. Newman (Eds.), The first child and family formation (pp. 244-265). Chapel Hill. NC: University of North Carolina.

Fein, R. A. (1976). Men's entrance to parenthood. The Family Coordinator 25(3), $341-348$.

Fein, R. A. (1978). Consideration of men's experiences and the birth of a first child. In W. B. Miller, \& L. F. Newman (Eds.), The first child and family formation (pp. 327-339). Chapel Hill, NC: University of North Carolina.

Flapan, M. (1969). A paradigm for the analysis of childbearing motivations of married women prior to birth of the first child. American Journal of Orthopsychiatry, $\underline{39}(3), 402-417$.

Friedman, D., Hechter, M.. \& Kanazawa, S. (1994). A theory of the value of children. Demography 31(3), 375-401.

Gerzi. S.. \& Berman, E. (1981). Emotional reactions of expectant fathers to their wives' first pregnancy. British Journal of Medical Psvchology 54. 259-265.

Giorgi, A. (1985a). Introduction. In A. Giorgi (Ed.), Phenomenology and psychological research (pp. 1-7). Pittsburgh: Duquesne University Press.

Giorgi, A. (1985b). Sketch of a psychological phenomenological method. In A. Giorgi (Ed.), Phenomenology and psvchological research (pp. 8-22). Pittsburgh: Duquesne University Press.

Giorgi, A. (1986). Theoretical justification for the use of descriptions in psychological research. In P. D. Ashworth, A. Giorgi, \& A. J. J. de Koning (Eds.). 
Qualitative research in psvchology (pp. 3-22). Pittsburgh. PA: Duquesne University Press.

Griswold, R. L. (1993). Fatherhood in America: A history. New York: Basic Books.

Gutmann, D. (1975). Parenthood: A key to the comparative study of the life cycle. In N. Datan, \& L. H. Ginsberg (Eds.). Life-span developmental psvchologv: Normative life crises (pp. 167-184). New York: Academic Press.

Hangsleben, K. L. (1980). Transition to fatherhood: Literature review. Issues in Health Care of Women 2, 81-97.

Herzog, J. M. (1982). Patterns of expectant fatherhood: A study of the fathers of a group of premature infants. In S. H. Cath, A. R. Gurwitt. \& J. M. Ross (Eds.). Father and child: Developmental and clinical perspectives (pp. 301-314). Boston: Little, Brown \& Company.

Hobbs, D. F. (1968). Transition to parenthood: A replication and an extension. Journal of Marriage and the Familv 30(3), 413-417.

Hoffman, L. W., \& Hoffman, M. L. (1973). The value of children to parents. In J. T. Fawcett (Ed.), Psychological Perspectives on Population (pp. 19-76). New York: Basic Books.

Jacobson. E. (1950). Development of the wish for a child in boys. In R. S. Eissler, A. Freud, H. Hartmann, \& E. Kris, The psychoanalytic study of the child. New York: International Universities Press.

Janis, I. L., \& Mann, L. (1977). Decision making: A psychological analysis of conflict, choice, and commitment. New York: The Free Press. 
Jenni, C. C. (1990). Men's perceptions of their former wives in the joint custodv family: A phenomenological analysis. Unpublished doctoral dissertation. Saybrook Institute, San Francisco, CA.

Jessner, L., Weigert, E., \& Foy, J. L. (1970). The development of parental attitudes during pregnancy. In E. J. Anthony, \& T. Benedek (Eds.), Parenthood: Its psvchologv and psvchopathologv (pp. 209-244). Boston: Little. Brown and Company. Johnston, P. I. (1992). Adopting after Infertility. Indianapolis. IN: Perspectives Press.

Kimball, K. K., \& McCabe, M. E. (1981). Should we have children? A decisionmaking group for couples. Personnel and Guidance Journal 60. 151-156.

Klein, B. (1985). Fathering: The first time. Social Work 30(3), 264-267.

Kruger, D. (1981). An introduction to phenomenological psvchologv. Pittsburgh: Duquesne University Press.

Lamb, M. E. (Ed.). (1987). The father's role: Cross-cultural perspectives. Hillsdale, NJ: Lawrence Erlbaum Associates.

Lein, L. (1979). Male participation in home life: Impact of social supports and breadwinner responsibility on the allocation of tasks. Family Coordinator 28. 529-534.

LeMasters, E. E. (1957). Parenthood as crisis. Marriage and Familv Living 19(4), $352-355$.

Levant, R. F. (1988). Education for fatherhood. In P. Bronstein. \& C. P. Cowan (Eds.). Fatherhood today: Men's changing role in the familv (pp. 253-275). New York: John Wiley \& Sons. 
Lieberman, V., \& Kastelowitz, L. (1986). An existential consideration of parenthood. Unpublished manuscript.

Lupton, D., \& Barclay, L. (1997). Constructing fatherhood: Discourses and experiences. London: Sage Publications.

Marciano. T. D. (1979). Male influences on fertility: Needs for research. The Familv Coordinator28(3), 561-568.

Marsiglio. W. (1991). Male procreative consciousness and responsibility: A conceptual analysis and research agenda. Journal of Family Issues 12(3). 268-290.

May, K. A. (1982). Factors contributing to first-time fathers' readiness for fatherhood: An exploratory study. Familv Relations 31. 353-361.

McAdams, D. P., Hart. H. M.. \& Maruna. S. (1998). The anatomy of generativity. In D. P. McAdams, \& E. de St. Aubin (Eds.), Generativity and adult development: How and why we care for the next generation (pp. 7-43). Washington. D.C.: American Psychological Association.

Miller, W. B. (1973). Conception mastery: Ego control of the psychological and behavioral antecedents to conception. Comments on Contemporary Psychiatry 1. 157. 177.

Miller. W. B. (1974). Relationships between the intendedness of conception and the wantedness of pregnancy. Journal of Nervous and Mental Disease. 159(6), 396-406.

Miller, W. B. (1978). The intendedness and wantedness of the first child. In W. B. Miller, \& L. F. Newman (Eds.), The first child and family formation (pp. 209-243). Chapel Hill, NC: University of North Carolina. 
Myers, S. M. (1997). Marital uncertainty and childbearing. Social Forces 75(4). $1271-1289$.

Nelson, M. L., \& Poulin, K. (1997). Methods of constructivist inquiry. In T. L. Sexton, \& B. L. Griffin (Eds.), Constructivist thinking in counseling practice, research. and training (pp. 157-173). New York: Teachers College.

Nute. M. (1986). Transition to fatherhood: A review. Family Perspective 21(2). $135-145$.

Nydegger, C. N. (1973). Timing of fatherhood: Role perception and socialization. Unpublished doctoral dissertation, Pennsylvania State University. University Park. PA.

Obrzut, L. A. J. (1976). Expectant fathers' perception of fathering. American Journal of Nursing $76.1440-1442$.

Ory, M. G. (1978). The decision to parent or not: Normative and structural components. Journal of Marriage and the Family. 40(3), 531-539.

Poffenberger, S., \& Poffenberger, T. (1952). Intent toward conception and the pregnancy experience. American Sociological Review. 17(5), 616-620.

Pohlman, E. (1969). The psvchologv of birth planning. Cambridge, MA: Schenkman.

Polkinghorne, D. E. (1989). Phenomenological research methods. In R. Valle, \& S. Halling (Eds.), Existential-phenomenological perspectives in psychology (pp. 41-60). New York: Plenum.

Presser, H. B. (1978). Social factors affecting the timing of the first child. In W. B. Miller, \& L. F. Newman (Eds.), The first child and family formation (pp. 159-179). Chapel Hill, NC: University of North Carolina. 
Rabin, A. I., \& Greene, J. (1968). Assessing motivation for parenthood. $\underline{\text { Journal of }}$ Psychology 69. 39-46.

Ross. J. M. (1975). The development of paternal identity: A critical review of the literature on nurturance and generativity in boys and men. Journal of the American Psvchoanalytic Association 23, 783-817.

Seccombe, K. (1991). Assessing the costs and benefits of children: Gender comparisons among childfree husbands and wives. Journal of Marriage and the Familv 53. 191-202.

Shecket, P. (1995). Support for fathers: A model for hospital-based parenting programs. In J. L. Shapiro, M. J. Diamond, \& M. Greenberg (Eds.). Becoming a father: Contemporarv. social. developmental. and clinical perspectives (pp. 135-143). New York: Springer Publishing Company.

Smith, M. B. (1973). A social-psychological view of fertility. In J. T. Fawcett (Ed.), Psychological perspectives on population (pp. 3-18). New York: Basic Books.

Smith, M. B. (1978). Decision making and psychosocial antecedents: A discussion. In W. B. Miller, \& L. F. Newman (Eds.), The First Child and Family Formation (pp. 266-272). Chapel Hill, NC: University of North Carolina.

Veevers, J. E. (1973). The social meanings of parenthood. Psychiatry. 36. 291310.

Veroff, J., Douvan, E., \& Kulka, R. A. (1981). The inner American: A selfportrait from 1957 to 1976. New York: Basic Books.

Whelan, E. M. (1975). A baby?...mavbe: A guide to making the most fateful decision of your life. Indianapolis: Bobbs-Merrill. 
Wyatt, F. (1967). Clinical notes on the motives of reproduction. Journal of Social Issues 23(4), 29-56.

Yalom. I. D. (1980). Existential psychotherapy. New York: Basic Books. 
Appendix A

Frank: Data Analysis

Levels 1-4 


\section{Frank - Levels 1-2}

So...what I'm aware of is that you have recently decided to have your first child. And I'd like you to tell me about the experience of making that decision.

/Okay. Let's see, I'll, uh, um...I think when I was about thirty I decided I was going to have kids, and perhaps not get married and that it may be better just to do it on my own, rather than try to make a relationship work. And uh... [interrupted by knock on door]....

\section{Okay, so at thirty...}

Uh, yeah, I was about thirty and I figured I was going to have kids but probably not get married. /And then when my wife and I met down at the University in school, uh, again I wanted to have kids right away. We ended up getting married after a year or two, something like that. /And uh, actually then my decision sort of changed as a focus become on making sure a relationship was going well enough to support a child. And it took a long time of sort of, uh, well, I guess we had to sort of adjust to one another, so that life as a single person, life as a married person required a certain number of changes that needed to be made. so both of us sort of went through a process of transformation, of making those kind of changes to...to accommodate to married life. /And then at that point we decided that we were ready to have kids, after our relationship had solidified to the point that it seemed like it made sense. And that we could support a child because we could support one another as well. And uh, so that was probably about two years ago. /And then, so we
1. At thirty, S. decided to have children without a partner.

2. When S. first met his wife, he wanted to have children with her right away.

3. In making sure his relationship with his wife was stable enough to support a child. S. went through a long process of adjustment and transformation in accommodating to the demands of married life.

4. S. and his wife decided they were ready to have children when their relationship had solidified to the point that they could support one another and could thus support a child. 
tried for - maybe about three years ago now since the first year of our relationship - so we tried for about two years. And then, had a, went through a number of surgical and medical kind of procedures and then after the end of the second year, finally we ended up conceiving after we'd stopped doing all this stuff, and finally it worked.

Right. That's the way it goes sometimes.

Exactly. Yeah, so that's kind of the process.

So you made the decision to have kids at thirty...um, and then - apart from a relationship.... You found yourself in a relationship and then the relationship factors become important about, sort of, how that would work. But you still - let me see if I understand this right - you still have the, you're still planning on having children through all of that time. The decision had been made and it stayed intact?

/Right. Well. I think it waned a little bit. I think there was time when we had it. we were pretty focused on having kids, II. no, let me say this for myself. I was pretty focused on having kids when we first started dating. /But it was sort of this honeymoon phase, so it didn't change much from my original intention when I was a single person. /But then after we got married there were some rough times there during the first year, and then my decision changed. And I thought, maybe it would be better if we waited a little bit longer before we jumped into this. /So, it was something that I was confident in and definitely
5. S. and his wife tried for several years before finally getting pregnant.
6. S.'s desire to have a child with his wife waned at times.

7. At the beginning of his relationship with his wife, S. was focused on having children.

8. At first, S.'s desire to have children with his wife was similar to his desire to have children as a single person.

9. After S. and his wife got married, they had some rough times which mads him believe it would be better to wait before having children.

10. S. was confident in his desire to have children from early on in his 
thinking of early on, but sort of had this gap and period of time where I thought. well maybe we shouldn't think about having kids until we can get ourselves together enough as a couple. Then we can begin to support a child. /So, yeah. we sort of had to go - I at least personally had to go through that...transformation. to feel. I guess. the way I term it is, I was living comfortably as a single person and could support that. And it wasn't until I was living comfortably as a married person that I felt that I could support it again.

\section{Support that...support...?}

A child. Yeah. A child of any kind of relationship. So, um....

So you came to a point where you, as a single person, where you felt you were ready to support a child.

Yeah, right.

\section{Could you tell me about that.}

Лm, well let's see. I think through a series of relationships I finally realized that it isn't going to happen, I probably wouldn't end up being involved in a kind of intimate relationship. And I sort of enjoyed the [laughs], the selfcentered, maybe, benefits that came from just dating somebody. And uh, so I thought maybe that would be a good way to go. /And, I'd also had some fears about getting married and uh...potentially losing a child to divorce or separation or anything of that kind. /Because I'd had a lot, a number of parents who've been married and divorced, you know, three times I guess my mom has. So they've all been divorced. IAnd uh, so I wasn't relationship with his wife. but for a time he felt they needed to get themselves together as a couple in order to be able to support a child.

11. Before he felt he could support a child, S. had to go through a "transformation" from living comfortably as a single person to being comfortable as a married person.
12. Prior to his marriage. S. had come to believe that he wouldn't end up in an intimate relationship and he thought that this might be a good way to go.

13. S. feared that if he was married he might lose a child to divorce or separation.

14. S.'s feelings about children were affected by the fact that his parents had been married and divorced many times. 
too sure about whether or not I was willing to have a child and lose it. The potential was there. So the models I've seen, this is the conclusion I've come up with, rightly or wrongly. And so I sort of thought that maybe, uh, that might be the outcome, /so rather than have that be a possibility I would simply make the decision to have a child by myself and in doing so it wouldn't be an issue. I could adopt a child, I wouldn ${ }^{\circ}$, never have to fear losing a child potentially. So it seemed to make sense to me at the time. /So then I had to grow up and all that other kind of crap.

[both laugh]

Yeah.

Unfortunately.

So up until that point what were you thinking about having children? Up until the point of making the decision to have a child on your own? Were you thinking...were you thinking about having children, or what were your thoughts about it at that point?

You mean, having uh. prior to getting married?

Yeah. Separate from...you know, separate from everything else in your life, was that a, were you going to have children at some point, or not?

Oh, separate from having them by myself?

Um...I don't know if I'm saying this all so well. But...yeah, before that point of deciding to have a child on your own, what were you thinking
15. Based on his childhood experience of divorce. S. was very aware of the potential for having a child and then losing it.

16. S. had decided that rather than risk losing a child. he would have a child by himself and not have to risk that loss.

17. S. felt that he "had to grow up." 

children?

/Huh. Let's see. I think for quite a long time I thought that I probably wouldn't have children at all. I've had a number of animals, dogs, and so, growing up in a crazy family I sort of figured that maybe a dog would be all I'd need for the rest of my life. /And at some point in time it sort of changed, that - and I've had one ever since I was probably, ever since I was...forever. I've had dogs forever, I think. Ever since I was born. So, growing up in crazy families, all this other kind of stuff, um, this sort of dog became my one, the one sort of force in my life that I knew I could trust and count on. /And uh, so. it got to the point though where I figured, well I could have a dog, but, and I would know that that would be something that wouldn't abandon or divorce out of our, my life or whatever the case might be. And, uh, and then probably have a child on my own as well. So it sort of continued to develop this perimeter of safety that allowed me to, to sort of possess what would never leave me in terms of giving and loving something else. The reason that a woman didn't quite fit into that. because, they have the potential to leave and not be a part of your life anymore and I didn't, wasn't really wanting to go through any kind of emotional turmoil as far as that was concerned. /So, it was very safe to have an animal. And it was very safe to have a child too- without somebody else.

\section{Um-hm.}

/So, it was, a lot of it was based on my own needs, what I figured would be safe for me, and uh...but it evolved and
18. For a long time. S. didn't think he would have children at all.

19. S. had always had dogs. which had been something he could trust and count on and he thought that maybe this would be enough.

20. S. knew that a dog wouldn't abandon him or divorce out of his life.

21. S. expanded his "perimeter of safety" of those who would never leave him to include the idea of having a child on his own.

22. S. knew that women had the potential to leave him and he didn't want to risk going through that emotional turmoil.

23. S. felt that it was safe to have an animal and that it was also safe to have a child outside of a relationship.

24. S. based his ideas about having children on his own needs for safety -- but those needs evolved. 
rightly so. That at some point I was able to trust that - trust the fact that I could trust somebody else and develop that relationship and then have kids enter into our lives, you know, in sort of a normal way. But it was through a, quite a process.

\section{Yeah, it sounds like it was a long kind of evolution.}

Yeah, it was probably, let's see from that time period my guess is probably, oh, well I was that way for, criminy my whole stinking life. /And then when we got together, maybe two years before I might have gotten to the point where I was able to trust that this person was going to always be a part of my life /and not sort of pursue this, oh, self-fulfilling prophecy of the fact that at some point in time she's going to leave, so, um, there's no reason to get too attached or fully invest yourself or have children for god's sake, that'd be stupid. /Um. so then at some point I just had to give myself up and resign myself over the fact that...by not giving fully I'm not giving at all. So I better go ahead and do that. IAnd uh, that then I think developed more structure in our relationship and we were a stronger couple as a resuli. And from there able to, then we could, you know, have children at that point. So, yeah.

Yeah, I hear the loss....is a big factor it sounds like through all of this, the possibility of losing...

The possibility of losing...?

\author{
Of losing...something, of losing the \\ child.
}

Yeah.
25. Through a long process. S. became able to believe that he could trust another person and develop a relationship and have children with them "in a sort of normal way."

26. In his relationship with his wife, $S$. was able to get to the point where he was able to trust that she would not leave him.

27. S. stopped pursuing the "selffulfilling prophecy" of abandonment which had led him to keep from getting too attached or invested or from having children.

28. S. had to give up his fear of abandonment and resign himself to the fact that "by not giving fully I'm not giving at all."

29. By strengthening his relationship with his wife. S. and his wife were able to have children together. 
It sounds like that was a major piece of...

IOh, sure. Yeah. It was all, uh, yeah, maybe if, if you were to sort of psychopathologize the whole thing, the fear of abandonment or needing to have a certain amount of control over your environment. /And I was certainly, up until the point at which I sort of evolved into. I need to just give all that stuff up because it's not helping me to further myself or grow or mature, um, control of everything. So that I could control...financial future, emotional future, intellectual future, you name it. IAnd at some point realizing that giving up control may be the best thing for me to continue to grow. And so, um, so it's a matter of I think sort of giving that up. /And maybe it was, yeah, kind of a loss in terms of needing to lose something to gain something in the process if that makes any sense.

Right. [pause] I'm trying to put together, to sort of understand how that relationship between having a child and the fear of being able to lose the child, if that weren't, if that fear weren't there for instance, would that, where would the...? I'm not asking that very well. Um. [pause] Maybe I could just ask sort of how that, how the two relate, the desire to have a child... is that the...was the only thing keeping you from it the fear that you could have that and get engaged with it and then lose it. Or was there more, other things going on?

Um, the only thing that was what now?

The fear of...?
30. S. describes his concerns about having children as a fear of abandonment and a need for control over his environment.

31. S. felt the need to give up his fear of abandonment and need for control in order to grow and macure.

32. S. realized that giving up control was what he needed in order to continue to grow.

33. S. experienced the giving up of control as a loss that was necessary in order to gain something else. 
You described, kind of, when you were describing it before you described the fact that, a dog you knew would always be there.

Oh, sure, right, okay.

And that a baby...

Yeah, would always be there too.

You would have the potential to lose that...in a relationship.

In a relationship, right.

I'm wondering if that....was that the entire factor in deciding. Was there more?

In deciding...?

That you could have a child.

Well...

Rather, that you wanted to have a child.

几m, let's see. I knew I could have a child even being a single person. So I knew that that was a possibility. /What it was all pretty much based on was this, just knowing that it was more or less controlled, having children was important to me, it was something that became a desire that I didn't have earlier on. but it made more sense to me to have a child and control...control, uh, let's see, it's relationship with me and with others in some sense. /And growing up in a family where you had a lot of, uh, divorce, there were times when I had step-brothers and step-sisters for five
34. S. knew that he could have a child as a single person.

35. S. had the need to have a child and he also felt a need to have control over the child's relationship with himself and with others.

36. Because $S$. experienced the sudden loss of step-brothers and sisters while growing up, the idea of having a child without another person made sense to him. 
years. And all of a sudden they're gone. One day they're there and I was playing with them having a great time, the next day, there no more. [laughs] So it seemed to make more sense to me to have a child and to have it just yourself, than to have it with somebody else. $\Pi \mathrm{t}$ was very selfish and uh, something that would be probably detrimental in many respects to a child not having a mother as well. /But it seemed to make the most sense to me, in a self-protective way of thinking, that this will serve my needs best. /And maybe I rationalized that it would also serve the child's needs best too, by there not being a divorce. Because everybody in my family was always divorced. Lots of times.

\section{So that's had a big effect on this decision making process for you, sort of this, what you experienced in your family.}

/Exactly. Exactly, yeah. The only experiences that I have with regard to, you know, what raising a child is going to be all about, the stability of a relationships and all those kinds of things. $I$ have a number of friends who got into marriages that weren't planned, had children that weren't planned, and uh, all of a sudden got caught with their pants down trying to figure out ways to make a relationship work and figuring out what they're going to do with their child. Man I've had some friends that have gone through hell trying to, you know, talking about things like moving out of the country, having their child on a milk carton for taking their child away, I mean all this kind of crap. It's not a good scenario. /So, a situation where I wanted to figure out how it could work best and be controlled to a certain degree. There's something else I was 
thinking of too, I can't quite remember what it was. Um.... It'll come back to me.

You said at one point that you weren't, you didn't think that you would have children.

$\Pi$ think just real...early on. More or less based on my age and level of involvement with friends and whatnot. It wasn't - but at a certain point, there wasn't a point at which I said I didn't want to have kids /and except for a time when I was with my wife and then I thought...oh, boy, I don't think we can have kids together, because I don't know if our relationship's going to work. /And the biggest - this is what it is - the biggest fear for me is like the fear of potentially having a child and not being in its physical presence.

\section{Um-hm.}

And it probably still is. That, uh...man, I just have no desire, I don t t even want to work and have a child, let alone have a child and potentially not have it in my own home and not live with it.

\section{Right.}

Phew, forget it. That's got to be the worst thing I can possibly think of. And uh. so, yeah that's something that I'm just not interested in one bit. /I've had a lot of...a lot of family, lot of friends, who, you know, try to still be - and especially try being a dad, because usually the mother has primary custody or at least back then there was, even more so. /But uh, yeah, I don't know. I
43. Early on in his life S. didn't want to have children at all.

44. There was a time in S.'s marriage when he didn't want to have children because he didn't know if the marriage would work out.

45. S.'s biggest fear is that he would have a child and then not have that child in his physical presence.
46. S. knows many people who are trying to parent without being the custodial parent of their child. 
don't know how people can go through their lives everyday without just being torn to shreds thinking about what their kid's doing and missing out on little things they're learning, you know, day after day and stuff like that. /And you know it's just the most important job that a person's ever going to do and I want to be fully engaged with it. And, I don't know, I just don't want to miss any of it. /And part of...part of that with us not wanting to have, or me thinking I'm not having kids was the possibility that our relationship wasn't working so well the first year and that there was a good chance that we... we may not make it through, so it was stupid to think about having kids unless we got on firmer ground.

Um-hm. Right.

/And then at that point, um, we got on firmer ground then it seemed like it made sense. So....

It must have been - given the intensity of what you're expressing about how awful it would be not to be with, have that physical presence with the child after they were born - it must have been quite a thing to give yourself over to that choice.

/Uh-huh. Yeah, definitely. Because it, man I hung on to it for a long time.

\section{Hung on to...what?}

I hung on to the need to have, the need to control what a child would be in your life - for, criminy, thirty-two years, something like that, thirty-one years. I guess, maybe thirty years. $/ \mathrm{Um}$, that it can all be well controlled and that I
47. S. imagines the experience of not being in the physical presence of his children and missing out on their development as one that would tear him to shreds.

48. S. feels parenting as the most important job a person ever does. He wants to be fully engaged with it.

49. Because S. did not initially feel that his relationship with his wife was on firm ground. he didn't let himself think about having children with her.

50. When S. and his wife got their relationship on "firmer ground." having children together made sense to him.

51. For a long time, S. hung on to his desire to control what a child would be in his life.

52. S. believed that if he controlled things well, he wouldn't have to face the potential of ever losing his child. 
wouldn't have to face that potential if I did things a certain way. /And, yeah, so at some point it seemed like this continued to get in my way and in the way of our relationship. So at some point I just had to let all that go, /knowing that the growth that could potentially come out of that would be a lot, a lot better and a lot healthier and that probably what was perpetually in our relationship not working was me not allowing that to happen. Not giving over fully and trusting fully and then allowing for the potential to be hurt or, whatever that might include. /And then once that happened, then we got on firmer ground and then we were able to move into thinking about having children at that point. So....

So it did, yeah, so you made that move in your relationship and then you were able to do it with the decision to have a child.

Y Yeah. Then we got to the point where we were able to, um, to take a good look at where we were at and what we were doing and whether or not having children was something we wanted. It was less of an "l" decision and more of a "we" decision at that point.

\section{Uh-huh.}

Something we could look at as a team rather than me think about in my own, my own personal needs and concerns. /So it was nice to get to that point. And we've been there ever since. So it's been real comfortable, there hasn't been that kind of fear that still hangs over me at all. /Making the relationship work is going to be up to the two of us. If it doesn't work it doesn't work /and you
53. S. became aware that his need for control was getting in the way of his relationship with his wife.

54. S. reached a point where he felt he needed to let go of his need for control.

55. S. believed that the growth that could come from letting to of his need for control was healthy and that his unwillingness to fully trust and to allow himself to be potentially hurt was holding back his relationship with his wife.

56. When $\mathrm{S}$. was able to trust his wife more fully, they were able to start thinking about having children.

57. S. and his wife arrived at the point where they were able to examine their relationship and the question of having children from a team perspective -- we rather than I.

58. $\mathrm{S}$. is contented with having arrived at a team perspective with his wife about the decision and he finds that this has reduced his fear.

59. S. believes that he and his wife had the responsibility together for making their relationship work and is realistic about the fact that it might not. 
know all you can do is put your best foot forward, not be trying to live a life based on fears. You're not going to live life very fully I guess. So at some - /it's not something that continues to come back very often at all. You know, once you get - maybe that was part of the difficulty - once I gave myself over there was no turning back.

Uh-huh. So could you tell me more about your experience, from your side, of giving yourself over to that decision and taking that risk.

Um, let's see. Part of it was that we had a pre-marital counselor that we worked with for nine months. And she's this, uh, very charismatic - in a good way African-American woman, who I respect tremendously. So we worked with her for nine months before we got married, pre-marital counseling. And we went back to see her every six months. We just haven't for awhile yet, but I continue to go back every once in awhile and still see her and meet with her and talk about life. And, uh [laughs], and she'd kick the living tar out of me whenever she' $d$ want to and just let me know what I needed to do. And what I'm not doing. /And I've always been a fairly engaged learner in terms of my own desire to struggle with personal issues and to try to grow from them and try to be healthy. It's a selfish process, there's nothing grandiose about it. /And she's been a good person to guide me in that process. And so there was a time when she said something like, um, needing to fully trust your partner, needing to let go, needing to.../not sort of live this self-fulfilling prophecy where you know it's going to happen so you continue to live based upon that fear
60. S. believes that he won't live his life fully if he lives it based on his fears.

61. Once S. gave himself over to his fear of loss of control. "there was no turning back." Those fears don't come back much.

62. S. and his wife saw a pre-marital counselor who helped $\mathrm{S}$. get over his fears by telling him what he should and shouldn't do. 
and you push for that direction. Because ultimately you know already it's not going to work, so why not just doom it right up front. /And so, I spent a lot of time thinking about that. And by her confronting me with that it was real hard for me then making a conscious decision about choosing differently. /And it was probably then at that point that I began to think about the fact that yes in fact I was probably creating more distance and pushing us further away and creating a lot of the turmoils and troubles that we were having. /So it was important to sort of let a lot of that stuff go that was a part of my past and start anew with regard to needing to buckle myself up to trust someone else. /That it was okay to do that. And certainly you might get hurt and you may even. um. you may be abandoned. But it's uh.... And I read a lot of stuff too that made me think more about it. This wasn't something that I consciously thought about very often in terms of my own stuff that I need to deal with and think about. But uh, it was something new for me to process /and I've read a number of books too that talked about people's need to experience life fully. And by not experiencing life fully, maybe not giving entirely of yourself or experiencing everything you can from love or everything you can from grief. IAnd you can't truly love unless you truly grieve. And so, you need to fully give yourself in order to deal with love. And sure there's going to be loss that's going to come of it, but you're never going to fully have appreciated love unless you give yourself over fully to it. /So I just spent a lot of time processing that. making sense of it. um, trying to figure out what this meant for me, /and also a lot of it was giving up life as a single person
66. S. thought a lot about his pre-marital counselor's advice regarding his fears about relationships. Based on this. he made a difficult decision to change.

67. S. came to recognize that he was creating distance and problems in his relationship with his wife.

68. S. felt that it was important to let go of his old fears and behaviors about relationships and to try to learn to trust someone else.

69. S. recognized that while it was possible to be hurt and even abandoned in a relationship, it was still okay to let himself trust someone else.

70. S. had not thought much before about his own trust issues in relationships. This was something new.

71. S. had read about the idea that by not giving of yourself fully, not experiencing both love and grief fully, you're not experiencing life fully.

72. S. had read about the idea that in order to truly love you have to be able to truly grieve. He recognized that love will involve losses and understood that it was necessary to give himself over to love fully in order to appreciate it.

73. S. spent a lot of time thinking about how the ideas about love and loss that he'd read about applied to him personally.

74. S. felt that he needed to give up life as a single person and grab hold of life as a married person. 
fully. And getting, grabbing a hold of life as a married person. /Because I was a person who, I really liked, who I had a lot of fun with, who was secure in himself as a single person. But - and now everybody that I ever meet with anymore I say, you know all that stuff you learned as a single person? Forget it. [laughs] Toss it out, it's not going to work for you anymore. You've got to learn a whole new set of skills and you might as well forget about that stuff. And especially at the age of thirty, I mean you get to a point where you, you know, involved in such a lifestyle and mindset, set of habits, whatever - and if you decide you're going to hang on to those in a relationship, you might as well forget it. /You know, unless you have two incredibly independent people who have their own lives and maybe connect with each other once in awhile. But it's not something that we' re desiring in a relationship. Yeah, so I think that that was sort of the whole process.

So that is, yeah, a good description of that. It sounds like that's mostly in the relationship...how does that, can you connect that for me to having a child, that letting go and living life fully and all of those things.

/Sure. Um, let's see. I don't know if there's much to that or not. Um. I think that...I think that maybe getting to a point in the relationship where I once again got to the point where I was a single person as a married person, perhaps my wife being at a similar point where, then as a married person we were able to look at ourselves and appreciate who we were and what we'd become and then have a very stable foundation. Then I think from there, sort of this
75. S. had felt very secure in himself as a single person. but he found that this identity didn't work for his life as a married person -- he needed to throw out his old skills and learn new ones.

76. Neither S. nor his wife desired the sort of relationship in which they were both very independent of one another.
77. S. and his wife got to the point in their relationship where they saw themselves as married people. They were able to see themselves and see what they'd become and this gave them a "stable foundation."

78. S.'s decision to have a child evolved 
decision to have a child just sort of naturally evolved. That...over a short period of time it was something that we then began to explore, talk about a little bit and consider it. There was a short period of time where I sort of said well I'm not really sure, you know, maybe we'll wait for a little while and bring it back up again and think about it. /And I, more or less I think I wanted to continue to test and see whether or not this was for real and our relationship really was this stable, that we really did go through this sort of transition where now we were a fairly stable unit that, um. there wasn't the potential for us to break up. /Because again, I didn't want to have a child if I was going to lose a child. And certainly l'd look at it in very black and white terms. /I guess if I. you know we'll have a baby now in two weeks or something - you know. I'd just follow it wherever, where it was going to go, no matter what the situation is, so it's not like I'm giving up everything in the world. But I guess I sort of saw it in those terms in some sense. $/ \mathrm{Um}$. So yeah, there was some time getting there. /We started to discuss a little bit and my wife was a bit more for it than I was. Um, but then after a little while I said okay we'll go ahead and try and start the process underway. Then we...sort of, well, what did we do? I think we ended up first going off birth control and going through this rhythm method, rhythm process to figure out exactly when she was ovulating. And we did that for about six months and nothing happened. And uh, let's see, what else did we do? Ovulation, we've done everything, so I don't know, whatever you know, whatever crazy stuff there is out there we've done. So we did this ovulation business and then, yeah, temperatures every morning and um, trying to have from the stable foundation that he'd built in his marriage. He began to explore the possibility of having children and to talk about it with his wife.

79. For a time, S. wasn't sure about whether he wanted children with his wife. He put off the decision.

80. S. put off the decision about having a child with his wife because he was still testing the stability of the relationship. He wanted to make sure that the marriage wouldn't break up.

81. S. didn't want to have a child if he was going to lose it. He saw this in black and white terms.

82. S. acknowledges that the absolute terms in which he saw the possible loss of his child were not entirely realistic. because he would always find a way to be with his child no matter what happened.

83. It took some time for $\mathrm{S}$. to get to the point where he could take the risk of having a child.

84. There came a point when $S$. wanted to go ahead and start trying to have a child.

85. Before they finally got pregnant. S. and his wife went through a twoyear process of trying to conceive their child, first just stopping birth control, then monitoring ovulation. taking fertility drugs, having sperm checks and finally surgery. 
intercourse during those times when she's ovulating. We did that for at least six months. At least six months. And then six months before that, we just said okay, we're not going to use birth control, see what happens. We did that for six months. And then we did this, this situation for six months. Then we went on Clomid, which is uh, I don't know if you know of it...

\section{I don't know much about it.}

Well yeah, it's kind of a way to promote fertility, a fertility drug. So we did that for another...eight months. That's way too long. It's only, apparently it should only be used about three months. And there's a higher rate of ovarian cancer if used over three months. So we did that for eight months. So that was, brought us to about twenty months. And then we, in between that period then there are many times. when we started this Clomid that we had...sperm checks, you name it, all kinds of exams, stuff like that. And then finally about twenty-two months my wife had microscopic surgery and found a little endometriosis, a few things like that, and we quit doing the drugs. And we actually saw a fertility specialist down in Dallas, Texas. And then two months later it worked. So, yeah.

\section{A long process.}

About two years worth. So it was quite a long time.

\section{After all of that working up to it, to have to wait that long must have been....}

/Right. Yeah, exactly. We just figured it wasn't going to happen, at some point.
86. During the process of trying to conceive, $\mathrm{S}$. and his wife came to believe that they weren't going to be able to get pregnant. 
/So we looked into adoption. Fairly early on. I think it was when we were about half way through the Clomid, four months into that. After about sixteen months or so, a year and a half, we went to an adoption agency and talked to them about adopting and either adopting internationally or locally or statewide or whatever. We checked that out for awhile /and we thought. well, my wife is still a little younger than I am so we still have quite a few years that we can try. /Part of it was for her it was very frustrating to go through this process that didn't work and continually be disappointed that she was never going to able to do this, what she had imagined her entire life doing. /For me, I didn't care whether it was adopted or my own or what. Just having a baby was fine with me. /Uh, so yeah that was. it was a long process, a lot of rigmarole and medically invasive procedures that we were going through.

Could you take me back, if you would go back again...

Sure.

...to that moment of, you said there was some moment where you said, you know, okay, let's give it a try. Perhaps you could tell me what that was like, you know, walk me through that. What - in the moment that you knew that for yourself - what happened?

/Let's see. You know, I think part of it, I think maybe there was a, if you took maybe a decision that was, that you might make that you're fully invested in -I think maybe I was about fifty percent invested. At the first point of saying
87. Because of difficulties conceiving. S. and his wife considered adopting a child. They spoke to adoption agencies about this.

88. S. and his wife decided against adoption because his wife was still young enough that they could keep trying.

89. S.'s wife had always imagined being pregnant and having a child and was frustrated and disappointed that she was having trouble conceiving.

90. S. didn't care whether the child was adopted or his own. He just wanted a baby.

91. The entire process of conceiving a child was long and intensive.
92. At the point of starting to conceive a child. S. was about fifty percent invested in the idea and fifty percent unsure. 
yeah let's go ahead and try it. And uh, fifty percent unsure. /So I was sort of moving from maybe being 10-90 to at least 50-50. And saying okay, let's go ahead and do it. /Part of it too was my wife brought it up again and again and again /and I finally said that's fine, we'll do it. But let's just go without birth control for awhile and see how it goes. /And I really didn't have any forseen... I wasn't an active participant in yeah, let's really go for it and get pregnant. It was more...okay, let's kind of just go, not have birth control, and we'll just see how it goes, and no need to get all stressed out about this....

[End of side one. The conversation continues for a short while with the tape recorder not running. Recording resumes with $S 1$ re-stating what he had been saying during the nonrecorded portion of the conversation.]

So we left off when I was asking you that question about where you made that decision, how that decision, that point of making the transition...

/Okay, got it. So, the point at which I began to, where I was sort of half, 50-50 invested, when we said okay let's go ahead and do this. Then we got to the point where I was 70-30 invested in doing this, when we started with the Clomid after six months, something like that. /But it wasn't until we interacted with other couples, primarily through the adoption situation, we went and saw these people who had been trying their entire lives but they had been unsuccessful, that they were maybe in their mid-thirties, some of them forties, but they'd never had children. That they sort of experienced this completeness in
93. Prior to trying to conceive. S. was ten percent invested in having a child and ninety percent unsure.

94. Before they made the decision. S.'s wife frequently brought up the subject of having children.

95. S. responded to his wife's repeated requests to have children by agreeing to try and stop using birth control, to "see how it goes."

96. At the beginning of trying to conceive, S. "wasn't an active participant." Rather than actively wanting to get pregnant. he wanted just to go without birth control and see how it goes.

97. S. went from a state of being fifty percent invested in the decision to have a child to feeling seventy percent invested at the point that his wife was using fertility drugs.

98. In meeting couples who had adopted because they were unable to have children of their own, S. saw that these people felt a sort of spiritual completion in their lives through the process of becoming parents. 
their lives. It seemed like this circle that they had, whether it was a spiritual circle or a whole person circle, whatever it might be, that it came round and sort of fully developed itself when these folks had experienced parenthood. That they got this child, this baby that was now a part of their lives, where all of a sudden they felt more whole and more complete and more... and I, I guess I would say maybe more spiritually connected to themselves than they'd ever been, through this process. /And I'd also talked with a guy at a wedding once about this child the entire time, and you could also sense that whole feeling of...completeness in him that he had /at work and at school and all that kind of stuff, that people spend all this time sort of talking about and thinking about, are maybe important at one level but it's, it was no way comparable to the kind of feeling that would come from the importance of the child and what they were as a part of your life. /And it was, as this one person mentioned to me once, I was talking to him about it, he said, he was about forty before he had children, and he said, "once you have children you have all these little doors inside you that you never had inside you before that all of a sudden all of them come open and there's this floodgate that sort of explodes inside of you that you never even realized were there." /Because you were a happy person prior to that, but all of a sudden you experienced life more fully than you've ever experienced before. So, I've heard a lot of people say that /and I get bits and pieces of it once in awhile, when we go in and, maybe feel the baby kick around or something like that. Then we go outside and look around, and we live out in the country so it's a beautiful area, and all of a sudden you get that, that
99. S. saw that through the process of becoming parents. other people became more whole. more complete and more "spiritually connected to themselves."

100. S. had a conversation with a father in which he perceived in the man a sense of wholeness or completeness.

101. S. came to believe that the importance ascribed to work or school is not comparable to the importance of having a child as part of your life.

102. S. was told by another father that the experience of having a child was like having door inside that you didn't know were there open up.

103. S. heard other parents describe the experience of being a parent as one which made you experience life more fully than you had before.

104. Through his wife's pregnancy, $\mathrm{S}$. experiences a part of the fullness that he has heard other parents describe. He describes a feeling of "connectedness" to the natural world. 
connectedness that you oftentimes don't feel in everyday life. /And so I know when this happens, that will undoubtedly occur. When... when this sort of floodgate opens. I can feel it. I know it's there. It's close. This whole birth process I'm sure is going to be the beginning of the end in terms of that. [laughs]

The beginning of the beginning.

Yeah.

Yeah, you were saying you'd felt it some when you worked in the hospital and seeing death.

/Yeah, I worked in the hospital for a lot of years and I worked with a lot of families who had, who had people who were dying and it was another time where they fully, it seemed like, again we're at a different level than we are right now, or whenever we're out here in the real world, we just don't experience the fragility of life, I guess, in such a degree, that you experience it through death, which I have seen, and what I perceive to be through life. /I haven't been a part of births and I haven't really seen the reactions of couples during this early time, but I imagine it to be the same kind of thing, / where all of a sudden you feel...it's just nerves, there's nothing that's cognitive about any of the process that's going on, it's, this is how fragile life is, this is where, what life is really all about. /And to see people struggle with that. as well as through birth to experience euphoria, I think is kind of those areas of the continuum we often haven't experienced and we sort of experience a lot of that in between.

More or less.
105. S. feels certain that once the baby is born he will experience the fullness and the opening of inner doors that he has heard others describe.

106. S. describes how past experiences working with people whose family members were dying made him appreciate the fragility and the larger dimensions of life.

107. Although S. hasn't been through a birth, he imagines that it is similar in some ways to the experience of having someone you love die.

108. S. imagines the experience of giving birth to be one which is entirely about feelings where there's nothing cognitive, just an awareness of the fragility and essence of life.

109. S. believes that experiences of both grief and the euphoria of birth are on the outer areas of the continuum of life's experiences. 
So something deeper and more real, it sounds like?

/I think so, yeah. Yeah, it's just. it's not something that you can consciously defend against or screen out.

We have great screeners it seems like for everything that comes up. But when something like that happens, there's no way of consciously screening it out. It's just going to, it's just a bzzzzzt [moves hand in toward chest], right in here.

\section{Um-hm.}

And there's no way to screen that out. It's not something that you process and go oh. yeah. well, whatever. I mean it's just going to. it's going to hit you where nothing else can potentially hit you. There's no avoiding it. /Yeah. And I've experienced that a couple of times, also working in psychiatric care with some adolescents there's some times when I couldn't screen out some of the craziness that had gone on. And it was something that just hit me directly. And it wasn't a matter of screening it out, making sense of it and processing it. It was something that would affect you more than anything eise you could possibly imagine. /And this process too, going through birth, is something that, and having a baby is something that I just, I can't imagine at this point. /I'm sure that once it happens that I'm going to be...I...I don't ever want to grow immune to it or even be accustomed to it, /but, be able to then sort of make that complete circle I guess in some sense. And continue to, to keep it completed I guess, and to build on it in some way. I don't know. Yeah.

\section{I think that's a wonderful description.}

110. S. envisions the experience of birth as something that cuts through all of our mental "screeners." which will "hit you where nothing else can potentially hit."
111. Working with adolescents, S. has sometimes experienced moments in which he couldn't screen things out and which as a result affected him profoundly.
112. S. can't imagine the process of going through a birth and having a baby.

113. S. doesn't want to grow "immune" to or become accustomed to the experience of having a child.

114. S. wants to make for himself the "complete circle" that he has heard others describe. He wants to keep the circle completed and to build on it. 
/Oh, really? That's part of the way I see it. I'm not sure if that's accurate or not. /But, yeah, I've heard a lot of people talk a lot about it. And they have a hard time putting it into words.

\section{Um-hm.}

Similar to labor. Nobody can really tell you exactly what it's about, the pain that women feel. They sort of go, well, it's kind of like this, a little bit like that. And it seems like the same way too when you have kids and, /and yeah, I'm sure it's everything you can imagine times ten or times a hundred, is what it's going to feel like.

\section{Um-hm.}

\section{/And I'm ready for it!}

\section{[both laugh]}

\section{That's cool. But it was a little while getting you ready, getting you to that point.}

\section{/A long while.}

So could you tell me, that 50-50, kind of describe what each of those was, what was on each side of the scale?

Sure. Let's see, I think at one point there was, the $50-50$ point was...I don't know, I just, when I look back, and I guess it's more retroactively thinking about the whole process of where I' $m$ at now or where I was at when we first got pregnant or where I was at along the way, um, there were just, it just doesn't seem like I was at a point that I was at, where I'm at today. It's been this evolving process that's made me become
115. S. is uncertain whether the way he sees the process of having a child is accurate or not.

116. S. has listened to many people talk about the experience of being a parent and he's noticed that as with describing the process of labor. they have a hard time putting the experience into words.

117. S. suspects that the experience of having a child will feel even more intense than he imagines.

118. S. is ready for the experience of having a child.

119. It was an evolving process through which S. became committed to wanting to have a child. moving from a point where he was fifty percent invested in the decision to the fully committed point that he's at today. 
more and more committed to wanting to have a child, that I wasn't at the point where I was sort of looking at this as a 50-50 kind of a decision. /Yeah, so there was some of me that wanted to do that, but I think it may have been something that may have been more of a desire for completeness on some level. But I think cognitively or intellectually I might have been thinking well, it's not the right time, we need to think about whether or not our relationship is working, whether, financially we've got to get this in line and blah blah blah and all this other kind of stuff that oftentimes confuses and or maybe makes that decision more complex. And having your affairs in order and having, you know, everything done that's on a list of things to do. /And again it's just something where ['ve been incredibly planful about everything that I've ever done, lincluding thinking about having a kid on my own so that there was no potential of loss. /I mean, this is like a master plan in my brain, it's, this is ridiculous. Really, having to spend my time doing this is idiotic. And, so part of it too was, okay, making sure, you know, this, all these things, a lot of them had been. in the past, financial. / $\mathrm{t}$ had a good friend who I just talked to this morning in fact, and he and I were both about twenty-two at the time, maybe twenty-three. and he had, he got pregnant at the time. And he and I were like brothers. That day that he found out $-I$ found out before he did - that day that he found out - I told him, I wasn't supposed to, it was a mess - but anyway, finally when it happened, then it started to resonate, that day I made, I developed this master plan.
120. At the point at which S. was fifty percent invested in having a child. the part of him that wanted a child desired the feeling of completeness that he imagined this would bring him, while the part of him that didn't was cognitively concerned about issues such as dynamics and financial stability.

121. S. has been very planful about everything in his life.

122. S.'s planfulness extended to his idea of having a child on his own so that he wouldn't potentially lose it.

123. S. had a "master plan" in his mind which contained things like financial issues which he wanted to get in order before having a child.

124. S. was very affected by an experience he had as a young man of watching a friend cope with an unplanned pregnancy. Watching this, he developed his "master plan" in order to avoid going through the same thing himself.

Hm. 
Of where I... [laughs]. That day, and it's continued to be there, I've sort of had to let bits and pieces of it go, it's so insane. /But he was absolutely in a tailspin and we were completely irresponsible, it could have happened to me a lot easier than it happened to him. And all of a sudden he was in incredible crisis and thinking about, okay, I got to go back to school, I've got to save money, I've got to, I don't even know if I want to marry this person, we're just sort of dating, I mean he had all these incredibly hard decisions. /So that I said, I want to avoid all of those. So if I have a child I want every single duck in a row. So I want to make sure that I've got my education finished, I've got a job that's in perfect shape, I have a house that is almost paid for so that I don't have to worry about that. So that at any point in time I can quit my job so I don't have to worry about working or I can work half time or part time and my wife doesn't have to work or can work part time or...I don't have to make an issue out of keeping the house at 65 degrees or something because I'm worried about paying the bill. I said I want none of that stuff to be a part of that, so that every single duck is in a row, /so that it's not, there's not worries about anything related to raising a child, so I can be fully invested in raising a child and not have all these other things that are out there that may potentially complicate it. /But it's just sort of a crazy way to think about putting all those things into order and instead let life come your direction, rather than needing to control all those aspects of life, /so.... Part of it was letting all that stuff go, as well. /But it's, fortunately, I've come to that realization of letting those things go, not having to have everything in order and letting life come my direction, and at the same time
125. S. still has his master plan in his mind. although he's had to let go of bits and pieces of it.

126. S.'s friend who had the unplanned pregnancy experienced this as a crisis which forced him to make incredibly hard decisions.

127. In order to avoid the sort of decisions that came with his friend's unplanned pregnancy, S. decided that before he had a child he would get "every single duck in a row." He wanted his education finished. a good job, a house that was mostly paid off. and financial stability.

128. S. decided that when he had a child he wanted to have all of the potential complicating worries out of the way so that he could be fully invested in raising his child.

129. S. believes now that it's crazy to try to control every aspect of life rather than letting life "come your direction."

130. S. had to let go of his need to control every aspect of his life before having a child.

131. At the same time that he's come to realize that he needs to let go of his need for complete control, S. has found that all of his ducks are in a row anyway. 
everything's gotten complete, so all of the ducks are, are in a row in a sense. It's sort of all come together at the same time.

\section{Right.}

Um. I was with a group of people for my other job. from around the United States, we have get-togethers every year. And we had a spiritual retreat last time and part of what we did was we drew pictures on where you're at personally in your life. And I drew a tree with these leaves on it that were just growing. So it was sort of like I'd built this foundation, got everything in line, beginning to grow out into different areas. But then at the bottom I had this dog taking a wiss on it. [laughs] Knowing that at any point in time this can all change and it could be affected in any way whatsoever. /So great that you developed all this and built all this and got all this in good shape, but just know that now it's going to. you have absolutely no control over what's going to happen to it from this point on.

\section{Uh-huh.}

/So I sort of talked about the need to now give up as much control as possible rather than trying to hang on to it.

Right. So it's a balance of control and letting go of control...

Exactly.

...starting from all the way back then and making a plan and having to let go of a lot of that.
132. S. describes the current state of his life as being like a tree with new leaves and a strong foundation -and a dog peeing on its trunk. He feels solid in his life but he recognizes that "at any point in time this can all change."

133. S. recognizes that while he's happy with all that he's built up in his life, he has "absolutely no control over what's going to happen" from now on.

134. S. feels the need at this point in his life to give up control rather than hanging on to it. 
Right. /And I also didn't want to get into the spot where, you see a lot of dads who are - and I have a lot of friends who travel a lot, who are worried about college educations. When something new comes along, there's a new grant out there or there's a book to write or, you know, looking for merit increases or whatever it might be - those are all very alluring and part of the lure of that is maybe you think you need to make a little more money or the kids need a bigger house or you gotta worry about college educations, or all those kinds of things. $/$ just wanted to make sure that I could just be a dad. As much as possible, just be a dad. And try to not have to, you know, work extra days and potentially.../the time of having a child should be I think a time of cutting back from work rather than taking more on. /And, and it's, that's all come together at a certain point, which I'm very fortunate for. /But...it's just my own craziness because there are many people who are fine dads and who have great lives even though they may have to take something else on. /I'm just real...I"m just really convinced about...my time is best spent being with my child and my wife.

\section{Right.}

/It's my most enjoyable... responsibility, I guess you can call that. I know it's not like a job. But it's what I enjoy the most and I know I'll enjoy more even with my child. And it's not going to be working. It isn't going to be any of that kind of stuff, for me to be making any more money.

\section{For you, that's where the priority is.}

135. S. didn't want to have to be very worried about having to work too hard to providing financially for his children, the way he sees other fathers doing.

136. Before having a child. S. wanted to make sure that he "could just be a dad" and not have to be working extra.

137. S. believes that having a child should be a time when parents cut back from work rather than taking on more.

138. S. feels fortunate that his financial and work situations have come together well at the point at which he's having a child.

139. S. acknowledges that his desire for financial stability is "my own craziness" given that many people are fine fathers even while having to take on extra work.

140. S. strongly believes that his time is best spent with his wife and child.

141. S. sees time with his wife and future child as an "enjoyable responsibility." He believes that this responsibility will be more central than his work and financial responsibilities. 
Exactly. Yeah. Exactly. Yeah, /and I had a grandfather who worked a hundred hours a week and they had a farm and never had any contact with his kids, uncles were doing the same thing. And uh, and any job you get into you realize that you're never going to get done with everything, so, I could work a million hours a week and I'd still have a thousand things I'd need to do the next week. So what difference does it make? /Why not figure out a way to make life better for you and your partner and your for child and make that work and make that feel really happy, including yourself, rather than getting ail caught up in that...crap. So, yeah. Other questions?

\section{I'm just thinking.}

/Sure. I got to the 50-50 part. And 7030 , did I get that?

Could you, actually it would be helpful if you went back and just described that 50-50 state a little bit, because I don't think I got the, I don't think the full description is on tape.

Okay.

So you were in...yeah, where you were in the relationship and where you were with that.

Okay. So the $50-50$ point was more a matter of...our relationship is still a bit unstable. I need to know for sure that there is no chance of us separating or divorcing or any of that kind of stuff, for fear of having a child and divorcing and having it not be as much a part of my life as I'd want it to be. /And my wife's desire to move into having a baby. So it was sort of...caught right between it.
142. S. describes male family members who worked all the time and had no contact with their children. He feels that in the end, work has less significance than does family.

143. S. believes that his first priorities should be making life better and happier for himself and for his family.
144. S. describes the point at which he was fifty percent invested in the idea of having a child as one at which he felt his relationship with his wife was a bit unstable, at which he was not sure that they wouldn't separate or divorce and that he might lose his future child. 
And they were sort of equal weight in some sense. /But then over time I think I became more invested with that over that six months of us trying and talking about it more and continuing to have real good months as a couple, where we're working well together, communicating well, things are looking very good. /And me thinking and processing more about having children and what's that mean in terms of my own life. And what is this craziness about needing to have everything in control or having all our finances in order, having all their college educations, I mean, what is all that about? /So a matter of processing that information and thinking through that a little bit and making some sense of it and just...time allowed for that opportunity to take place. /And then maybe after six months, when we started this Clomid, getting to the point where I was leaning more heavily toward having a child and some of that other stuff that sort of got in the way, it didn't weigh as heavily anymore. /t was sort of like, yeah that stuff is still out there, but it's incredibly insignificant compared to what I'm now thinking of and seeing as the potential outcome of... and selfishly thinking about what this will mean for your life. /Whether it's going to be a completeness or a wholeness that's going to come into my life that is beyond what I know today. /Although I feel very complete and whole. It sounds to me like, talking to other people, there's more to it. /And that seemed like a place I wanted to go further toward. So I got to that 70-30 position. /And then, by the time we went and visited with those folks that had adopted children and talked to the guy who had just had children, a couple of young kids, then feeling it more and more and talking with people and Realizing that there's something that
146. Through the six months that $S$. and his wife spent trying to conceive.

$\mathrm{S}$. became more invested in having a child because he felt that he and his wife began to work together and to communicate better.

147. During the first six months that he and his wife were trying to conceive, $\mathrm{S}$. became more invested in having a child because he thought more about what this would mean in his life and he challenged his own need to have everything in control.

148. Having the time to process the idea of having a child allowed S. to become more invested in the decision.

149. After six months of trying to conceive, when his wife started taking fertility drugs. S. was leaning more heavily toward having a child. He still had his worries, but they didn't weigh as heavily on him.

150. As he became more invested in the decision to have a child. S. was still aware of his worries, but they came to seem incredibly insignificant compared to the potential change that having a child would bring.

151. S. began to look forward to the completeness or wholeness that he anticipated would come into his life with a child.

152. Although $\mathrm{S}$. felt whole in himself already, talking to other parents had given him the idea that "there's more to it."

153. S.'s desire to achieve the greater wholeness that other parents described, led him to get to a point of being seventy percent invested in the decision to have a child. 
they're experiencing that I haven't experienced yet. And I will never be able to experience it unless I - or, my wife and I decide to have kids. Then it seems like I might be able to experience the same thing I hear being described to me all the time.

How do you imagine your...to be, what's your vision - and has that changed through this process?

/I don't think it's changed at all, I've just felt twinges of it from time to time. But, it. so every once in awhile I'll feel a little bit of that euphoria that people seem to describe, more connectedness to themselves or a spiritual uplifting that I sort of envision or hear talked about that I" $\mathrm{m}$ thinking is probably going to be something that will evolve from this. But I've just felt little bits and pieces of it from time to time. But I really don't, I really probably won't believe it or fully appreciate it until it actually occurs. Um, yeah, I'm an incredibly emotional person and I don't know, I'll be bawling like a stinking baby when that thing is born, I know it. [laughs] I'm going to be useless. And...I just can't imagine. iAnd, it's sort of this, I don't know, this bond and this connection that happens through that process that, you know, I think it's just inescapable. I mean. I don't know that there's anyway you can get around that...feeling what that process is all about. /Unless you yourself have experienced tremendous abuse or neglect or haven't been loved yourself in some sense. And you know, I'm sure there's many folks that are looking at it much differently, or it being a burden, or you know, it's not planned,
154. Through talking with adoptive and other parents. S. realized that parents were experiencing something that he hadn't yet experienced. and that he wouldn't experience unless he decided to have children.

155. S. believed that by having children he could experience what other parents described to him.

156. S. still hasn't felt much of the euphoria and connectedness or spiritual uplifting that other parents have described to him. He feels bits and pieces of it, but he believes that this feeling will evolve. that he won't fully appreciate it until the child is actually born.

157. S. anticipates that the birth of his child will be a very tearful, emotional experience for him.

158. S. anticipates that the birth process will inescapably create an emotional bond or connection.

159. S. recognizes that those who have experienced great abuse or neglect, or those whose pregnancy is not planned. might see the birth of a child as a burden. 
or a lot of competing variables. /But in our birth class too we've got a lot of young parents who are there, I'm sure they didn't plan their pregnancy, who are at much different places. You know, some of them say, god I just wish I was done with school or I wish I was at a different place in my life. You know, we're not thinking that one iota. /And we're just incredibly lucky that way, that we've been able to plan for it, get all set up for it. you know had names picked out a long time ago, got our house remodeled and in order and we've got the car seat already set up - I mean we were so much ready, we were ready forever. So it's not like we're sitting around fretting about, oh, boy, I wish it were a different time or I wish that maybe we got a little more money saved - there's none of that.

\section{So there's still room for some of that master plan it sounds like.}

Yeah. [laughs] Exactly.

Because as I hear you describe it, it's sort of, in a way, a fight between your heart and your head.

/Exactly. Yeah, that's exactly what it is. Spending too much time in academia can create that problem. And it is a problem, it's a huge problem. And the person we had this premarital counseling with, says I'm just so sick and tired of you intellectualizing about things, I' $m$ going to throw up. And she's absolutely right. After awhile you forget how to really be a normal person. And I really think being able to be consistent with your heart is more important than being able to be in your head. /Unfortunately, if you spend your entire day just being in
160. S. sees other expectant parents whose pregnancy was unplanned or who wish they were at a different place in their lives. He and his wife don't feel this way at all.

161. S. feels lucky that they have been able to plan and prepare well for his child. He and his wife have no sense of wishing things were different.
162. S. sees his tendency to overintellectualize as a big problem. He believes that it's more important to act consistently with his heart than with his head. 
your head, it's hard to get back into your heart. So it's a matter of being able to, I don't know, maybe have people guide you back there or coming back there yourself or whatever you need to do I think in order to get back to that point, but yeah, spending too much time in your head.

\section{You described that as a process of letting go.}

/Letting go of the too much time in your head kind of stuff?

Yeah, to go back to the point at which you were using that term, it was within the relationship and the decision to have a child there was a letting go. Does that connect with this?

Yeah, um, I'm trying to think. I think when I, after I met with our counselor we worked with for a number of years, she brought it to my attention. /And then I spent time thinking about it. And through that process of thinking about it was a process of also letting that control go, bit by bit, piece by piece. So that I could begin to maybe try out what she was talking about a little and try out what it meant to be on more of an emotional level than on a cognitive or intellestual level, try out the emotional part of a relationship, the emotional part of having a child, what does that mean, /what is it that you desire, versus what is it that is in your plan for how this is all going to wind up before you can allow this to occur. So sort of letting some of that go, yeah. Getting rid of some of that stuff. And questioning it, spend time finding out where that's coming from and why and does that make sense some difficulty doing so after spending too much time in his head.
164. S.'s pre-marital counselor brought to his attention the fact that $S$. spent too much time in his head.
165. The process of leaming to be on an emotional level more than on a cognitive level in terms of his relationships and his decision to have a child came about through a process of consideration and of letting go of his need for control.
166. Through comparing his master plan to his true desires and questioning and analyzing his need for control, S. was able to let go of the master plan and to his need for control. This was a big struggle for him. 
or doesn't it. And yeah, so I think, probably it was letting go.

And...struggling with that one a little bit. A lot a bit. Yeah. More than anything it becomes a matter of just trusting that...trying to trust my wife, being able to fully trust her. She's not going to freak out. She's not going to just up and leave. She's not just some flake. She's not just going to have kids and then all of a sudden go to Jamaica. /You know, all these scenarios that potentially run through my mind that have to do with this potential fear of...I'm going to have a kid but I'm not going to have a kid. You know, this is not going to be a good situation because I'll go nuts if that happens. Yeah. [sighs] Crazy process. /Yeah, I think a process of letting go is probably accurate.

Okay. Yeah, coming to terms with that and letting go of some of that.

Yeah, sure.

One thing that I just wanted to kind of follow up on is this...you used the word "selfish" several times here and I just was curious what that word meant to you.

/Sure. I guess what I thought of. having a child now and deciding to have a child has been a process of two people coming together as a team, making a decision and talking through this, figuring out what works for each person, whether or not a relationship is in a certain place to make that happen /and thinking how's this going to benefit my wife and thinking, thoughtful consideration of that land the process of making those decisions for myself in terms of I can have a child but I need to have a child
167. S. had to learn how to trust his wife fully -- that she wouldn't leave him and take his children.

168. S. imagines many scenarios through which he could have children and then lose them. He will go "nuts" if that ever happens.

169. S describes the process of deciding to have children as "a process of letting go."
170. For S., having a child is a process of making a decision in a relationship as a team. considering what works for each person and the overall state of the relationship.

171. In making the decision to have a child, S. considered how it would benefit his wife.

172. S. felt that he wanted to have children without having a wife. 
without a wife in order to make sure that I've got - I've even thought about having children, adopting a couple of kids and then getting married. Because then I would know I would these, these kids would be mine.

\section{Uh-huh.}

[Laughing] So I wouldn't have to worry about them ever being with their mother if things didn't work out. /And I'd, all I'd ever seen is relationships not working out.

\section{Right.}

So I didn't have a very good basis for thinking any differently. /So what I term as selfish is a very self-centered process of thinking about how is this going to work best for me. My needs are that I"d like to have kids. My needs are that I'd like to have kids that aren't going to live with their mother and be away from me. /My kids - my needs are to have all the financial stuff in place, whatever else that might include. /So that means not getting married and adopting kids. That's the way to do it. /So it was very self-centered I would conclude. Yeah. But then having all that stuff challenged is good. Kicking it around with a few people and trying to make sense of it and all that was good to do. /And it's been the best thing for me to do, has been to learn how to fully trust someone that's not a dog or a child that really doesn't have any choice in terms of they're going to love you no matter what in some way. Sure there's going to be times when they tell you probably go to hell, but probably it isn't going to mean that, you know, if you don't love them they don't love you. But there's that potential for that to happen in a love relationship.
173. S. considered adopting children prior to getting married so that he would be certain that they were his and he wouldn't have to worry about losing them if the relationship didn't work out.

174. Because $S$. hadn't seen successful relationships in the past. he expected them not to work out.

175. S. first used a "self-centered" process of considering how the process of having children would work best for him.

176. S. needs to have children that aren't going to live away from him.

177. S. needs to have his financial affairs in order before having children.

178. S.'s needs led him to believe that he should adopt children with out getting married.

179. S. feels that it was a good process to challenge his self-centered way of thinking about the decision to have children.

180. S. feels that it's been good for him to learn how to fully trust another person, someone who could potentially leave him. 
[long pause]

One last question.

Sure.

Which is again going back to this sort of point that I'm kind of fascinated with here, that 50-50 point, if you could describe for me a little what it was like when you were in that still pretty ambivalent state about it, knowing that you could conceive a child and would likely...

/Right. At any point in time.

\section{What was that like for you?}

Well, it wasn't...it wasn't that I would be terribly disappointed if that occurred. That...here's what I think it was. I think it was a way to not fully invest in the decision, and also into my wife's decision and where she was at. I think maybe it was another safety mechanism. If I say that I'm not fully invested and I don't get to the point where I am, then if it doesn't happen...it's great. If it doesn't happen, things are still good for me. If it does happen, then, things are good in terms of having a baby, but things are not so good in terms of giving up a certain amount of this safety and comfort. /So it was - I think I was more or less in the process of still needing to hang on to...it still would be good for it to not work. Because that will work fine for me. Because I'm not really fully ready to give over to you a hundred percent, in terms of trusting you and being fully committed to you and fully committed to the relationship. When we have a baby, I' $m$ done. I am fully committed and I have to fully trust at that point. /I really don't have any

181. At the point at which S. was fifty percent invested in the decision to have a child. he wouldn't have been disappointed if his wife got pregnant.

182. S. describes his fifty percent investment in the decision to have a child as a "safety mechanism," a way to keep from fully investing in the decision.

183. At the point at which S. was fifty percent invested in the decision to have a child. $S$. felt that things would be okay whether or not his wife got pregnant, although he recognizes that if they conceive, he will lose a degree of safety and control.

184. Because S. wasn't ready to fully trust and commit to his wife at the point at which he's fifty percent invested in the decision. he hung on to the fact that he would be fine if they were unable to conceive.

185. S. feels that once he and his wife have a baby together, he is fully committed and he has to fully trust her.

186. At the point at which S. was fifty percent invested in the decision to 
desire to do that quite yet, I'm still at a point where I'm sort of ambivalent, so if that doesn't happen that's okay too. /So I win either way.

\section{Okay.}

In some sense. [laughs]

\section{Kind of hedging your bets.}

/Yeah. [laughing] My wife would laugh her butt off if she heard me say that. She used to describe our entire relationship dating that way as well. I'd sort of say well, I'm not really asking you on a date, but you want to go someplace, you know, what do you think about going out and eating something? So it was never a full investment. It was always - I was winning, because I could have the pleasure of your company without having to fully commit. It drove her nuts. [laughs] Oh, man, I was so bad at doing that, it's horrible. /So it's a winwin for me in many ways. And even at this 70-20, or 70-30 I'm still winning in some sense if it doesn't happen. It's great, I'm still doing fine. My wife is completely disappointed if it doesn't happen. Um, but I'm still going to protect that safety factor to some degree and I still have that to rely on if you don't get pregnant so that's absolutely fine. /So it was more a matter of then getting to the point where it's like okay, I fully trust the fact that you're not going to leave, that you're not going to freak out and need a new person or I'm not going to not love you anymore. So I'm there. And I'm willing to fully trust you. And now I'm also willing to have a child with you.

\section{Right.}

have a child. S. was not ready to trust his wife fully -- he's still ambivalent..

187. At the point at which S. was fifty percent invested in the decision to have a child. S. felt that he would win no matter what happens.

188. S. describes his past behavior in his relationship with his wife as being not fully invested or committed.

189. When he was not fully invested in the decision. S. is fine even if it doesn't work out. He has a safety factor which his wife doesn't have.

190. S. had to get to the point at which he could fully trust his wife not to freak out and leave before he was fully willing to have a child with her. 
So I think that might have been part of it as well. Yeah. And I'm stubborn. Yeah, I'm a stubborn guy [laughs] Incredibly stubborn. My wife is too, so you get the two of us together and oh my god, it's horrible. But at least we realized ahead and we sort of evolved over time with that whole process. It's crazy.
191. S. says that both he and his wife are very stubborn. but that they've evolved in this regard. 


\section{Frank - Level 3}

S.'s feelings about having children have been strongly affected by the fact that both of his own parents have been divorced and re-married several times. As a result. S. has been very aware of that if he had a child of his own the potential existed that he could lose the child. While growing up, S. experienced the sudden loss of step-brothers and sisters when parents would split up. This past experience with divorcing parents shaped his sense of what raising a child of his own would be like. Because he hadn't seen successful relationships in the past, S. expected that his own relationships would not work out.

S.'s feelings about having children have also been affected by friends who have had unplanned pregnancies, who have had to try to make relationships work and who have "gone through hell" doing so. He knows many people who are trying to parent without being the custodial parent of their child. He sees expectant parents who wish they were at a different place in their lives when they were having children. As a young man, S. watched a close friend cope with an unplanned pregnancy. For this friend. the unplanned pregnancy as a crisis which forced him to make incredibly hard decisions. S. felt his friend's crisis keenly: "we were completely irresponsible. it could have happened me a lot easier than it happened to him." Watching this friend in crisis led S. to develop a "master plan," through which he hoped to avoid having to go through the same thing himself. He decided that before having a child he would get "every single duck in a row." He wanted his education finished, a good job, a house that was mostly paid off, and financial stability.

Early on in his life S. didn't want to have children at all. Prior to his marriage, he had come to believe that he wouldn't end up in an intimate relationship. He thought that this might be a good thing. He had always had dogs, which had been something he could trust and count on and he thought that maybe this would be enough for him. For a long time he maintained this feeling that he didn't want to have children.

At thirty, S. decided that he wanted to have children without a partner. He already felt that it was safe to have an animal -- he knew that a dog "wouldn't abandon or divorce out of...my life" -- and he came to believe that it was also safe to have a child outside of a relationship. He expanded his "perimeter of safety" of those who would never leave him to include the idea of having a child on his own. S. had decided that rather than risk losing a child, he would have a child by himself so as not have to risk that loss. He considered adopting a child prior to getting married so that he would be certain that the child was his and he wouldn't have to worry about losing it if the relationship didn't work out.

The idea of having a child without a partner made sense to $S$. because of his childhood experience of divorce. He knew that women had the potential to leave him and he didn't want to risk going through that emotional turmoil. He knew that he was capable of having a child as a single person and he believed that from a self-protective 
perspective, having a child without a partner would serve his needs. He "rationalized" that it would be best for the child to have only one parent because this would eliminate the possibility of divorce.

S.'s needs led him to believe that he should adopt children with out getting married. But S. now believes that his desire to have a child without a partner was "selfish" and would probably have been detrimental to the child in some ways. He describes the process of considering how children would work best for him as "selfcentered."

S. didn't want to have a child if he was going to lose it. He saw this issue in black and white terms. He felt the need both to have a child and also to have control over the child's relationship with himself and with others. He hung on to his desire to control what a child would be in his life for a long time. He wanted a situation in which he could control his relationship with his partner and his children. His biggest fear was that he would have a child and then not have that child in his physical presence. He needed to have children that weren't going to live away from him. These concerns about having children centered around his fear of abandonment and his need for control over his environment. He feared that if he were married he might lose a child to divorce or separation. He believed that if he controlled things well, he wouldn't have to face the potential of ever losing his child.

S. imagines many scenarios through which he could have children and then lose them. He imagines the experience of not being in the physical presence of his children and missing out on their development as one that would "tear me to shreds." He will go "nuts" if that ever happens.

S. has been very planful about everything in his life. This planfulness extended to his idea of having a child on his own so that he wouldn't potentially lose it. His "master plan" included all the things that he wanted to get in order before having a child. He needed to have his financial affairs in order before having children. When he had a child, he wanted to have all of the potential complicating worries out of the way so that he could be fully invested in raising his child.

While S. still has his master plan in his mind, he's had to let bits and pieces of it go. He now believes that it's crazy to try to control every aspect of life rather than letting life "come your direction." He describes that his desire for financial stability as "my own craziness" given that "there are many people who are fine dads and who have great lives even though they may have to take something else on."

S. has always felt the desire to struggle with his personal issues and to grow from that struggle. He describes this as a "selfish" process. This process became more important when he began his relationship with his wife. He felt that it was important to let go of his old fears and behaviors about relationships and to try to learn to trust someone else. Before this, he had not thought much before about his own trust issues in relationships -- this was something new. He felt the need to give up his fear of 
abandonment and need for control in order to grow and mature. He had to give up his fear of abandonment and resign himself to the fact that "by not giving fully I'm not giving at all." And so he attempted to stop pursuing the "self-fulfilling prophecy" of abandonment which had led him to keep from getting too attached or invested or from having children.

Before he felt he could support a child within his relationship with his wife. S. had to go through a "transformation" from living comfortably as a single person to being comfortable as a married person. In making sure his relationship with his wife was stable enough to support a child, he went through a long process of adjustment and transformation in accommodating to the demands of married life. He had felt very secure in himself as a single person prior to his marriage, but he found that this identity didn't work for his life as a married person - he needed to throw out his old skills and learn new ones. He felt that he "had to grow up," that he needed to give up life as a single person and grab hold of life as a married person. Through a long process, S. became able to believe that he could trust another person and develop a relationship and have children with them "in a sort of normal way."

S. had felt that before having a child he needed to have control over every aspect of his life. He reached a point where he felt he needed to let go of this need for control. He realized that giving up control was what he needed in order to continue to grow. S. experienced this giving up of control as a loss that was necessary in order to gain something else. He believed that the growth that could come from letting go of his need for control was healthy and that his unwillingness to fully trust and to allow himself to be potentially hurt was holding back his relationship with his wife. Once S. gave himself over to his fear of loss of control, "there was no turning back." Currently, those fears don't come back to him much.

Another aspect of letting go of control is S.'s tendency to over-intellectualize, which he sees as a big problem. He believes that it's more important to act consistently with his heart than with his head. He's had moments when he has experienced this. For instance when working with adolescents he has sometimes experienced moments in which he couldn't screen things out cognitively and which as a result affected him profoundly. While he feels the importance of staying in his heart, he experiences some difficulty doing so after spending too much time in his head. The process of learning to stay on an emotional level more than on a cognitive level in terms of his relationships and his decision to have a child has come about through a process of consideration and of letting go of his need for control.

Before they got married, S. and his wife saw a pre-marital counselor who helped S. get over his fears. She would "kick the living tar out of me whenever she'd want to and just let me know what I needed to do." She told S. that he needed to let go and fully trust his partner, advising him against living out a self-fulfilling prophecy regarding his fear that his relationships were doomed and bringing to his attention the fact that $\mathrm{S}$. spent too much time in his head. He thought a lot about his pre-marital counselor's advice 
regarding his fears about relationships. Based on this, he made a difficult decision to change.

This change was also influenced by S.'s past experiences working with people whose family members were dying, which helped him to appreciate the fragility and the larger dimensions of life: "whenever we're out here in the real world. we just don't experience the fragility of life, I guess, in such a degree that you experience it through death." S. had read about the idea that in order to truly love you have to be able to truly grieve. He recognized that love involves losses and understood that it was necessary to give himself over to love fully in order to appreciate it. He had read about the idea that by not giving of yourself fully, not experiencing both love and grief fully. a person is not experiencing life fully.

S. spent a lot of time thinking about how the ideas about love and loss that he'd read about applied to him personally. He believes that experiences of grief and the euphoria of birth are both on the outer areas of the continuum of life's experiences and that he won't live his life fully if he lives it based on his fears. He recognized that while it was possible to be hurt and even abandoned in a relationships, it was still okay to let himself trust someone else.

Currently S. feels the need to give up control rather than hanging on to it. He has based his ideas about having children on his own needs for safety -- but those needs have evolved. Through comparing his "master plan" to his true desires and questioning and analyzing his need for control, he has been able to let go of the master plan and his need for control. This has been a big struggle for him, but $\mathrm{S}$. feels that it's been a good process to challenge his self-centered way of thinking about the decision to have children. He feels that it's been good for him to learn how to fully trust another person, someone who could potentially leave him.

S. describes the current state of his life as being like a tree with new leaves and a strong foundation -- with a dog peeing on its trunk. He feels solid in his life but he recognizes that "at any point in time this can all change." While he recognizes that he's happy with all that he's built up in his life, he has "absolutely no control over what's going to happen" from now on. When thinking about having children. S. didn't want to have to be very worried about having to work too hard to provide financially for his children, the way he sees other fathers doing. Before having a child, he wanted to make sure that he "could just be a dad" and not have to be working extra. And at the same time that he's come to realize that he needs to let go of his need for complete control, S. has found that all of his ducks are in a row anyway. He feels fortunate that his financial and work situations have come together well at the point at which he's having a child. He feels lucky that he and his wife have been able to plan and prepare well for his child. They have no sense of wishing things were different in their lives right now.

S.'s desire to have children with his wife has evolved with the relationship. When he first met his wife, he wanted to have children with her right away. At first, this desire to have children with his wife was similar to his desire to have children as a single person. His 
wife was also very focused on having children at the beginning of their relationship. Before they made the decision, she frequently brought up the subject of having children.

S. was confident in his desire to have children from early on in his relationship with his wife, but he felt they first needed to get themselves together as a couple in order to be able to support a child. At times, his desire to have a child with his wife waned. For a time, he wasn't sure about whether he wanted children with his wife. He put off the decision.

After S. and his wife got married, they had some rough times which made him believe it would be better to wait before having children. At times he didn't want to have children because he didn't know if the marriage would work out. Because S. did not feel that his relationship with his wife was on firm ground at this point. he didn't let himself think about having children with her. He put off the decision about having a child with his wife because he was still testing the stability of the relationship. He wanted to make sure that the marriage wouldn't break up.

S. became aware that his need for control was getting in the way of his relationship with his wife. He came to recognize that he was creating distance and problems in his relationship with his wife. He had to learn how to trust fully that his wife wouldn't leave him and take his children. Before he was fully willing to have a child with her, he had to get to the point at which he could fully trust her not to freak out and leave. When S. was able to trust his wife more fully, they were able to start thinking about having children.

Neither S. nor his wife desired the sort of relationship in which they were both very independent of one another. But he says that both he and his wife are very stubborn, although that they've evolved in this regard. He describes his own past behavior in his relationship with his wife as being not fully invested or committed. It took some time for S. to get to the point where he could take the risk of having a child.

S. and his wife got to the point in their relationship where they saw themselves as married people: "we were able to look at ourselves and appreciate who we were and what we'd become and then have a very stable foundation." When their relationship had solidified to the point that they could support one another and could thus support a child, $\mathrm{S}$. and his wife could decide that they were ready to have children. They arrived at a team perspective from which they were able to "take a good look at where we were at and what we were doing and whether or not having children was something we wanted. "It was less of an 'I' decision' and more of a 'we' decision at that point." $\mathrm{S}$. is contented with having arrived at this team perspective with his wife about the decision and he finds that this has reduced his fear. He was able to get to the point where he was able to trust that his wife would not leave him. By strengthening his relationship with his wife, he and his wife were able to have children together. Because he and his wife got their relationship on "firmer ground," having children together made sense to him. 
S. now acknowledges that the absolute terms in which he saw the possible loss of his child were not entirely realistic, because he would always find a way to be with his child no matter what happened. Currently, S. believes that he and his wife had the responsibility together for making their relationship work and is realistic about the fact that it might not.

S.'s decision to go ahead and start trying to have a child evolved from the stable foundation that he'd built in his marriage. He believes that having a child is a process of making a decision in a relationship as a team, considering what works for each person and the overall state of the relationship. He began to explore the possibility of having children and to talk about it with his wife. He responded to his wife's repeated requests to have children by agreeing to try and stop using birth control. to "see how it goes." He describes the process of making this decision to have children as "a process of letting go." At the beginning of trying to conceive, S. "wasn't an active participant." Rather than actively wanting to get pregnant, he said "okay, let's kind of just go, not have birth control, and we'll just see how it goes, and no need to get all stressed out about this."

S. and his wife spent several years trying before they finally got pregnant. They went through a two-year process of trying to conceive, first just stopping birth control. then monitoring ovulation, taking fertility drugs, having sperm checks and finally surgery. During the process of trying to conceive, he and his wife came to believe that they weren't going to be able to get pregnant. The entire process of conceiving a child was long and intensive.

Because of difficulties conceiving, $S$. and his wife considered adopting a child. They spoke to adoption agencies about this. They decided against adoption because his wife was still young enough that they could keep trying to have a child together. S.'s wife had always imagined being pregnant and having a child and was frustrated and disappointed that she was having trouble conceiving. In making the decision to have a child, S. considered how it would benefit his wife. However, he didn't care whether the child was adopted or his own. He just wanted a baby.

It was an evolving process through which $\mathrm{S}$. became committed to wanting to have a child, moving from a point - prior to trying to conceive -- at which he was only ten percent invested in the decision, to a point where he was fifty percent invested in the decision to the fully committed point that he's at today.

During the first six months that he and his wife were trying to conceive, $\mathrm{S}$. became more invested in having a child because he thought more about what a child would mean in his life and he challenged his own need to have everything in control. He became increasingly invested in having a child because he had time to process the idea and because he felt that he and his wife had begun to work well together and to communicate better.

After six months of trying to conceive, when his wife started taking fertility drugs, S. was leaning more heavily toward having a child. He still had his worries, but 
they didn't weigh as heavily on him. As he became more invested in the decision to have a child, he was still aware of his worries, but they came to seem incredibly insignificant compared to the potential change in his life that having a child would bring.

At the point of starting to conceive a child, S. was about fifty percent invested in the idea and fifty percent unsure. He describes this point as one at which he felt his relationship with his wife was a bit unstable, at which he was not sure that they wouldn't separate or divorce and that he might lose his future child. At this point he was still not ready to trust his wife fully -- he's still ambivalent. He was caught equally between his worries about the potential instability of his marriage and his wife's desire to have a baby. The part of him that wanted a child desired the feeling of completeness that he imagined this would bring him, while the part of him that didn't was cognitively concerned about issues such as marital dynamics and financial stability.

Because S. wasn't ready to fully trust and commit to his wife at this point, he hung on to the fact that he would be fine if they were unable to conceive. He describes his fifty percent investment in the decision to have a child as a "safety mechanism," a way to keep from fully investing in the decision. He wouldn't have been disappointed if his wife got pregnant. He felt that he would "win" no matter what happens. He felt that things would be okay whether or not his wife got pregnant, although he recognized that if she became pregnant, he would lose a degree of safety and control. When he was not fully invested in the decision, S. was fine even if it didn't work out. He had a safety factor which his wife didn't have.

At the point that his wife was using fertility drugs, $S$. went from a state of being fifty percent invested in the decision to have a child to feeling seventy percent invested. He was led to this point of greater investment by his desire to achieve the greater wholeness that other parents described to him. At the same time he recognized that once he and his wife have a baby together, he would be fully committed and he would have to fully trust her.

S. has listened to many people talk about the experience of being a parent and he's noticed that as with describing the process of labor, they have a hard time putting the experience into words. He has heard other parents describe the experience of being a parent as one which made you experience life more fully than you had before. He has seen that through the process of becoming parents, other people became more whole, more complete and more "spiritually connected to themselves."

Although S. felt whole in himself already, talking to other parents had given him the idea that "there's more to it." During his decision-making process, S. had a conversation with another father at party who talked for the entire time about his child. S. perceived in this man a sense of wholeness or completeness. He was told by another father that the experience of having a child was like having doors inside you open that you didn't know were there. 
S. and his wife met with couples who had adopted because they were unable to have children of their own, and he saw that these people felt a sort of spiritual completion in their lives through the process of becoming parents. Through talking with adoptive and other parents, he realized that they were experiencing something that he hadn't yet experienced, and that he wouldn't experience unless he had children of his own.

S. believed that by having children he could experience what other parents described to him. Through his wife's pregnancy, he experiences a part of the fullness that he has heard other parents describe. He describes a feeling of "connectedness" to the natural world. He still hasn't felt much of the euphoria and connectedness or spiritual uplifting that other parents have described to him. He feels bits and pieces of it, but he believes that this feeling will evolve, that he won't fully appreciate it until the child is actually born.

S. feels that parenting as the most important job a person ever does. He wants to be fully engaged with it. He recognizes that those who have experienced great abuse or neglect, or those whose pregnancy is not planned. might see the birth of a child as a burden. But he does not feel that way himself. He feels that in the end, work has less significance than does family. He describes male family members who worked all the time and had no contact with their children. He strongly believes that his time is best spent with his wife and child. He believes that his first priorities should be making life better and happier for himself and for his family.

He sees time with his wife and future child as an "enjoyable responsibility." He believes that this responsibility will be more central than his work and financial responsibilities. He believes that the importance ascribed to work or school is not comparable to the importance of having a child as part of your life. He believes that having a child should be a time when parents cut back from work rather than taking on more.

S. looks forward to the completeness or wholeness that he anticipates will come into his life with a child. He wants to make for himself the "complete circle" that he has heard others describe. He wants to keep the circle completed and to build on it. He doesn't ever want to grow "immune" to or become "accustomed" to the experience of having a child. He feels certain that once the baby is born he will experience the fullness and the opening of inner doors that he has heard others describe.

Although $\mathrm{S}$. has never been through a birth, he imagines that it is similar in intensity to the experience of having someone you love die. He imagines the experience of giving birth to be one which is entirely about feelings, in which there's nothing cognitive, just an awareness of the fragility and essence of life. He envisions the experience of birth as something that cuts through all of our mental "screeners," which will "hit you where nothing else can potentially hit." He anticipates that the birth of his child will be a very tearful, emotional experience for him and that it will inescapably create an emotional bond or connection. 
S. still has trouble imagining the process of going through a birth and having a baby. He is uncertain whether the way he sees the process of having a child is accurate or not, but he suspects that the experience of having a child will feel even more intense than he imagines. He is ready for the experience of having a child. 


\section{Frank - Level 4}

Due to his painful childhood experience of multiple parental divorces. S. has long had ambivalent feelings about the idea of having children. He has an acute awareness of his expectation that relationships between men and women do not last and a constant knowledge that if he were to have a child he could potentially lose it to its mother in a divorce or separation. In addition, he has observed the negative effects of unplanned or badly-timed pregnancies on other parents. As a result of these experiences and expectations, $\mathrm{S}$. had made a conscious decision to control all aspects of his life as much as possible. He developed a master plan for his life.

One aspect of this master plan is S.'s need to have the financial and career aspects of his life completely in order before having a child so that he could invest himself fully in the raising of his child. Another aspect is the deep need never to lose physical or emotional access to a child that he has fathered. The idea of losing access to his own child is tremendously frightening to $\mathrm{S}$. He believes that such an experience would be emotionally devastating. As a result, he has had a strong need to have control over both his relationship with his partner and his relationship with any children they have together, in the hope that by controlling these relationships, he won't have to face the possibility of losing his child.

Early in his adulthood S. did not believe that he would have children at all, because he didn't believe that he would end up in a stable, intimate relationship. But around the age of thirty, he realized that he could adopt a child without having a partner. Having a child in this way would give him the control that he desired over his relationship with the child and eliminate the risk that he could lose the child. Even if he were to get married afterwards, the child would be his. S. now believes that while this scenario would have served his self-centered personal needs, he was in some ways rationalizing the negative affects this decision would have had on a child because of his own fear of loss.

When S. married his wife, his thoughts about having children were affected by the transformation he had to go through from his identity as a single person to a new identity within the partnership of the marriage. This was a difficult process of maturing. of learning new skills, letting go of his need for control and learning to trust another person more deeply than he had been able to before. Although he continues to hold on to certain aspects of his master plan, he has had to let go of much of it. He had to let go of the selffulfilling prophecy of abandonment in relationships which had led him to keep from being too attached or invested or from being able to have children. He had to let go of his need for complete control and his inability to trust and expose himself to the possibility of being hurt. In addition, he's had to learn to pay more attention to his emotions and less attention to his thoughts, to reduce his tendency to intellectualize matters.

In making these changes, S. was influenced by his interactions with others. A counselor advised him to let go of his fears about relationships and to try to curb his 
tendency to intellectualize too much. In addition, S. considered what he'd observed in grieving families - that in order to be able to truly love it's necessary to be willing to truly grieve. He came to accept the idea that if he wasn't willing to risk the loss and pain that can come in a relationship, that he wasn't living as fully as he could be. Instead of protecting himself from painful experiences. he came to value the importance of experiencing the full range of human experiences. This inevitably involved letting himself trust another person enough to risk being hurt within a relationship.

These changes were very difficult for $\mathrm{S}$. He puts a high value on his new ability to trust another person. He wants to take the risks that this involves in order to experience both the grief and euphoria that he believes are on the outer edges of the continuum of life experiences. He feels a strong desire to experience life fully. Currently he feels that he has built a strong foundation in his life but at the same time he acknowledges that there are forces that will affect him which are beyond his control. It is with this attitude that he has made the decision to have a child.

Through the evolution in his marriage. his feelings about having children with his wife have also evolved. At the beginning of their relationship. S. and his wife were focused on having children right away. But for S., this desire was much like his desire to have children on his own: it did not truly take the marital relationship into account. A period of strain in the marriage brought back all of S.'s doubts and fears. Uncertain whether the marriage would work out, he became more reluctant to have children. He found himself testing the stability of the relationship and putting off the decision about children until he felt certain that the marriage would last.

In order to get to the point where he was willing to risk having children with his wife, S. had to acknowledge the problems that he was creating in the relationship with his excessive need for control and his lack of trust. He needed to let go of his need for control and to learn to trust, to commit to and invest himself fully in the relationship. Eventually, S. and his wife arrived at a point at which they felt they had a stable foundation. They began to act together as a team rather than as individuals. This allowed S. to develop sufficient trust to overcome the fear that he would be abandoned. which allowed him to start the process of considering with his wife whether they wanted to have children together.

S.'s decision that he wanted to have a child with his wife arose out of this stable foundation. But the initial decision was not unequivocally made. The fears and ambivalence that $\mathrm{S}$. had felt all along were still present throughout the process of their efforts to become pregnant. Over the two-year period during which $\mathrm{S}$. and his wife attempted to conceive a child, $\mathrm{S}$. went from a point of being ten percent invested in the decision to a point of being fully invested.

At the initial point of the decision to have a child, S.'s wife was significantly more invested in having a child than he was. For S., the choice to have a child was not so much an active decision as it was an act of letting go of his fears and hesitations. As his wife went off of birth control, $\mathrm{S}$. was willing to see what happened but was not actively 
desiring that they quickly get pregnant. By not investing fully in the decision. he was protecting himself emotionally - he would be okay no matter what happened.

During the process of attempting to conceive $S$. and his wife were communicating and working well together as a couple. S. began to consider more thoroughly what having a child would mean in his life and to as a result he became increasingly invested in the decision. At the point of beginning to try to conceive he was fifty percent invested. His worries were still present, but they weren't weighing as heavily on him as they once were. He was still concerned about some of the instability in the marriage. still uncertain that he could trust his wife completely. But at the same time, these concerns were now counter-balanced by his awareness of the benefits he would experience by having a child. Cognitively, he still worried; emotionally he had a strong desire for the completeness that he believed a child will bring to his life.

As S. and his wife experienced some difficulty conceiving, S. moved to a point of being seventy percent invested in the decision to have a child. While he continued to recognize that having a baby together would mean that he had to take the difficult step of trusting fully in his wife. S. was strongly affected by descriptions from other parents of how having children has affected their lives. In conversations with other fathers and with adoptive parents about their children. he heard parenthood described as an experience which makes a person experience life more fully. He's aware of the difficulty that others have in describing the experience of becoming a parent. He understands it as a process of becoming more whole, more spiritually complete, of having doors inside you open up. S. has a limited sense of what this expanded experience might feel like. He has experienced it to some small degree during the pregnancy, as a feeling of being more deeply connected to the natural world. He believes that having a child of his own would open him fully to this feeling and he desires this increasingly.

S. has a strong belief in the importance of parenting and he is emphatic in his belief that the care of his family should be a higher priority than financial concerns or his career. He looks forward with excitement to experiencing the completeness and wholeness and sense of spiritual connection that he hears others parents describe. Although he has trouble fully imagining the birth of his child, he believes it will be a transformative experience, purely emotional, one which will affect him more profoundly than he can know and connect him deeply to his child, in which he will experience an awareness of the essence of life. 


\section{Appendix B \\ Dylan: Data Analysis \\ Levels 1-4}




\section{Dylan - Levels 1-2}

So...I know that you've recently made the decision to have your first child. And what I'd like you to tell me about is the experience of making that decision.

Um. actually it was kind of hard. $\mathrm{Me}$ and my wife got married - we're coming up on a year in September. And a few months after we got married we kind of talked about - she was on depo-provera for endometriosis, um, we talked about it off and on but never actually did anything about it. /Finally, we were at the doctor's and he said that - because her depo-provera wasn't working right anymore, she started getting cramps really bad - and he told us it was kind of a now, get pregnant now or you know, it's just going to keep growing type thing. /And we'd already discussed it and we wanted to move in this direction. /But the doctor was saying it would take at least a year for her to get pregnant after the depo-provera and that he still doubted she would ever become pregnant because she had a surgery to remove some of the endometriotic tissue. /So we decided, we talked about it for a couple of weeks, we decided that we would, you know, try and have a baby. II think she was kind of skeptical about it. /But we finally took her off her depoprovera, we had talked to her doctor about it and he was saying, you know, you can do that, you know, I can't make you take this, but I doubt anything is going to progress from it. So, uh, we did it and he was still talking at least a year before she started her cycle again and twenty-eight days later she had had her cycle and we found out she was
1. The decision to have a child was difficult for $\mathrm{S}$.

2. S. and his wife talked off and on about having a child after they got married, "but never actually did anything about it." His wife was on depo-provera for endometriosis

3. S.'s wife's doctor told her that if they didn't get pregnant, the endometriosis would just keep growing.

4. S. and his wife had discussed getting pregnant and they wanted to move in this direction.

5. Their doctor told S. and his wife that it was unlikely they'd be able to conceive a child because of the endometriosis and past surgery that had been done to remove it.

6. S. and his wife talked about it for several weeks before they decided to go ahead and try to have a baby.

7. S.'s wife was skeptical about her chances of getting pregnant.

8. When S.'s wife went off of depoprovera, her doctor doubted that they would get pregnant and told them it would take at least a year. But after 28 days she'd started her cycle and had gotten pregnant. S. was pleased at how well this worked out. 
pregnant. So it worked out really well that way. /And then at first we looked at the pregnancy test and I've heard. you know, those are wrong, those can't be right all the time, so we ended up buying, we have like six of those things laying around. They all kept coming up positive and I was thoroughly convinced it was something she had drank, you know. We went into the doctor and it came up positive. And I was still having a hard time believing it, thinking about what the doctor said and everything. Then she finally actually got to see a sonogram - I have them hanging up at work, I don't have a picture of the baby so I have sonograms hanging up. And it kind of sunk in. /I still don't think it sunk in all the way, though. I think it's still kind of sinking in.

\section{You still don't quite believe that it's real.}

Yeah, I mean I know, but then again I'm still kind of, you know... [laughs]. But I guess the $17^{\text {th }}$ we'll get to hear the baby's heartbeat. That's what I'm looking forward to.

Yeah, I bet. That makes it a lot more real. So it was hard to get, sort of the process of getting pregnant and believing that it was possible was kind of difficult.

/Yeah. The fact of getting pregnant, um, at the grace of God you know it happened. I, you know, I started to lose hope, /I'd decided you know, ever since my father passed away, geez, when I was only five, six years old, of a mass cardiac, his heart exploded, um. probably from about thirteen years old on I always knew I wanted a baby, I wanted - it's kind of a psychological,
9. S. was unconvinced by the positive results of multiple home pregnancy tests. He had a hard time believing even the tests given by the doctor. because of the doctor's previous skepticism.

10. It "kind of sank in" that his wife was actually pregnant when S. saw the sonograms of the baby, which he has hanging up at work.

11. It still hasn't sunk in all the way for S. that his wife is pregnant. He's looking forward to hearing the baby's heartbeat.
12. S. feels that the fact of his wife's pregnancy happened "at the grace of God." He'd started to lose hope that it would happen.

13. Because S.'s father died when he was five years old, he knew from the age of thirteen that he wanted to have a child. His desire to have a child was a desire "to make it right for this child" and to "be there for this child." 
you know, "I'm going to make it right for this kid, I'll be there for this child" thing. /But when I got married, my whole aspect of why I wanted a child changed.

Hm.

/It was no longer a - it was probably a selfish thing at first, why I wanted to get my wife pregnant. /But, um, after I got married actually a lot of things changed when I got married. But now it's not a "I'm going to be there for the child," it's more of a...I don't know, when I talk about it I get all grinny and stuff.

\section{Hm. What is that?}

Well, you know, I just kind of get smiley and...you know, it's just one of those things, /I can't believe this happened to me. Statistically, she shouldn't have a baby, statistically I shouldn't have a baby. When I was a young man I spilled turpentine down my front, sitting on the hood of my mother's car. And the doctors had told me that chances of having a baby are pretty slim after something like that, just because of the chemicals and all that.

\section{Wow. So you're very lucky.}

II'm more than sure this is a miracle. I'm kind of crossing my fingers hoping God has a plan of what He's doing in all of this.

Huh. That's quite a story. You were, your father died when you were five and you said that from when you were thirteen or so you knew you wanted to have a child. Could you tell me about that?
14. The reason S. wanted a child changed when he got married.

15. S.'s desire to get his wife pregnant "was probably a selfish thing at first."

16. Many things changed after S. got married. His desire to have a child was less motivated by a feeling of "I'm going to be there for the child." Now when he thinks about it, he feels "grinny" and "smiley."

17. S. cannot believe that this is happening to him. Statistically, he believes neither he nor his wife should be able to conceive. When he was younger he spilled turpentine on himself, after which doctors told him that "chances of having a baby are pretty slim."

18. S. believes that this pregnancy is a miracle. He's "crossing his fingers, hoping God has a plan for what He's doing in all of this." 
/Well, I sort of raised myself. I hate to talk bad about my mom, but you know, I mean she was our with different guys all the time. One of my mom's boyfriends had beaten my brother up pretty bad. So, we were living in Minnesota at the time and he ran away and came to live with my grandmother. Um, my sister ran away with him. And my mom was never home. So I pretty much raised myself in Minnesota /and then out of the blue one day she came in and I was sitting in the room with a couple of my friends, and said to start packing, we had like three days to pack, we were moving to New Jersey. We moved up there, and then in New Jersey, um, I started raising myself once again. Then I found this guy, this kid up there, about my age, and most of my time in New Jersey was spent getting raised by them.

\section{By his family?}

Yeah.

So you were how old when you went to New Jersey?

Probably about seven, eight years old.

Okay.

That's just always been a thing for me, I've always wanted to make life better for a child.

Uh-huh.

I don't know, it's kind of a sick thing, I guess.

Because your experience wasn't so good, you had a feeling of kind of
19. As a child, S. raised himself. His mother was dating different men. one of whom had beaten up his brother. His brother and sister ran away to live with their grandmother.

20. When $\mathrm{S}$. was seven or eight, his mother abruptly moved them to the east coast. After the move. S. "started raising myself once again." He found a friend there and spent his time "getting raised by them."
21. S. has "always wanted to make life better for a child" than it was for him. He wonders if this is "kind of a sick thing." 
wanting to make it better for someone else.

YYeah. But I don't know, I think I grew up pretty good. You know, I like the way I am.

Um-hm.

It's one of those "if you don't like me then you know don't come around me" things.

Was there any moment there that, you know, that you could pinpoint - you mentioned, you said thirteen and I was kind of curious.

/Well, I guess when I was thirteen, um, wanting a child, obviously I wasn't going to have one.

\section{Right.}

I just. you know, decided one of these days, you know, I was going to grow up, I was going to have kids, I was going to be the dad.

Huh.

/And then, um, for awhile there that part of my life had died off. /And then I moved back down here. I got sick of New Jersey, I couldn't live there anymore. And one of the times I'd seen my mom I told her that I was moving back to Montana, you know, and whether she wanted to or not was up to her. I think I had just enough money for a bus ticket, for a one-way to get me to Missoula. And I was going to have my grandma pick me up there. And my mom had taken off for about another week and I was trying to decide what I wanted to take, she came back and said
22. S. is pleased with the way he has turned out: "I like the way I am." His attitude is that "if you don't like me...don't come around me."

23. When at thirteen he decided that he wanted to have a child. S. "decided one of these days... I was going to grow up, I was going to have kids, I was going to be the dad."

24. For awhile the part the part of S. that decided at thirteen to have children "died off."

25. S. decided on his own that he was sick of the east coast and was going to move back to Montana. He told his mother about this decision and she decided to move with him. It was a hard move. 
she'd move up here with me. We had an old - gosh, it was an '89 Dodge Daytona Sport and a full-size U-Haul trailer we'd strapped to the back of it and that's what we moved in. Quite possibly the worst move I ever had in my life. But that's how we got back to Montana. /And when I got back here around my family and stuff, that part of my life had started. you know, building up again. Then when I got married and me and my wife had talked about it - geez, we talked about it even when we were dating. Not, you know, let's me and you have kids, but, you know, do you ever want kids when you are, you know, married and down the road. /When we had talked, we' $d$ kind of agreed that we didn't want children for at least a few years. /And then one day out of the blue we were just kind of laying there talking in bed and the subject came up. We decided you know, that, we'd...she'll try and if we're not supposed to have kids then, you know, God wouldn't bless us with them. And if we were then.... /So I mean...I really hope God knows what He's doing on this one. [laughs]

\section{So you have a feeling of really it not being in your hands in some way.}

/Yeah, um, it's tough. My wife had complications in the pregnancy with endometriosis. She had to quit work. And it's tough, you know, I'm the only one working and it's hard to make it you know, I pretty much lived from paycheck to paycheck now, it's 400 and some odd bucks every two weeks. And it's tough trying to make ends meet. /And I still find myself questioning Him. Man, did You know what You were doing? You know, it's kind of one of those things. /Actually, every paycheck has been a few dollars over what we
26. When S. returned to Montana and was around his family again. his desire to have children started building up again.

27. S. and his wife discussed the idea of having children even when they were just dating. They asked each other whether they wanted to have children "down the road."

28. When they first discussed having children, $\mathrm{S}$. and his wife agreed that they didn't want children "for at least a few years."

29. S. and his wife made the decision to start trying to have a child "out of the blue." They decided that "if we're not supposed to have kids then...God wouldn't bless us with them."

30. S. really hopes that "God knows what he's doing on this one."

31. Things have gotten hard with the pregnancy. Medical complications have forced S.'s wife to quit work, so $\mathrm{S}$. is the only one working. It's hard to make ends meet.

32. S. finds himself questioning God, asking: "Man. did You know what You were doing?"

33. Because every paycheck has been a little over what they need to pay their bills, S. assumes that God "knows what He's doing." 
need to make our bills. So I'm assuming He knows what He's doing.

There's sometimes, there's a voice that's in doubt like do you really, do you know what you're doing?

Yeah. And my wife, she, you know, gets depressed. She sits around the house all day, the doctor told her no working at all. So she hangs out here in the day and I know she gets depressed, you know, not being able to work. /And all of her friends when they found out she was pregnant were pretty supportive - yeah, that's great, and I haven't seen any come over for the last four months now. You know, there's only one friend she has that calls her and she stops in when I'm at work, if she doesn't have to work she comes over and visits with Melissa.

\section{So you kind of lost some of your social life.}

/Yeah, yeah. Um, it's not actually that bad of a thing, if anything I think it's pulled us closer together. I mean, if we have a problem we don't have a variety of friends to talk to, we have each other. So I mean, in a sense I'm glad, /but in a sense, you know, I see Melissa when I get off work and she's depressed and.... and you know that makes it hard, because she doesn't want to sit around the house when I get off work and I'm just wanting to relax. /So usually we just go out. I bought a camera - my mom bought me a camera, because she said she wouldn't be able to make it to the baby shower. And she said that we're going to need a good one for all the pictures we'll be taking. /And that's kind of what we do. It's kind of conceited, I don't have anyone to take
34. S.'s wife gets depressed because her doctor has told her she can't work during the pregnancy.

35. Although S.'s wife's friends were excited for her when she first got pregnant, only one has come by to visit during the pregnancy.

36. S. believes that the social isolation he and his wife are experiencing is "not actually that bad of a thing" because it has brought them closer as a couple. They talk to each other instead of their friends.

37. It's hard for S. to get off work and come home to a wife who is depressed.

38. S.'s mom bought him a good camera to take pictures with because she won't be able to make it to the baby shower.

39. S. and his wife go out on sunny days and take pictures of each other. S. thinks this is "kind of conceited," 
pictures of except her. so you know on sunny days we just kind of go out to parks and snap pictures together, just have fun you know. Try to make the best of what we can.

Can I ask what... when you're worried that it may not, that you're not quite sure what you're doing, what it is you worry about?

/Probably the same thing every father worries about. $/ \mathrm{Mm}$, I wonder if we're going to make bills /and I wonder you know, if, um, I understand from the doctor you know, as soon as you can see the baby's heartbeat the chance of a miscarriage are really dropped. You know, like right now a direct blow to the abdomen is the only thing that would.... But you know, I'm worried about that still, I'm worried about, you know, is the baby going to be formed right, is something going to go wrong. $/ \mathrm{im}$. mostly ['m worried about Melissa, you know she's just depressed so much. And you know I try and - it sounds bad - but I try to find friends and all. I'm at work and I'll encourage them, why don't you go up to the house, man, visit Melissa for awhile. You know. And of course if she knew I did that she'd probably come home and beat me to death....

\section{No, she's going to need you around.}

/But, uh, I've slept in the car a few times, feeling that she lost some of her sense of humor. And I'll be laying there in bed and make a crude joke about a beached whale or something... and my blankets and my pillow are going outside or out here.

\section{Uh-huh.}

but they're trying to "make the best of what we can."

40. S. worries about "probably the same thing every father worries about."

41. S. worries about whether he can pay the bills.

42. Although he understands that the chances of a miscarriage drop greatly after the heartbeat is visible on a sonogram. S. still worries that the baby won't be formed right or that something will go wrong.

43. S. worries about his wife's depression. He tries to find her friends and encourages others to visit her. He believes she'd be mad at him if she knew he did this.

44. S. has made some crude jokes during the pregnancy which have caused his wife to make him sleep on the sofa or in the car. He feels that she's lost some of her sense of humor. 
So....

So it's increased the strain a little.

Yeah.

Not uncommon.

/But for the most part we, I don't know, it was actually, the hardest part was actually coming down to making the choice of whether we would have a baby or not.

Yeah, so could you tell me more about that. Sort of walk me through that in more detail.

/Um, we'd talked about it and the first few times we talked about it I think we both just kind of blew it off. We talk about a lot of stuff we want to do, but it never gets done. I still smoke and I've talked about quitting a thousand times. /But, um, after about the third day we talked about it, I think we scared each other, knowing that we were both serious about what we were talking about.

\section{Right.}

/'m, she'd go to sleep and I'd stay up, you know, sitting at the table figuring out bills or whatever, mostly ['d think of a cheap excuse, $I$, in my mind was trying to figure out if we could afford it.

\section{So the money was a big concern.}

/Yup. A very big concern. You know, I didn't want to bring a baby into the world if I couldn't, you know, provide a meal for it when I needed to, you know,

48. As they were making the decision to have a child, S. would come up with excuses to stay up at night so that he could try to figure out if they could afford to do it.

49. In making the decision to have a child, money was a very big concern for S. He didn't want to bring a child into the world if he couldn't provide for it's basic needs. 
diapers, bottles, you know, all that stuff. /And the nights I did sleep, you know, she was up pacing around making sure that we had enough room /and, you know there was a few nights when we'd sit up and we'd talk about it. Most of it was talking about, you know, the apartment. /We'd pretty much decided in our minds we wanted one, so we never just talked really about, you know, do we want one - it's, well where are we going to put this when the baby's bom, what about the crib, what about that? /We had jumped so far ahead of ourselves you know, we, before we even tried to get her pregnant we... [laughs], you know, already had the first eight years planned out for her.

\section{Uh-huh. So you really thought about it and sort of worked through it all.}

/Yeah and then, we went back to the basics of, you know, can we afford this, how's this going to affect, you know, how's this going to affect...um, we were kind of prepared that, you know, that as soon as you became pregnant some friends were going to leave. /Our priorities had shifted once again. Um, my priority was usually, bring home, you know, put food on the table, stuff like that. Um, you know, but they shifted once again. My priorities also became my wife, my child, and you know, our house, which I call "our little world." /And, you know, most of the friends that did hang with us, after the first priority changed, left, the second one, there's probably, you know, four or five friends that have actually stayed around and talked to her. /But, I mean for weeks we had talked about, you know, the baby. Our biggest concern was, well, what if you can't get pregnant, you know, is that going to
50. S.'s wife stayed up nights, worrying about whether they had enough room in their apartment for a baby.

51. A few nights, $S$. and his wife stayed up together talking about the decision to have a child. Mostly they talked about the apartment.

52. At the point when $S$. and his wife were staying up nights making the decision. S. says "we'd "pretty much decided in our minds that we wanted one." They didn't talk so much about whether they wanted a child as how they would manage the space in their apartment.

53. At the point of making the decision to have a child. S. and his wife had jumped ahead of themselves. They'd planned out the first eight years of the child's life before they were even pregnant.

54. S. and his wife went back to worrying about whether they could afford to have a child.

55. S. and his wife were aware that having a child was going to affect their friendships, "that as soon as you become pregnant some friends were going to leave."

56. S.'s priorities shifted when he and his wife decided to have a child. His priorities had been to put food on the table, but then it also became "my wife, my child...our house, which I call 'our little world."'

57. After S.'s first priority changed, most of their old friends left. Only three or four have stayed around.

58. When $\mathrm{S}$. and his wife were discussing having a baby, S.'s biggest concern was whether his wife might not be able to conceive and how that would affect her. 
affect you, you know. /Emotionally, she's a pretty weak creature. She was adopted as a small child. She never grew up with a real family, she bounced from family to family from, you know, five years old up until, you know about ten years ago. /And, you know I think that's most of her drive for wanting a baby, was, pretty much the same thing as mine, you know I. I want to make this baby's life right. /Well, um, we'd just made contact with the real mother and father...

\section{With her real mother and...}

Yeah. and I don't think she's much for her father. He lives here in Missoula and when he's not coming over drunk, he's coming over asking for money. And you know, that's really hard for her. There's been a thousand times when she "s called me at work because he'd called here drinking. And she's crying out. But her and her real mother are getting really close. Her mom came and visited us about a month ago....and Melissa had all these questions and her mom was explaining to her, you know, why she had left her father and all this stuff. And it really, you know, filled in a big blank part of my wife's life. /If nothing else, that certainly kicked her into overdrive, she knew then that she wanted a baby.

\section{So this was before $-I$ 'm getting the timing straight on this - this was before...}

/Yeah, this was before and during. You know, even then after that, we were still kind of hesitant. /Her dad's made this really hard on us. Her dad tries to tell me, you know, you can do this, you
59. S. perceives his wife as "a pretty weak creature" emotionally. She was adopted as a young child and was bounced from family to family for most of her life.

60. S. thinks that the forces driving his wife to want a child are similar to those driving him: "to make this baby's life right."

61. S. and his wife have recently made contact with her biological parents. Her biological father behaves badly, coming over drunk and asking for money. But her mother and she are getting close, discussing the past and filling in the blank spots in S.'s wife's life.

62. S.'s wife's experience of re-uniting with her birth parents has "kicked her into overdrive" in her desire to have a child."

63. Even after thinking through the issues involved in having a baby, $\mathrm{S}$. and his wife "were still kind of hesitant."

64. S.'s father-in-law has pushed S. away from wanting to have a baby, making things hard by telling $S$. what he can and can't do with the child. 
can't do that. And he kind of pushed me away from wanting to have a baby, just because he started trying to tell me and Melissa what we could and couldn't do with his grandchild.

\section{Huh. That created some doubt.}

/Yeah, that really got on my nerves. And most of the time I could just sit there and kind of block him off and do whatever it was I do. Until one day I, I don't know what was going on with him, but I think he has this fear that if she gets to know her real parents again, she s going to lose the love she has for her adopted ones. And uh, he told me that if Melissa's real mother was around the baby when it was born, he was going to have the social workers come and take it. And it took all the guys at work to stop me from going to beat on him, because I was, you know, really mad. /And that's one of those things in my life, another big issue, I have this thing with my temper. And I've really got it under hamess the last few months. But, you know, it could certainly use some improvement. /Um, me and Melissa, one of our big things was my temper. you know, if I could handle, you know, having a baby and.../but you know, my temper's been dropping so dramatically, my driving is really altered, I used to drive obscenely to get to where I was going [laughs], and I'm stopping at yield signs now instead of just slowing down.

\section{Is that since...}

Yeah, since we found out Melissa was pregnant, she says, especially recently, she asks me why I stop at yield signs instead of slow, something as big as
65. The pressure from S.'s father-in-law really got on S.'s nerves. Mostly he can just block this out.

66. S. believes that his father-in-law is threatened by his wife's biological parents. He told them he would have social workers take the baby away if S.'s wife's real mother was around the baby when it was born. S. was extremely angry at this.

67. S. says that controlling his temper is a big issue in his life. He's "got it under harness" lately but it could use some improvement.

68. S. and his wife were concerned about S.'s temper and how it would affect his ability to handle having a baby.

69. S.'s temper has been dropping dramatically since his wife got pregnant. Instead of driving "obscenely" now, he's "stopping at yield signs instead of just slowing down." 
I drive, I'm not going to get hurt. /But you know, I still...I'm not in as big a rush. It seems like just yesterday we found out she was pregnant - this pregnancy thing is going by so fast.

\section{Yeah.}

II ve learned to really take my time and appreciate - you know, it sounds bad but. you know. I kind of appreciate not having the baby yet - I mean we're still not harnessed down and, we want to go out on a Friday night. you know, / we don't drink, we don't do drugs, we never have - it's, you know, that's a really hard thing at our age, to find people to hang out with that don't drink and don't do drugs on Friday, Saturday night, it's really hard.

So you're still aware, you have that feeling like things are going to change...

/Yeah, I know they're going to change.

....and you're feeling pleasure in your single - not single, but you're not parenting yet.

YYeah. And right now our biggest thing is, we can't afford you know to fill up the gas, the tank in the truck and just go crazy Friday night and do whatever. Our thing is, we scrape a few bucks off every paycheck and...you know, on Friday nights we go out to dinner or something, or we go out to a movie, /you know, something where we can just - and it sounds stupid because we're alone all the time. but something where we can be alone and enjoy whatever it is we're doing. We're not talking about bills,
70. S. is "not in as big a rush" since the pregnancy: "this pregnancy thing is going by so fast."

71. Although he worries that it sounds bad. S. has learned to take time and "appreciate not having the baby yet." He sees that he and his wife are "still not harnessed down" and they can go out on a Friday night if they want.

72. S. and his wife don't drink or do drugs so it's hard to find likeminded people to hang out with on weekends.

73. S. knows that things are going to change.

74. S. and his wife can't afford to do whatever they want right now, but they "scrape a few bucks off every paycheck" and go out on Friday nights.

75. S. and his wife appreciate the time they can have to be alone and not be talking about bills or worrying about things -- time to "unplug from our world and plug into reality for a bit." 
we're not worrying about this or that, you know, just our time to kind of unplug from our world and plug into reality for a little bit.

Yeah, that sounds great. That sounds really important.

/But you know, it's always a tossing it's a juggling game, from the time you decide you want to get pregnant to the day you find out you are, it's a constant juggle. Especially for me. /One day I was all for it, the next day I was, you know, "no, no, we can't do this, we're too young," you know. /And then. probably right around the time that we decided this is it for sure, no turning back, I decided that, you know, I was done listening to everyone, you know. /One day I get the readings of "yeah. you'll be a great dad, you'll be great parents," the next day everyone told us "you're too young for that, you're too young," you know, "don't have a baby yet, you're going to ruin your life." One day I decided to quit listening to everybody. And I decided to make up my own mind. /And I actually feel sorry for the people that said I that I was going to ruin my life by having a child. /It's been hard - the mood swings, the staying up with her at three in the morning watching her throw up, but I mean, thus far I have more joys than complaints. She's just now starting to get her belly. It's kind of cute - she sees me looking, I'm in trouble. /But you know, I feel sorry for them, they're going to miss all this stuff and then one of these days they're going to wake up and roll out of bed and they're going to be single or with their wife going to realize it's too late or they should have done this, you know, a long time ago.
76. From the time $\mathrm{S}$. and his wife decided to get pregnant to the day the found out they were, it's been "a juggling game" for him.

77. S. went back and forth in his feelings about having a child. "One day I was all for it. the next day I was, you know, 'no, no, we can't do this, we're too young."'

78. At the point when $S$. and his wife decided that they were going to have a child for sure -- "no turning back" -- S. decided that "I was done listening to everyone."

79. S. got mixed messages from others about the decision to have a child. One day he was told that he'd be a great dad, the next day he was told that he was too young and was going to ruin his life.

80. One day S. decided to quit listening to everybody: "I decided to make up my own mind."

81. S. feels sorry for those who warned him against having a baby.

82. The pregnancy has been hard, but $S$. has "more joys than complaints." He's excited by the changes in his wife's body.

83. S. feels sorry for those who warned him against having a baby. He believes that they're going to miss what he is now experiencing, that they'll wake up one day and realize it's too late. 
So you feel really strong in your decision. It sounds like that point where you just decided to stop listening to everybody and decide for yourself...was a big moment.

/Yeah, it was actually, I was at work when I did it. Some lady had come in that, she had a baby. And we were just sitting there kind of talking back and forth. And I don't remember exactly what it was that she had said, something about she used to listen to everyone and she was, you know, an older lady, and she said that her biggest regret was that she' $\mathrm{d}$ waited so long to have a baby because she was scared of what people would think and this and that. Then you know she said that if she could give advice to anybody, it' $d$ be, if you want to have a baby, have it when you think you can handle it, not when you think your friends can handle it. And that was kind of the big snap in it all.

Yeah, so you were just standing there having that conversation and it kind of clicked for you?

/Yeah, um, there's a few people who come into the shop, there's a couple of regulars, and you know, they're mostly girls at the shop, it's just one of those things, you don't see a guy standing there buying chemicals and, "hey, man, if you were thinking about...."

Yeah.

But so, you know, we'd go outside and we' $d$ sit on the hood of their car and have a cigarette or whatever and you know, we'd just kind of talk about it and you know, when they've had babies, you know, how did you decide, what did
84. S. had an experience at work which caused him to stop listening to others about the decision to have a child. He was talking to an older woman who told him that her biggest regret was having waited too long to have a baby because of the fear of what other people would think. Her advice to S. was that "if you want to have a baby, have it when you think you can handle it. not when your friends think you can handle it."

85. S. spent time at his job talking to other women about their decision to have children. 
you think, /and all of them had the same story - they got so hung up in their friends and what their friends would think, and they all had the same thing is, you know, forget what everyone says, if this is what you want, do it. /So yeah, I mean once I came to that conclusion... and I don't know how Melissa came to the conclusion, but about the same day, I came home and I was like, "all right, Melissa, I've really thought about this" /and somewhere around here we have this piece of paper. If we're having this big conflict of what to do, we'll each take a piece of paper, draw a line down the middle and list the pros and cons of everything. And then you know, we combine them, and we mix out all the other ones and we compare them. And we had so many more pros - I think we had like four cons and a page and half of pros. /And so we decided then, if this is it, let's do it. And we called our doctor, like I had said. And we took her off the shots and he said all right, when you start your cycle the last day of your cycle count however many days, put a circle. He goes, and that day, no matter what happens. he goes. I don't care if Allan's passed out from a car wreck. you have got to do this. /Well her cycle started almost immediately after they took her shots. you know, two, three weeks after she had stopped it, she started. And, um, we were driving down the road and she was wearing white shorts and I just kind of looked over at something, I was looking to see what she was playing with on her knee, when she goes down the road she'll like, play with stuff, I looked down and just about killed us trying to stop the car - "Oh my god. you're hemorrhaging"! She looks down, and "oh my god, go to a store"! It was kind of one of them really funny things. And
86. The women at work with whom S. discussed having children all told him that they'd worried too much about what their friends thought about the decision. They said to "forget what everyone says. if this is what you want, do it."

87. S. doesn't know how his wife came to her conclusions about having a child, but once he came to his he came home and told her what he'd been thinking.

88. S. and his wife have a system for working through difficult decisions together. They each list out the pros and cons and then they combine their lists. They did this with the decision to have a child and came out with four cons and a page and a half of pros.

89. After comparing the pros and cons of having a child. S. and his wife decided to do it. They called the doctor and stopped their birth control and learned how to time S.'s wife's cycle.

90. S.'s wife's cycle started immediately after she went off of birth control. S. realized this when they were driving one day and he saw that she was bleeding. 
then she was mad at me the rest of the day for saying something.

Yeah. Huh.

/But yeah, it was really exciting, I mean it was... kind of disgusting but exciting all at the same time, you know, and she had started her cycle that fast and you know, it started running in my mind, man, there's a chance of this happening. there's really a chance of this happening.

Right. It sounds like there's a whole sort of series for you of, stages of it becoming increasingly more real.

Yeah, it. you know I mean it started out kind of, uh-uh. this isn't right. And when I seen the first sonogram it's this little circle about the size of dime. "Now, that's the baby" - I'm like, man, that's dust on there. You guys have got to be able to fake this somehow. Then they got to their second sonogram and you could see the heart beating - once again I was thoroughly convinced he had slipped a videotape in the VCR and he was pretending. /But the biggest thing was. for me, that kind of snapped it thus far into reality was....she hates fish, she despises fish, she won't eat seafood at all. Um, we were sitting at the table and she made me make her a tunafish sandwich, and that's what really sunk it in to me. You know, she - and I'm all "ha, ha, that's funny." "No, make me a tunafish sandwich." "Really?" That was the biggest thing for me that set it off, I mean, she can't even stand the smell of it without throwing up, let alone eating a whole sandwich.

Undeniably something had changed.
91. S. was excited by seeing his wife bleeding, even though it was "kind of disgusting" -. "it started running in my mind. man. there's a chance of this happening."

92. At first. S. could not believe that his wife was actually pregnant. $\mathrm{He}$ convinced himself that the sonograms had been faked.

93. The experience which finally convinced $\mathrm{S}$. that his wife was actually pregnant was when she asked him to make a tuna fish sandwich. even though she's always hated seafood. 
Yeah. That or she's the best darn faker I have ever seen.

So...I'm interested in knowing more about, going back a bit to the, a little earlier on where you said you first were both talking about it and realized that you both could, you both wanted the same thing - if I have that right - and then it sort of, how long a period was that in between there, and sort of what, could you describe that a little for me? Because that sounds like it's the first point where it was like, oh my gosh this is real, I could really do this, but... but a lot of other concerns that you had to wrestle with came in.

/It's, it's you know, the biggest thought was...mine personally, I don't really know what was going through her mind, my biggest thoughts about it. and they were the things that really, you know, set it off balance for me, that made me wonder, were could I afford it, was my biggest thing. My second thing was will my insurance cover any of this. And then I looked at my wife's car and it's very undependable.

[end of side 1 of tape]

We were talking about the concerns in that middle period there before you actually were trying to have it but you sort of realized that you were probably going to...cars and stuff.

/Basically, I, I don't know, you know, I don't have any other fathers to talk to.

Right, right. You'd talked to women through this.

So I'm assuming my fears are, you know, what every father has. You know,
94. S.'s biggest concerns about having a child were whether he could afford it, whether insurance would cover it and the dependability of his wife's car. He's not sure what his wife's concerns are.
95. S. doesn't have other fathers to talk to, but he assumes that his fears are the same as those of other fathers. He hopes this is true. but wonders if he's "geared a little bit differently." 
I'm assuming. And I'm hoping. And if not, then, you know, perhaps you know I'm geared a little bit differently. /I don't think any father has correct worries, I think each father worries according to their situation.

Yeah.

Um, but the cars definitely was my biggest thing. And then. like I said, the affording it thing. I had decided that if need be, towards the end, that I'd work as many jobs as I had to and take as many Vivarins as I could, you know to make sure I could make ends meet. Well, her father ended up giving me a raise. He'd said he was sick of seeing me come in to work and not sleeping for two or three days at a time and I looked like a zombie sitting there. /You know, the same worries every night kept me up. You know, can I afford this /and how is this going to affect our relationship. And that was the biggest, the absolute biggest thing was, how is this going to affect me and my wife. /My brother and sister have both been married, and it seemed like as soon as the baby came into the picture, they, you know. had gotten torn apart, them and their spouses. And I' $d$ been so worried about, I' $m$ going to be just like them, you know, a baby's going to come in and I'm going to feel jeopardized and it's going to end and.... /But, um, I realized you know a few different things about them and me is I' $\mathrm{m}$ so determined not to be like them, you know it's not funny. But, you know, it's one of those things is, it might happen, it might not, but you know I choose to put my faith in God right now. /There's a sign I seen - saw - when my wife was in the hospital. When we went
96. S. doesn't believe that there are "correct worries" for a father to have. He believes that "each father worries according to their situation."

97. S. worries about cars and about finances. He decided that he'd work as many jobs as he had to in order to make ends meet. His father-in-law gave him a raise because $S$. was so tired from lack of sleep.

98. S.'s worries about being able to afford the baby were keeping him up at night.

99. S. was very concerned about how having a child was going to affect his relationship with his wife.

100. S. had seen his brother's and his sister's marriages get tom apart after the birth of a child. He worries that he'll be like them. that when the baby comes "I'm going to feel jeopardized and it's going to end."

101. S. is very determined not to be like his brother and sister.

102. S. recognizes that the birth of a child might hurt his relationship with his wife, but he chooses to put his faith in God.

103. When S.'s wife was in the hospital, she sent him home to get a teddy 
to the hospital it was a blank board, and I got her a teddy bear when we were dating and she sent me out to get that teddy bear, she doesn't go anywhere without it, if we're going camping that bear's with us, and I was driving back to the hospital and I looked up on this board that was blank and it said..."Man sees the problems, God sees the progress." And that really helped me out on everything. And the next moming I went home to get a shower and get something to eat and the sign was changed. It was only there for a matter of a few hours, literally. Which was the weirdest thing I'd ever seen and nobody else I've talked to seen it and if they did, it didn't stand out in their mind. But you know I mean it's, every time I'm having doubts and stuff like that, I think about that. And you know, I mean....

\section{Yeah, so for you there's a faith that's involved in this, that you can trust in this larger power....}

You know, I think this is more faith than it is anything.

\section{Yeah?}

/There's obviously the boyfriend girlfriend in the back of their car fooling around. that happens. But I guess I kind of believe everything happens for a reason. /If she came home hemorrhaging and lost the baby, it' $d$ be hard, you know really hard, but I mean, I'd eventually realize you know, even though it's a problem for us, perhaps you know there was a problem with the baby, the baby wasn't going to be normal, her body aborted it.

\section{Right. You'd see some larger meaning to that.}

bear and as he was driving back with it he saw a sign which had been blank before that now read: "Man sees the problems. God sees the progress." The next day the sign had been changed. which was "the weirdest thing" he'd ever seen. That message helped S. a great deal: "every time I'm having doubts and stuff like that. I think about that."

104. S. believes that his decision to have a child "is more faith than it is anything."

105. S. acknowledges that people have sex casually and get pregnant. But he believes that "everything happens for a reason."

106. If his wife had a miscarriage, $S$. believes that he would recognize that even though it was a problem for them, there would be a reason for it happening -- a problem with the baby or a deformity which caused it to be aborted. 
Yeah. The doctors say that a mother's body I guess is really good with that, if there's going to be a problem with the baby, if it's going to be deformed. a lot of the times the mother's body will abort it. And, so....

It's a natural worry at this stage of things.

I'm hoping so.

You said before about sort of worrying about, wondering about how it would change both of you. And I wonder about that, could you tell me more about sort of what you wonder and how you imagine it's going to change you, what you think about with that.

The first thing I thought was I looked at my brother and my sister and that kind of shot me off in one direction again. If it was going to jeopardize my and her relationship, I, I wanted nothing to do with it.

So you would have chosen not to have a child if it would have been, if you knew it would have been harmful to the relationship.

/Yeah, right now we have a relationship - I think of it this way - we have a relationship, when I was thinking about it, we didn't have a child. So it would be harder for me to lose a relationship than it would be to lose a child that we never had. /But then again, I'd go through life wondering, if we hadn't decided this, I know I would have went through life wondering what if we would have had that baby, would we would have been all right, you know? /And I mean, everyone has decisions like that they'll look back
107. S. thought that if having a child was going to jeopardize his relationship with his wife the way it did to his brother and sister. he "wanted nothing to do with it."
108. As S. sees it now, he and his wife have a relationship but not a child. It would be harder to lose the relationship that already exists than to lose a child that they never had.

109. If S. and his wife hadn't decided to have a child, he "would have went through life wondering what if we would have had that baby, would we would have been all right?"

110. S. sees that everyone has decisions in their life that they look back on 
on their life and if I would have done this different would I would have been all right here or there and....

\section{Right, turning points.}

So I mean, this is just one of those things. / didn't want to go through life wondering.

\section{Right.}

/So, I mean we're here now and it's too late to turn around and go back, so.... /And you know, other decisions in there. The cats were my biggest issue. I've heard lots of negative things about cats. I finally, you know, talking to different people they all said the same thing - cats are fine, don't let her change the litter box.

\section{Right.}

/So, you know, the girls at the shop there aren't any that work there, but the ones that come in have been the biggest decision maker for me, it's just talking to them and asking them, you know. what they thought, you know, how the baby affected their lives. /And a few of them said yeah, the baby coming in, you know it split me and my husband up. But none of them regretted it, that it had split them up. They said that um, before they were pregnant they couldn't imagine life with a baby and now that they had one they couldn't imagine life without it. /And you know, it's one of my thriving goals, I want to be the best father I can be, I want to be there. /And I wasn't sure about myself, I didn't know if, if you know I was cut out to be a dad, I didn't know if I, you know, a lot of, can I be a dad, you know, can I hold my temper? and wonder how things would be different if they'd chosen differently.

112. S. acknowledges that where he and his wife are now, "it's too late to turn around and go back."

113. For $\mathrm{S}$., the decision to have a child involved making other decisions as well -- for instance. he had to decide whether or not they could keep their cats during the pregnancy.

114. For S., talking to the women who came into his shop has been a big factor in making the decision to have a child. He asked them what they thought about it and how their babies had affected their lives.

115. Some of the women S. talked to about having a child said that having a baby had split up their marriage. But none of them regretted it.

116. The women S. talked to about having a child said that "before they were pregnant they couldn't imagine life with a baby and now that they had one they couldn't imagine life without it."

117. S. wants to be the best father he can be. "I want to be there."

118. S. was unsure about whether he was "cut out to be a dad." $\mathrm{He}$ 
When my son falls on his bike when he's first learning to ride, you know, can I be there for him or am I going to be stuck at work?

\section{So, being cut out to be a dad means...holding your temper, and being there....}

Yeah there's a lot of, there's so much responsibility that goes with it.

\section{Yeah.}

But I mean, if nothing else, the way I thought about it is, you could have all the responsibility in the world. it's what you can handle. /And that was another thing that set me off for a while, is can I handle this? Am I physically and emotionally strong enough to handle all this. /Guys have this macho front. and I don't care who the guy is, they all have these wonders, they all have this and that. And I think any father who's planned it out. I'm hoping once again, has these worries, you know, can I handle this, can I handle that? /So you know, now I'm juggling, when we first got married I was juggling my single life versus my married life, you know, /then I was juggling, you know, geez, we just got used to be being married, we just got used to, you know, there's Friday night, no spontaneous hop in the car and cruise downtown and go visit with everyone. And now I'm juggling the, you know, we just got used to being married, and you know it's a, you know even if we want to go out to dinner, can we find a babysitter, this, this, that. /Our families - both of our families - have been really supportive of it. My cousin Ann and my cousin Milly have been really supportive of it. They said, you know, if we ever wondered if he could hold his temper and whether he would be able to be there for the big moments in his child's life.

119. S. believes that there's a lot of responsibility that goes with being a father. He believes it's a matter of what you can handle.

120. S. worried about whether he was "physically and emotionally strong enough to handle all this."

121. S. hopes and believes that any father who has planned it out has the worries and wonders that he has. Guys have a macho front, but they worry, "can I handle this? Can I handle that?"

122. When S. first got married, he had to juggle his single life versus his married life.

123. S. feels that he has just gotten used to the limitations of married life and now he's starting to juggle the demands of life as a parent. There's no more going out spontaneously, they'll have to arrange babysitting.

124. Both S.'s family and his wife's family have been very supportive. S.'s cousins have offered to babysit. 
needed a babysitter by all means give them a call. Her best friend Ann and her sister and her mother in law, you know. they've all been really supportive. /And they know this is hard on us. My boss knows there's going to be a few days I'm going to come in to work and I'm going to be dragging my behind because I've been up all night with this crying baby. /But I mean, it gets over that.

So you lost some of the social support from the friends but you got a lot of support from your families.

Yeah. Our families have always been real close, I've been real close with my family, she's always been real close with her family. Her dad - I complain about him a lot but for the most part he's been great. If we're struggling, like Memorial Day my grandmother just passed away in March, Memorial Day was the day I found out my checks were stolen. I was going to write a check for gas money to go down to the house there. because I'm the keeper of the cemetery, I'm the superintendent, it's my job to keep it clean. My grandfather had bought an acre plot up there. So I mean he's realized it's been hard on us. he's, you know, been helping us out when he could. /But you know I mean it's still really hard, one day he's really cool about it, the next day he's trying to tell me what I can and can't do and where I can and can't go. I think he knows now I have my limitations of what I will and won't do.

\section{Um-hm. Yeah, so working out those family relationships is important.}

II knew my family would be really supportive of it. My family's been
125. S.'s family knows that having a child is going to be hard on S. and his wife. His boss knows that $\mathrm{S}$. will come into work tired some mornings because of the new baby.

126. S. believes the baby will get over the period when it keeps him up at night.

127. S.'s family and his wife's family have both been close and supportive. Although he complains about her father, "for the most part he's great." $\mathrm{He}$ helped out when $S$. had some difficulty with stolen checks.

128. S. describes his relationships with his father-in-law as being "really hard." One day he's really cool, the next "he's trying to tell me what I can and can't do." S. believes that his father-in-law "knows now I have my limitations of what I will and won't do."

129. S. is happy about how supportive his family has been of the pregnancy. 
really free-going, they're just kind of...you have to meet them, we're different from most families I've seen, we're really different. And you know, my family is great with it, they're just as good as I thought they'd be. /Her family I still don't know that great. But you know, I mean they've all been really good about it.

\section{So you haven't got so much of that "you're too young" from them.}

Not from them. My brother teases Melissa a lot about, you know, having my child and all that. He teases the heck out of her about that. But I mean, you know it's all in good fun. Sometimes she understands it. and sometimes she grabs, you know, parts to throw at him out of cars.

\section{It's the risk you take.}

/But yeah, they've been super supportive of. the friends we do have have been really supportive. Her brother's girlfriend, I've known her, geez, for a long, long time. We used to live down in the reservation together, we lived across the street. and every time I needed to talk to someone, if I can't get a hold of. I have a friend, Kyle, and me and him are really close, but I usually go talk to Jill. I'll give her a call or we'll go out and we'll sit there and have coffee for hours upon hours talking, $/ I$ mean sometimes you just need to get away from it all. And that's kind of my tension release. /She'll go out with her friends or she'll have friends over or she's out doing this or that and her tension release I think is, her biggest thing is, even though we can't afford it right now, she likes to go out and look at baby clothes and you know, car seats

132. S. has several very supportive friends with whom he can spend hours just talking. 
and toys and all this stuff. I mean, we both know we can't afford it but it's kind of fun you know, it gives us an idea of what we're going to need to afford when it comes time. /And while she's looking at baby clothes I'm going through every stat sheet I can on child safety seats. And you know I'm trying to dig up all these safety standards on that thing especially [points outside to truck]. $\Pi$ wanted a station wagon, because I thought, kid, twenty thousand diaper bags. stroller, you know all this and that, and I was thinking you know this isn't a Geo Metro car that we're going to need. we're going to need something big. Well she hates station wagons. And I'm not much for vans. And I hate new cars, because you know these ones I can still work on and all that, you know I don't need a computer next to me to read my computer. So I have this guy that was at work recently, we just got this [the truck], and he was great, he came in, said he wanted to get rid of it and he wanted my pick-up. Well he had just got done putting all kinds of money into this, making sure it ran good. So we traded. /And that really, you know, took a big release off of me, was, you know, knowing we were going to have something dependable, something we could get parts for fairly easily. So that was, you know, the best thing that happened.

\section{Yeah.}

/Sleep, I mean, /I guess I worry about really stupid things, especially when we were deciding this whole thing, I worried about dumb things. I work at a vacuum shop - most fathers wouldn't think twice about their vacuum. Well we had this, I don't remember what it was, but the very first thing I did when
135. S. spends time looking at stat sheets and safety standards for baby seats and for their vehicles.

136. S. was concerned with what sort of car he and his wife would need with the new baby. He wanted something big like a station wagon, but not something so new that he couldn't work on it himself. He traded someone for a truck, with which he's very happy.

137. It was a big relief for $\mathrm{S}$. to have a vehicle that was dependable.

138. S. worries about sleep with the baby.

139. S. says he worries about "really stupid things." The first thing he did when they were talking about having a baby was to review stat sheets on vacuum cleaners because he wanted to get the best system he could find in terms of his wife and the baby's health. 
we were talking about it was I went and I pulled every stat sheet I could find on vacuums, I pulled out Consumer Reports and all that, and I was gearing our vacuum to something, you know I wanted a filtered air system so we weren't throwing dust, especially by the cat box. So you know, I got the best filtered air system I could find. /And then you know there was just so many things I wanted to make sure we could get before I shot off into this thing. You know, let's go! /And we'd already had our animals then. I've always wanted to go to college for veterinary science and she's, she's a certified C.N.A. is what she is. and that's always been her thing, she's always wanted to go to college to be an emergency room nurse. you know, an ambulance person.

C.N.A. is...?

A certified nurse's assistant.

Okay. So, you wind up worried about... really particular things.

/Yeah, I mean, you know is this going to mess up our life, you know, in that aspect. /I'm taking home school right now. I had a lot of trouble in school - if I wasn't in a fight at school or I wasn't asleep at school. I wasn't at school. II've been one of those people, I need something to work around my schedule, I have a hard time working my schedule around something. And that was another big, big factor when we were deciding is, I"m going to have to learn how to work around the baby's schedule, because this baby is not going to work around my schedule.

Yeah, right. So you're realistic about that.
140. S. says that there were many things he wanted to make sure they could get before he "shot off into this thing."

141. S. keeps animals and he wants to go to college in veterinary science. His wife is a Certified Nursing Assistant and she wants to go to college to be an emergency room nurse.

142. S. worried whether having a child was going to mess up his and his wife's life in terms of their future school plans.

143. S. is taking home school. He's had a lot of trouble with school in the past.

144. S. has a hard time adjusting his schedule to someone else's. He knows that he's "going to have to learn how to work around the baby's schedule, because this baby is not going to work around my schedule." This was a big factor in his decision to have a child. 
And that's been my biggest thing is, if I get a chance to work my schedule around something else to get to this certain point where I want to be, I take full advantage of it, you know, I'm used to it. My biggest thing is, when I go to bed at night, I hate being woke up, you know, like anyone, I can't stand it. And that's my biggest thing is am I going to be really grouchy with this baby when it wakes up at three in the morning screaming. /And that was another thing, I decided when that was all going, that how could I possibly be mad at this small, perfect little baby. /And I, you know, when Melissa looks at she's going to see me, when I look at this baby I'm going to see her. And you know it just finds...hard to be mad at that. That was another thing was, can I punish this child? You know, my first child, am I going to be able to spank it, you know, when the child needs spanking? Or am I going to be one of them parents that lets them get away with everything? /And that was another thing, before we even had decided to get pregnant. was, I wanted to know what she thought about discipline, and....

\section{So working that out in your relationship, deciding things.}

Yeah, that was kind of tough. We'd both decided, we both had the same idea about discipline. If our child comes with a baseball bat and he's playing around and hits something and breaks it, like the iguana tank. The first time, you know, give them a warning or perhaps send him to the comer. Now if he does it again, and purposely does it the second time, yeah, he's going to get a spanking. You know, I mean, we both feel it's warning first, spanking the second time. And then you know we both decided
145. S. hates to be woken up after he's gone to sleep at night. He worries that he's going to be really grouchy with the baby when it wakes him up at night.

146. When making the decision to have a child. S. wondered how he could possibly be mad at a "small perfect little baby."

147. S. believes that he will see his wife in their child and that his wife will see him. He believes that this will make it hard to be mad at the child.

148. S. wondered about his ability to punish a child. Would he be able to spank it if it needed spanking, or would he let it get away with everything?

149. Before they decided to get pregnant, S. and his wife discussed discipline. They both had the same idea about it: a waming first and a spanking the second time. They also discussed how hard to spank. 
on how hard to spank, was another thing.

You really thought through all this stuff.

Y Yeah, Melissa tells me I'm more brawn than brain. And I tease her, I mean, she's, she really has her head on straight. And it's kind of true, from what she teases me, is I'm the sheer power of the family and she's kind of the mind. /I mean, my temper was really bad. If she told me anything, my first intent was that I was going to go find whoever it was that she told me this about and they'd. you know, meet my knuckles and then we'd talk about it.

\section{Right.}

IShe has really helped me with my temper. /And then, on my own accord, I used to take the last hour and a half off of work and I told my boss, you know. don't tell Melissa I'm doing this. and I went to anger management classes with Jeff Greer. And that helped me tremendously. I hadn't noticed anything until one day, she does this thing that annoys me really bad. And she does it on purpose, like if I'm trying to figure out bills or something. And every so often she wants to just play, wants to wrestle around or you know tickle each other, or...she kept doing it, trying to get a rise out of me and through the whole thing, like an hour and a half of this I just sat there and you know, didn't move, and she sat down and she goes, "what have you been doing?" And I went "what, what are you talking about?" And this was still when we'd been deciding to have a baby or not. She goes, "what have you been doing?" I'm like, "what are you talking about?" She goes. "I have been annoying the heck out
150. S.'s wife tells him he's "more brawn than brain." He believes that this is true: "I'm the sheer power of the family and she's kind of the mind."

151. S. had problems with his temper. His reaction to a provocation was to fight first and talk about it later.

152. S.'s wife has helped him with his temper.

153. Without telling his wife, S. took anger management classes. He realized that this had helped him tremendously one day when his wife kept teasing him and he didn't react. This gave him a lot of confidence in his ability to control his temper. 
of you for the last hour, you haven't so much as gave me a dirty look." And, you know I knew then I was like, man, yeah, this is, this is working, I can do this. And that gave me a lot of confidence in myself.

\section{Huh. So that's connecting back to} having a kid.

Knowing I could adapt to having a baby. If I had to, I can adapt. So, you know, that was a great spot in my life. right there, deciding, was you know I knew that - and I guess anybody can adapt. I mean, it was just, I think everyone's just so unsure of it, if they can. Mankind adapts accordingly. I mean, if you look at, you can take a man and you can drop him anywhere in the world. and he'll adapt to his surroundings, he'll adapt to survive.

\section{So adaptation, that's interesting.}

/So yeah, I mean, and I know, she's so much of a mother anyway, her cat is so darned spoiled, she's going to have to do little to no changing, which is, it's so cool with her. /I don't feel comfortable talking to her dad, he always states his own opinion, always works in a way to tell me what to do about it. Her mom scares the hell out of me, she's taller than me and she has a broader shoulder spread than me. So I mean I'm scared she's really religious too - I'm scared I'm going to say the wrong thing, it's going to come out wrong or something and you know, I'm going to pick up my teeth in a few minutes. And her sister's more of a happy, funny person. But you know, I mean, it's kind of weird.

Yeah. So I think there was one, if I could go back to one thing if that's
154. Learning to control his temper helped $S$. to realize that he could adapt to having a baby. He describes this realization as "a great spot in my life." He came to understand that although everyone's unsure about whether they can, "mankind adapts accordingly."
155. S. believes that his wife will have to do "little to no changing" to adapt to being a mother.

156. S. does not feel comfortable talking to his father-in-law. His mother-in-law scares him. He gets along better with his wife's sister. 
all right, which is way back at the beginning, you talked about when you moved back here and sort of something about being around your family it sounded like, sort of made you, got you back into a mode of thinking about having a kid. And I just am curious about hearing a little bit more about that transition, what made that happen.

/Oh, watching, you know, just looking at different things. I've been around my brother and sister when they had their first children, you know, I seen how happy it had made them. It kind of made their life a little bit complete in it all. And it just, you know, I seen how a family changed a person. /And it works in one of two ways, it either throws them into this super, you know, relationship with the family and the children and their wife and their family's relation. Or it shoots them completely away from everything. I've seen it shoot them both ways. /And I strongly believe that okay, well actually hope - but I'm really trying to believe that I'll be the kind that it'll pull us really tight together, you know, I mean, and it'll lock us a bit, /and that really geared me into thinking, if my brother can be a dad, anyone can be a dad. The biggest thing is me admitting I'm wrong. And you know, I mean, that's going to be a killer for me.

\section{It's always hard.}

So I, but you know I'd thought on and off about it, I'd always known, you know I'm not having a baby until I get married. Inconceivable, you know. I just didn't want one. /I've seen my sister and brothers kids grow up out of marriage, without, you know, a mom
157. Watching his brother and sister when they had children made S. see that having children made them happy, "made their life a little bit complete in it all." He saw "how a family changed a person."

158. S. has seen that the change that comes with having a child works in one of two ways -- either it turns the couple into a "super... relationship with the family" or "it shoots them completely away from everything."

159. S. hopes that he and his wife are the kind of people who will be pulled tightly together by having a child, that "it'll lock us a bit."

160. S. believes that if his brother can be a dad, anyone can be a dad.

161. It's hard for $S$. to admit it when he's wrong.

162. Although he thought about on and off, S. always knew that he wasn't going to have a child until he was married - that was inconceivable to him.

163. S. has seen his brother and sister's children' growing up without both parents present. He believes that this is hard on a child. 
and a dad. And that's got to be hard on a kid. They were married when they had the child. but you know, I mean it's just, II'd just as soon give the child the opportunity to grow knowing his mom and his dad together than I would having them grow up and you know, "mom, when are we going to visit dad?" or "when's dad coming to visit me?"

\section{So having the family intact is important.}

/Yeah, and our family keeps in contact really well with each other. So you know, I mean even if it doesn't work out between me and my wife, I'll most assuredly go out of my way to see the child part of it. /Because I want to be a big part in my child's life, regardless. /Like I said, another thing I worried about, is am I going to be a big part of my child's life? And I certainly want to be that part of his life, you know, I want to be his dad, I don't want to come over one day and see, you know, my eight year old son calling her new husband or boyfriend "dad," because it would just tear me apart. /So I'm going to make sure - and I swore this before I even met my wife, you know - I'm going to make my way to see my child. That child is going to know who his dad is, one way or the other.

That sounds great. I think that's about what I need to know. Is there anything else do you think that should be...

/As for new fathers, I was actually thinking about... whether their friends or anybody will care is, the biggest thing I can stress is to anybody is forget what
164. S. wants his child to grow up knowing both its parents and not have it have to worry about visitation.

165. Even if things don't work out between him and his wife. S. says he will "most assuredly go out of my way to see the child."

166. S. wants to be a big part of his child's life.

167. S. worried about whether he would be a big part in his child's life. He wants to be. He doesn't want to hear his child calling someone else "dad" -- "it would just tear me apart."

168. S. swears that he is going to make sure that he sees his child. "That child is going to know who his dad is, one way or the other."

169. In making the decision to have a child, $\mathrm{S}$. believes that men should "forget what people say, they're not the ones living with it, you are." 
people say, they're not the ones living with it, you are.

\section{Right.}

That's the biggest thing I can think of. 


\section{Dylan - Level 3}

S.'s father died when he was five years old. After his father's death his mother dated different men, one of whom beat up his brother. His brother and sister ran away to live with their grandmother. He says that he raised himself. When he was seven or eight. his mother abruptly moved them from Montana to the east coast. After the move. he says he "started raising myself once again." He found a friend and got "raised by them" during this time. After awhile, he decided that he was sick of the east coast and was going to move back to Montana. He told his mother about this decision and she decided to move with him. It was a hard move. Although he has had a difficult life. he's likes the way he has turned out. His attitude is that "if you don't like me...don't come around me."

Because of his father's early death, S. knew from the age of thirteen that he wanted to have a child. His desire to have a child was a wish "to make it right for this child" and to "be there for this child." He decided one of these days...I was going to grow up, I was going to have kids, I was going to be the dad." For awhile the part of him that had decided at thirteen to have children "died off." But after he returned to Montana and was around his family again, his desire to have children started building up again.

S. and his wife discussed the idea of having children even when they were just dating. They asked each other whether they wanted to have children "down the road." After they got married they talked off and on about having a child "but never actually did anything about it." When they first discussed it they agreed that they didn't want children "for at least a few years."

For S., the decision to have a child was a difficult one. He had thought about it on and off throughout his life, but he always knew that he wasn't going to have a child until he was married - that was inconceivable to him. The hardest part for him was "actually coming down to making the choice of whether we would have a baby or not." He says that he has "always wanted to make life better for a child" than it was for him. He wonders if this is "kind of a sick thing." He believes that his desire to get his wife pregnant "was probably a selfish thing at first." But the reason he wanted a child changed -- as did many other things - when he got married. His desire to have a child was less motivated by a feeling of "I'm going to be there for the child." He has a hard time describing his motivation now. He says that when he thinks about having a child now he just feels "grinny" and "smiley."

S. thinks that the forces driving his wife to want a child are similar to those driving him: "to make this baby's life right." She was adopted as a young child and was bounced from family to family for most of her life. She has recently made contact with her biological parents. Her biological father behaves badly, coming over drunk and asking for money. But her mother and she are getting close, discussing the past and filling in the blank spots in her life. S. believes that his wife's experience of re-uniting with her birth parents has "kicked her into overdrive" in her desire to have a child." 
S. was influenced by other people in the process of making his decision. both positively and negatively. He got mixed messages from others about the decision to have a child. One day he was told that he'd be a great dad, the next day he was told that he was too young and was going to ruin his life.

S.'s father-in-law has pushed him away from wanting to have a baby. making things hard by telling S. what he can and can't do with the child. The pressure from S.'s father-in-law really got on S.'s nerves. But mostly now he can just block this out.

S.'s brother and sister both had children and both had divorced. Having seen his brother's and his sister's marriages get torn apart after the birth of a child. he worries that he'll be like them, that when the baby comes "I'm going to feel jeopardized and it's going to end." He believes that if his brother can be a dad, anyone can be a dad. But he is very determined not to be like his brother and sister.

At the same time, watching his brother and sister when they had children made S. see that having children made them happy. It "made their life a little bit complete." $\mathrm{He}$ saw "how a family changed a person." He has seen that the change that comes with having a child works in one of two ways -- either it turns the couple into a "super...relationship with the family" or "it shoots them completely away from everything." He hopes that he and his wife are the kind of people who will be pulled tightly together by having a child, that "it'll lock us a bit."

S. spent time at his job talking to other women about their decision to have children. This was a big factor in his decision process. He asked these women what they thought about having children and how their babies had affected their lives. They all told him that they'd worried too much about what their friends thought about the decision. They said to "forget what everyone says, if this is what you want, do it." Some of the women he talked to about having a child said that having a baby had split up their marriage. But none of them regretted it. They said that "before they were pregnant they couldn't imagine life with a baby and now that they had one they couldn't imagine life without it."

S. had one experience in particular which caused him to stop listening to others about the decision to have a child. He was talking to an older woman who came into the store who told him that her biggest regret was having waited too long to have a baby because of the fear of what other people would think. Her advice was that "if you want to have a baby, have it when you think you can handle it, not when your friends think you can handle it." In making the decision to have a child, S. believes that men should "forget what people say, they're not the ones living with it, you are."

One day S. decided to quite listening to everybody: "I decided to make up my own mind." At the point when he and his wife decided that they were going to have a child for sure -- "no turning back" -- he decided that "I was done listening to everyone. Now he says that he feels sorry for those who warned him against having a baby. He 
believes that they're going to miss what he is now experiencing, that they'll wake up one day and realize it's too late.

Because S. and his wife had already discussed getting pregnant. they knew they wanted to move in this direction. The first few times they talked about having a baby. they "both just kind of blew it off." They talk about a lot of things that they never do. After the third day of talking about having a baby, they scared each other. "knowing that we were both serious about what we were talking about." S. doesn't know how his wife came to her conclusions about having a child, but once he arrived at it he came home and told her what he'd been thinking. They talked about it for several more weeks before they decided to go ahead and try to have a baby.

As they were making the decision to have a child, S. would come up with excuses to stay up at night so that he could try to figure out if they could afford to do it. His wife would stay up worrying about whether they had enough room in their apartment for a baby. For him the decision to have a child involved making other decisions as well -- for instance, whether or not they could keep their cats during the pregnancy. Sometimes he and his wife stayed up together talking about the decision, especially about whether their apartment would be all right and about whether they could afford it. At this point he says that they'd "pretty much decided in our minds" that they wanted to have a child. They didn't talk so much about whether they wanted a child as how they would manage the space in their apartment.

S. says that when he and his wife finally made the decision to start trying to have a child it was "out of the blue." They decided that "if we're not supposed to have kids then...God wouldn't bless us with them." They have a system for working through difficult decisions together. They each list out the pros and cons and then they combine their lists. They did this with the decision to have a child and came out with four cons and a page and a half of pros. After comparing the pros and cons of having a child, they decided to do it. He says that at this point they'd already talked about it so much that they had jumped ahead of themselves. They'd planned out the first eight years of the child's life before they were even pregnant.

But even after thinking through the issues involved in having a baby, $\mathrm{S}$. and his wife "were still kind of hesitant." They knew that having a child was going to affect their friendships, "that as soon as you become pregnant some friends were going to leave." $\mathrm{He}$ says that his biggest concern was whether his wife might not be able to conceive and how that would affect her. He perceives her as "a pretty weak creature" emotionally.

From the time he and his wife decided to get pregnant to the day the found out they were, S. has gone back and forth in his feelings about it. "One day I was all for it, the next day I was, you know, 'no, no, we can't do this, we're too young." It's been "a juggling game" for him. But now that he and his wife have made the decision, he acknowledges that "it's too late to turn around and go back." 
S. describes his decision to have a child as "more faith than it is anything." He feels that the fact of his wife's pregnancy happened "at the grace of God." He'd started to lose hope that it would happen. He believes that this pregnancy is "a miracle." He's "crossing his fingers, hoping God has a plan for what He's doing in all of this." He says that he really hopes "God knows what he's doing on this one." At times he finds himself questioning God, asking: "Man, did You know what You were doing?" Because every paycheck has been a little over what they need to pay their bills, he assumes that God "knows what He's doing."

S. had one experience which particularly confirmed his faith. When his wife was in the hospital, she sent him home to get a teddy bear and as he was driving back with it he saw a sign which had been blank before that now read: "Man sees the problems. God sees the progress." The next day the sign had been changed, which was "the weirdest thing" he'd ever seen. That message helped S. a great deal: "every time I'm having doubts and stuff like that, I think about that."

He believes that "everything happens for a reason." If his wife had a miscarriage, he believes that he would recognize that even though it was a problem for them. there would be a reason for it happening -- a problem with the baby or a deformity which caused it to be aborted.

S. says that if he and his wife hadn't decided to have a child, he would have gone through his life wondering how it might have been. He sees that everyone has decisions in their life that they look back on and wonder how things would be different if they'd chosen differently. He didn't want to go through life wondering.

When they made the decision to have a child, S. and his wife called the doctor and stopped their birth control and learned how to time his wife's cycle. At the time, his wife was on depo-provera for endometriosis. Her doctor had told her that if they didn't get pregnant soon, the endometriosis would just keep growing. He told them that it was unlikely they'd be able to conceive a child because of the endometriosis and past surgery that had been done to remove it. When his wife went off of depo-provera. her doctor doubted that they would get pregnant and told them it would take at least a year.

S.'s wife was skeptical about her chances of getting pregnant, but her cycle started immediately after she went off of birth control. After 28 days she'd started her cycle and had gotten pregnant. S. was pleased at how well this worked out. He realized that her cycle had started when they were driving one day and he saw that she was bleeding. He was excited by seeing this, even though it was "kind of disgusting" -- "it started running in my mind, man, there's a chance of this happening."

At first, S. could not believe that his wife was actually pregnant. He still cannot believe that this is happening to him. Statistically, he believes neither he nor his wife should be able to conceive. When he was younger he spilled turpentine on himself, after which doctors told him that "chances of having a baby are pretty slim." He was unconvinced by the positive results of multiple home pregnancy tests. He had a hard 
time believing even the tests given by the doctor, because of the doctor's previous skepticism. He convinced himself that the sonograms had been faked.

It "kind of sank in" that his wife was actually pregnant when S. saw the sonograms of the baby, which he has hanging up at work. But it still hasn't sunk in all the way for him that his wife is pregnant. An experience which finally convinced him that his wife was actually pregnant was when she asked him to make a tuna fish sandwich. even though she's always hated seafood. Although he understands that the chances of a miscarriage drop greatly after the heartbeat is visible on a sonogram. he still worries that the baby won't be formed right or that something will go wrong. He's looking forward to hearing the baby's heartbeat.

S. says that he is not sure what his wife's worries about having a child are, but he believes that the sorts of things he worries about are "probably the same thing every father worries about." Although he doesn't have other fathers to talk to, he assumes that his fears are the same as those of other fathers. While he hopes this is true. he also wonders if perhaps he's "geared a little bit differently" than other men. He doesn't believe that there are "correct worries" for a father to have. He believes that "each father worries according to their situation." He has worried about whether he was "physically and emotionally strong enough to handle all this." He hopes and believes that any father who has planned it out has the worries and wonders that he has. Guys have a macho front, but they worry, "can I handle this? Can I handle that?"

S. says he worries about "really stupid things." The first thing he did when they were talking about having a baby was to review stat sheets on vacuum cleaners because he wanted to get the best system he could find in terms of his wife and the baby's health. He says that there were many things he wanted to make sure they could get before he "shot off into this thing." He spends time looking at stat sheets and safety standards for baby seats and for their vehicles.

S. worried about the dependability of his wife's car. He was concerned with what sort of car he and his wife would need with the new baby. He wanted something big like a station wagon, but not something so new that he couldn't work on it himself. He traded someone for a truck, with which he's very happy. It was a big relief for him to have a vehicle that was dependable.

Another big factor for S. in making the decision to have a child was money. $\mathrm{He}$ didn't want to bring a child into the world if he couldn't provide for it's basic needs. He worries about whether he can pay the bills and says that biggest concerns about having a child were whether he could afford it, whether insurance would cover it. He decided that he'd work as many jobs as he had to in order to make ends meet. It helped that his fatherin-law gave him a raise because he was coming to work so tired from lack of sleep from working so hard.

While making the decision, S. wondered about his ability to punish a child. Would he be able to spank it if it needed spanking, or would he let it get away with 
everything? Before they decided to get pregnant, he and his wife discussed discipline. They both had the same idea about it: a warning first and a spanking the second time. They also discussed how hard to spank.

S. worries about getting enough sleep once the baby arrives. He worries about the baby were keeping him up at night. He hates to be woken up after he's gone to sleep at night. He worries that he's going to be really grouchy with the baby when it wakes him up at night. He has a hard time adjusting his schedule to someone else's. He knows that he's "going to have to learn how to work around the baby's schedule, because this baby is not going to work around my schedule." This was a big factor in his decision to have a child. But he believes the baby will get over the period when it keeps him up at night.

S. worries whether having a child was going to mess up his and his wife's life in terms of their future school plans. He has had a lot of trouble with school in the past. He's taking home school now. He keeps animals and he wants to go to college in veterinary science. His wife is a Certified Nursing Assistant and she wants to go to college to be an emergency room nurse.

S. was very concerned about how having a child was going to affect his relationship with his wife. He says that that if having a child was going to jeopardize his relationship with his wife the way it did to his brother and sister. he "wanted nothing to do with it." As he sees it now, he and his wife have a relationship but not a child. It would be harder to lose the relationship that already exists than to lose a child that they never had. He recognizes that the birth of a child might hurt his relationship with his wife, but he chooses to put his faith in God.

When S. first got married, he had to juggle his single live versus his married life. He feels that he has just gotten used to the limitations of married life and now he's starting to juggle the demands of life as a parent. For instance, there will be no more going out spontaneously. they'll have to arrange babysitting. His priorities shifted when he and his wife decided to have a child. His priorities had been to put food on the table, but then it also became "my wife, my child...our house, which I call 'our little world."

S. wants to be the best father he can be. "I want to be there." He believes that there's a lot of responsibility that goes with being a father. He believes it's a matter of what you can handle. He wants his child to grow up knowing both its parents and not have it have to worry about visitation. He has seen his brother and sister's children' growing up without both parents present. He believes that this is hard on a child. He wants to be a big part of his child's life. Even if things don't work out between him and his wife, he says he will "most assuredly go out of my way to see the child." He worried about whether he would be a big part in his child's life. He wants to be. He doesn't want to hear his child calling someone else "dad" - "it would just tear me apart." He swears that he is going to make sure that he sees his child. "That child is going to know who his dad is, one way or the other." 
Controlling his temper is a big issue in S.'s life. He has had a lot of problems with his temper. His reaction to a provocation was to fight first and talk about it later. His wife has helped him with this. He's "got it under harness" lately but it could still use some improvement. He and his wife were both concerned about his temper and how it would affect his ability to handle having a baby. He was unsure about whether he was "cut out to be a dad." He wondered if he could hold his temper and also whether he would be able to be there for the big moments in his child's life. He wondered how he could possibly be mad at a "small perfect little baby." But he believes that he will see his wife in their child and that his wife will see him. He believes that this will make it hard to be mad at the child.

Without telling his wife. he took anger management classes. He realized that this had helped him tremendously one day when his wife kept teasing him and he didn't react. This gave him a lot of confidence in his ability to control his temper. Learning to control his temper helped him to realize that he could adapt to having a baby. He describes this realization as "a great spot in my life." He came to understand that although everyone's unsure about whether they can, "mankind adapts accordingly." Unlike himself, he believes that his wife will have to do "little to no changing" to adapt to being a mother.

But things have gotten harder for S. and his wife since the pregnancy. Medical complications have forced his wife to quit work, so he is the only one working. It's hard to make ends meet. His wife gets depressed because here doctor has told her she can't work during the pregnancy. He worries about his wife's depression. It's hard for him to come home from work to a wife who is depressed. Although his wife's friends were excited for her when she first got pregnant, only one has come by to visit during the pregnancy. Most of their old friends left since their priorities started to change with the pregnancy. Only three or four have stayed around. S. tries to find her friends and encourages others to visit her. He believes she'd be mad at him if she knew he did this. $\mathrm{He}$ and his wife don't drink or do drugs so it's hard to find like-minded people to hang out with on weekends.

S. and his wife appreciate the time they can have to be alone and not be talking about bills or worrying about things -- time to "unplug from our world and plug into reality for a bit." He believes that the social isolation he and his wife are experiencing is "not actually that bad of a thing" because it has brought them closer as a couple. They talk to each other instead of their friends. They can't afford to do whatever they want right now, but they "scrape a few bucks off every paycheck" and go out on Friday nights. In addition, each has ways of relieving their tension. His wife relieves her tension by looking at baby clothes and gear. Even though they can't afford it, looking gives them an idea of what they're going to need to afford. S. has several very supportive friends with whom he can spend hours just talking. Sometimes he needs to "get away from it all" and talk with these friends. In addition, he and his wife go out on sunny days and take pictures of each other with a camera that his mother bought him. He thinks this is "kind of conceited," but they're trying to "make the best of what we can." 
S.'s wife tells him that he's "more brawn than brain." He believes that this is true: "I'm the sheer power of the family and she's kind of the mind." He has made some crude jokes during the pregnancy which have caused his wife to make him sleep on the sofa or in the car. He feels that she's lost some of her sense of humor. But it's also hard for him to admit it when he's wrong.

Both S.'s family and his wife's family have been very supportive of their decision. His family knows that having a child is going to be hard on him and his wife. His boss knows that he will come into work tired some mornings because of the new baby. His cousins have offered to baby-sit. His brother teases his wife about the fact that she's having his child but it's in good fun. He is happy about how supportive his family has been of the pregnancy. Although he still doesn't know his wife's family well, "they've all been really good about it." although he doesn't feel comfortable talking to his father-inlaw and his mother-in-law "scares him. He gets along better with his wife's sister. He describes his relationships with his father-in-law as being "really hard." One day he's really cool, the next "he's trying to tell me what I can and can't do." He believes that his father-in-law "knows now I have my limitations of what I will and won't do." He believes that his father-in-law is threatened by his wife's biological parents. He told them he would have social workers take the baby away if his wife's real mother was around the baby when it was born. He was extremely angry at this. His family and his wife's family have both been close and supportive. Although he complains about her father. "for the most part he's great." He helped out when he had some difficulty with stolen checks.

The pregnancy has been hard, but all in all S. has "more joys than complaints." He's excited by the changes in his wife's body. He knows that things are going to be changing. One thing that has already changed for him is that his temper has dropped dramatically since his wife got pregnant. Instead of driving "obscenely" now, he's "stopping at yield signs instead of just slowing down." Although he worries that it sounds bad, he has learned to take time and "appreciate not having the baby yet." He sees that he and his wife are "still not harnessed down" and they can go out on a Friday night if they want. He finds that he's "not in as big a rush" since the pregnancy: "this pregnancy thing is going by so fast." 


\section{Dylan - Level 4}

S.'s decision to have a child is intimately connected to his own childhood experience. The death of his father and the neglect he received from his mother created in him a desire to make things right for a child of his own and to be present in his own child's life. This wish rose and diminished in strength but it was always there in some form. S. feels uneasy about whether this desire to create a corrective experience is an appropriate reason for having a child. He wonders if it is perhaps "selfish" or "sick" on his part. This has made the decision a difficult process for him. He vacillated between enthusiasm and doubt, worrying that he wasn't old enough to take on the responsibilities of fatherhood and that he wasn't emotionally strong enough to handle the role.

In managing his doubts, $\mathrm{S}$. has relied upon his faith in God. Although he has done a great deal of thinking and planning and worrying about the arrival of this child, he places his faith in God above all of this. In this sense, he sees the decision to have a child as something which is outside of his own control. In many ways this is a comfort -- the idea that God is watching over the larger picture eases his mind when he has doubts -- but at times he questions whether God knows what He's doing. He looks to particular signs as evidence that God does in fact know what He's doing.

As he has gone through the process of deciding to have a child. S. has been powerfully affected by what others have told him about becoming a parent. This has been both a positive and a negative influence on him. Some have encouraged him to have a child and others have warned him against it. The most important conversations he had were with other women about their experience of making the decision. The advice they gave was that he should follow his own heart rather than worrying about what others thought. They also suggested to him that even if having a child damaged his marriage, he would not regret the decision.

Through these conversations. S. reached a point at which he could put aside his concerns about what other people thought and make the decision for himself. He recognized that if he didn't decide to have a child now he would go through his life wondering whether he should have done it. He did not want to feel this regret. It was at this point that he was able to go ahead and make the decision to have a child.

In making this decision, S. experienced -- and continues to experience -- many worries. He struggles to understand whether his worries are normal and appropriate for someone in his position, but he knows no other men with whom he can compare himself. $\mathrm{S}$. attaches a great deal of importance to his ability to protect and provide for his wife and future child. He worries about his ability to provide financially for his family and about the safety of their vehicles and other mechanical objects. Taking care of these things gives him a greater sense of security. But his biggest worries center around his ability to adjust to and manage the changes in his life that he knows are coming. He worries about his ability to adapt to the needs of an infant regarding such issues as sleep, scheduling and discipline. He worries about the difficulty he has had in the past managing his anger. He worries that he will get too angry with his child. But he has done a lot of work to get 
his anger under control and has seen a dramatic change in his behavior. This has made more him optimistic generally about his ability to adapt to the changes that are coming.

S. worries that the new child will jeopardize his marriage. He has observed in the marriages of his siblings how the arrival of a child can harm a relationship. But he has also seen how having a child can change a person in positive ways. how it can make a person feel more complete. He believes that having a child either brings a couple closer together or it breaks them apart. He places his faith in God that that his marriage will be the type that comes closer together, but he's not certain that this will be true. He would not have consciously sacrificed his relationship with his wife in order to have a child. but at the same time he sees his role as father as one that will continue regardless of what happens in the marriage. He believes that a father should always be an active presence in his child's life. He is committed to making sure this happens for his own child. It would be a devastating experience for him if a child of his ever came to consider another man its father.

S. and his wife surprised and scared themselves by realizing that they were both serious about having a child together earlier than they had originally planned. S. believes that his wife's motivation for having a child was similar to his own: she was very influenced by the difficulties of her own difficult childhood and her evolving relationship with her family. They discussed the practicalities of the decision in great detail, not just in terms of finances and living space and their beliefs about child-rearing, but also in terms of how having a child would affect their individual plans for the future. In order to make the decision, they went through a structured process of identifying the advantages and disadvantages of having a child. The results of this process helped them both realize that this was what they wanted to do, but in the end they put the question in the hands of God. He would ultimately decide whether or not they were meant to have children. A failure to conceive or a miscarriage might be a sign that they were not meant to have a child.

While the process of conceiving threatened to be quite difficult because of medical complications, it turned out to be surprisingly simple and quick. Within a month of going off of birth control, S.'s wife was pregnant. S. believes that the fact of the pregnancy itself is a miracle. While he was very excited by the realization that he could truly become a father, he has found it difficult to believe that his wife is truly pregnant. He has doubted the evidence confirming the pregnancy. But changes in his wife's behavior and tastes have been a strong confirmation for him that the pregnancy is real.

S. has great faith in his wife's abilities as a mother, but he also worries about her well-being. He is interested in and excited by the changes in her body as the pregnancy has progressed. But his somewhat insensitive comments about this have sometimes caused strain in the marriage. In fact, the pregnancy as a whole has a made things more difficult between him and his wife. While both their families have been generally supportive of their decision, S.'s father-in-law has been intrusive with his attitudes about the child which has made him angry. In addition, they have lost friends and this has made things difficult, especially on his wife, who has been kept at home because of 
medical complications. As a result, they have both been rather isolated and that has been a strain. But $\mathrm{S}$. also sees some benefits in this isolation. He believes that it is bringing them closer as a couple. They find inexpensive ways to manage their tension and to take care of themselves and to enjoy each other's company

At this point, S. realizes that there's no turning back. His life is changing so fast that he wishes he could slow it down a little and appreciate the time he has left before the responsibilities of parenthood arrive. Although he has many worries, his joy is stronger than his doubts. He finds that his original motivations for having a child have expanded since the pregnancy. While he originally pictured his role as a father primarily in terms of providing for and protecting his family, he is now beginning to experience something which is harder to define, a deep pleasure in the anticipation of the birth of his child. 
Appendix C

Nathan: Data Analysis

Levels $1-4$

Reproduced with permission of the copyright owner. Further reproduction prohibited without permission. 


\section{Nathan - Levels 1-2}

So...I know that you've decided to have your first child recently. And what I would like to know about is your experience of making the decision to have that child.

/The process of how my wife and I determined we would have another child...or have a child...

Or how you...

Or how I felt personally.

You personally, right.

Well...last May...March, before March, February...I met my wife. Who already had two children of her own. /And we are in the same religion, /so we talked. We got so we really enjoyed being with each other, so we started, so we talked about families and how if we got married, would we have children or not? /Because she had children already, so it was not necessary that we really have more children unless we really felt we wanted to.

2. S. and his wife are in the same religion.

3. When S. and his wife met and started talking, they found that they really enjoyed one another. They discussed whether or not the would have children if they got married.

4. Because S.'s wife already had children, "it was not necessary that we really have more children unless we really felt we wanted to."

\section{Right, so it was a real choice.}

/So when, during the conversation she mentioned that she had had the feeling that she was going to have a daughter.

5. S.'s wife already has two boys of her own. She told S. that she felt she was going to have a daughter.

\section{She has boys.}

She has two boys, and she had a feeling that there was a daughter waiting to be born to her family. /And so we were, you know, we just, things

6. The relationship between $\mathrm{S}$. and his wife progressed and they got married. 
progressed and we did get married. /And after we got married, um, we decided initially that we weren't, that we would probably hold off a year before even thinking about having a child. /Because we wanted the relationship between the two of us to be fairly strong as a unit before we thew in another, another cog in the wheel. /But as I prayed about it, and as I had the feeling internally that it, whether, you know the proper thing to do was to have another baby now as opposed to wait. /And I kept thinking, you know. I want to hold off on this thing here. So I did, I prayed about it several times, I said "now are You sure about this?" /because I, I, you know, am willing to do what I need to do, /because that's a big, big jump to go from a single guy, never been much around kids, to having three kids under five. Now I've got two kids under four, but at the time, they were four and under I figured with Emily why it's going to be three kids under five. Four and a half and down.

\section{Right.}

/So - and I wasn't sure that my nerves were up to it. But... after praying with some consideration and thought, the feeling came that it's, no it's time. /And so I asked Kathleen, I said, I have this feeling that we really shouldn't be wasting, going a whole year before we have a child. And she looked at me and said, you know, I've been having the same feeling but I didn't want to tell you that.

Hm.

/So then we both prayed about it and had the same experience, that it was
7. After they got married. S. and his wife first decided that they would wait a year before "even thinking about having a child."

8. S. and his wife wanted to make sure that their relationship was strong enough before they threw "another cog in the wheel" by having a child.

9. S. prayed about having a child and had a feeling inside that "the proper thing to do was to have another baby now as opposed to wait."

10. Because S. had wanted to hold off on having a child for awhile. he kept praying and asking God if $\mathrm{He}$ was sure.

11. S. was willing to do what he felt God wanted him to do.

12. S. recognizes that it is a big jump in his life going from being a single man with little exposure to children to having three children under age five.

13. S. was uncertain whether he was up to the burden of this extra child. but prayer confirmed his feeling that it was time.

14. S. went to his wife and told her his feeling that they should have a child together immediately rather than waiting. She told him that she had been having the same feeling.

15. S. and his wife prayed together about the decision to have a child and they both felt that it was time. 
time and that things would work out, we just didn't know how.

\section{Right.}

/And things have worked out and so the fact of the matter is that the decision. um, the decision wasn't that difficult...based on the religious perspective.../that we knew that we were going to have a child, it was just a matter of timing. /And then when we were, when we had the...answer, that basically... well then I have the answer from my side that said, "you know it's time, I know you don't feel like you're ready for it yet, but it's time." And so I, I kind of...started there. /So it was all completely planned, from beginning to end.

\section{Right. Prayer was really, it sounds like, a major part of the decision.}

\begin{abstract}
/A big aspect of it, yeah. Frankly, if spiritually it's not right, it's not right. /You know, there's no point in having the hormonal strain of a pregnancy if it's an unwanted circumstance. Now, when I say that I'm not advocating abortion whatsoever, in any way shape or form. But I'm just saying that abstinence is the key. I mean if having children isn't what you plan to do, then your actions need to reflect that, you know. And that's how, that's how we looked at it. /And frankly it, uh, from the timing aspect, we planned on having a child at the beginning of the summer, so that Kathleen could take her finals and get them done and then have the child and go from there.
\end{abstract}

\section{Right. So that worked out.}

They believed that things would work out. although they didn't know how.

16. S. feels that "based on the religious perspective," the decision to have a child "wasn't that difficult."

17. S. and his wife knew they were going to have a child, "it was just a matter of timing."

18. S. had his answer from God regarding the decision to have a child: "I know you don't feel like you're ready for it yet. but it's time."

19. The child was planned, "from beginning to end."

20. Prayer was a big part of the decision process for S.: "if spiritually it's not right, it's not right."

21. S. wouldn't choose to go through the strain of a pregnancy if it were "an unwanted circumstance." $\mathrm{He}$ doesn't believe in abortion but does believe that if a person doesn't want children they should abstain from sexual relations.

22. S. is happy at how the timing of the pregnancy has worked out. 
/Just peachy, except that we had preterm labor.

Oh, gosh.

Which put her on bed rest. Which scared me to death. My first opportunity to enjoy a pregnancy, the hormones and everything. but then plus I have the other situation. /It's been very scary throughout the pregnancy because each of the changes have been things that I wasn't really prepared for. But I...I've found it fascinating. /It is helpful, you know, that there's spiritual backing.

Um-hm. What do you mean by that?

By spiritual backing?

\section{Yeah.}

I have a belief in my Heavenly Father. I have faith that he's not steering me in the wrong direction. /And so therefore, when I make that decision I make it with the full knowledge that it's the right decision. And that it's something that we'll work out in a positive way, that the child will be okay. /that all of those things that you worry about. that families find to worry about in that time, have not been a particular worry to me, because even if the child were to have a medical deficiency problem, I would know that things will still work out.

\section{Okay.}

/And there's never been and never will be a question of abortion.

\section{Right, Right.}

23. S.'s wife has had pre-term labor which put her on bed-rest and scared S.

24. S. has found the pregnancy to be "very scary" but also fascinating.

25. S. has a belief and a faith in God that $\mathrm{He}$ is not "steering me in the wrong direction." This "spiritual backing" is helpful to him.

26. S.'s faith in God allowed him to make the decision to have a child "with the full knowledge that it's the right decision." He believes that it will work out positively and that the child will be okay.

27. The usual things that families worry about regarding the decision to have a child have not been a particularly big concern to $\mathrm{S}$. because of his faith in God. Even if the child had "a medical deficiency problem." he knows things will work out.

28. S. would never consider abortion. 
That's kind of, to me, that's the key. If you get married and plan to have a family, that you need to focus on the family. /And... learning how to support my wife emotionally has been an interesting experience through the forty weeks. /Because not having been around people who were pregnant very much. there's just a lot of things that I didn't know [laughs]. And so the stress factors involved. for me, were pretty high. And I'm sure they were pretty high for her, based on hormones. /But for me, liking to be able to plan things and be pretty systematic in the approach, it's been quite a change in my life.

\section{Less ability to plan things.}

/Yeah. Well you have two little boys are mixed into the weave, woven into the. into the... if you will, into the blanket. And they have a way of changing your plans for you. I mean, you have everything all planned and they get an ear infection and they're not feeling well, or they start throwing up while you're going down the highway, and you've got something you've had planned for weeks. but you turn around and bring them home, because you want to keep them near some kind of medical care that will be sufficient to treat them if they need the treatment. These are things that I have learned over the first year of our marriage.

So that um, that process of praying about it and coming to the decision, it sounds like that was, doing that you kind of over came some of, some of your own concerns.
29. S. believes that if you get married and plan on having a family, that the key to success is to focus on the family.

30. For S., learning how to support his wife emotionally through the pregnancy has been "an interesting experience."

31. Because $S$. doesn't have much experience with pregnant people, the stress factor is pretty high for him.

32. The pregnancy has been a big change in S.'s life. Ordinarily he likes to be able to plan things in a systematic way.

33. S.'s experience with his two stepsons has been one which has taught him that he has to be more flexible in his plans with them than he would be on his own. For instance, medical decisions that he might take lightly for himself he has to take seriously for them, even if it means an abrupt change in plans.

/Sure, sure. 


\section{And I wonder if you could tell me about that.}

Frankly I've been saying that my main concerns were...

\section{[Interrupted by phone]}

\begin{abstract}
All right, so I was asking
about...through the process of

prayer...
\end{abstract}

What my concerns were.

Yeah, what were those concerns and...

One of the big concerns that I had was, as I moved. I'd just moved over here. So I wasn't very stable in employment. /And to me, being able to be financially responsible is a big issue where families are concerned. And I wanted to feel comfortable in my job, I wanted to know that financially I'd be able to take care of my family and meet the needs of my family. And the first job that I got wasn't, it didn't turn out that way, and I left them. So there I was - whoa, this is scary. [laughs]

\section{Right, right.}

That's real scary. /And right at that time was when we made the decision. So you know I was right there in the middle of that. /And that was why I spent a little bit of extra time praying about this decision, because...it took a bit of a leap of faith.

\section{Right.}

To say okay, You're telling me that it's the right thing to do, /I need a confirmation of this, it would help to
34. One of S.'s main concerns in making the decision to have a child was the stability of his employment. especially because he had just moved to this area.
35. $\mathrm{S}$. is very concerned with taking financial responsibility for his family. Taking care of his family in this regard is important to him. Because of this it was a scary experience when he had to leave the first job that he had in this area.
36. S. and his wife made the decision to have a child at a time when $S$. was in the middle of changing jobs.

37. Because of his employment situation, S. took extra time praying about the decision. He felt that God was telling him that it was the right thing to do, but still "it took a bit of a leap of faith."

38. S. needed a confirmation from God regarding his decision. He received an internal confirmation. 
have a burning bush or something really great, you know. But at least an internal confirmation. And that's what I received. /And the other thing that I really addressed was... would I be a good father?

\section{Right. What was that to you, what did that mean?}

/To me. to be able to meet the emotional needs of all of my children. of both the two step- my two step-sons, and my daughter to be, that's going to be born. /Would I be able to adjust sufficiently to this whole change in mental perspective? /Would I be able to get past this workaholic syndrome? And that's been perhaps the biggest issues. That was one of the bigger reasons why I left my last job was because I was away from my family all of the time. From Monday through Friday I was on the road. /And that's just not a way to raise. I mean when you have little boys that need to see daddy, they need to have him there to play with him and get down on the carpet with them and roll around. you know, just do all of those things that you need to do to build a trust and the respect in the child, that they know that you care about them. /And maybe even more so then. to be able to demonstrate the love and the cherishing that you should do as a parent. From my perspective you should, you know, these are things that over the years as I've grown up I've kind of felt...there are a lot of keys to being a parent and one of them is paying attention to your children. /And giving them a feeling of...stability. So that they know that there's a solid base there and that the love is never in question. Their behavior might be, but your love for them is never. /And it's hard, and it has been hard for me to do. Because
39. S. wondered whether he would be a good father.

40. For S.. being a good father means meeting the emotional needs of his children.

41. S. wondered if he would be able to "adjust sufficiently to this whole change in mental perspective."

42. S. wondered whether he could "get past this workaholic syndrome." He left his last job because it required him to be away from his family too much.

43. S. believes that it is important that a father is present in his children's lives, doing the things that "build a trust and the respect in the child that they know you care about them."

44. S. believes that the key to being a parent is paying attention to your children, being able "to demonstrate the love and the cherishing that you should do as a parent."

45. S. believes that parents should give their children a solid base, a feeling of stability and the knowledge that "the love is never in question" even if their behavior is a problem.

46. Because of S.'s many years of military training and service, he is 
I have had a lot of military training, I'd been in the military for twenty years almost, about fifteen, fifteen going on sixteen. And not around children very much. So my commanding groups, telling them to do things, not expecting anyone to ask questions about what they're doing. You say do this, they do this. They've got a question, they come back later, after the job is done. Unless it's an illegal order. which I don't do. /So that's the thing, when you have that background then you go to a little two and a half to three year old, and you tell them to do something, your first instinct is that child does it now. Their first instinct is... [lets eyes wander around the room]. You know? And rather than respond in anger, which is very easy to do, it's taken me a while to learn how to soften my response, saying "son, you have to do this, it's a non-negotiable. [laughs] You will do it." And whereas, in the military I would not give that long of an explanation.

So some of the question is, for you is, how, can you really overcome what you've learned to do....

/Can I overcome the, the uh, trained response. and be the father. Instead of the commander, be the father. And that has been the big area of debate in my heart when I made the decision. /You know, these are areas I know I'm weak in, that I have real problems emotionally. And then I, it creates emotional stress to me when I tell a child to do something and they don't do it.

\section{Right.}

/Well, to a mom, that's not emotional stress, that's just normal every accustomed to a style of giving orders and having them obeyed without question.

47. Because of S.'s military background he is having to adjust to a different way of communicating his requests to young children, to soften his response when they don't comply immediately, not to respond with anger.

48. As he was making the decision to have a child, a big area of debate in S.'s heart was whether he could overcome his military training, "instead of the commander, be the father."

49. It is emotionally stressful for $\mathrm{S}$. when he tells a child to do something and the child doesn't respond. He sees this as an area of weakness in himself.

50. S. believes that women don't experience the same degree of emotional stress that he does when children are disobedient. 
day. They laugh. In my world it created a lot of stress. /And so I've been learning to deal with it. It's good for me, but it isn't easy to deal with. And that's the transition that I had. Now in a few days, or weeks, depending on how it works out, I'm going to be in an even bigger transition, dealing with this little infant that doesn't understand English. that has needs that I don't necessarily understand.

\section{Right.}

/And that was the other thing that I prayed about. As I was working with this young infant, that I would be able to treat her the way that she needs to be treated, to have her happy and be delighted to be here in my family, as part of my family. And that is - you know, those are the types of questions that I had.

What was your concern with that, that sort of being able to treat a young infant as she needed to be treated.

/I felt with the youngest boy, he doesn't speak very well. And I found that communication was extremely difficult understanding what he wants and needs and him understanding what I want him to do. And that created a great deal...[laughs]... of stress. Partially because I couldn't be there around him a lot because of all the travel. And I was trying to learn his language....in just little pieces, over a month, you know. And I was feeling frustrated with that and $/ \mathrm{I}$ was concerned that having a little baby girl, I was going to be in worse shape.

\section{Right.}

51. S. has been learning to deal with his emotional stress over his children's disobedience. Although he feels that it's is good for him to learn how to do this. it's a difficult transition.

52. S. knows that he will soon face a big transition with the birth of his daughter. He envisions her as an infant who wants to be able to communicate, but whose needs he won't necessarily understand.

53. S. prayed that he will be able to treat his new daughter appropriately, that she will be happy and take pleasure in being part of his family.

54. S. has difficulty communicating with his youngest step-son. This creates a lot of stress for $\mathrm{S}$. He was frustrated at not being around enough so that they could each learn to understand each other.

55. S. worried that his new daughter would aggravate the communication problems he is already experiencing with his step-son. 
Yeah. So these were my concerns.

So you, yeah, these concerns about sort of yourself and your own life and you're praying about this and trying to make the decision. Was there a moment, can you describe kind of how that turning happened? Or maybe there wasn't a moment, I don't mean to suggest that there was.

/Yes there was. There was a moment. And I'm going to give a. try and be as clear as possible. I felt inside that it was something I needed to talk with Kathleen about. And say honey, this is how I've been feeling, what do you think? And she said she felt the same way. /And I said well then I suspect that we ve both got to pray about it. Let's get down together and address this seriously, and let it go at that. So - and act upon which ever way we feel at the end of the prayer, however we are impressed at that point, that's going to be our deciding point. /And so we did. We knelt down and spent, oh, I think it was about fortyfive minutes to an hour, just asking Heavenly Father to help us to know if this was the direction we were supposed to go. And what we thought we were supposed to be doing and we wanted to know, of a certainty. /And we both got confirmation at that time of warmth and peace and solitude of spirit, that this is where you are and you're supposed to be doing this. And at that point, we knew then that we were going to have a child now as opposed to a year from now.

So this was a confirming, solid feeling, peaceful feeling it sounds like.

56. When S. spoke with his wife about his feeling that they should have children sooner rather than later, she said that she had been feeling the same way.

57. S. and his wife decided that they would pray together about the decision to have a child and that however they felt at the end of the prayer would decide what they would do.

58. S. and his wife prayed together about whether they should have a child, asking God "if this was the direction we were supposed to go."

59. When they prayed about the decision, both S. and his wife got a "confirmation," a feeling of "warmth and peace and solitude of spirit" about having a child. 
That's right. We acknowledged that it was the right thing to do at the right time. And that we would make it through, there would be trials but we would do fine. We would make it through. /And even with problems between the two of us - because that was an issue - we' $\mathrm{d}$ only been married a few months then. That we knew that the hormonal situation was going to affect the emotional relationship between the two of us. That all of those questions, everything would work out. /He didn't tell us all of the answers. We've had to work through some of them - some of them aren't worked through yet, you know. And so it's an ongoing thing. We're. uh, we are facing each day as it comes. /But we have the peace and solitude of spirit to know that it's going to work out fine.

\section{Right.}

/Sometimes we have moments of sheer panic. And I have moments of sheer terror. Because I...just tell myself that oh. my, what have I gotten into?

\section{Uh-huh.}

/And I have never felt at any time, since making the decision. that it was the wrong decision as far as having a child was concerned.

\section{Right.}

/I have occasionally had a certain amount of doubt in my ability to survive through the pregnancy. [laughs]

\section{I understand.}

So that's about as... what other issues, am I leaving some things out that
60. When they received a confirmation to their prayer. S. and his wife "acknowledged that it was the right thing to do at the right time." They knew that even though there would be trials, they would make it through.

61. At the point of deciding to have a child. S. and his wife had only been married a few months. They knew that a pregnancy would increase the emotional problems between them. but they had a faith that everything would work out.

62. Although $\mathrm{S}$. feels that God gave him and his wife a confirmation regarding his decision to have a child. "He didn't tell us all of the answers." They continue to have to work through problems on their own.

63. S. and his wife have "peace and solitude of spirit" about the decision. They know things will work out.

64. At times both $\mathrm{S}$. and his wife have moments of "sheer panic" and "sheer terror." At times he wonders "what have I gotten into?"

65. S. has never felt that he made the wrong decision regarding having a child.

66. S. has had some doubts about his ability to survive the pregnancy. 
you particularly wanted to point at?

I don't think so, you know, I don't even know, I'm not looking for anything specific.

I'm trying to very candid about how I approach everything, so...

Yeah, you are being very much so and I appreciate that. It sounds like - I'm interested in that, even after you've got that sort of confirmation for yourself, you still have kind of a...the doubts are kind of still there.

The moments of sheer terror?

Yeah

Yeah, the doubt is part of having a child.

\section{Right, right.}

What the doubt is, is the emotional, the emotional relationship. /Remember I mentioned that I was concerned at how I was going to work in here and be able to handle all of that and Heavenly Father kind of assured me that it would work out.

\section{Right.}

But He didn't tell me the whole key to how I was going to make it work. So I'm working though that, /so I have moments of wondering, have I done... what do I need to do here to straighten things, make things better, or help things work. /And I think part of it, my problem is, is I'm used to being in control.
67. The doubt and "sheer terror" that $S$. experiences regarding the decision have to do with his emotional relationship with his new child.
68. When he prayed about having a child, $S$. received a confirmation regarding his worries over "how I was going to work in here and be able to handle all of that." But while God assured him that things would work out, "He didn't tell me the whole key to how I was going to make it work." S. has to work this out on his own.

69. S. wonders whether he's done all he needs to do "to straighten things, make things better, or help things work."

70. S. is used to being in control. It's difficult for him not to be in control with the pregnancy.

\section{Okay.}


Of the circumstances. $/$ d don' $t$ know if you know this or not, but when your wife is pregnant, the individual that's in control is that little baby. So she's in control. /And I love her to pieces. But I don't want her in control. I want to be able to say, okay Emily, we're going to schedule the birth, it's going to be at four p.m., tomorrow. /And so those are the emotional things that I'm dealing with. And they're completely unrealistic and they're completely unreasonable if you look at it analytically. When I look at it from a full spectrum of being emotional...see, so I understand those things. They're there, and you just deal with it as they come. /And you recognize that nobody, nobody starts out being a perfect father. Or a perfect parent. It's - and if you think it should be that way before you got married and before you had a child. you would never get married and you would never have a child. Because there is no, I don't care how many years of college or how long you went to study at being a parent, you will learn to be a parent one day at a time, with the child under your responsibility. /And I am learning slowly, sometimes I think way too slowly, for somebody with my business acumen and my ability to learn, I'm just amazed at how slow I learn how to be a parent.

\section{It's a different kind of domain.}

It is. Well, you don't own it. [laughs]

\section{Right, you're not in control of it.}

That's right, you don't have total control, you have to deal with a lot of variables that you don't have any control over. And that is my weakness, my area
71. S. believes that when a man's wife is pregnant it is the child who is in control of the situation.

72. S. loves his child, but he doesn't want her to have so much control. He wishes he could plan the birth according to his own schedule.

73. S. understands that his desire to have more control over his daughter is unrealistic. He knows that this is something he will simply have to deal with.

74. S. recognizes that nobody starts out as a perfect father or a perfect parent. He believes that it's something you learn from experience, one day at a time and that if you thought about it that way you would never marry and have children.

75. S. feels that he is learning slowly how to be a father. He wishes that it wasn't such a slow process, since he knows he has good business acumen and an ability to learn.

76. S. sees that in parenting there are a lot of things that you don't have control over. He sees his difficulty dealing with a lack of control as a weakness in himself which he is trying to face directly. 
of weakness and I've tried very hard to face it front on, to recognize I'm weak in the area and subject myself to it. /And my wife's there to help counsel me after the fact. She's very good, she doesn't criticize me for what I do as far as, in fact she supports me in decisions we make with the children. And sometimes at night we'll have really long discussions over...she didn't like necessarily the way that I disciplined the child. Now, we don't spank the children at all. We don't do physical punishment. But I sometimes use more of a military approach and she uses a little gentler approach. And sometimes I'm. I respond a lot rougher to action or inaction - I count them both the same than she would have. /And so when she talks about. she says ['m not sure it's necessarily wrong. but we do need to talk about these things so that we don't get at cross purposes. /And so it has been a very growing experience. This last year has been...one of the haircurlers par excellence. I mean, being newlywed and also expecting.

\section{A big change.}

Right, at my age. [laughs]

Okay, so I have a pretty good understanding of the, where you were with that after you made the decision, you had those - let me see if I've got it right anyway - you had those kind of moments of panic but you were able to get through them. So you had that kind of faith that, "I know this is going to be okay."

/Sure, it's just like, it can either be a stumbling block or a stepping stone, and I'm looking at it as a stepping stone.
77. S.'s wife counsels with him about his parenting decisions. They discuss the way he disciplines the children. She supports him and doesn't criticize.

78. Although $\mathrm{S}$. and his wife don't use physical punishment on her children, he tends to take a rougher, more militaristic response to action or inaction on their part.

79. S.'s wife thinks that they need to talk about discipline so that they don ' $t$ ' get "at cross purposes."

80. Being a newlywed and also expecting a child has made the past year in S.'s life a "hair curler." It's been "a very growing experience." 
It's just that sometimes the surface of the stone's a bit rough.

\section{Right.}

You might bang your shins a little bit. roughen your knees, get a bloody nose once in awhile, but you know, it's all survivable.

Right.

/And not take yourself too seriously. ['m trying to learn. [laughs]

82. S. is trying to learn not to take himself too seriously.

So, a lot of changes that you're making. And I'm interested in knowing...the decision to have a child happened in this relationship, but where were you on it before? Did you always think you were going to have children?

/Oh, before I, before I got married, I kind of knew I was going to raise children. I didn't know whether I would actually have any naturally born to me, because I was getting a little older in life. /But I kind of felt that it was a trial that I needed to go through. You know. it was something I needed to learn how to do, how to be around little ones. /I tried to teach little ones at one time several years ago and I found that it was very stressful for me. I had difficulties speaking at their level, communicating with them. /So I kind of had a, I had a hunch that it was in my future. That I was going to have a family and was going to have to learn how to put away all of this education. put away all of those big words and learn to seek and listen to those two and, you know, one and above, and get my point across without being overly frustrated. I'm

83. Before he got married, S. "kind of knew" he was going to have children, although he didn't know if he would have any that were naturally born to him.

84. S. felt that having children was "a trial that I needed to go through." He felt he needed to learn "to be around little ones."

85. S. has found the experience of trying to teach young children a stressful one. He found it difficult to communicate on their level.

86. Because of the difficulty and stress he experienced trying to communicate with young children, S. "had a hunch" that having children was in his future. He thought that he needed to learn to communicate on a child's level without being too frustrated. He feels he's better at this than he used to be, but he still has a ways to go. 
doing better now than I was a year ago.

But I've got a ways to go.

That's interesting, it sounds like that difficulty, is that right, that that difficulty in doing that actually made you feel like that was something you needed to learn to do?

/Yes. That it was a challenge. That it was something that I had to face, something that I had to recognize and be willing to recognize my own weakness there. So it could become a strong point. /You know, one of the things that I have discovered through life is you can't allow the difficulty of the past to be the determining factor as to whether you do something or not.

\section{Okay.}

/You have to recognize the goal that you're aiming at. And if you're aiming at becoming a better person. becoming a husband, a father, then there are certain things, a type of goal that you need to make is...it may be a long ways down the road, but the steps to get there start today. And that has been, and that's where it's at. The other thing was, I wanted to be young enough to still enjoy my children when they graduated high school. And I'm forty years old now and it's going to be eighteen years, it's going to be when I'm 58 . Well at $58 \mathrm{I}$ can probably bounce a basketball and maybe play a little bit of ball with my son. But he'll be - with both of them but they'll be able to run rings around me. I mean I'll be, I might be able to do a rebound or two because I think my two boys, at least Matt and Jake will be shorter than me. So I'll just hold them off.
87. An aspect of the decision to have a child for $\mathrm{S}$. was that he thought it was important to face his weakness and make it into a strong point.

88. S. believes that "you can't allow the difficulty of the past to be the determining factor as to whether you do something or not."

89. S. believes that if his goal is to become "a better person, becoming a husband, father," that he needs to take the steps necessary to get there in the present.

90. S. is concerned about how his present age will affect his relationships with his children as they grow older. He thinks ahead to what his step-sons' physique and temperament will be as teenagers. He expects that their parents' physique and temperament will show up in the children. He imagines how he will interact with them when they play sports together. He looks for ways in which he'll be able to counteract the effects of his age. 


\section{There you go.}

And they'll have to jump six inches before they can get to it. And if I jump two inches then they've got to jump eight, see. So I'll have a chance to. that'll maybe even it out just a little bit. Because their father was short of stature and their grandparents were and so on and so on. So I think I've got a good chance that they'll be five foot six or five foot eight. And my wife is fairly short. /But my daughter's going to be another problem. She's going to be my daughter, she will probably be taller than her mother. And when she goes out there to play basketball I'm going to be older yet. And she'll be just as homery as can be, and I know these things. /And she'll be a delight. As are the other, the two boys. II mean you, you revel in the miracle of how children make you grow. You kind of, it has been a great experience to go into this learning how to be a father with my two step-sons. /And then having our first child together, the dynamics of communication and how things happen between the boys and my wife and the boys and our infant to be and the boys and myself. When they feel that I have equal love for them as I do for my wife and the baby on the way, they are...that's their sister. /And they already talk to her, when mommy's there. They say hi, hi Emily. And that has been very eye-opening to me. It's very humbling too, because it's their acceptance. They didn't have any choice in the matter.

\section{Right, it wasn't their decision.}

That's right. And yet they are wholeheartedly, they're already getting their toys ready for their baby sister that's going to be coming. /In fact, they chose
91. S. looks ahead to imagine playing sports with his daughter. He imagines that she will grow to be quite tall and that she'll be "as hornery as can be."

92. S. says that his step-sons are a delight and his daughter will be too.

93. S. revels in "the miracle of how children make you grow." He values the experience he's had "learning to be a father" with his two step-sons.

94. S. thinks ahead to how the dynamics of communication in the family will change with the arrival of his daughter. He hopes his step-sons will feel that he has as much love for them as he does for his wife and daughter.

95. S. has been very moved by the ways his step-sons have whole-heartedly accepted their new sister, since "they didn't have any choice in the matter." This has been humbling and eye-opening to $S$.

96. S.'s step-sons wanted to have a sister. 
to have a baby sister. They wanted to have a baby sister. When they knew mommy was pregnant. they said, we want a little baby girl. So they got it. /I, of course, suggested that we ought to have a boy. [laughs] I said well, if we're going to choose, why don't we start with a boy. Knowing that we were eventually going to have a girl, I just thought well it would be fun this time to have a little boy. I'm just as delighted to have a little girl. It is fun. It's scary. you always the worry about hospita! bills, all those things. But I know it'll work out.

So yeah, you really, you've spent some real energy imagining into the future with this family and that's a part of it for you.

/Well, you have to. If you don't have a goal, you're not going to get that.

How is - you've been talking about the experience with the two step children, did that play any role, your experience with them before you decided to have the child, your own child with your wife?

/ff anything it made it harder to make the decision to have another child. Because initially it was a change in their life, a different man living with mommy, and they weren't sure that they wanted me. And so emotionally, they weren't willing to have me in their circle. They wanted it to be just mommy. This other guy, he's only here for a short time, we can get rid of him eventually, he'll go. So that made it tough. That part made it tough. So yeah, it played a role, but it was a role to the adverse, not a role to the pro.
97. S. hoped to have a boy, "knowing that we were eventually going to have a girl." But he's "delighted to have a little girl."

98. The experience of having a child is both fun and scary for S. He worries about hospital bills but he knows things will work out.

99. S. believes in the importance of having goals and looking forward to the future.
100. The fact that his wife already had two children made it harder for him to make the decision. When he first entered their life they weren't accepting of him and thought that they could get rid of him. 
So yeah, it was even more to overcome in terms of making the decision.

/And they are terrifically well-behaved boys. But it was just that change in their lives that was making it really rough on them. IAnd I - intellectually, you know that, but I'll tell you what, emotionally, even as an adult, you're wondering if you want to deal with it. You're saying, do I want to go through having another child and dealing with these two? And that was part of it. /Like I said, it took me awhile before I went to my wife and said honey, I've got this feeling that we ought to go ahead and have a child now... and I don't know why. [laughs]

And I don't know why.

Yeah, I don't know why. You know. and that's the thing, you know that that...that was in there, that was part of it.

As you say that, I'm thinking about your own individual process as you're praying alone. It sounds like there's kind of, you might have, you know you had your concerns and this concern that you're just talking about. I wonder if you could describe that for me more, as you had this affirming feeling....

/How did I, how did I... get to the point... how did I ask about this relationship with my stepchildren? I'm not following exactly what you're asking.

Okay. Let me see if I can say it a little better. All of the concerns, the relationship with the stepchildren sounds sort of similar to the concerns
101. S.'s wife's sons are well-behaved boys. but the changes that came with their mother's re-marriage were tough on them.

102. S. understood his step-sons' hesitance to accept him. but it made him wonder if he wanted to deal with having another child at the same time he was having to deal with them.

103. It took S. awhile before he went to his wife and told her about his feeling that they should have a child. He's not sure why this was. although part of the reason was his step-sons' reluctance to accept him.

104. S. describes his conversation with God in prayer over the decision to have a child as one in which he had to "spell out" to God exactly how he felt and also what he thought the answer to his question was. S. has come to follow this process in prayer as a result of coming to accept how "hard-headed" he is. how "difficult to bring about." 
about the finances, about your own emotional changes. As you were - you had those concerns and you were praying about it for yourself, if you coulud describe for me the feelings you got and kind of how that debate played out.

Oh, how the colloquy was with my Father in Heaven...

\section{Exactly.}

...and it brought about the answer.

Yeah, exactly.

I have learned that I'm somewhat hardheaded. And kind of difficult to bring... about, if you will. And so I've come to a point in my life where I've recognized that I need to spell out exactly how I feel to my Father in Heaven. And spell out what I think the answer is.

Okay.

/And nine times out of ten I'm wrong in my answer, because I make the answer based on how I want it to be.

\section{Right, right.}

/So in essence what I did was I brought this out. I explained each of those things, just as I did to you, to my Heavenly Father. And I said look, I don't feel that I am ready right now to have a child because of this this this this this - all of these different things. And so I would prefer that You kind of let me know that it will be all right to wait. /And $\mathrm{He}$ gave me the strongest feeling that I wasn't asking the right way. And
105. Usually the answers that $S$. arrives at to his questions are not the answers that God gives when S. prays about them. S.'s answers are based on how he wanted it to be.

106. In his conversation with God regarding the decision to have a child, S. described his concerns and explained the reasons why he felt he wasn't yet ready to have a child. S. told God that he "would prefer that You kind of let me know that it will be all right to wait."

107. When S. told God that he wanted to wait before having a child, he got a strong feeling that this was the wrong answer. 
it was a feeling kind of like, you know you get, "wrong answer," you know that? Wrong answer. Try again.

\section{Right.}

[laughing] /And so I said, are You suggesting that we go ahead and have a child now, in spite of all of these other feelings I' $m$ having? Is that what You're saying? /And He definitely confirmed. I mean, there was warmth...yes. I mean it was almost like putting a big nineteen by eleven size sign with big letters "YES" on it, you know, to tell me, you got it right. /And I'm saying, are You sure? Always, you reconfirm, you say, uh. this is not the kind of indigestion I like. You know? And you learn - He's always had to do that to me. /Because I almost invariably will choose the opposite of what $\mathrm{He}$ really wants me to do, until He forces me to the point of humbling myself. to be teachable, to do what I need to be doing. /Because like I said, I like to be in control. /And part of the way you grow is to allow somebody else to be in control. To learn how to follow. To learn how to be directed and do so with a happy heart. And I don't know if that answers your question very clearly. but that's kind of how it's been. /It's been a situation of where I've had to give a little bit of control over my response. To not use the same discipline factors that I had when I was a kid. That's the kind of thing that has been going on... all throughout my life, even before I got married. /Each time - things seemed to always happen on a different time frame than the one I had planned. /But before I got married I had a lot more control. A lot more control. I could postpone things. I could think, okay, so I feel
108. S. asked God if He was suggesting that he should have a child in spite of his concerns about doing it so soon.

109. God gave S. a very powerful internal confirmation that he was meant to have a child. It was as clear as a billboard.

110. S. asked for a re-confirmation of God's response that he should have a child. He asked God "are You sure?" He didn't want to have a child if he wasn't certain that this was what he should do.

111. S. will "almost invariable" choose the opposite of what God wants for him. God forces S. to humble himself and make himself teachable.

112. S. likes to be in control.

113. S. believes that the process of personal growth involves letting go of individual control, learning how to follow and doing so happily.

114. S. has experienced this need to let go of personal control throughout his life. It involves letting go of what he knows from childhood.

115. Things have happened for $S$. on a different time frame than the one he planned on.

116. S. had a lot more control in his life before he got married. He could schedule his life the way he pleased. 
really rotten today. I don't want to go to the doctor, anyway. So I wouldn't. /But when the child is not feeling well. you take them to the doctor's office. You don't risk it. And that's the kind of thing.

\section{Okay.}

II'm a very stubborn learner I guess.

So, yeah, that's a good description of that process. And it came to a point where you, it sounds like it was just, you just had to say okay.

/To say it's obvious that this is something I need to do and the trepidation in my personal abilities doesn't detract from the fact that it needs to happen.

\section{Okay.}

/And the recognition that it is not just my abilities that are involved here. That was what, what. I guess you could say swung the deal, was I realized that all of my weaknesses are there yes, but I have the strength of my Heavenly Father and of my wife and her wisdom. And we're a team. All three of us are a team in raising these children. And if we're working together. it's going to work.

\section{Right.}

/And when it doesn't work. I need to again re-look at why it's not working. And nine times out of ten it's because I was thinking me, not us.

\section{Right.}

/If you're being selfish - like I say, I'm a workaholic by nature - so if, I had a
117. S. recognizes that children's schedules take precedence over his own need for control. If they're sick, you take them to the doctor immediately.

118. S. describes himself as "a very stubborn learner."

119. S. reached a point in the decision to have a child where he realized that "it's obvious that this is something I need to do and the trepidation in my personal abilities doesn't detract from the fact that it needs to happen."

120. S. was helped in making the decision by his recognition that he would not be alone in it: "it is not just my abilities that are involved here." His personal weaknesses are counteracted by the strength of God and of his wife's wisdom. He pictures the three of them as a team in raising the children.

121. S. believes that when things aren't working in terms of raising his children, "nine times out of ten it's because I was thinking me, not us."

122. S. has had to change aspects of himself that he considers "selfish" 
great time working for this other company, I was out of town all the time. But my family was going to pieces. Well as soon as I moved to this job, where I'm enjoying my job a great deal, enjoying the people I work with, the people I work for, it's a complete change, a complete...my family sees me every night, the boys are happy, and all the different things that go with it. It's been a fascinating experience. [laughs]

It's bigger than you, it sounds like.

Much bigger than me. Much bigger.

That's the bottom line on it.

\section{[brief interruption]}

So I think the one thing that I'd like to just go back to a little more and ask you about is...have your past feelings about having kids or not, you know, if you could tell me a little bit more about how that developed, even from early on.

When I was a young man, in my early twenties, I thought hey, it might be nice to have a family, to have children. But I really don't want to get married until I turn twenty-six, because I want to be fairly mature and have lived a little bit of life before I get married and have to deal with other people.

\section{Right.}

So...take care of me first. /And I used to think, you know, it would be a lot of fun to have a couple of kids. Show them the - take them out camping and do those things that I enjoyed doing when I was
- like his "workaholic" nature. He left a job which kept him out of town all the time in order to be able to see his family every night. This is a big change for him.

123. S. sees being a parent as something which is "much bigger than me."

124. As a young man, $S$. thought that it would be nice to have children. But he wanted to wait until he'd turned twenty-six to get married. He wanted to live life and to mature, to "take care of me first," before he made the transition to having "to deal with other people."

125. When he used to imagine having children, S. thought about doing the things that he had enjoyed doing when he was young. 
young. /But I was raised in a fairly disciplinarian type family.

Very...physical. Spanking was not unheard of. And it was in an era where it was...the norm. That was how you were raised, I mean, if you misbehaved, your tail got tanned. That was basically the story, and, each time you disobeyed you got tanned with a little more vigor and a little more excitement, to try and encourage you to not disobey. /So, being as rebellious and hard-headed as I am, and was at the time, it, it became a battle between myself and my parents, as to who was going to win this. /And I was just stubborm enough that nobody really won. I mean, it was like a beat me till I'm dead kind of a deal. And finally, what it did was, is escalate my temper. /And it's not my parents fault. It's just society...it's the way that society looked on discipline, of the day. So it was a normal way to discipline children during that era. There were other ways to discipline, but they weren't that - I mean, your parents, they learn how to raise children the same way that they were raised. And that's how my folks were raised so that's how [ was raised.

\section{So your discipline experience growing up, how does that connect to your feeling about having kids yourself?}

/Well, you kind of, you look at how other families are raising their children, you look at how other people are getting divorced. all the different things that enter into that....

\section{[brief interruption]}

So...discipline, growing up, and how that played into your decision and feeling about having kids.
126. S. was raised in a "disciplinarian type family" in which spanking was an ordinary thing. He sees this as normal for the time. Physical punishment was used to "encourage you not to disobey."

127. As a child, S. was "rebellious and hard-headed." He got into power struggles with his parents.

128. Growing up, S. was stubborn enough that he could hold his parents to a draw. His attitude was "beat me till I'm dead." This situation escalated his temper.

129. S. doesn't blame his parents for the physical punishment they used on him. He believes they were just following the "normal way to discipline children during that era."

130. S. looks at how other families are raising their children. He looks at how many people get divorced and thinks about what the cause of that is. 
The desire not to repeat. Not to utilize that method of raising children.

/Recognizing that I'm highly likely to have a child with the same amount of stubbornness that I have. With the hardheadedness. And trying to figure out a more effective means to channel the talents of the child than the one that was used with me.

Right.

/Hopefully to get a better result. I don't think I turned out poorly, but it's just a matter of focusing energies. /nstead of being so combative to rules and regulations. To teach my children how to be aware of the rules, to live within the rules. but don't allow them to be the end all that be's all. You have a fine line there where whatever daddy says is law...but you also have to recognize that there is a court of appeals. You know, that sometimes you can come to daddy and you can say, daddy this is how things are, and I want you to understand the whole scope of things and re-look at your decision. Not say, change it please, but just to re-look at it and recognize that the child has.... different perspective than you do as a parent. And sometimes - not very often - but sometimes the child's perspective is worth....ceding to. /Allowing the child to make a decision that affects a change in your decision. And so they recognize that they have a weight in the decision process. And in so doing they also incur the responsibility of the decision.

\section{Right.}

/It's part of the learning process - a part that wasn't as encouraged in my family as I want to encourage in my current family.
131. S. wishes not to repeat the way he was raised as a child. He doesn't want "to utilize that method of raising children.

132. S. believes that he's "highly likely to have a child with the same amount of stubbornness that I have." He wants "to figure out a more effective means to channel the talents of the child than the one that was used with me."

133. While S. doesn't believe that he turned out poorly, he'd like to focus his energies in raising his children differently, "hopefully to get a better result."

134. S. envisions a different way of disciplining his children than he himself was disciplined. He wants to teach them respect for rules without letting the rules be absolute, to find the "fine line" between parental authority and flexibility. He imagines himself as the judge but acknowledges that there is a court of appeals. He believes that once in a while, "the child's perspective is worth...ceding to."

135. S. wants his children to sometimes be able to influence his decisions, to recognize that they have a say in the decision process and to take on responsibility for the decision.

136. S. wants to encourage a learning process in his children with regard to the process of making decisions. This is something that wasn't encouraged when he was growing up. 
So - you sort of had a feeling but not a certainty that you'd like to have kids after I'm twenty-six. Or that that would be a nice idea....

/Kind of a nice idea, but you know, it's going to have to be the right girl and it's going to have to be perfect before I do this.

\section{How did that evolve. Walk me through that.}

/Oh, I'll tell you what, that's quite a story. I went to Italy for a few years when I was about nineteen - no I was twenty. I'm sorry. I came back when I was twenty-two. I hadn't found any women I was - I mean, some nice women yeah, but I was not interested in making a family with them.

/And... went into the military when I turned twenty-three. And when I turned twenty-three I found out that I had a lot of growth yet to do. you know. That there was just a little bit of maturing that I had room to do. There was just delays there. /So when I went over to Europe, Germany to start with. I started meeting people and looking at them in a different light. Looking at them from the aspect of. as a spiritual strength, how would they affect my life? Were they compatible with this kind of a focus? Were they going to be interested in going the same way that I was? /Because I had noticed in my friends, that the ones that got divorced were the ones that didn't really have any goal in common, weren't really aiming to raise children. They got married because it seemed like a "nice" thing to do at the time. And weren't, didn't have a common goal. And weren't willing to work through things together. If you put the common goal and non-
137. When he was young. S. thought that having children was "a nice idea" but he thought "it's going to have to be the right girl and it's going to have to be perfect before I do this."

138. In his early twenties. S. went to Europe where he met some nice women but not anyone with whom he was interested in making a family.

139. S. went into the military at twentythree and "found out that I had a lot of growth yet to do." There "was just a little bit of maturing that I had room to do."

140. In the military, S. started looking at the people he met in a different light. He looked at them in terms of their "spiritual strength, how would they affect my life? Were they compatible with this kind of a focus? Were they going to be interested in going the same way that I was?"

141. S. had observed in couples he knew that got divorced, they didn't have a goal in common, they "weren't really aiming to raise children." They got married casually and they "weren't willing to work things through together."

142. S. believes that a lack of a common goal, combined with noncommunication in a relationship will lead almost inevitably to divorce. 
communication of working things together, then you've pretty well in every case wound up with a divorce. /And so I said, well those are two things I'm going to have. I decided okay, if I'm going to get married and have a family, these are going to have to be there.

\section{So that goal of having a child actually wound up shaping how you got into relationships.}

That's right. It started to change how I looked at meeting people. How I looked at furthering or progressing relationships. I would say, well. this lady's too flaky. It isn't going to happen, there's no logic here anywhere. Now, after I realized that...all women are flaky...at one time or another. I could have just caught her on a bad day. I wasn't quite as forgiving that day.

\section{But that's what was operating in your mind, was sort of that principle that}

/Right, just to kind of look for someone that's stable, someone who's pretty well together. And smart. Intelligence was required. Because... when I was around people that didn't have any brains, I just kind of would go quiet. And there just wasn't any... warmth to the relationship. So all these little things. /As I passed one then I realized, hey, there's something else she's got to have before we go there. And so each time, I'm learning more about me, more about how I relate to people. Not as a negative shine on the individuals that I was meeting, just that I recognized in my own make-up what I would need to be comfortable with getting married.
143. S. decided that if he was going to get married and have a family that he would have to have common goals in the marriage and good communication.

144. S. started to look differently at the people he met in terms of how he would further his relationships with them. If a woman seemed too flaky, he wouldn't pursue her. He knows that he might not have been seeing people completely accurately, but at the time he was unforgiving about this.

145. S. was looking for a partner who was stable, smart and "pretty well together." He didn't feel any connection or warmth in relationship with people who weren't intelligent.

146. Through increasing experience with people, S. came to recognize more and more what he needed in another person in order to be comfortable getting married. 
So it was a process of clarifying your own needs.

\section{[end of tape]}

/Recognizing what I needed to complement my particular personality, to become a parent. The growing process for me, to recognize the weaknesses in me. so I could look for strengths in other people to counterbalance. And it became much more obvious over the years, as I got a little older. /After I turned about 30, 32, 33. I started thinking, you're never going to get married, kid. You know, I mean, because you're so set in your ways. And that was a concern. Because I had that feeling. There's no woman on the planet that will be willing to deal with how you are. / can be very grating in my personality. And usually it's somebody who is not used to expecting that if you say you're going to do something that's how it happens. And I hold people to those kinds of things. If they say they're going to do it, they're going to do it. And I may put them on the spot. You know, I may light a fire under them. right where they stand.

So you had kind of high standards and how did that, maybe you could just kind of move through to...

/How did I wind up with Kathleen?

\section{How did you sort of work that out?}

I recognized...first of all, Kathleen did not ever want to marry me, or into my family. She had met my father and...she didn't like him. And she met my brother and she really didn't
147. S. went through a process of recognizing "what I needed to complement my particular personality to be a parent." He looked for strength in others that counter-balanced his own weaknesses. These qualities became more obvious to him over the years.

148. In his early thirties, S. became concerned that he would never get married because he was too set in his ways. He had the feeling that there was "no woman on the planet" that would be willing to deal with him.

149. S. can be very grating in his personality. He holds people to what they say they're going to do and he puts people who aren't used to this on the spot.

150. S.'s wife had met several members of his family before she met him. She hadn't liked them and had a negative idea about his family. 
like him. And so she didn't really feel like she'd ever like to meet another Jackson...period. Not another one. she'd already met two. /So...I went ahead and, one day this really cute, darkhaired, green-eyed girl comes up to me and tells me that choir practice is at 5:30. Doesn $t$ tell me her name or anything. That was the start of it. As you can tell, I'm pretty shy, I don't meet people very well at all, and...this kind of intrigued me. Why someone who had never met me before. never talked to me, would put up, put that kind of a distance between me and them. So I did everything I could to break through it. /So it started out, we started talking and got - well actually, I kind of...took the step getting to know her. I was trying to find out who she was. And it took me three or four weeks to find out who she was. Then once I found out who she was. then we started to talk. /Once she started talking with me, we started realizing that our likes and dislikes and our thought processes were very similar as far as our goals in life were concerned. /And I saw that she was very gentle with the boys and she was very kind. /And she was very shy. Well. I'm not very shy. And so. there I found out the story about my brother and my dad, and she'd already been subjected to them and wasn't interested in more of that. /And then she started to think, well I'd make a pretty good friend. /Well, before we started dating though, I found out how old she was. And I was stunned. Twenty-two years old. And I thought she was older than that. She was very, you know, very mature, very wise for her age. /All of those things went together and I realized that age wasn't really a factor. And it had more to do with our compatibility. Whether we were able to make a team,
151. S. and his wife first met at church. S. was intrigued by the fact that she kept a distance from him even though they'd never met before. This made him try harder to break through the distance.

152. Before S. and his wife met. it took him three or four weeks to find out who she was and start to talk with her.

153. Once they started talking, S. and his wife realized that they had similar tastes and similar goals in life.

154. S. saw that his wife was very gentle and kind with her children.

155. S. discovered that his wife was very shy. He was not and he discovered that she had had bad experiences in the past with his father and brother.

156. When she was getting to know S., his wife started to think he'd make a good friend.

157. S. was stunned to discover how young his wife was. She seemed very mature and wise for her age.

158. S. realized that age wasn't a factor in his relationship with his wife. Their ability to work together as a team and solve problems was more important. 
to work together and solve problems, etc.

\section{And that connects back to having kids, together.}

/Yeah. And it worked out. Yeah. And it all worked out. And so one thing led to another. /We decided. we started dating and getting to know one another with a goal in mind, as opposed to just being friends. So and then we decided to get married. /And she was coming over here to the university. So I had to leave my comfort zone, and come to an area that I hadn't planned on being in. So I hadn't done any networking, I hadn't done anything to prepare work over here. /So in the space of three months. my whole life was completely distraught, thrown into the wind. But it was a fascinating experience and the adventure is still on-going.

\section{Yeah, yeah. Getting more exciting every moment.}

/Every day is a new day. "Dear, how are the contractions doing?" Oh, we're still five minutes apart. [laughs]

Oh, my gosh.

But not strong enough, yet. They're just there. I said, "honey, tell the girl...ah, forget it." [laughs]

\section{Well, that's great. Is there anything else about that experience that ought to be....}

I'm trying to think... 


\section{I feel like you've given me a really good description of the whole process.}

YYou have - there were lots of ins and outs, but the nuts and bolts of the thing was that, once we put age aside initially it was an issue, because frankly I would have never gone out with someone that young. I was just startled and so. and I was concerned about the communication aspect of things. /Once you put that blinder away and you sincerely open your heart and recognize the balance factor. that's where the decision's made. If you can do that. you know that's the only way to do it. If you can't, then it's not right, then don't get married. you know that's, that was the key factor to me. /Yeah, there are still times when I' $m$ wondering, because she still is a twenty-three year old. So she hasn't had the years and years of experience that I have. But in the years and years of experience that she has had, she's had different experiences than I have. /So as long as we keep that in perspective and as long as I can keep that ego under control, then things are going to work very well. /And I think I'm not going to have that great a difficulty doing that, because of the incredible values that she has. I mean she is a very terrific lady, and a friend and someone whom I love. /And I think that is the key to all of this that we've said. If you do not have love and a genuine concern and caring for your spouse, that is mutual, children are not the area that should be happening. And I guess that that's probably as solid a response as a person can give to that particular question as to why did you make that decision and how. Once you know, once you have that base, then all of the rest is part of the decision, the initial decision.
164. S. had to put aside his concerns with his wife's young age and his worries about "the communication aspect of things."

165. S. believes that what's important in a marriage is that you "open your heart and recognize the balance factor." If you can't do that. you shouldn't get married."

166. S. still worries about his wife's young age, but he recognizes that while her experience has been more limited than his. she's had different experiences.

167. S. believes that if he and his wife can keep their perspective on the difference in their experiences, and if he can "keep that ego under control," that their marriage will work out.

168. S. thinks his wife is "a very terrific lady" with "incredible values." This will make it easier for him to make the relationship work.

169. S. believes that if a couple does not have a genuine concern and caring for one another, "children are not the area that should be happening." "Once you have that base then all of the rest is part of the decision. the initial decision." 


\section{Nathan - Level 3}

In making the decision to have a child. $\mathrm{S}$. has been influenced by his experience as a child being raised a "disciplinarian type family." Spanking was an ordinary thing when he was growing up. which hsees this as normal for the time. He doesn't blame his parents for the physical punishment they used on him but says that it was what was used to "encourage you not to disobey." He believes his parents were just following the "normal way to discipline children during that era." Nonetheless. this environment led to difficulties as he got into power struggles with his parents. This was a situation which escalated his temper. He says that he was "rebellious and hard-headed" and was stubborn enough that in their disputes he could hold his parents to a draw. His attitude was "beat me till I'm dead."

While S. doesn't believe that he turned out poorly, he'd like to focus his energies differently in raising his won children, "hopefully to get a better result." He doesn't want "to utilize the same method of raising children that his parents did. He believes that he's "highly likely to have a child with the same amount of stubbornness that I have." $\mathrm{He}$ wants "to figure out a more effective means to channel the talents of the child than the one that was used with me." He doesn't want to repeat the way he was raised as a child.

As a young man. S. thought that it would be nice to have children. He imagined doing the things with them that he had enjoyed doing when he was young. But he wanted to wait until he'd turned twenty-six to get married. He wanted to live life and to mature. to "take care of me first," before he made the transition to having "to deal with other people." He thought of having children as "a nice idea." But he thought "it's going to have to be the right girl and it's going to have to be perfect before I do this." As he grew older, he "kind of knew" he was going to have children, although he was not certain that he would have any that were naturally born to him.

When he was in his early twenties, S. went to Europe where he met some nice women but not anyone with whom he was interested in making a family. He went into the military at twenty-three and "found out that I had a lot of growth yet to do." There "was just a little bit of maturing that I had room to do." In the military, he started looking at the people he met in a different light. He looked at them in terms of their "spiritual strength, how would they affect my life? Were they compatible with this kind of a focus? Were they going to be interested in going the same way that I was?"

S. decided that if he was going to get married and have a family that he would have to have common goals in the marriage and good communication. He started to look differently at the people he met. If a woman seemed too "flaky," he wouldn't pursue her. He knows that he might not have been seeing people completely accurately, but at the time he was unforgiving about this.

S. was looking for a partner who was stable, smart and "pretty well together." He didn't feel any connection or warmth in relationship with women who weren't intelligent. 
Through increasing experience with people, he came to recognize more and more what he required in another person in order to be comfortable getting married with them. He describes this as a process of recognizing "what I needed to complement my particular personality to be a parent." He looked for strength in others that counter-balanced his own weaknesses.

In his early thirties, $S$. became concerned that he would never get married because he was too set in his ways. He had the feeling that there was "no woman on the planet" that would be willing to deal with him. He says that this is in part due to the fact that he can be very grating in his personality. He holds people to what they say they're going to do and he puts people who aren't used to this on the spot.

S. and his wife first met at church. S. was intrigued by the fact that she kept a distance from him even though they'd never met before. This made him try harder to break through her distance. It took him three or four weeks to find out who she was and to start talking with her. Once they started talking, he discovered that she was very shy. He on the other hand was not. He found out that the reason for her hesitation around him was that she had met and had bad experiences in the past with his father and brother She hadn't liked them and so had a negative idea about his family in general.

As they talked, S. and his wife realized that they really enjoyed one another and that they had similar tastes and similar goals in life. They are in the same religion. She already had two children of her own and he saw that his wife was very gentle and kind with her children. As she got to know him, his wife started to think that he would make a good friend. They started dating and getting to know each other, "with a goal in mind." Their relationship wife progressed and they decided to get married.

When they were dating, S. was stunned to discover how young his wife was. She seemed very mature and wise for her age. He had to put aside his concerns with his wife's young age and his worries about "the communication aspect of things." He still worries about his wife's young age, but he recognizes that while her experience has been more limited than his, she's had different experiences. He realized that age wasn't a factor in his relationship with his wife. Their ability to work together as a team and solve problems was more important. He believes that if they can keep their perspective on the difference in their experiences, and if he can "keep that ego under control." that their marriage will work out. And things have worked out well between S. and his wife. He thinks she is "a very terrific lady" with "incredible values" and believes that this will make it easier for him to make the relationship work.

The fact that his wife already had two children made the decision about whether or not to have a child together harder for S. In making the decision, they wanted to make sure that their relationship was strong enough before they threw "another cog in the wheel" by having a child. When he first entered their life his step-sons weren't accepting of him. They thought that they could get rid of him. They are well-behaved boys, but the changes that came with their mother's re-marriage were tough on them. He understood their hesitance to accept him, but it made him wonder if he wanted to deal with having 
another child at the same time he was having to deal with them. Since the pregnancy. he has been very moved by the ways his step-sons have whole-heartedly accepted their new sister, since "they didn't have any choice in the matter." This has been humbling and eyeopening to him.

In making the decision to have a child with his wife. prayer played a central role for S. He had initially wanted to hold off on having a child with his wife for awhile. He says he wouldn't choose to go through the strain of a pregnancy if it were "an unwanted circumstance." He is emphatic that he doesn't believe in abortion but he does believe that if a person doesn't want children they should abstain from sexual relations. Because of his unsteady employment situation when he and his wife got married. he took extra time praying about the decision. When he prayed about the decision he had a feeling inside that "the proper thing to do was to have another baby now as opposed to wait."

In his prayers over the decision. S. described his concerns to God and explained the reasons why he felt he wasn't yet ready to have a child. He told God that he "would prefer that You kind of let me know that it will be all right to wait." He spelled out to God exactly how he felt and also what he thought the answer to his question was. This is a process that he has has come to follow in prayer as a result of coming to accept how "hard-headed" he is, how "difficult to bring about." He will "almost invariably" choose the opposite of what God wants for him. God forces him to humble himself and make himself teachable. And usually the answers that God gives when S. prays about his questions are not the answers that he arrives at to his own questions. S.'s answers are based on how he wants things to be.

In his prayers, S. told God that he wanted to wait before having a child. But he got a strong feeling that this was the wrong answer. When he asked God if He was suggesting that he should have a child in spite of his concerns about doing it so soon. God gave him a very powerful internal confirmation that he was meant to have a child. It was as clear as a billboard. S. asked for and received a re-confirmation of God's response that he should have a child, especially regarding his worries over "how I was going to work in here and be able to handle all of that." He kept praying and asking God "are You sure?" He didn't want to have a child if he wasn't certain that this was what he should do.

Although S. was uncertain whether he was up to the burden of this extra child, prayer confirmed his feeling that it was time. He had his answer from God regarding the decision to have a child: "I know you don't feel like you're ready for it yet. but it's time." He was willing to do what he felt God wanted him to do. But while God assured him that things would work out, "He didn't tell me the whole key to how I was going to make it work." S. has to work this out on his own. So even while he felt that God was telling him that having a child was the right thing to do, but still "it took a bit of a leap of faith" to act on it. Finally he reached a point in the decision to have a child where he realized that "it's obvious that this is something I need to do and the trepidation in my personal abilities doesn't detract from the fact that it needs to happen." He feels that "based on the religious perspective," the decision to have a child "wasn't that difficult." 
S.'s spiritual beliefs have guided him throughout the process. He believes that "if spiritually it's not right, it's not right." He has a belief and a faith in God that He is not "steering me in the wrong direction." This "spiritual backing" is helpful to him. allowing him to make the decision to have a child "with the full knowledge that it's the right decision." He feels that he's not alone in it, that "it is not just my abilities that are involved here." His personal weaknesses are counteracted by the strength of God and of his wife's wisdom. He pictures the three of them as a team in raising the children. $\mathrm{He}$ says that when things aren't working in terms of raising his children. "nine times out of ten it's because I was thinking me. not us." He sees being a parent as something which is "much bigger than me." And so the usual things that families worry about regarding the decision to have a child have not been a particularly big concern to him. Even if the child had "a medical deficiency problem." he has faith that things will work out.

The child that $\mathrm{S}$. and his wife are having was planned, "from beginning to end." Even when they were dating they discussed whether or not the would have children if they got married. Because his wife already had boys of her own. "it was not necessary that we really have more children unless we really felt we wanted to." His wife told him that she felt she was going to have a daughter. They knew they were going to have a child, "it was just a matter of timing."

After they got married, S. and his wife first decided that they would wait a year before "even thinking about having a child. But as it turned out, they decided whether to have a child after they'd been married a few months. This came about in relation to his prayers regarding the matter. It took him awhile before he went to his wife and told her about the feeling that he was getting from his prayers that they should have a child sooner rather than later. He's not sure why this was. although part of the reason was his stepsons' reluctance to accept him.

When S. spoke with his wife about his feeling that they should have children together sooner rather than later. she told him that she had been feeling the same way. Because she had been having the same feeling they decided to pray together about the decision. They decided that however they felt at the end of the prayer would determine what they would do. They prayed together. asking God "if this was the direction we were supposed to go. They got a "confirmation," a feeling of "warmth and peace and solitude of spirit" about having a child.

When they received this confirmation to their prayer, S. and his wife "acknowledged that it was the right thing to do at the right time." Still, "He didn't tell us all of the answers." They continue to have to work through problems on their own. But they both felt that it was time. They believed that things would work out, although they didn't know how. They knew that even though there would be trials, they would make it through. They knew that a pregnancy would increase the emotional problems between them, but they had a faith that everything would work out. At times they both have moments of "sheer panic" and "sheer terror." At times S. wonders "what have I gotten into?" But still they have "peace and solitude of spirit" about the decision. They know things will work out. 
In the three months during which he met and married his wife. S.'s life changed completely. When they got married, he had to leave his "comfort zone" and start up fresh in a new area so that his wife could attend the University. In addition. they made the decision to have a child at a time when he was in the middle of changing jobs. This has been "a fascinating experience" for him and he says "the adventure is still on-going." $\mathrm{He}$ recognizes that it is a big jump in his life going from being a single man with little exposure to children to having three children under age five. He has wondered if he would be able to "adjust sufficiently to this whole change in mental perspective and whether he's done all he needs to do "to straighten things. make things better, or help things work." Being a newlywed and also expecting a child has made the past year in his life a "hair curler." It has been "a very growing experience." He values the experience he's had "learning to be a father" with his two step-sons.

S. felt that having children was "a trial that I needed to go through." An aspect of the decision to have a child was that he thought it was important to face his weakness in communicating with children and make it into a strong point. But he believes that "you can't allow the difficulty of the past to be the determining factor as to whether you do something or not." He felt he needed to learn "to be around little ones."

S. is very concerned with taking financial responsibility for his family. Taking care of his family in this regard is important to him. Because of this it was a scary experience when he had to leave the first job that he had in this area. One of his main concerns in making the decision to have a child was the stability of his employment. especially because he had just moved to this area. At the same time, he has also felt that he has had to change aspects of himself that he considers "selfish" -- like his "workaholic" nature. He left his last job which kept him out of town and away from his family too much, in order to find work that would allow him to see his family every night. This marks a big change for him. But still he wonders whether he can "get past this workaholic syndrome."

S. has wondered whether he would be a good father. For him this means meeting the emotional needs of his children. He believes that it's important that a father is present in his children's lives, doing the things that "build a trust and the respect in the child that they know you care about them." He believes that the key to being a parent is paying attention to your children, being able "to demonstrate the love and the cherishing that you should do as a parent." He believes that parents should give their children a solid base, a feeling of stability and the knowledge that "the love is never in question" even if their behavior is a problem.

S. believes that being a parent is something you learn from experience, one day at a time. He recognizes that nobody starts out as a perfect father or a perfect parent. If you thought you should know it all before you started, you would never marry and have children. He believes that if his goal is to become "a better person, becoming a husband, father," that he needs to take the steps necessary to get there in the present. He feels that he is learning slowly how to be a father, although he describes himself as "a very 
stubbom learner." He wishes that it wasn't such a slow process. since he knows he has good business acumen and an ability to learn.

S. has looked at how other families are raising their children. He looks at how many people get divorced and has thought about what the cause of that is. He has observed in couples he knew that got divorced that they didn't have a goal in common. they "weren't really aiming to raise children." They got married casually and they "weren't willing to work things through together."

S. believes that a lack of a common goal, combined with non-communication in a relationship will lead almost inevitably to divorce. He believes that if you get married and plan on having a family, that the key to success is to focus on the family. He believes in the importance of having goals and looking forward to the future. He believes that what's important in a marriage is that you "open your heart and recognize the balance factor." If you can't do that, you shouldn't get married." He believes that if a couple does not have a genuine concern and caring for one another. "children are not the area that should be happening." "Once you have that base then all of the rest is part of the decision, the initial decision."

As he was making the decision to have a child, a big area of debate in S.'s heart was whether he could overcome his military training. "instead of the commander. be the father." Because of his many years of military training and service, he is accustomed to a style of giving orders and having them obeyed without question. It is emotionally stressful for him when he tells a child to do something and the child doesn't respond. He sees this as an area of weakness in himself. He has been learning to deal with his emotional stress over his children's disobedience. He is trying to learn not to take himself too seriously. Although he feels that it's is good for him to learn how to do this. it's a difficult transition.

S. believes that women don't experience the same degree of emotional stress that he does when children are disobedient. His wife counsels with him about his parenting decisions. They discuss the way he disciplines the children. Although they don't use physical punishment on her children, he tends to take a rougher. more militaristic response to action or inaction on their part. She supports him and doesn't criticize. She thinks that they need to talk about discipline so that they don ' $t$ ' get "at cross purposes."

S. envisions a different way of disciplining his children than he himself was disciplined. He wants to teach them respect for rules without letting the rules be absolute, to find the "fine line" between parental authority and flexibility. He imagines himself as the judge but acknowledges that there is a court of appeals. He believes that once in a while, "the child's perspective is worth...ceding to." He wants his children to sometimes be able to influence his decisions, to recognize that they have a say in the decision process and to take on responsibility for the decision. He wants to encourage a learning process in his children with regard to the process of making decisions. This is something that wasn't encouraged when he was growing up. 
S. is accustomed to being in control. He likes to be in control. It's difficult for him not to be in control with the pregnancy. In this regard, the pregnancy has been a big change in his life. Ordinarily he likes to be able to plan things in a systematic way. But he sees that in parenting there are a lot of things that you don't have control over. He sees his difficulty dealing with a lack of control as a weakness in himself which he is trying to face directly. He believes that the process of personal growth involves letting go of individual control, learning how to follow and doing so happily. He has experienced this need to let go of personal control throughout his life. It involves letting go of what he knows from childhood.

S. had a lot more control in his life before he got married. He could schedule his life the way he pleased. Since then, things have happened for him on a different time frame than the one he planned on. He recognizes that children's schedules take precedence over his own need for control. His experience with his two step-sons has been one which has taught him that he has to be more flexible in his plans with them than he would be on his own. For instance, medical decisions that he might take lightly for himself he has to take seriously for them, even if it means an abrupt change in plans. If they're sick, you take them to the doctor immediately.

S. has found the experience of trying to teach young children to be a stressful one. He found it difficult to communicate on their level. Because of his military background he is having to adjust to a different way of communicating his requests to young children. to soften his response when they don't comply immediately, not to respond with anger. Because of this difficulty he always "had a hunch" that having children was in his future. He thought that he needed to learn to communicate on a child's level without being too frustrated. He feels he's better at this than he used to be, but he still has a ways to go. He envisions his daughter as an infant who wants to be able to communicate, but whose needs he won't necessarily understand. He knows that dealing with this will be a big transition in his life. He already has experienced difficulty communicating with his youngest step-son, which has created a lot of stress for him. He has been frustrated at not being around enough so that they could each learn to understand each other and he worries that his new daughter will aggravate the communication problems he is already experiencing with his step-son.

The experience of the pregnancy has been "very scary" for S.. but also fun and fascinating. His wife has had pre-term labor which put her on bed-rest and scared him. $\mathrm{He}$ and his wife are monitoring her contractions daily. He worries about hospital bills but he knows things will work out. He first hoped to have a boy. "knowing that we were eventually going to have a girl." But he's "delighted to have a little girl." He wishes he could send a message to his daughter, but he knows there's no point. He has had some doubts about his ability to survive the pregnancy. Because he doesn't have much experience with pregnant people, the stress factor is pretty high for him. He describes learning how to support his wife emotionally through the pregnancy as been "an interesting experience." 
The pregnancy has heightened S.'s awareness that he doesn't have as much control over his life as he would like. He believes that when a man's wife is pregnant it is the child who is in control of the situation. He loves his child. but he doesn't want her to have so much control. He wishes he could plan the birth according to his own schedule. $\mathrm{He}$ understands that his desire to have more control over his daughter is unrealistic. He knows that this is something he will simply have to deal with.

The doubt and "sheer terror" that S. experiences regarding the decision have to do with his emotional relationship with his new child. He feels that the moments of panic he has experiences "can either be a stumbling block or a stepping stone." He chooses to see them as a stepping stone. He thinks ahead to how the dynamics of communication in the family will change with the arrival of his daughter. He hopes his step-sons will feel that he has as much love for them as he does for his wife and daughter.

S. looks ahead to imagine playing sports with his daughter. He imagines that she will grow to be quite tall and that she'll be "as homery as can be." He says that his stepsons are a delight and his daughter will be too. He is concerned about how his present age will affect his relationships with his children as they grow older. He thinks ahead to what his step-sons' physique and temperament will be as teenagers. He expects that their parents' physique and temperament will show up in the children. He imagines how he will interact with them when they play sports together. He looks for ways in which he'll be able to counteract the effects of his age.

S. prays that he will be able to treat his new daughter appropriately, that she will be happy and take pleasure in being part of his family. He is happy at how the timing of the pregnancy has worked out. He believes that things will work out positively and that the child will be okay. He revels in "the miracle of how children make you grow." He has never felt that he made the wrong decision regarding having a child. 


\section{Nathan - Level 4}

For $\mathrm{S}$. the decision to have a child was inseparably linked to both his personal religious beliefs and to his beliefs about marriage. He believes that the decision to have a child cannot be separated from the commitment that is made to the marriage and that having children is inappropriate unless the couple is committed to working things through in the marriage. In addition, his religious faith has guided him throughout this experience. By exposing his doubts and worries to God he received reassurance and was able to make this difficult decision with confidence.

As a young man $\mathrm{S}$. sensed that he would have children one day. But this idea was not very concrete and he was in no rush to get married and become a parent. He felt that he needed to grow and mature before he took this step. As he grew older. he became increasingly deliberate in choosing his relationships. As a result of observing the failed marriages of other couples he developed a theory that a lack of a common goal in a marriage combined with non-communication leads to divorce. As a result, he developed a systematic approach to choosing a partner, looking for a woman's spiritual strength and gauging whether she shared his goals and was able to communicate well with him. In addition. he examined his own weaknesses in areas such as communication and his need for personal control and he sought a partner who would match those weaknesses with complimentary strengths.

While S. believes that he found the qualities he ner is in his wife. his decision to have a child with her was complicated by the fact that she already had two children of her own. They discussed having children early on in their relationship and they felt that they would have a child together at some point. But because they did not need to have additional children, because the wanted to strengthen their own relationship and because S. experienced some reluctance to do so based on the difficulties he was having adjusting to his role as step-father to his wife's children, they decided to delay having a child for a time.

However, through the process of prayer S. came to believe that he and his wife were meant to have a child together immediately rather than waiting. This decision took the form of a conversation with God in which he spelled out the reasons why he felt unprepared and why he wanted to wait before having a child. He received in response to this prayer a strong feeling that he was meant to have a child now rather than waiting. He was uneasy with this answer and continued praying, asking for and receiving a confirmation that this was indeed what he was meant to do. This process then repeated itself within the relationship. When S. informed his wife about what he was feeling it turned out that she had been feeling the same way. They prayed together and received a response which confirmed their feeling that they were meant to have a child together immediately rather than waiting. But while God told them what they should do, He didn't give him all the details about how to make it work out. As a result, his decision to have a child required a "leap of faith." His faith has supplied him with the confidence to do this. He has a peaceful feeling about the decision and he knows that things will work out. 
S. has had a variety of worries and concems about what becoming a father will mean for his life. At times he has moments of terror and panic about his decision to have a child. On one level these feelings reflect the tremendous transition that he is going through. his generalized anxieties about his ability to adapt to the demands of this new role, and his concerns about how relationships within his new family will be affected by the birth of his daughter. He wonders about his ability to live up to his ideal of what a good father should be. On a practical level this means fulfilling obligation to provide financial support for his family, an obligation which sits uneasily alongside his "workaholic" tendencies. He believes that the key aspects to fatherhood are keeping an active presence in his children's lives, building trust and respect in them. demonstrating his love and concem for them. He sees his role as father as one of providing a solid base of unconditional love for children. He is seeking a way to balance the competing obligations of financial support and emotional presence. And so for $\mathrm{S}$. this experience involves a process of personal transformation. He wonders how he will be able to change the aspects of himself that he considers selfish, egotistic or stubborn in order to live up to the ideal of being an active presence in his family's life. He reassures himself that this is necessarily a gradual process which he can only learn through lived experience. He is uncomfortable with how slowly he is learning to be a father, but he is working to make himself humble and teachable.

In addition to these global worries about how he will adapt to the role of fatherhood. S.'s worries also coalesce around several specific areas, especially concerning his ability to communicate with and to discipline his children. These difficulties are part of a larger issue for him regarding personal control. He is accustomed to having a great deal of control over the way he schedules his life and he is quite concerned about how he will learn to be more flexible, to adapt to the lack of control and sometimes unpredictable schedules that go along with having children. He believes that his difficulties with communication and discipline reflect areas of personal weaknesses, which he in turn conceptualizes as opportunities for personal growth and learning. He sees having children as a "trial" that he needs to go through in order to confront and overcome his weaknesses. He believes that personal growth will come from learning to let go of control.

Some of S.'s perceived weaknesses have arisen out of his past experience trying to communicate with children, which he finds in general to be a stressful experience. Others relate back to his own childhood experiences with his rigidly disciplinarian parents who used physical punishment to discipline him and thus created in him a reaction in him of stubbom resistance and anger. In addition. he worries about his ability to move beyond the militaristic style of interaction with which he is accustomed to learn a more gentle style of communicating with children. He worries that his daughter will be as stubborn as he was and he doesn't want to repeat with his children the same problems that he experienced growing up. He hopes to find an appropriate balance between parental authority and flexibility, to teach them to take responsibility in decision-making by allowing them to have some influence over the decisions he makes. 
His wife's pregnancy has intensified S.'s fears and hopes about the future of his family. He thinks ahead to what his children will be like -- physically and in temperament -- in the future, calculating his own age and abilities in relation to what he imagines theirs will be. His religious faith has been an important tool in helping him to manage the stress of the pregnancy, which has been both exciting and frightening to him. His worries about the pregnancy reflect his larger worries about having a child. He wishes he could have more personal control and he worries about how to meet the emotional needs of his family. But in spite of his worries, he feels confident about his ability to work with his wife in solving their problems. He feels that his marriage has the support of God, who makes a third member on their child-raising team. He sees the enterprise of parenting as one which transcends his own experience and abilities. $\mathrm{He}$ believes that God is actively involved in the process and that his own weakness will be balanced out by the strengths of his wife and of God. This gives him faith that things will work out and confidence that he has made the right decision. 
Appendix D

Tobin: Data Analysis

Levels 1-4 
Tobin - Levels 1-2

\section{So...I know that you've recently made the decision to have your first child and what I'd like you to tell me about is the experience of making that decision.}

/Well, I went through quite a bit of agonizing about making the decision. /It took - my wife and I had what seemed like endless discussions, although they were really more episodic and we'd talk about the prospect of having a child and certainly the pros and cons of it and how we both felt about it. /For me, I had not until probably the last four or five years very seriously considered having any children. /And it was, it felt like I was trying to go through a process of sort of balancing the negatives and the positives, as.... /Maybe I should back up a little bit and say that Leslie, my wife, was nearing forty. We started realizing, if we're going to have any children it's going to have to be fairly soon. And we need to start talking more seriously about whether we want to do this or not. /So, but really up until the last five years or so I think I have really not pictured myself being a father. /And then the idea started to be slightly more appealing but not real compelling for me. It was, I started thinking about my own history, my own enjoyment of childhood and particularly learning things from both my father and my grandfather and other adults, my mother. And wanting to pass some of that on. I think there was some sense of wanting some continuity to that... and to that learning process. Just being able to pass on knowledge and experiences and opportunities, I guess.
1. S. went through "quite a bit of agonizing" about the decision to have a child.

2. S. and his wife had episodic and seemingly endless discussions about the prospects of having a child and the pros and cons of it and how they both felt about it.

3. S. has only seriously considered having children in the last four or five years.

4. In making the decision to have a child. S. went through a process of "balancing the negatives and the positives."

5. Because S.'s wife was nearing forty, they knew that if they wanted children they had to have them fairly soon. Because of this they started discussing the decision more seriously.

6. Up until the last five years, S. had not really pictured himself as a father.

7. The idea of having a child was "slightly more appealing but not real compelling" for $\mathrm{S}$. as he thought about his enjoyment of his own childhood and the things he'd learned from older relatives. He felt some sense of wanting continuity, wanting to pass on the knowledge and experience and opportunity that he'd had. 


\section{What sort of experiences?}

/Oh, you know, it's nothing incredibly profound, I think. My grandfather -- I just have a lot of memories of going out, getting up at four o'clock in the morning, getting in his old Scout and driving to some little remote farm pond in Illinois where he lived. or Missouri across the river. And fly fishing for bass. He taught me how to fly fish. And we spent just days and days doing that sort of thing, roaming around in his canoe and.../he, along with my parents, and I have to give them actually most of the credit, steered me in the direction of, I think they really shaped me in some ways to really love the outdoors. And I appreciate that and value it /and that's really something I'd like to pass on also. And hopefully some of that -- I'm not sure to what degree you can actually pass that on. but at least to expose a child to that kind of, that kind of childhood.

\section{To share your appreciation.}

Yeah. /But I think largely, up to that point, I, up to the point where I started thinking about that as a more positive kind of aspect of childhood, I think my view of being a parent was more, I would say it was relatively negative. This. having this feeling of I'm going to lose my freedom to kind of do whatever I want to do, you know, when I want to do it. /But that's maybe a little bit illusory anyway, because I didn't, you know, being married and I still have the responsibility of...

\section{Right, right. You don't have complete freedom.}

8. S. describes the experiences which he wants to pass on from his own childhood as "nothing incredibly profound." He remembers days spent fishing for bass with his grandfather.

9. S.'s parents and grandfather shaped his childhood love of the outdoors. He values and appreciates this.

10. S. would like to pass on his appreciation of the natural world to his own child -- or at least to expose his child to that.
11. Up until the point at which S. started thinking about his own experiences as a positive aspect of childhood, his view of being a parent was "relatively negative."

12. When $\mathrm{S}$. imagined having a child, he had "this feeling of I'm going to lose my freedom to do whatever I want to do... when I want to do it."

13. S. wonders if his fear of losing his freedom when he has a child is "a little bit illusory," since the responsibilities of marriage already mean that "I don't have complete freedom just to pick up and go where ever I want, any time." 
I don't have complete freedom just to pick up and go where ever I want, any time. /And then the responsibility of it, the permanence of it was kind of frightening to me. The idea that once the child is born, it's a life-long, feels like a life-long responsibility to most parents anyway.

\section{Right. They're not going to go away and you can't...}

No, no, it's not like with dogs where I could, you know, we could take them to the kennel for two weeks and -- and even that's sort of... unpleasant, for us to do that. So....

So that state, tell me more about, kind of the state before you kind of started to consider it. Were you in a state of not...were you thinking, I just am not going to have children, were you thinking I don't want to think about it?

/I think there were distinct periods where, I think up until probably thirty years old I was fairly definite I wasn't going to have children.

\section{Okay.}

Some of the reasons for that were...more, I guess more sort of internal ideas about loss of freedom and the respons--not wanting the responsibility. /And some of it had to do with not wanting to add to the population. /And then in my, I'd say in my thirties...I don't know of any profound change in that thinking, I just began to realize that, you know, maybe there would be some things that would be kind of fun about having a child, some more positive things.
14. The permanence of the responsibility of having a child is frightening to S.. "the idea that once the child is born. it's a lifelong...responsibility."

15. When $\mathrm{S}$. imagines the permanence of his responsibility for a child. he thinks of how with a dog you can drop them off at a kennel -- and even that is unpleasant.

16. S. went through distinct periods in his ideas about having children. Up until he was thirty, he was "fairly definite that he wasn't going to have children."

17. The reasons that $S$. didn't want to have a child concerned the idea that he would lose freedom and the fact that he didn't want the responsibility it would involve.

18. Some of S.'s reasons for not wanting a child had to do with his concerns about population.

19. In his thirties, S. began to realize that "maybe there would be some things that would be kind of fun about having a child, some more positive things." 
You hadn't seen any positives at all before that?

II don't know that I would say I didn't see anything positive. It was just that none of it felt like it would be very positive for me personally. /You know I, it was...the negatives seemed very concrete to me and the positives seemed somewhat more abstract. /And gradually, throughout my thirties I think. that began to slowly creep slightly, so that the negatives still seemed mighty concrete, but the positives began to seem a little bit more like things I could sort of put into some sort of images or, or a little more concrete, you know.

\section{What sort of things?}

Things like watching a child learn and develop. Just the, like I said before, the sharing of the experiences that I've enjoyed. Hopefully providing a good, at least the environment for a good childhood. /You know, those things started to seem more plausible to me [laughs], or more appealing.

It sounds like you were more able to imagine this as well...

Yeah.

\section{...this thing became a little bit more} vivid.

YYeah, they seemed more, yeah, more like I could picture myself involved in that whole process. /Where as before I had a. I had a pretty clear perception I think, I mean, you know, watching other people, other parents, that they really cherished, many of them just cherished and loved and enjoyed their children. But I also saw a lot of the pain that
20. Before he started thinking positively about the idea of having children. S. recognized that there were positive aspects. but "none of it felt like it would be very positive for me personally."

21. When S. imagined having children, "the negatives seemed very concrete... and the positives seemed somewhat more abstract."

22. Through his thirties, the balance between the positives and negatives "began to slowly creep" for S.. "so that the negatives seemed mighty concrete but the positives began to seem a little bit more like things I could sort of put into some sort of images."

23. The positive experiences that $S$. began to imagine more concretely involved the idea of "watching a child learn and develop," sharing his own positive experiences. and providing "the environment for a good childhood."

24. The positive aspects of having a child began to seem "more plausible" to S.. "or more appealing."

25. S. began to be able to imagine himself "involved in that whole process" of raising a child.

26. Before he arrived at a positive feeling about having a child. $S$. watched other parents and saw how they cherished and loved and enjoyed their children. But he also saw "the pain that parents went through with children." 
parents went through with children. /And I think I really tended, until relatively recently, within the last few years. to focus much more on all the pain, the worries, the anxieties that I saw parents going through with kids. And maybe pretty selectively focusing on that rather than something, like I say, maybe somewhat more abstract aspects.

It's more difficult to imagine positives.

Yeah.

It sounds like you really had a scale almost in your mind and it's like, there's two sides...

Yeah...

...kind of shifting as you move through your life.

/And my wife and I went through like a, an earlier sort of long, they weren't endless discussions but long discussions, trying to figure out what is really, do we want to do this, why would we want to do it, and what are the positives and negatives? /And trying to. kind of. I really think we struggled to come to a logical conclusion. And at some point I realized this is not really a logical decision in a lot of ways. /It's more, do you, do we want the experience of having a child and raising a child? /t became - it felt to me like there were definitely, I think there were definitely some logical elements to making a decision. Are you financially ready? Or do you have the temperament for it? Those are the two kind of, foremost I think. You know will you be able to spend enough time with the child, and those sorts of things. /But I think it
27. Until recently. S. tended to focus selectively on "all the pain. the worries, the anxieties that I saw parents going through with kids." rather than the more abstract. positive aspects.
28. S. and his wife had long discussions in which they tried to figure out if they wanted to have a child, why they would want one. and what the positives and negatives of having one would be.

29. S. struggled with his wife to make a logical decision about having a child, but at some point he realized "this is not really a logical decision in a lot of ways."

30. The question for $\mathrm{S}$. was "do we want the experience of having a child and trying to raise a child?"

31. There were some purely logical components to making the decision to have a child for $\mathrm{S}$. Was he financially ready? Did he have the temperament to be a parent? Would he be able to spend enough time with the child? 
finally came down to more just saying, yes we want the experience.

\section{And that's kind of a less logical, less rational kind of thing.}

/It felt like that to me, like it was a little more based upon just a feeling rather than on any kind of -- that we'd put all of the positives and negatives on the scale and it tipped in favor of the positives. /It didn't feel...it didn't feel as if. I mean it felt like it was more sort of an emotional decision, or a decision of the heart than of the mind in some ways.

Yeah. What was it like to make that, it sounds like sort of a leap almost, to make a decision that's not...logical.

YYeah, you know, there wasn't a grand...leap. It wasn't like suddenly one day we were saying well no, I don't think we want to have children, or we're still really uncertain, then all of a sudden one day we were positive, or I was positive. /It was... you know, at some point it did start to feel more like yes, this is what I want to do, have a child. But you know, there wasn't any epiphany where it was suddenly like I see where, I fully understand now that I want to have a child and I have no doubts.

\section{Okay.}

/It never, in fact it still isn't at that point for me. I still struggle with the idea. I still wake up at night thinking, oh my god [laughs].

\section{And what are you thinking when} you're thinking oh my god, what are the worries in your head?
32. For S.. the decision to have a child came down to "just saying, yes we want the experience."

33. For S. the decision was "based upon just a feeling" rather than on a sense of having weighed the positives and negatives and seeing where the balance fell.

34. The decision for $\mathrm{S}$. "felt like it was more sort of an emotional decision. or a decision of the heart than of the mind."

35. There was no one moment when $\mathrm{S}$. and his wife switched from not wanting a child to wanting one, or from being uncertain to being certain.

36. For S., "there wasn't any epiphany where it was suddenly like I see where, I fully understand now that I want to have a child and I have no doubts." There was simply a point at which "it did start to feel more like yes, this is what I want to do, have a child."

37. S. still hasn't arrived at the point where he has no doubts about the decision: "I still struggle with the idea. I still wake up at night thinking, oh my god." 
/Oh, just, they're not, they're not really focused, they're more these feelings of the burden of responsibility. And this is... a creature, a child that can't function without me and my wife being there pretty much constantly. I've never had any - I've never had any situation in my life like that before. It's a little bit fear of the unknown in a sense. It's. I've never had a responsibility of that magnitude where someone was that dependent on me. /So...that sometimes strikes a little awe in me, the idea of that.

It's a hard thing to make a decision about something that you don't know...you don't know fully what it's going to be. Like you say, it's not a logical decision.

Yeah.

But it's interesting to me that the kind of negative stuff still stays there even though you're on your way, or that now you've made the decision.

/Yeah. if I'm honest with myself, I still worry about... most of the same things I was worried about before. /But...I think I have more, sort of, maybe somewhat purposefully since this is happening, I think, there's a certain amount of cognitive dissonance that comes into play I think, you know, that, I'm having a child, I better get geared up and enthusiastic about it. At the same time. I mean I think that that plays a modest role in it, /but I think at the same time, I'm starting to look forward to it a lot more than when I would think about it a couple of years ago when we were trying to make the decision, /it always felt more, uh...I'm not sure what the word I'm grasping for is. It just felt more like there was going to be a loss than a gain,
38. S.'s worries about having a child are "not really focused." They concern "the burden of responsibility" for a child who can't function without the constant presence of him and his wife.

39. S. has never before experienced the level of responsibility that comes with having someone dependent on him. He fears this in part because it is unknown.

40. The idea of a child being completely dependent on S. "strikes a little awe in him.

41. S. continues to worry about most of the same things he worried about before making the decision to have a child.

42. Since having made the decision to have a child. $\mathrm{S}$. is aware of a modest amount of cognitive dissonance in his thinking -- because he knows he's going to have a child he gears himself up for it mentally.

43. S. is starting to look forward to having a child more than when he and his wife were trying to make the decision.

44. When $\mathrm{S}$. was trying to make the decision about whether or not to have a child, it felt "more like there was going to be a loss than a gain, overall, that there were more losses than gains." 
overall, that there were more losses than gains.

\section{Right.}

/And now it -- you know , I'm really looking forward to it. I mean, it feels like it's going to be something of an adventure. And I'm starting to think of it more that way, without forcing myself to think of it that way. /And I think before it felt a little more forced and now it feels a little bit more like it's just... I start thinking about all these things I'd like to do with it...

\section{Right.}

... with the child. /And I started, and one of the interesting things that's happened to me in probably the last three months, is that even though this child isn't here yet exactly, I started looking at things around $\mathrm{me}$ in a little different way than I have before, I think, just, to some degree trying to go back and look at things as I did when I was a kid.

\section{Huh. That's interesting.}

/I haven't had a whole lot of success with actually getting back to that point, but [laughs]....

\section{Yeah.}

But I, you know, I do remember just how, how much fun it was to go on hikes with my parents and to go camping. We didn't exactly live in the outdoors all the time. but it was a major theme in our family.

\section{Right.}

45. S. is starting to think about having a child as an adventure. He's looking forward to it without forcing himself to think of it that way.

46. Before making the decision to have a child. S.'s feelings about it were "a little more forced." Now he starts thinking spontaneously about things he'd like to do with the child.

47. Since his wife has been pregnant, $S$. has started looking at things around him differently. He's trying to recall how things looked when he was a child.

48. S. has not had much success in trying to get back to seeing things the way he did as a child. But he remembers the pleasure he took as a child in outdoor recreation activities with his family and friends. 
And our recreation and so on. And I just have lots and lots of good memories of kind of sitting around camping with my parents and cousins and friends.

So going back to your own childhood has been a big - a really big part...

/Yeah.

...of being able to make this decision. It sounds like now you're coming to a point where you're really imagining your child itself. Was that not there so much before when you thought about it?

No.

\section{Or was it just negative about kids?}

No, it wasn't. I really never, I mean I've thought about it before, I don't think I ever really had this image of a child exactly. It was sort of more just this balance sheet.

Huh.

/You know. my life will change so much, it's going to be a big loss if I...I won't be able to...oh. kind of the things I like to do is last year we did a Grand Canyon trip for three weeks, and I thought, you know, things like that I would think, I'll never be able to do that ever again, for the rest of eternity. /And also I guess, part of what has changed my thinking somewhat is, there were people on the Grand Canyon trip that had kids. And I was kind of selectively being negative about it, you know. /There may be restrictions on. I mean
49. Before making the decision to have a child. S. didn't have an image of what it would be like to be a father. "It was more just this balance sheet."
50. In making the decision to have a child. S. thought about how much his life would change and what a big loss it would be. He thought about the sort of things he was able to do without a child and imagined he'd never be able to do them again.

51. S. came to realize that he was being selectively negative when he imagined parenthood. People with children were in fact doing the sorts of things he imagined not being able to do. 
there will be restrictions on how much I can, how free I am to take off and do that kind of thing, but it won't last forever.

\section{Right. So your view of it kind of lightened and became less selective.}

Yeah. right. /I think one thing. too. is I became less, I was fairly cynical about parenthood for many years. And I still have some of that in terms of people just. kind of just making the decision what I feel like is pretty thoughtlessly or for motives that don't seem very, very legitimate reasons for having children. /And...I don't know if I was actually applying those in any way to myself, but I definitely had a cynical kind of feeling about, just, our sort of, what seemed to me like a kind of thoughtless urge to reproduce without thinking about sort of the global consequences of it.

Right. Yeah, that's why I'm interested in hearing that, how that connects to your own decision, you know sort of what that...

How did...?

How did that impression of how people kind of thoughtlessly reproduce influence your own decision-making process?

/Well...I think that... at some point...that's a really difficult question to answer for me, because I never thought of myself as somebody who would just thoughtlessly have children.

\section{Right.}

That just wasn't even in the, even in the picture at all.
52. S. recognized that having children would place restrictions on his freedom. but that this wouldn't last forever.

53. S. has been "fairly cynical about parenthood." feeling that people often make the decision to have children "thoughtlessly" or for reasons that don't seem legitimate.

54. S. had a cynical feeling about other people's "thoughtless urge to reproduce without thinking about...the global consequences of it." He doesn't know if he was applying this idea to himself.
55. S. never thought of himself as "somebody who would just thoughtlessly have children." 


\section{And you obviously didn't.}

/Yeah. Um, to some degree though, the general cynicism about parents, about sort of just, to put it real bluntly. I sort of had this feeling of, you know, people are just, just driven to re-create their own protoplasm almost, you know [laughs], it's just like, a mindless kind of thing that's, maybe it's a biologically-driven thing. /But the absence of what I saw as real thought in it, I think to some degree influenced me toward the idea of, well, I'm not going to do that. And I went a step further of saying I'm just not going to have children. I'm not going to add to the world's problems by having children. /And to some degree I think that view was self-serving because I was also at the same time worrying about loss of freedom, the responsibility.

\section{Right. A justification in a way...}

Right, right.

\section{...for doing what you wanted to do.}

Yeah, to some degree it was a justification. /And I think I just began to become aware that there was sort of a faulty bit of reasoning that I was going through with that. I was somehow sort of applying all that to myself, and maybe denying myself some experience that I really would enjoy and that my wife and I would enjoy, having a child. The other thing, this is sort of, I think, a rationalization, but it worked for me anyway, is, my wife and I are both in our late thirties, or my wife is -- when we made the decision my wife was in her late thirties and I'm actually forty-four now [laughs]. Maybe that's some
56. S. had the feeling that people are "just driven to recreate their own protoplasm" in a mindless. biologically-driven way.

57. The perception that other people had children thoughtlessly partially influenced $\mathrm{S}$. toward the idea that he wasn't going to have children in that way and that he wasn't going to have children at all: "I'm not going to add to the world's problems by having children."

58. S. believes that his concerns about population and about people reproducing thoughtlessly were in part a justification, because he was also worried about the responsibility and loss of freedom that having a child would mean.

59. S. became aware that he was using some faulty reasoning when he applied to himself the thoughts about parenting that he had about others. He might be "denying myself some experience that I really would enjoy."

60. S.'s understanding of the dynamics of population growth helped him make the decision to have a child. Because he and his wife are both older, the impact on population if they have a child is less. 
wishful thinking. She's forty-one at this point. But, I know a fair bit about population growth and the older you are when you have children, the easier it is. the less impact it has on population growth. It's a pretty dramatic difference, if you look at three sixteen year old girls who have children versus three thirtyfive year old women who have children and then continue that trend. And the population explodes with the lower age. And it's a very gradual increase with the older age. /And then we just made this decision, we won't have -- this will probably be our only child. We may adopt a child, we're not, I don't think. my wife feels fairly clear that it will be our only natural born. or our only biological child. /At this point I really, for me I feel like, well, we'll see how this goes for the first year.

\section{Yeah.}

/We've thought fairly seriously about adopting a child, maybe a Chinese child because they're having so much, there are so many orphans.

\section{With the population issues there.}

Yeah. /So, the process of going from more cynical to making the decision to have a child, I think it wasn't a giant leap, it was more of a, just a beginning to have the recognition that maybe it's not such a terrible thing to have a couple of children. And maybe it could be a really positive thing. /And I began to, you know once that was, once that thought was in there, that it could be actually a joyful, fun -- or have those aspects to it anyway -- then it really did began to sway me in the other direction.
61. S. and his wife decided that they would probably only have one biological child, although they might adopt a second.

62. Regarding the possibility of having more children, $S$. currently feels like "we'll see how this goes for the first year."

63. S. and his wife have thought about adopting a Chinese child.

64. For S., the process of going from a cynical view about having children to making the decision to have a child wasn't a great leap but rather a gradual recognition that "maybe it's not such a terrible thing to have a couple of children. And maybe it could be a really positive thing."

65. Once S. had recognized that having a child could be a joyful experience, he began to sway toward the idea of having one. 
Yeah, so it sounds like you opened up a little door to that and once that was open it really kind of switched things.

/Yeah, it was just opening up to the idea that it could, for me that it could be a positive experience. You know, that there wasn't, I think the main thing to making the leap may have been to say, it's not irresponsible to have a child, or one or two children.

You had the feeling that it was.

That added to it, yeah, and somehow, I would even see people with really large families and think they, you know, they've cancelled out any of my efforts. And feel sort of resentful about it. That, maybe, may have some basis in reason but it's pretty futile to be thinking that way. [laughs]

It's one of those cases where if you want to prove something you can find what you want to prove it.

Right.

There's something I wanted to go back to -- this may be leaping around a little bit but to hear a little bit more about that you mentioned, I think it's more with where you are in the present, but that cognitive dissonance, I wonder if you could just sort of describe that a little more, in terms of the negatives and the positives and how you're framing it.

Y Yeah. Well, I think just from the cognitive dissonance standpoint it may be a little bit of a mis-use of the term, but the idea that, you know, here I am getting ready to be a father. Having those negative feelings is not, there's
66. What allowed S. to make the leap to decide to have a child was his opening up to the idea that it could be a positive experience and that it wasn't irresponsible to have one or two children.

67. Before he'd made the decision to have a child, S. would look at people with large families and feel resentfully toward them because they'd "cancelled out" his efforts for population control. He believes now that this was a futile way to think.
68. S. wonders whether his current positive feelings about fatherhood are in part due to "cognitive dissonance." Having negative feelings seems incompatible with the excitement and anticipation. 
kind of sense that it's not compatible with the excitement and anticipation of fatherhood.

\section{Okay, right.}

/I think I'm enough of a - I know myself well enough to realize that I'm always going to have some of those doubts. /And I expect I'll probably continue to have some real doubts about this whole, the whole...fatherhood package. /I guess that's one thing too, I know that there are things that change in your, in your...there's some intangible, sort of ineffable things that happen when you have a child. that people describe to me or try to describe to me about how you feel about that child, that I'm aware are probably going to be there for me. Yet I can't really feel those exactly right now.

\section{What's your sense of what those are or will be? Do you have a sense of what they are?}

/You know I, beyond just... you know I suspect I'll feel kind of a feeling of love that is...tangibly for me. if not very easily expressed. different than other kinds of love I've felt. But beyond that, you know, it's...I'm guessing, you know? /I think it's one of those, those experiences that are pretty hard to, I mean I've noticed parents having difficulty sometimes putting it into words. /Having not experienced it, I feel like I'm just sort of speculating, you know. [laughs]

\section{But you say you sense it from seeing and talking to other parents?}

/Yeah, and them basically saying, you know, there's just this experience....
69. S. knows that he's always going to have some doubts about having a child.

70. S. expects that he will continue to have doubts about "the whole... fatherhood package."

71. From listening to other parents talking. S. is aware that "there's some intangible sort of ineffable things that happen when you have a child." He expects that these changes will happen to him. although he can't feel them yet.

72. S. feels that he can only guess about the emotional changes that will come from having a child. He imagines it will be a feeling of love that will be different from those he has known in the past.

73. S. has noticed that other parents have difficulty putting their experiences into words.

74. Having not experienced what it's like to have a child, $S$. feels like he can only speculate about it.

75. S. remembers talking to another parent about the experience of 
I remember talking with my dissertation committee chair, that had a baby... her little girl's about a year old now. She was just talking about how she hadn't realized what this sort of feeling of love for this child would be like. And it was something very different than she'd experienced before. And she's a very, very articulate person. And that's about as far as she went with it. /And I thought, well it's, it is a kind of ineffable kind of, difficult to explain kind of feeling. Um, I'm not quite sure where I was going with that, I think it was, we were talking about the cognitive dissonance.

And that's something that, I really appreciate your talking about because it's, I think that ambivalence, the ongoing ambivalence is really difficult to talk about because there is that impulse to kind of stay with the good stuff.

/Right. yeah. I tend to be something of a. I'm not, I wouldn't label myself a pessimist, but in some domains I can be that way. So, it'll be an ongoing effort for me I think. I'll have to give myself some...I don't know what I'd call them, pep talks. [laughs] /Because I do still have a lot of ambivalence and my wife does too, /I mean, that's one thing that has felt pretty healthy to me about this, is that we've both been able to express that. And there hasn't been this sense that it has to all be positive. You know, we talk about both of our fears about it. /She's had some fears about, not, she tends to be a pretty stoic person, but she's a physician and she's delivered about a hundred and fifty babies. She doesn't do it now, but during her residency she did. And she saw all having a child. Although this person was very articulate, she couldn't describe the feeling much beyond saying that it was a feeling of love that was different from what she'd experienced before.

76. Based on his conversations with other parents. S. thought that the experience of having a child was an "ineffable kind of. difficult to explain kind of feeling."
77. Because $S$. can be a pessimist, he feels that he'll have to give himself some "pep talks."

78. S. and his wife both still have a lot of ambivalence about having a child.

79. S. doesn't have the sense that everything about having a child has to be positive. He and his wife discuss their fears about it. He feels that it's healthy to be able to express these feelings.

80. S.'s wife has some fears about the medical aspects of delivering a baby. She knows "it's not all a joyful process." 
these, she saw some pretty bad things along with the good.

Yeah.

So she's got some fears. I don't think they're very intense. But she knows...she knows it's not a, it's not all a joyful process. [laughs]

Yeah, right.

/You know, that there are some things, I mean beyond whether things go wrong or not, it' s just kind of a...traumatic process, at least in stages of it.

\section{Right. So I wonder if you could take} me through - to go back to the beginning, you were talking about sort of where you were kind of prior to your relationship and your marriage and everything - and take me through more kind of how the decision-making went when you got together, maybe start with that, kind of where were you both and, the details.

/Oh. sure. Prior -- let's see. I met Leslie when I was thirty-five, prior to that like I say I really had had very few thoughts about being a parent, other than that I really didn't want to be a parent.

\section{Right.}

/Um, and, I'm just going to back up a little and say part of that was that I knew, I think a little bit of it anyway was I saw what kind of torture in some ways I put my parents through. [laughs] And my siblings did, and that they went through some pretty painful times with us, especially in our teens, mainly in our teens.
81. S. sees the process of giving birth as in some senses a "traumatic process."
82. Before he met his wife. S. rarely thought about being a parent. His only thought on the subject was that he didn't want to be one.

83. S.'s ideas about having children were influenced by his knowing the "torture" and "pretty painful times" that he and his siblings put his parents through as teenagers. 
So that influence of your childhood was, it was both positive and negative.

/It was positive in childhood and in teenage years, I really, I really think I was so rebellious as a teenager, I really caused my parents a lot of concern and worry. /But anyway, in my, after I met Leslie and we got together, and we decided after about a year and a half of our relationship to get married. We talked -- my recollection is that we talked a little bit about children and it just didn't seem like a topic of great interest to either one of us at that point. /Leslie had said I think at that point. well. maybe some day, but we don't have to decide right now. /And that was great for me. I was like. okay, we'll be fine. [laughs] Maybe this can just sort of be an ongoing sort of, put-off decision until it's too late. And I think that was my basic approach.

Huh.

/And then, with going into, I was, at the point that we got married, three days later we drove out here for me to start graduate school. And then just with graduate school it just seemed like we were so -- I was so busy and she was busy starting into her new practice. I just. especially during my first two years of graduate school could not have survived it probably with having a child. The first year particularly was just the most miserable psychologically unhealthy year of my life. And it gradually improved to just a low level of torture. [laughs]
84. S. was very rebellious as a teenager and caused his parents a lot of concern. But his earlier childhood has had a positive influence on his thoughts about having children.

85. Before $\mathrm{S}$. and his wife were married. the subject of children came up but it wasn't a topic of much interest to either of them.

86. S.'s wife had said that she might want to have children some day. but that they didn't have to decide right away.

87. S. was happy with the idea of putting off the decision about whether or not to have a child with his wife. He thought that maybe "this can just sort of be an ongoing sort of put-off decision until it's too late."

88. S. started graduate school right after he got married and he felt so busy with the first years of school that he "could not have survived it probably with having a child."

89. The first year of graduate school for S. was "the most miserable psychologically unhealthy year" of his life.

\section{Yeah.}


Actually that's putting it a little bit too strongly. But it was, I don't recall graduate school as an ultimately positive experience. /And all through it -- I mean there were big positive aspects. but a lot of unpleasant aspects too -- and all through it I can remember just thinking that if I had any other responsibilities right now, this would like weigh me down like a stone.

\section{Right.}

/And so that, as it became apparent that a miracle was going to occur and I was going to get finished with the program and graduate, when that happened, it began to become more apparent to me at the point that I defended my prospectus, I thought, yeah, okay, well they've approved my project, I know I can finish this project even if it takes a long time. I was going on internship, and that's when Leslie and started to really more seriously discuss having a child.

\section{During those years previous to that, while you were in school, did you talk about it at all?}

/We were talking about it, but not... usually it took the form of beginning to talk about it then both of us feeling kind of overwhelmed by the idea. Me more so than Leslie, definitely, she, I think she was beginning to feel a little more of a sense of urgency to make the decision.

To make a decision one way or another?

Yeah.
90. Throughout graduate school, S. felt that if he had any other responsibilities "this would weigh me down like a stone."

91. When S. realized that he was actually going to be able to finish his degree, he and his wife "started to really more seriously discuss having a child."
92. While S. was still in school, the subject of children would come up between him and his wife but then they would both feel "kind of overwhelmed by the idea."

93. S. felt more overwhelmed by the idea of having a child than did his wife. She was feeling some urgency to make a decision. 
So it would come up and then it would be just too stressful...

/Well, it would be...I think it would be...I think it would be somewhat stressful and then it was also just this feeling, this conclusion we'd come to that everything is this stressful now, we don't need any other stressors.

\section{Right.}

Right now a child, regardless of how positive it would be to have one, is going to be pretty tough. /And then I also knew I was going on internship and going to be gone, almost unavoidably I was going to be gone for a year. And that really. you know, that's actually an important stumbling block once we started talking about it. It's like, well what are we going to do? I don't want to be gone for the first year of... you know, /it just felt as if we could kind of put it off for a little while and wait until I was done with internship and then, and then if we still felt like we wanted to have a child, then we could. /And we also we're both fairly, Leslie a lot more so than me. fairly financially cautious. And conservative I guess, financially conservative. We just felt like, you know, we want to do this at a time when it doesn't feel financially, like a major strain.

Right.

And so we were, there was that aspect of it. I'm trying to think what your question was.

Kind of walking through the decision, you know, the decision within the relationship. So you went through a period where you just really couldn't
94. While he was still in graduate school, S. felt that regardless of how positive it might be to have a child it would still be pretty tough to have this additional stressor.

95. S. was going to be away for a year on an internship. He didn't want to have a child during that time.

96. S. felt that he and his wife could put off the decision to have a child until he was done with his internship and then "if we still felt like we wanted to have a child. then we could."

97. Both S. and his wife are financially cautious. They wanted to have a child at a time when it wouldn't be a major strain financially. 
conceive of doing it because you were so busy and stressed.

I think both of us, yeah, felt like this isn't a good time to do this. We've got too much going on.

\section{Then what happened from there?}

/Well, I think just beginning to see that our lives were going to change relatively, become relatively less stressful when I finished graduate school. I was pretty unhappy in a lot of respects during graduate school. I just, I think some people are able to thrive in that environment and I always, you know I just can't wait to get done with this. Even though I really enjoy it, an intellectual, academic environment, the evaluative component of it all just got tiresome to me. And I started having this feeling like. I'm too old to put up with this amount of, sort of, feeling of being one-down all the time.

\section{Yeah, right.}

So once I saw that I was going to be finished with graduate school and everything, I started to feel a lot more like, if there's ever a time that's going to be a good time to have a child, it's coming up. /And the time pressures were also significant at that point. We had pretty much -- Leslie felt like. beyond the age of 41 she didn't want to keep trying to have a child. But it was just for...genetic problems, there's just too great a risk.

\section{So there's some pressure coming in.}

Yeah, there started to be a little biological clock urgency.
98. When S. was in graduate school, both he and his wife felt that it wasn't a good time to have a child.

99. Graduate school was an unhappy time for $\mathrm{S}$. His life became relatively less stressful when he finished.

100. Once S. was near finishing graduate school, he began to feel that "if there's every a time that's going to be a good time to have a child, it's coming up."

101. S. and his wife felt "a little biological clock urgency" to make a decision about having a child. They were concerned about possible genetic problems if they waited to long. 


\section{Right.}

The one thing that did sort of, setting it on the negative side of the scale, was this feeling of finally I'm about to be done with graduate school, we'll be able to do all of these things, we're going to travel and we'll just have so much more freedom. I won't be in a sort of semianxious, mildly depressed state...

\section{Right.}

...that it felt like I'd been in for six years, you know, five years. /And, I don't know, I think on balance though we sort of, at least I certainly did, I felt real. that's just kind of not very realistic, my life. life isn't going to change that drastically, there's still going to be pressures, you know, at work, whatever job I end up doing is going to have pressures. It's not going to be like this totally idyllic time.

It's not going to be vacation time.

Right. /So it's not as if this sort of life of leisure is, or that a child is going to prevent me from having a life of leisure and travel. because that wasn't in the picture to the degree that I was hoping it would be anyway. [laughs]

Right. There are plenty of other things that will prevent you from doing that if you don't have a child.

So....

Still there's a lot of stuff I hear sort of as you were edging up on this decision, a lot of stuff that was in your way that you had to work through, sort through.
102. S. felt that since he'd finally finished graduate school he would have more freedom and would feel less anxious and depressed. This weighed negatively on his thoughts about having a child.

103. S. felt that it wasn't realistic to believe that after graduate school his life was going to be idyllic and free of stress. He was still going to have pressures.

104. S. recognized that having a child wasn't "going to prevent me from having a life of leisure and travel, because that wasn't in the picture...anyway." 
Work through, I think.

How did you do that? What was the...what was your process of figuring it out?

/Well, a lot of it. I think, it ended up being a very mutual decision that my wife and I came to. /We had talked about it so much, we agonized over it. And we had explored all these possibilities. Are we doing this just to please our parents? Or to sort of do what married people are kind of like, expected to do? Is there some societal pressure to have kids? /And clearly there is that societal pressure and it may not come very directly, but there's definitely, I feel there's that strong pressure. You hear from a lot of people. well when are you guys going to have kids?

\section{Right, right.}

We didn't want to make the decision for the wrong -- what we felt like would be the wrong reasons. Just because we were, sort of like, what people do, or expect. or.... /So we talked about that quite a bit and I think, you know, we just gradually to some degree talked each other into the more positive view. /I don't know, it's, I mean we were both gravitating in that direction. I think. And there was a little bit of mutual, well this could, you know, this could be an experience that could be just great for us. And we don't know that. You know, it was kind of like, to some degree, let's trust that this is going to be something positive for us.

Can you say more about that, what that is, that trust?
105. S. and his wife came to "a very mutual decision" about having a child.

106. S. and his wife spent a lot of time discussing and agonizing over the decision, asking themselves about their motivations. wondering if they might be acting on the desire to please their parents or on social pressure and expectations about marriage.

107. S. feels a strong but indirect societal pressure to have children. He experiences this when others ask him when he and his wife are going to have children.

108. S. and his wife were concemed that because of social pressures and expectations, they might make the decision for "what we felt would be the wrong reasons."

109. S. and his wife gradually "talked each other into the more positive view" about having children.

110. S. and his wife were both gravitating in the direction of having children. They both started to consider the possibility that this could be a positive experience. They didn't know whether having children would be positive, but they got to the point where they decided to "trust that this is going to be something positive for us." 
/Well...well, I think it was. to some degree, some. going a little bit in the opposite direction of my more cynical view of parenthood /and thinking... you know, an awful lot of people had told us that us that they just really enjoyed their children. That the process, that it does change your life, but that they truly enjoyed raising their children. and seeing them grow, develop and have triumphs and disappointments and just seeing the whole process.

\section{So hearing that from other people} helped?

Y Yeah and. I guess I've always been a little skeptical of that at some level and thinking well, because of cognitive dissonance they have to think that. [laughs]

\section{And now you're there, you're doing} the same thing.

Yeah. /So some, so yeah I think when I say trust, you know, the trust came in maybe thinking well these people aren't solely operating on cognitive dissonance. /there's a. I think my selective attention to the negative has really been blinding me to the fact that there could be some really enjoyable aspects to being a father.

Um-hm. Yeah. For a person with a kind of cynical look at things, the trust, that's like a polar opposite in a way.

Yeah, yeah. /I still have a lot of cynicism about the motives people have...

\section{About other people, yeah.}

111. In making the decision to have a child, S. went against his previously cynical view of parenthood.

112. Other parents had told S. that while having a child changes your life they enjoyed their children. raising them. "seeing them grow, develop and have triumphs and disappointments and just seeing the whole process."

113. S. had always been skeptical of parents who talked about the pleasures of raising children. $\mathrm{He}$ figured that "because of cognitive dissonance they have to think that."

114. S. came to trust that the positive experiences that other parents described to him weren't solely the result of cognitive dissonance.

115. S. came to believe that "my selective inattention to the negative has really been blinding me to the fact that there could be some really enjoyable aspects to being a father."

116. S. remains cynical about people's motivations for having children. In his work he seees the result of "the way that some people operate as parents." 
...for parents, I see an awful lot of...I see the, in our profession we won't be out of work for a long time because of the way that some people operate as parents. /So in that sense I suppose that there's still some really pretty strong cynicism. But it doesn't feel like I'm applying it to myself...in really any way that I was before.

Yeah, that word also makes me, reminds me of what you said in the beginning about trying to make a rational decision about something that wasn't, that had a different component than rational. Trusting is a non-rational process in a sense.

/Yeah, it's not a...yeah, it just doesn't feel like -- it feels like the most irrational decision I've made in my life, I guess [laughs], in some ways.

Yeah.

/And it almost feels like, if I were to list out the positives and negatives on a balance sheet sort of approach, it to some degree feels like it sort of trivializes the whole thing. Especially the positive aspects.

\section{Right.}

/You know, even when I, when I try to articulate some of the more positive things in my life - I just have a very strong love for what I would call the natural world absent of people, um. it's very difficult for me to put into words why that strikes me the way it does. Whenever I do it kind of trivializes, it feels like I'm trivializing the sort of feeling I have about it.
117. S. still has "some really pretty strong cynicism" about parents. but he's not applying this to himself in the way he once did.

118. S. describes his decision to have a child as "the most irrational decision I've made in my life."

119. S. feels that it would trivialize the decision to list out the positive and negative aspects of it on a balance sheet.
120. S. believes that trying to articulate the positive aspects of the decision to have a child -- or of other areas in his life such as his love of the natural world -- winds up trivializing the feelings involved. 
Right. That sounds like the way, yeah, you described having a child as well, sort of, your anticipation of what that is is hard to put into words.

YYeah, yeah it is. It...the more positive, what I kind of think of the positive aspects of it. particularly.

So what, going back to the chronology, you kind of talk each other into it. And where do you go from there? It sounds like, I was going to say or ask, it sounds like the process of making the decision for you happened very much in the relationship.

/Yes, it did.

More than inside yourself? Or is that, was there a kind of internal, solitary part to it as well?

I can't separate it, /because... we started talking about it probably, seriously, five years ago. Where we, you know, where actually we focused on it and discussed it.

\section{Right.}

And we kept intermittently having discussions about it. /And although I was thinking about it for myself, I was just, this is not only my decision. it really felt very much like we had to decide together. And...kind of, it feels impossible for me to really separate at what point it was a more internal process of me deciding yes this is okay, and both my wife and I deciding yes this is okay. /Although I do have to say, I think, looking back on it, I think maybe...I really think that the decision, the mutual
121. For S.. the positive aspects of having a child are hard to put into words.

122. S. cannot separate his own decision process from the process that happened within the relationship.

123. S. and his wife started talking seriously about having a child five years ago -- they kept having intermittent discussions about it.

124. S. finds it very difficult to separate "at what point it was a more internal process of me deciding yes this is okay. and both my wife and I deciding yes this is okay." He was thinking about it for himself, but it was not only his decision. "It really felt very much like we had to decide together."

125. S. feels that "the mutual decision to have a child...preceded my deciding at some internal level, yes this is okay." 
decision to have a child, somewhat, well, it proceeded my deciding at some internal level, yes this is okay.

\section{Tell me about that.}

Yeah, it, it...I was pretty close to that point where the ambivalence felt...or the negative aspect of the ambivalence was waning somewhat and I was feeling definitely more positive about the idea. /And then it really does feel like at some point I had to just philosophically throw up my hands and say what the hell. let's go ahead and do this. /And yet, and I think that it would have been harder to make that decision then internally, if...I have a pretty strong understanding that my wife was ambivalent about it. but that it was also something that she would get a lot of enjoyment. And she'd just be a great mother. /And that was, I think that was part of it too, is frankly just. with all my doubts about being a father, I mean I definitely had misgivings about the child having my childhood temperament because I was a little, you know. looking back on myself as a kid I have to wonder if I was kind of ADHD or something [laughs]. Yeah, and knowing that she would be so, you know, just so nurturing as a mother. AAnd...it made me feel a little more confident as to my role too, you know, just, I think had I been married to someone who I had a lot of doubts. or any doubts about their ability to be nurturing I would have really worried, well the two of us together may really have some problems with a child.

\section{Right, right.}

/So. I tend to be relatively inefficient and disorganized too, and in a lot of ways my wife is much more efficient. And
126. Before reaching the point of deciding to have a child. $S$. was at a point where "the negative aspect of the ambivalence was waning somewhat and I was feeling definitely more positive about the idea."

127. S. reached the point at which he "had to just philosophically throw up my hands and say what the hell, let's go ahead and do this."

128. The decision to have a child was made easier for $\mathrm{S}$. by the knowledge that in spite of the fact that his wife shared some of his ambivalence, he knew that she would be "a great mother."

129. S. had doubts and misgivings about having a child that rose out of his memory of his own childhood temperament. Because of these doubts, he found comfort in knowing how "nurturing as a mother" his wife would be.

130. S. gained confidence about his role in the decision because of his trust in his wife's nurturing ability. It would have been hard to have a child with her if he had had doubts about this.

131. S. was concerned with his disorganization and inefficiency, because he know how much work 
that actually. I mean it sounds like a trivial part of it, but I kept thinking, my gosh, a child just takes so much work and so much daily attention. You know, sometimes I feel like I can barely feed myself [laughs].

\section{So there was some concern about yourself and your own ability to do what was necessary with a child.}

Yeah. /And once I, once I started to feel more sure that she was pretty sure about a child, about having a child, it started to feel more okay to me. /And I think then, you know then I started internally I think more feeling like yeah, this...I've got. certainly still got doubts, but it just feels like this could be...just, we could have a lot of fun together with, start kind of seeing. thinking about ourselves as a family too. I started to be able to do that a little bit more. Although that's still fairly abstract, too.

\section{So thinking about, yeah, thinking about your relationship differently, and how it would change.}

YYeah. yeah, and that was, yeah and that was frankly on the negative side. A lot of our discussions included this, we're pretty happy in general as we are. Why, you know, why throw a wrench in the works, or a potential wrench?

\section{Right. Why risk it?}

Y Yeah, and...I don't know, really sort of how we...resolved that. I don't think we actually ever did come to something I'd call a logical conclusion to that one.

\section{Yeah.}

and daily attention a child required: "sometimes I feel like I can barely feed myself. His wife is much more efficient.

132. Once S. felt that his wife was pretty sure about having a child. "it started to feel more okay to me."

133. Although he still had doubts about having a child. S. began to be able to see the fun that he and his wife could have together. He started to be able to see them as a family. But this is still fairly abstract in his mind.

134. S. was concerned about how having a child would affect his relationship with his wife. He felt since that they were pretty happy, "why throw a wrench in the works?"

135. S. isn't sure that he and his wife ever came to a "logical conclusion" regarding their concerns about how having a child would affect their relationships. 
/Yeah, but we did have some discussions too about how it would affect our relationship. That... when we introduced another person into the equation, the dynamics can start -- of a relationship inevitably change. /And you know, I felt a little bit fearful about that. I think Leslie probably did too, just kind of, how is it going to change what we....

\section{Right.}

/And I had just, in one of my classes had done a lot of reading about the empty nest syndrome. And marital satisfaction during child-rearing and all those things. And it wasn't a real pretty picture, you know what I'm saying? [laughs]

\section{It's amazing anyone who knows about that would have a child, isn't it?}

So, actually the empty nest literature was essentially that marital satisfaction, happiness, tends to go up after the children leave. So being aware of all that. you know, it was like. wow this is... will this be foolish to do this?

Maybe that will prove to be the case. [laughs]

\section{There's a lot of unknowns.}

/It's too late now! [laughs]

\section{Well, that cognitive dissonance will kick in and...}

Right, right, it'll help a little bit, I'm sure. It would help if I didn't know about cognitive dissonance. [laughs]
136. S. and his wife discussed the fact that when they introduced another person into their relationship. "the dynamics... of a relationship inevitably change."

137. S. and his wife were fearful about how having a child would change their relationship.

138. S. was influenced by what he'd read about the empty nest syndrome and marital satisfaction. He knew that marital satisfaction is greater after the children leave home and this made him wonder if it was foolish to have children.
139. S. knows that it's too late now to worry about how having a child will affect his relationship with his wife. He wishes he didn't know about cognitive dissonance so that that phenomenon would help him more. 
So, I'm going to go back to this, you were saying that you, it sounded like you - I want to understand it better you were starting the process, you were starting trying to have a child even before you were all the way there yourself?

/I think...I certainly would not have gone ahead with the process of trying to have a child if I hadn't gotten more towards thinking that this could be a positive thing.

\section{Right, right.}

II really do think that I hadn't sort of fully...it's not the right word because I still have ambivalence about it, but...yeah, I think that there was at some point kind of a. oh, well, I'm not, I've done all the thinking I can do about it, I'm not coming to anything that feels like a logical conclusion, or that, you know, that I've got this balance beam that's weighed way down on this side toward the positive, you know. /So, I'm not going to be able to make a rational decision. /Leslie wants to have a child. And I feel very positive it would be a positive experience. /And you know, once I started feeling more like she was fairly positive - I think it was a litile bit of a bootstrapping process for both of us. We're both kind of. to some degree sort of. monitoring each other on that. /And she was, she had. I'm sure she had no doubt early on that I had great ambivalence about it. much more toward the negative, a lot of fearfulness about it, but definitely a fairly overwhelmingly negative attitude about having kids.

Right. So how was it when you said, okay - I know you said that there wasn't a particular moment you
140. S. wouldn't have started trying to have a child if he hadn't gotten part way "towards thinking that this could be a positive thing."

141. S. did not arrive at "anything that feels like a logical conclusion" regarding the decision to have a child. He'd done all the thinking he could do about it and he still had ambivalence and the balance beam didn't tip all the way toward the positive side.

142. S. recognized that he was not going to be able to make a rational decision about having a child.

143. S. knew that his wife wanted to have a child and he felt certain it would be a positive experience.

144. S. describes the process of making the decision to have a child as "a bootstrapping process" for both him and his wife. They each monitored one another. As his wife felt more positive about it, it was easier for him to make the decision.

145. S. knows that his wife was aware of his ambivalence and fearfulness and his "overwhelmingly negative attitude about having kids." 
know, where you really, an epiphany moment -- but when you started doing it, kind of where you were at this point that you just described... what was happening?

/Yeah, yeah. I remember the sense of relief. Just at...there definitely a sense of okay, the decision's made. Now we've just got to see if it happens, or not. There was still definitely some sense of...have I gone insane? [laughs] /Or have I, am I doing this. am I making this decision kind of casually? And it wasn't really fair to myself because it was anything but a casual decision.

Yeah, yeah.

/But yeah, there was no one moment where it was sort of an "ahah" experience, this is the thing to do. I just never had that. /I did, I'll tell you. there was a moment later one. once we started trying to have a child, Leslie got pregnant and had a miscarriage. And that happened after she was pregnant for about a month and a half. I think that's what we estimated. So there was a period of about five days between when we knew that she was pregnant and when she miscarried. That was pretty early on, like within a month and a half. And it was really much more painful for me than I thought it would be. You know I expected almost, if that happened, to almost feel a sense of relief.

\section{Right.}

/And you know, there might have been this, a mild sensation of that, but mostly it was just kind of a feeling of...it wasn't a feeling of losing anyone in particular, it's not like I had really identified very
146. After making the decision to start trying to have a child. S. felt a sense of relief.

147. After making the decision to start trying to have a child. S. had a sense of wondering "have I gone insane?"

148. After making the decision to start trying to have a child. S. wondered if he was making the decision too casually. He feels this was unfair to himself because "it was anything but a casual decision."

149. S. never had an "ahah" moment during which he realized that having a child was the right thing to do.

150. When S. and his wife first started trying to conceive, his wife had an early miscarriage. This was a much more painful experience than he anticipated. He expected that he would feel a sense of relief. 
strongly with the child, or potential child at that point. It really more was, it did feel like a loss. /And it felt -- I think that that...more than anything, up to this point, made me realize, yeah, this is something I want to do. From a kind of emotional standpoint, not the intellectual.

That makes sense. It sounds like that made you....

It connected it more as an emotional experience more than an intellectual decision.

Right. It sounds like it connected you to the positive stuff too, you know, or it made the....

/Yeah. that there was a sense of loss.

Instead of relief.

And I was really surprised at my own reaction to it. I would have thought that it would have felt like, okay, the freedom and the absence of responsibility is still [laughs] potentially there.

\section{Still a possibility.}

/But no, it turned out to be, it. I don't think. we didn't go through anything what I could call a major grieving process. It...the pregnancy was so short-lived. I mean we had basically five days where we were starting to anticipate it, for getting excited about it. And also I was still like, oh my god, you know, and then the miscarriage happened.
152. The feeling of loss S. experienced when his wife miscarried made him realize not just on an intellectual level but on an emotional level that "yeah. this is something I want to do."
153. S. was surprised at his sense of loss over his wife's miscarriage. He expected to feel that "the freedom and the absence of responsibility is still potentially there."

\section{Right.}

154. S. and his wife didn't go through a major grieving process over the miscarriage because the pregnancy was so short-lived. 
/I just don't think -- if it had happened three months later I think it would have been more -- or even later on - I think it would have been much more difficult than it was.

But it changed the way you felt, going forward?

/Yeah, I think it, again, it almost... helped guide me in more trusting that l'd made the right decision. the sort of disappointment that I felt, the loss.

\section{Right. It was confirming in a way.}

Y Yeah. It was...it was much more acute than the sense of relief. There was that. a little bit of that as I recall. Sort of a sense of, okay, well. But it was much more of a feeling of loss than

a...reprieve.
155. S. believes that if the miscarriage had happened later in the pregnancy, it would have been a much more difficult experience.

156. The disappointment $\mathrm{S}$. felt after his wife's miscarriage helped him to trust that he'd made the right decision.

157. S.'s reaction to his wife's miscarriage contained a bit of relief but much more of a feeling of loss. 


\section{Tobin - Level 3}

S. has gone through distinct periods in his life in terms of his views about having children. Up until he was thirty, he was "fairly definite" that he wasn't going to have children. Before he met his wife he rarely thought about the subject. His only thought about it was that he didn't want to be a parent. The subject of children came up with his wife even before they were married. but it wasn't a topic of much interest to either of them. His wife said that she might want to have children some day, but that they didn't have to decide right away. S. was happy with the idea of deferring the decision. He thought that maybe "this can just sort of be an ongoing sort of put-off decision until it's too late."

Because S. started graduate school immediately after he and his wife got married. the entire question of having children was put on hold until he had finished his degree. The subject of children would come up occasionally between them but they both felt that it wasn't a good time to have a child and felt "kind of overwhelmed by the idea." S. was so busy during his first years of graduate school that he "could not have survived it probably with having a child." Graduate school was an unhappy time for him and the first year in particular was "the most miserable psychologically unhealthy year" of his life. His life became relatively less stressful when he finished, but while he was in school he felt that any other responsibilities would have weighed him down "like a stone." Regardless of how positive it might have been to have a child, during this time it would have been very difficult for him to have this additional stressor.

In general, S. has been "fairly cynical" about parenthood. He feels that people often make the decision to have children "thoughtlessly" or for reasons that don't seem legitimate. He questions people's "thoughtless urge to reproduce without thinking about...the global consequences of it." He feels that people are "just driven to recreate their own protoplasm" in a mindless. biologically-driven way. His perception that other people have children in this thoughtless way led him to decide that he wasn't going to have children in this manner -- and that perhaps he wasn't going to have children at all. He told himself that he wasn't "going to add to the world's problems by having children."

S. continues to have "some really pretty strong cynicism" about people's motivations for having children. As a psychologist, he sees in his clients the results of "the way that some people operate as parents." But while he and his wife were both concerned that social pressures and expectations might lead them to make the decision for "what we felt would be the wrong reasons," he also became aware that he was using some faulty reasoning when he applied to himself the thoughts about parenting that he had about other people. He never thought of himself as "somebody who would just thoughtlessly have children." He came to feel that he might be denying himself "some experience that I really would enjoy." He is no longer applying his cynical beliefs about parenthood to himself in the way he once did. 
Another of S.'s reasons for not wanting a child had to do with his concerns about population. Before he made the decision to have a child, he would look at people with large families and feel resentfully toward them because they'd "cancelled out" his efforts on behalf of population control. He believes now that this was a futile way to think. He thinks that his concerns about population and about people reproducing thoughtlessly were partly a justification for his own worries about the responsibility and loss of freedom that having a child would mean for him personally. One thing that helped him make the decision to have a child in the face of these concerns was his understanding of the dynamics of population growth. Because he and his wife are both older. the impact on population if they have a child is less than if they were young. When they made the decision, they decided that they would probably only have one biological child. although they might adopt a second. Now that they have made the decision to have one. they continue discussing the possibility of having more than one. They have considered adopting a Chinese child. About each of these possibilities. S. says "we'll see how this goes for the first year."

S. and his wife were both fearful and concerned about how having a child would affect their relationship. They knew and talked about how when another person is introduced into a relationship, "the dynamics... of a relationship inevitably change." S. was also influenced by what he'd read about the empty nest syndrome and marital satisfaction. He knew that marital satisfaction is greater after a couple's children leave home and this made him wonder if it was foolish to have children. He wondered. since he and his wife were pretty happy, "why throw a wrench in the works?" He is aware that it's too late now to worry about how having a child will affect his relationship with his wife.

Many of S.'s reasons for not wanting to have a child centered around issues of freedom and responsibility. He wasn't sure that he wanted the responsibility that parenthood would involve and he was concerned that in having a child he would lose his freedom. These worries were "not really focused." They concerned "the burden of responsibility" for a child who won't be able to function without the constant presence of him and his wife. The idea of a child being completely dependent on him "strikes a little awe" in him. He has never before experienced the level of responsibility that comes with having someone so dependent on him. This is more frightening in part because it is unknown. He is frightened by the idea that "once the child is born, it's a lifelong... responsibility." He thinks about how with a dog you can drop them off at a kennel - and even that is unpleasant for him to do.

When he has imagined having a child, S. has had "this feeling of I'm going to lose my freedom to do whatever I want to do... when I want to do it." He thought about how much his life would change and what a big loss it would be. He thought about the sort of things he was able to do without a child and imagined he'd never be able to do them again. When he finished graduate school, he looked forward to having more freedom and feeling less anxious and depressed. Because of this, he was reluctant to take on the new stress and responsibility of having a child. But he feels now that it wasn't realistic to believe that after graduate school his life was going to be idyllic and free of stress. He 
was still going to have pressures. He recognized that having a child wasn't going to prevent him "from having a life of leisure and travel. because that wasn't in the picture... anyway." He wonders now if his fear of losing his freedom when he has a child is "a little bit illusory," since the responsibilities of marriage already mean that "I don't have complete freedom just to pick up and go where ever I want, any time."

S. had always been skeptical of parents who talked about the pleasures of raising children. He figured that "because of cognitive dissonance they have to think that." $\mathrm{He}$ saw how parents cherished and loved and enjoyed their children. But he also saw "the pain that parents went through with children." Parents told him that while having a child changed their life, they enjoyed their children, raising them, "seeing them grow. develop and have triumphs and disappointments and just seeing the whole process." He has now come to trust that the positive experiences that other parents described to him weren't solely the result of cognitive dissonance. He has noticed that other parents have difficulty putting their experiences into words. Based on his conversations with parents, he believes that the experience of having a child is an "ineffable kind of, difficult to explain kind of feeling." He remembers talking to one parent in particular. a very articulate woman who was unable describe the experience of having a child beyond saying that it was a feeling of love that was different from anything she'd experienced before.

S. has only seriously considered having children in the last four or five years. Up until then he had not really pictured himself as a father. He went through "quite a bit of agonizing" about the decision. His memory of his own childhood has influenced him both positively and negatively in making that decision. His doubts and misgivings about having a child rose out of his memory of his own childhood temperament. especially as a teenager when he was very rebellious and caused his parents a lot of concern. He thought back to the "torture" and "pretty painful times" that he and his siblings put his parents through as teenagers.

Because of these memories. his view of being a parent was "relatively negative" until he started thinking about some of the positive aspects of his own experiences of childhood. Remembering his early childhood made him feel more positively about having a child. As he thought back to his enjoyment of his own childhood. the idea of having a child became "slightly more appealing" if still "not real compelling." $\mathrm{He}$ remembers the things he learned from older relatives -- days spent fishing with his grandfather, how his parents and grandfather shaped his love of the outdoors. He says that these experiences were "nothing incredibly profound," but he values and appreciates them and has felt some desire to pass on the knowledge he gained by exposing his own child to similar things. He would like to pass on to his child this opportunity to experience and appreciate the natural world.

S. came to understand that when he had imagined parenthood in the past he had been selectively negative. He tended to focus selectively on "all the pain, the worries, the anxieties" that he observed parents going through, rather than the positive aspects of parenthood -- which were more abstract and difficult to imagine. In general, when he 
thought about having children, "the negatives seemed very concrete... and the positives seemed somewhat more abstract." He still finds the positive aspects of having a child hard to put into words. An example of this was his belief that he would lose his freedom when he had a child. He saw that people with children were in fact doing the sorts of things he imagined we would no longer be able to do. As he puts it. he came to see that "my selective inattention to the negative has really been blinding me to the fact that there could be some really enjoyable aspects to being a father."

In making the decision to have a child. S. was working against his previously cynical view of parenthood. The balance between the positives and negatives "began to slowly creep" for him through his thirties, "so that the negatives seemed mighty concrete but the positives began to seem a little bit more like things I could sort of put into some sort of images." The process of moving from his cynical view about having children to making the decision to have a child wasn't a single great leap but rather a gradual recognition that "maybe it's not such a terrible thing to have a couple of children." He thought that "maybe it could be a really positive thing." He began to realize that "maybe there would be some things that would be kind of fun about having a child, some more positive things." The positive aspects of having a child began to seem "more plausible" to him, "or more appealing." He began to be able to imagine more concretely what it would be like to watch a child learn and develop. He imagined sharing his own positive experiences, and providing "the environment for a good childhood." He was able to imagine himself "involved in that whole process" of raising a child. He recognized that having children would place restrictions on his freedom. but that this wouldn't last forever. He reached a point where "the negative aspect of the ambivalence was waning somewhat" and he "was feeling definitely more positive about the idea."

S. and his wife started talking seriously about having a child five years ago - they had episodic, intermittent and seemingly endless discussions about the prospects of having a child and the pros and cons of it and how each of them felt about it. They had long discussions in which they tried to figure out if they wanted to have a child. why they would want one, and what the positives and negatives of having one would be. They spent a lot of time discussing and agonizing over the decision, asking themselves about their motivations, wondering if they might be acting on the desire to please their parents or on social pressure and expectations about marriage. S. is aware of a strong but indirect societal pressure to have children. He experiences this when others ask him when he and his wife are going to have children.

In addition, their discussions were made more serious by the fact that $\mathrm{S}$. and his wife felt "a little biological clock urgency" to make a decision one way or another. They were concerned about possible genetic problems if they waited too long before having a child. Because his wife was nearing forty, they knew that if they wanted children they had to have them fairly soon. The timing of S.'s academic and professional life also played a role in the decision. Both he and his wife are financially cautious and they wanted to have a child at a time when it wouldn't be a major strain financially. They "started to really more seriously discuss having a child" at the point when he realized that he was actually going to be able to finish his degree. He knew he didn't want to have a 
child while he was away for a year on his internship and he felt that they could put off the decision until he was done with his internship. Then "if we still felt like we wanted to have a child, then we could." Once he was near finishing graduate school. he began to feel that "if there's every a time that's going to be a good time to have a child. it's coming up."

Once he recognized that having a child could be a positive experience and that it wasn't irresponsible to have one or two children. S. began to lean more toward the idea of having one and was eventually able to make that leap. Up until this point. he had recognized that there were positive aspects to having children. but he says that "none of it felt like it would be very positive for me personally." He didn't have an image of what it would be like to be a father. "It was more just this balance sheet." And when he was trying to make the decision about whether or not to have a child, it felt "more like there was going to be a loss than a gain, overall, that there were more losses than gains."

Together with his wife, S. had struggled to make a logical decision about having a child. But at some point he realized "this is not really a logical decision in a lot of ways." He isn't sure that he and his wife ever came to a "logical conclusion" regarding their concerns about how having a child would affect their relationships. There were some purely logical components to making the decision to have a child. Was he financially ready? Did he have the temperament to be a parent? Would he be able to spend enough time with the child? In making the decision to have a child, he tried to go through a process of "balancing the negatives and the positives." But in the end, it "felt like it was more sort of an emotional decision. or a decision of the heart than of the mind." The decision was "based upon just a feeling" rather than on having weighed the positives and negatives and seeing where the balance fell. He feels now that it trivializes the decision to list out the positive and negative aspects of it on a balance sheet. He believes that trying to articulate the positive aspects of the decision to have a child winds up trivializing the feelings involved.

S. and his wife had both been gravitating in the direction of having children. They both started to consider the possibility that this could be a positive experience. $\mathrm{S}$. knew that his wife wanted to have a child and he came to feel certain it would be a positive experience. But still he never arrived at "anything that feels like a logical conclusion" regarding the decision. He had done all the thinking he could do about it and he still had ambivalence and the balance beam didn't tip all the way toward the positive side. He recognized that he was not going to be able to make a rational decision about having a child. The question for him became "do we want the experience of having a child and trying to raise a child?" The decision came down to "just saying, yes we want the experience."

There was no one moment when S. switched from not wanting a child to wanting one, or from being uncertain to being certain. "There wasn't any epiphany," he says, "where it was suddenly like I see where, I fully understand now that I want to have a child and I have no doubts." He never had an "ahah" moment during which he realized that having a child was the right thing to do. There was simply a point at which it started 
to feel "more like yes, this is what I want to do, have a child." He and his wife didn't know for sure whether having children would be positive. but they got to the point where they decided to "trust that this is going to be something positive for us." He reached the point at which he "had to just philosophically throw up my hands and say what the hell. let's go ahead and do this." In this sense, he describes his decision to have a child as "the most irrational decision I've made in my life."

S. cannot separate his own decision process from the process that happened within the relationship. He and his wife came to "a very mutual decision" about having a child. He finds it very difficult to separate "at what point it was a more internal process of me deciding yes this is okay, and both my wife and I deciding yes this is okay." $\mathrm{He}$ was thinking about it for himself, but it was not only his decision. "It really felt very much like we had to decide together." He says that "the mutual decision to have a child...preceded my deciding at some internal level, yes this is okay." He describes the process of making the decision to have a child as "a bootstrapping process" for both him and his wife in which each monitored the other's feelings and reactions. He felt more overwhelmed by the idea of having a child than she did. She was aware of his ambivalence and fearfulness and his "overwhelmingly negative attitude about having kids." She was feeling more urgency to make a decision. As she came to feel more positive about the decision. it became easier for him to decide. Gradually they "talked each other into the more positive view" about having children. Once he felt that his wife was pretty sure about having a child he says, "it started to feel more okay to me."

The decision was made easier for him by the knowledge that in spite of the fact that his wife shared some of his ambivalence, he knew that she would be "a great mother." Because of his own doubts, he found comfort in knowing how "nurturing as a mother" she would be. He worried about his own ability to be a good enough father. He was concerned with his disorganization and inefficiency, because he know how much work and daily attention a child required: "sometimes I feel like I can barely feed myself. His wife is much more efficient. He gained confidence about his role in the decision because of his trust in his wife's nurturing ability. It would have been hard to have a child with her if he had had doubts about this.

S. says that he couldn't have started trying to have a child if he himself hadn't gotten part way towards "thinking that this could be a positive thing." But he continued to have doubts even after he had made the decision and had started trying to conceive a child. He wondered "have I gone insane?" He wondered if he was making the decision too casually. He feels this was unfair to himself because "it was anything but a casual decision." After making the decision to start trying to have a child. he felt a sense of relief. But he still hasn't arrived at the point where he has no doubts about the decision. $\mathrm{He}$ and his wife both still have a lot of ambivalence about having a child. "I still struggle with the idea," he says. "I still wake up at night thinking, oh my god." He continues to worry about many of the same things that he worried about before making the decision to have a child. He knows that he's always going to have some doubts about the decision. His thoughts in this regard begin with the birth itself. He knows that his wife has some 
fears about the medical aspects of delivering a baby. She knows "it's not all a joyful process." He sees the process of giving birth as in some senses a "traumatic process."

S. expects that he will continue to have doubts about "the whole... fatherhood package." Because he can be a pessimist, he feels that he'll have to give himself some "pep talks." But he doesn't have the sense that everything about having a child has to be positive. He and his wife discuss their fears about it and he feels that it's healthy to be able to express those feelings. He still has doubts about having a child. but he is also beginning to be able to see the fun that he and his wife could have together. He's aware that having negative thoughts about having a child feels incompatible with the excitement and anticipation that he is also experiencing. He sometimes wonders whether his current positive feelings about fatherhood are in part due to cognitive dissonance. He is aware of a modest amount of cognitive dissonance in his thinking -- because he knows he's going to have a child he gears himself up for it mentally. In some ways he wishes he didn't know about cognitive dissonance so that that phenomenon would help him more.

Since his wife has been pregnant, S. has started looking at things around him differently. He tries to recall how things looked to him when he was a child. Although he has not had much success in getting back to seeing things the way he did as a child. he does recall the pleasure he took as a child in outdoor recreation activities with his family and friends. Although this new view of himself is still fairly abstract in his mind. he has started to be able to see himself as part of a family. Before making the decision. his positive feelings about parenthood were "forced." Now he starts thinking spontaneously about things he would like to do with the child. He is starting to look forward to having a child. He is starting to think about having a child as an adventure. He looks forward to it without having to force himself.

S.'s positive feelings about parenthood were confirmed in a surprising way when his wife had an early miscarriage. He expected that he would feel a sense of relief in reaction to this event. that he would feel that "the freedom and the absence of responsibility is still potentially there." But instead of relief, he experienced much more of a feeling of loss. He was surprised to find that the miscarriage was a much more painful experience than he had anticipated. This feeling made him realize not just on an intellectual level but on an emotional level that "yeah, this is something I want to do." The disappointment that he felt helped him to trust that he'd made the right decision. He and his wife didn't go through a major grieving process over the miscarriage because the pregnancy was so short-lived. but he believes that if the miscarriage had happened later in the pregnancy, it would have been a much more difficult experience.

S. is aware that "there's some intangible sort of ineffable things that happen when you have a child." He understands this from listening to other parents describe their experience and although he hasn't yet felt these changes himself, he expects that they will happen to him. Having not experienced what it's like to have a child, he feels like he can only speculate about it, that he can only guess about the emotional changes to come. He imagines it will be a feeling of love quite different from those he has known in the past. 


\section{Tobin - Level 4}

S.'s thoughts about having children have been shaped by both his memories of his own childhood and by his observations of other parents. When he thinks back to his childhood he tends to remember the pain and trouble that he caused his parents as a teenager. And when observes other parents he sees the pain and trouble that their children were causing them. In general. he has a cynical attitude about parenthood. He mistrusts the human impulse to reproduce, seeing it as a mindless urge which creates psychological problems for children and population problems for the planet. In recent years, however, his thoughts and feelings about parenthood have evolved. He has come to realize that he was being selectively negative in both his own memories and his observations of other parents. With some difficulty he has been able to separate his negative view of the unconscious human reproductive impulse from his own highly. conscious personal decision about whether or not to have a child.

As he came to acknowledge the possibility that having a child was not necessarily irresponsible and that it might be a positive experience for him, it became easier for $\mathrm{S}$. to remember the positive aspects of his own childhood. This was a significant change in perspective, as he has found in general that the negative aspects of parenthood tend to be quite concrete and easy to picture while the positive aspects are more abstract and difficult to imagine. Even very articulate people, he has found. have trouble putting the positive side of parenthood into words. By drawing on positive experiences from his own childhood, $\mathrm{S}$. began to be able to transcend to a certain degree his general cynicism about parenthood. In the past he had tended to discount the positive claims of other parents, believing that they were the distorted result of cognitive dissonance. Now he believes that these claims are at least to some extent genuine.

As he became more willing to explore the possibility of having a child. S. faced a new dilemma: what was an appropriate way to make the decision? He was unwilling to have a child without addressing this question. which involved weighing a variety of practical, moral and social concerns. Chief among these was a question about whether he had the temperament that would allow him to constructively accept the responsibilities of parenthood. When he thought about having a child he pictured a balance sheet of gains and losses, on which the losses far outweighed the gains. The foremost of these loses was his freedom. He was overwhelmed when he thought about the duration of the responsibility involved in having a child and by the degree of dependence that a child would have on him. He believed that in making this decision he faced an all or nothing choice between parenthood and freedom.

The evolving process which S. went through in making his decision was mirrored by and intimately bound up with the decision-making process that took place within his relationship with his wife. They began their relationship with no clear agreement on the subject of children and this uncertainty made the subject a stressful one which arose intermittently and always remained unresolved. Because of his cynicism about parenthood, S. partly hoped that he and his wife would defer the decision indefinitely until it was too late. But their advancing age made them feel some urgency to make a 
conscious choice. They agonized over the decision together, analyzing the pros and cons. scrutinizing their motivations, trying to distinguish between their genuine desire for a child and their responses to social pressures and expectations. They were aware that having a child can affect a relationship in negative ways and they worried about what the impact of a child would be on their marriage.

While the mutual decision to have a child ultimately preceded S.'s personal decision, the two processes went on simultaneously and played off of each other in a way which he describes as "bootstrapping." The increasingly positive feelings of one reinforced similar feelings in the other. Because of the dialectical nature of this process. S. cannot separate the internal process by which he arrived at the decision from the process through which he and his wife arrived at the decision together. He found that his perception of his wife's nurturing qualities gave him a confidence which counteracted his doubts and ambivalence about the decision.

Slowly for $\mathrm{S}$. the balance between the positive and negative aspects of having a child began to shift. This transformation occurred gradually. At first it had a hypothetical quality: "maybe" having a child could be a good thing. He began to construct a more concrete image of what it would be like to be a parent. In so doing he became more able to project his current identity into the future role of father. He also revised his ideas about the loss of freedom that he feared he would experience as a father. He acknowledged that this loss wouldn't be as absolute as he had previously imagined.

As S. and his wife gravitated toward having a child together, they had struggled to find a logical way to make the decision. Eventually S. had to accept that this was not a decision which could be rationally made. He had tried to make the decision by weighing the positives against the negatives. But he came to realize that there was no process which would allow him to come to an unequivocal decision on this matter. Instead he had to accept that the ambivalence he felt was going to remain with him no matter what decision he made. Thus the nature of S.'s question began to shift. What he had perceived as a positivistic inquiry now became an existential choice. Instead of asking whether having a child would be positive or negative for his life. he began asking whether or not having a child was an experience which he wanted to have. Gradually he realized that his desire to experience fatherhood was more important to him than were his logical arguments against having a child. He thus experienced the decision to have a child thus as a philosophical leap, a deeply "irrational" decision, in which he discarded his logical concerns in favor of a choice for an experience about which he felt profoundly ambivalent.

The change in S. which led to his decision to have a child was an evolutionary process. It didn't happen in a single epiphanic moment. And the balance between positive and negative feelings, between rational decision-making and the desire for experience, has continued to shift through the conception and pregnancy. S. continues to feel both an excited anticipation and a worried ambivalence. His relief at having come to a decision rests beside his continuing doubts. These doubts themselves as intrusive, worried thoughts: what have I done? He continues to worry that he has made the wrong 
decision or that he has made it for the wrong reasons. And he has new worries as well. which center around the "traumatic" quality of the birth itself and of the medical risks involved.

The fact of the pregnancy has made S. look at the world differently. He finds himself trying to see things through a child's eyes. Without forcing himself he is looking forward to being a father. The pleasure of anticipation has been added to his awareness of the burden of responsibility. This change in attitude was brought home by his reaction when his wife had an early miscarriage. Instead of feeling relief. he experienced a surprising sense of loss and pain. He found that he was more emotionally committed to the decision than he had realized. Although he can't yet comprehend how, he knows that this decision will transform him. He anticipates experiencing a feeling of love that is quite different from anything he has known in the past. He has achieved a sense of balance between his cynicism about parenthood and his need to express honestly the negative feelings that he knows he will continue to experience. He is coming to trust that he has made the right decision. 


\section{Appendix E}

Evan: Data Analysis

Levels 1-4 


\section{Evan: Levels 1-2}

I know that you've made the decision recently to have your first child and I'd like you to tell me about the experience of making that decision.

/Well, it was...I guess we had been talking about it for quite awhile. I guess back in the earlier part of this year we were seriously contemplating it. /We decided that we were going to wait until June and see where we were at, and we'd kind of go from there as far as, how are things looking, are we staying here in the state, am I happy at the shop, blah blah blah blah blah. So we said okay. We'll wait until June. /That was tough for Alice. She wanted -- she's been wanting kids since the day we got married. /And I wanted kids, but I wanted to be more...a little more stable. /Then in June... June came and we talked about it. I was, I guess I was still a little unsure if I was, if this was the right time. /Just because... I'm not happy at work. And I know that I want to go somewhere else, to provide a little better for the family. And that would mean moving out of state.

\section{Right. That would be a big change.}

/So, with mulling it over, contemplating it, like, well, even if we have a little one, it's not that tough to move. Yeah, it would be a little hard on the baby. But overall it probably won't be too bad, it's not going to be like, okay, we're going to move when she's eight months pregnant. Mmmm, no. /So, you know another thing, when we started a family I didn't want to feel trapped at a job. Like, okay, we have a family going, you know, I'm unhappy, yes we have insurance, yes for everything, so I'm going to need to stay. 


\section{Right.}

/So. But, as it is right now, I think we made a good choice of starting when we did.

So, you wanted to be more stable. Could you tell me what that is for you.

Um, a little more, more job stable. I mean, somewhere where I was happier than I am now. $\mathrm{Um}$, financially I know one is never, ever ready. So you can't say, we're going to wait until we're financially ready because you know, it'll never happen. /But I just wanted to be more stable in a job that I was enjoying more and kind of felt, felt happy to go, versus, well, gotta pay the bills, time to go to work.

\section{Right, right. That work was a big} factor it sounds like, a major factor.

Yeah, um-hm.

\section{Were there other issues that you considered?}

/Well...deciding to, no. I just, I think it was just a basic case of very cold feet.

\section{Hm. Can you tell me about that, what} the cold feet were?

/Well, whenever we talked about it I always tried to avoid the issue. Like, no, I just... and then try to just leave it at that. /Alice would poke and prod and try to get me to talk about it. And I think that it's - let me back up.

\section{Okay.}

/Um...I think that I wasn't happy at the
9. S. feels like he and his wife made "a good choice starting when we did."

10. S. wanted to be happier and more stable in his job before having a child.

11. S. believes that a person never feels financially ready to have a child and that there is no point waiting for that to happen.

12. Before having a child. S. wanted to be "more stable in a job that I was enjoying," rather than just going to work in order to pay the bills.

13. In making the decision to have a child, $\mathrm{S}$. had "a basic case of very cold feet."

14. Before making the decision to have a child, $S$. would "always try to avoid the issue" whenever it came up with his wife.

15. S.'s wife would "poke and prod" him and try to get him to talk about having children.

16. Because S. wasn't happy at his 
shop, so I wanted to wait. And that's why I was always, no, no, no. Just, let's just wait. And I was telling her that -- I told her that I didn't want to feel trapped at the shop. That if something better came along, I was going to take it. Um, I think that was about it. I mean it was just. I was always trying to avoid the...the discussion.

And so the cold feet was sort of a, not wanting to deal with the work situation?

/Well, I think the work situation was having the...helping me -- that was the excuse in my head I was using. Work. Okay, let's not try for a family yet, I don't. I'm not ready. Right. Because in my mind, I wanted to be at a different job. be more stable. before we tried.

Right. So that was the excuse. Was there, was there more? Was that an excuse for something?

/Oh, no, I don't think so.

Okay.

I haven't been able to think of anything else. Now that it's happened, I always wonder why I waited.

Uh-huh. Right. So you had discussions and you kind of tried to put it off and not deal with it.

/Yeah. I am like my father, I'm a man of few words. And Alice has to pull information out of me.

So...you wanted to have children, but you weren't sure that it was the right time. work. he wanted to put off having a child. He told his wife that he didn't want to feel trapped at his job and that if something better came along he was going to take it.

17. S. "was always trying to avoid" discussing the question of children with his wife.

18. S.'s work situation was the excuse he used to delay making the decision to have children. He wasn't ready to "try for a family" yet because he wanted to be at a more stable job first.

19. Now that his wife is pregnant, $\mathrm{S}$. wonders why he waited so long.

20. Like his father. S. is "a man of few words." His wife has to pull information out of him. 
/Yeah. I knew I always wanted kids. But I wanted to make sure that I was ready. /And of course everyone says, you're never ready. But I think there's a point when you're not ready and when you're not not ready.

\section{Hm. What do you mean by that?}

/Well, everyone says you're never ready to have kids, usually. Like financially ready, you're never ready. There's no way you'll ever be ready financially. /But then there's a point also when you're just plain not not ready, meaning, where can we pinch from to have money to provide for this little one. Because, what, like bills, like okay well, we've got bills from now until eternity, we can't very well say oh, excuse me Mr. Bill Collector, we need to pay you less because we have a baby on the way. They're not going to go for that /and that's kind of what I mean by not not ready. There's a point where you're really really not ready and when you're just not ready.

\section{Uh-huh. So it's, there's kind of less in the way.}

The lesser of two evils, so to speak.

\section{Huh.}

/I guess would be the way, I mean, if there's absolutely no way you can provide in any way, shape or form. then you're just, there's no way. But then if you're, if you can pinch and. okay, well, we can do without this. and you're just not ready, you just don't, you're not ready to make the lifestyle change. so to speak.

\section{Right. So less to change, as opposed}

21. S. always knew he wanted to have children. but he wanted to make sure he was ready before he did.

22. S. knows that "everyone says, you're never ready" to have children. But he thinks "there's a point when you're not ready and when you're not not ready."

23. S. knows that people say you're never ready to have children. For example, you're never ready financially.

24. S. believes there's a point when "you're just plain not ready" to have children. This is the point at which you acknowledge that while your bills will never go away you start asking "where can we pinch from to have money to provide for this little one?"

25. S. says that "there's a point where you're really really not ready and when you're just not ready."

26. S. sees in the issue of readiness to have children a distinction between being truly financially unable to provide for a child and having the ability to do it by "pinching" but not yet being ready "to make the lifestyle change." 
to something that would really be

a...disaster.

Um-hm.

But at the point, you're still at a point where you don't have to do it yet, you could put it off. And I'm wondering what kind of, what kind of tipped the balance for you?

Um....

Was there a moment where you were sort of, that you can identify, where you kind of said okay, let's do it?

Could you talk about that a little bit?

No, not. I mean...I figured it was going to be, I mean Alice has talked to lots of people and they said oh, yeah, it took us a year and a half, it took us two years, it took us...this long. And we were both thinking. good lord! And we'd gone to Barnes and Noble and I'd been reading books and she'd been reading books and it's like, you're damn lucky if you get pregnant!

Yeah, some of those will really make you feel that way.

I mean, it's like... geez. /And I guess there wasn't really any one point that it was, um, like okay, let's just go for the gusto, let's try. /Um, the first month we tried, she had a lot going on. She had her wisdom teeth pulled and all that and it didn't happen and she was crushed. /But I'm one that doesn't get my hopes up. So my let down -- she didn't -- my let down wasn't that bad. I mean. I was disappointed, yes. But it wasn't like...the world stopped.
27. From reading books and talking to other parents, S. and his wife had gotten the idea that it would take them a year or two to get pregnant. He had the impression that "you're damn lucky if you get pregnant."
28. There was no one point in making the decision to have a child at which S. said "okay let's just go for the gusto, let's try."

29. When $\mathrm{S}$. and his didn't get pregnant after trying the first month, his wife was "crushed."

30. When they didn't get pregnant after trying the first month, S. was disappointed but not too badly. He's the sort of person who doesn't get his hopes up too much.

Right. 
/And I'm thinking to myself. and she even said, that there's no way she could handle a year and a half of tries and fails and wanting so much.

Yeah, monthly disappointments.

Um-hm. /So, I never got my hopes up but I figured well, if we try and it happens... great. It was just one of those, okay, we'll try. /Because she was ready a hundred and twenty percent. I wasn't up there.

Yeah. So you were okay if it took a little while.

Yeah. And it took two months.

Which is not that long.

No, but...long enough. [laughs]

Yeah, it's also very long. I understand. So I guess I'm still trying to understand a little bit and I'm wondering if you can kind of walk me through how the balance tipped for you, sort of inside your experience, from...still holding off, putting off this discussion to--

/Um. we started talking about it more. Um. one I knew the issue was not going away. I mean, I'm going to have to talk about it in one way, shape or another, /so I just...okay. You wanted me to talk about it. I'm going to talk about it. And...she still had to pull. /But then we talked about it more and I guess it was kind of like, I could see where she was coming from as far as, I mean that's all she ever wanted to be was a wife and a mom. So we had one of the two taken care of, we just didn't have the other one taken care of quite yet. /And she didn't
31. S. felt that there was no way his wife could handle a year and a half of unsuccessful attempts to get pregnant when she wanted it so much.

32. S. never got his hopes up about his wife getting pregnant. He figured "if we try and it happens...great."

33. S.'s wife wanted a child "a hundred and twenty percent." S. "wasn't up there" at the level of enthusiasm.

34. It took S. and his wife two months to get pregnant.

35. When S. and his wife started talking more about having a child, S. "knew the issue was not going away." $\mathrm{He}$ knew that he was "going to have to talk about it in one way, shape or another."

36. Because he knew he was going to have to talk with his wife about having a child, S. did. But "she still had to pull."

37. As S. talked with his wife about having a child, he could see "where she was coming from." All she had ever wanted was to be a wife and a mother. 
want to wait until we had our bills paid off because we'd be waiting another four years. And I knew I didn't want to wait that long. /So it was kind of more or less, okay, when, when do I want to start? /And I mulled it over in my head, thinking about it at work... and all that, I would think, well...I guess it won't be, it isn't going to be that bad. /I mean. it's not a question of, Am I going to be a good father? It wasn't, it was never anything like that. /tt was...Am I really ready? And the more. the more I thought about it, it's like... well, yeah, I am ready. /Because, like when our next door neighbor comes over, she's got a little. a little boy and an older girl. I love playing with them. I'll sit there and mess around with them and I usually. David is her son and I usually mess around with David more than Jodie. And Alice would say stuff like, you know, you ought to see how you are when you're around David. So I sort of started thinking about it. Yeah. I do do a good job, don't I?

\section{$\mathrm{Hm}$. So that was a real confirmation then.}

Um-hm. Yeah, it was like, I think I can do this. It will take a couple of years to get where David is, but.... [laughs]

\section{Right.}

You can't very well go chasing a brand new baby around the house or anything, so.

Right. That's cool. That makes a lot of sense. The...I'm trying to remember the phrase you used..."am I really ready for it yet?" I wonder if you can talk about that, kind of, as you thought about that question, I
38. S.'s wife didn't want to wait until they had their bills paid off before having a child. She felt that would be too long.

39. The question for S. came down to: "when do I want to start" trying to have a child?

40. As S. mulled over the decision about when to start trying to have a child. he thought that "it isn't going to be that bad" to have a child.

41. S. never had any question of "am I going to be a good father?"

42. The question for $S$. was "am I really ready" to have a child? The more he thought about it, he realized that "yeah. I am ready."

43. In making the decision to have a child. S. thought about how he enjoyed playing with his neighbor's children. His wife pointed out to him how he played with them and this got him thinking "I do do a good job, don't [?"

44. Although he recognized that it would be a few years before his own child was at the same point as his neighbor's children were, playing with them made S. think "I can do this." 
know you weren't concerned that you would be a good dad, but kind of, what "being ready" inside yourself meant?

/I guess I really didn't realize how ready I was until I went with Alice on Friday to the first appointment. We're sitting there, we're talking to the midwife and stuff and she's checking everything out and says, just with her exam and talking with us she figured that everything was going really great and all that, and then when we had the ultrasound done I could see the little baby. Then when I heard the heartbeat...I melted. I was like, there's no way I'd ever pass this up.

Yeah.

/And I knew right then that yeah. I am definitely ready, it was just, it's so hard to describe that feeling. I mean it just, you're looking at the picture and the ultrasound tech is going yeah, everything looks great and this is this and she's taking measurements and doing all this stuff and then she put on the heartbeat...it was just, the heart beating, and I just melted. /It's just like... why did I put this off? Why was I so...? And I can always, the only thing I could come up with was I'm...stupid! I don't know anybody that would want to pass this up. It was just like you. why were you so put off about this when it makes you feel so good?

So people do have worries, they have worries of Am I ready?, you know, that's a pretty big and common kind of worry. And I'm wondering, you know, still, what was in that worry for you? What were you worried about? You talked about the money and the job stuff, but sort of more personal?
45. S. didn't fully understand how ready he was to have a child until his first doctor's appointment at which he saw an ultrasound of the baby and heard the heartbeat. At that point he "melted." thinking "there's not way I'd ever pass this up."

46. S. finds it hard to describe the feeling he got at the doctor's office when he was hearing that the baby "looks great" and seeing the ultrasound and hearing the heartbeat. He "just melted."

47. When $S$. heard the baby's heartbeat at the doctor's office. he wondered "why did I put this off?" He thought he'd been stupid to do so and asked himself "why were you so put off about this when it makes you feel so good?" He thought that he didn't know anybody "that would want to pass this up." 
Um.... I had all kinds of stuff going through my head. I had...I worried about work and staying in Montana. I want to get ahead in life, I know I want to move, I don't know how well Alice's going to take it. Yet I know I don't want to stay here. I'd love to. I mean, we could survive. But it would just be surviving.

\section{Right.}

We'd still be living paycheck to paycheck. I want to stop that as soon as I can. $/ \mathrm{Um}$. I talked to a friend back in California. He had...talked with...some old friends of mine and his in high school. And it brought back some feelings for a woman that never, that I was never able to act upon. And, so I kind of was going, dang, because I haven't talked to this person in probably, two and a half, almost three years. I talked to her on the phone one month. the next month I called back, the phone was disconnected, it was just one of those.... And we had grown really close when I was in the service, because I kept in touch. I always saw her. So that was kind of swimming around in my head. /And I guess the big thing was just.... is it...am I in the right situation to do this now?

What did you...what did you imagine? This is kind of before you had that kind of click with the neighbor kids, where you really sort of realized that you could from there be a good dad. But I wonder what you imagined it would be like when you thought about it, at that point?

/Imagined...being a dad?

Yeah.
48. S.'s worries about having a child involved his job and whether or not they would be moving. He wants to move. in order to get ahead and not just be surviving paycheck to paycheck the way he is now. He's not sure how his wife will feel about this.

49. As he was trying to make the decision to have a child, $S$. was reminded of a woman he had been in love with in high school and for whom he still had feelings. He hadn't talked to her in almost three years and it was upsetting to hear about her again.

50. In making the decision to have a child. S. wondered "am I in the right situation to do this now?"

51. When he imagined being a father, $\mathrm{S}$. thought about how it would be when 
I...everything that I had imagined was later. like when they were older. Nothing was when they were real little. /Both Alice and I would like to have a boy and a girl. We would like the boy first and then the girl second.

\section{Um-hm. You've got a plan.}

So we know we're going to get the girl first. /But I would...I guess in a way I'd like to be like my own father, in a way, as far as being there, him and I getting involved in certain groups and going camping and going fishing and...doing guy stuff.

\section{Right.}

/Because my mom and my sister were close. I was. I'm close to my mother I think a little more than my father, but. /Heck. I was in scouts and I was in Indian Guides and I was in a whole bunch of other little programs that just he and I would do because that's pretty much what it was for, dads and their sons. And I would like to do that. I mean I would like to be able to be able to go camping, throw a ball around, or I imagine stuff like that. /And then also. knowing how when I was growing up. how I felt about my father, seeing if I could change some of it. just as far as...trying to be more of a friend. also. /Because there were times that... and I don't know if it was just me, but I just wasn't really turned on by certain sports. I was never -- I mean, I played soccer for a couple of years and that kind of dwindled out, and that was about the only team sport that I played when I was really young. I just was not a sports person. And I don't know if that was from him, or just luck, but I mean -we'd watch it on TV, it wasn't like there the children were older. He didn't think much about what it would be like when they were very young.

52. S. and his wife both want to have a boy and girl. They'd like to have the boy first and the girl second. Because they want it this way. S. suspects that they'll get the boy first instead.

53. S. says that he would like to be like his own father "as far as being there" being involved in groups and "doing guy stuff together."

54. S. was a little closer to his mother than to his father. His mother and his sister were close.

55. When $\mathrm{S}$. was a child. he and his father were involved in a lot of programs that were for dads and their sons. S. imagines doing things like that with his child. He imagines doing things like camping and playing ball.

56. In addition to the ways he would like to be like his father, S. would also like to see if he "could change some of it. just as far as...trying to be more of a friend, also."

57. S. was "not a sports person" as a child. He doesn't know if this was because of his father or not. He just never took to sports. 
was no sports in the house at all, but I never took to it. II was more happy building things. I was a tinkerer. I tore everything I had apart, drove them nuts! /And I guess I just want to try to be more of a friend where, growing up, my kids would feel like they could come to me and talk to me about anything. /Because I. I kept a lot of stuff from my parents. I never went to them and talked to them about this. that.

\section{Right.}

/And then when I got in the service, I guess that's when I realized, hey, I missed something. /And that's when. that's when I think the open relationship that I have with my parents really happened. Because I can talk to them and say, hey, this and this and this and this is going on.

\section{Tell them the story.}

Yeah. /Whereas in high school, something would go wrong and it was like, talk to my parents? Yeah, right. Of course, that's every teenager.

\section{That's true.}

Talk to my parents? Come one, what are you talking about? /But I want that with my kids. Don't know how I'm going to pull that one off, but I'd like to have it. /Because I see that in some families and I think that's really neat. /And that's kind of where I picture myself as being a father, doing the stuff that I did with my father and then trying to go a step above that.

\section{Is that kind of the motivation to have a kid? When you think about that, is}

58. As a child. S. was a "tinkerer." $\mathrm{He}$ liked to build things. He drove his parents nuts by taking everything apart.

59. S. wants to "try to be more of a friend" to his children than his own parents were to him. He hopes that his children "would feel like they could come to me and talk to me about anything."

60. As a child. S. "kept a lot of stuff from" his parents. He didn't talk to them about some things.

61. When he was in the service, S. realized that he had missed something in his relationship with his parents when he was growing up.

62. S. now has an open relationship with his parents in which he "can talk to them and say, hey. this and this and this and this is going on."

63. In high school. S. couldn't have imagined talking to his parents when something went wrong. He thinks that this is in part just what it is to be a teenager.

64. S. isn't sure how he can pull it off, but he'd like to have a relationship with his children in which they can talk openly with him.

65. S. sees other families where the children feel comfortable talking to their parents and he thinks "that's really neat."

66. In picturing himself as a father. $S$. imagines "doing the stuff I did with my father and then trying to go a step above that." 
that something that made you want to have a kid in the first place?

/Well, it's like, if I don't have kids how can I take them fishing or take them camping, or something like that. It's like, you don't have any, if you don't have a kid how can you take a kid camping or fishing or something?

There's a feeling that you'd miss out on things if you don't.

Yeah. Then and that's why I knew I always wanted kids and I wanted no more than two. /My family has never, the biggest families on my part of the family is three.

\section{So they're all pretty small.}

Like my mom, her sister and her brother, and her sister has three girls. My dad's brother had a boy and two girls. And that's been it. But like when he was...I think. yeah, it was just my dad and his brother. and. yeah. So it's been. no one's got five kids.

\section{Right.}

And I even think, um, some of my cousins on my mom's side, only have two kids too. So no one really has a big family land I knew I didn't want that because then it was like too many kids to divide up, too many, too much.

I wonder if...always wanting kids, that always intrigues me. I wonder when you first started thinking about it and how you thought about it, were you a little kid and you just kind of knew? Did it happen later?

/Well I know... well, I guess it was later.
67. In order to become the sort of father he imagines begin. S. will of course have to have children first.

68. S. always wanted to have children and he always wanted no more than two.

69. No one on either side of S.'s extended family has had large families.
70. S. knew that he didn't want a big family because it would be too many kids to "divide up." 
I mean, when I was in high school I wasn't really worried about getting married, because I never had a girlfriend in high school.

\section{So it wasn't really a thought in your head at that point.}

Yeah, it wasn't.../and even in the service, I guess, when I was in the service. um, was when it kind of hit me because there was a girl in high school that...I had become very close to and her mom had put the stop to us seeing each other. On grounds that I never went to church. And I never knew what the whole reason was until I was in the service and I was visiting on leave and I'd go down and visit with her and just hang out and stuff. And then her mom was the one that told me why. And she and -- her daughter and I -- were really close, I mean, she was probably at the time, probably my best friend, because I could call her on the phone and talk with her. what's going on. And she had kept the fact that she was pregnant from me, for, until I came home one time and she said oh, why don't you just come down. Sure. I come in and...there's a little person. What's going on?

\section{That's a shock.}

Boy, she said it was the hardest for her not to say anything when I would say, hey. what's going on, you know, what's new? But....with her...I, that's when I sort of started thinking about family and stuff. You know, in the service.

Because of the feelings I had for her and she already had a daughter land I knew, if I married anybody it wouldn't matter. I wouldn't want to marry anyone that had more than two kids. But it didn't bother
71. S. wasn't really worried about getting married or having children when he was in high school.

72. S. first started thinking about having children when he was in the service. A relationship with a girl from high school ended abruptly because the girl's mother prevented them from seeing each other. S. was very close to this girl and he found out some time later that she had become pregnant. She kept this a secret from him. It was in connection to his feelings about this girl. after she had a child and they started talking again, that $\mathrm{S}$. "started thinking about family and stuff." 
me. Say Alice had a child. It wouldn't have bothered me one iota. I mean. I don't. I knew I could handle coming into a quote-unquote ready-made family.

\section{Right.}

That didn't bother me at all. /And I knew. I knew I could be a good father to that child. Even if dad was still in the picture. I could still be a good dad.

\section{Right.}

/And I knew, no matter what happened I knew that if I did marry into a readymade family I would want one child that was ours.

\section{Right.}

Whether it would have been a third. that's fine.

So that all kind of came to you pretty clearly and that wasn't a very difficult thing to arrive at.

No.

\section{You had a sense of this is what I want in a relationship for a family.}

/Yeah, I knew what I wanted, /and when Alice and I met, then we were talking, we basically had the same ideas about family -- two. No more. /But who knows, maybe one, but, I think if you have one it gets spoiled too much. /Besides, as Bill Cosby put it, if you only have one child and something's broke, you know who did it.

That's a good point.

I mean, come on. children. It wouldn't have bothered him if his wife already had a child when they met. He knew that he could handle coming into a "readymade family."

74. S. knew that he could be a good father to a child that wasn't biologically his, "even if dad was still in the picture."

75. S. knew that if he married someone who already had a child, he "would want one child that was ours," even if it was a third.
76. S. knew what he wanted in a family.

77. When S. met his wife he found that they "basically had the same ideas about family."

78. S. would consider having only one child. but he's concerned that it would get spoiled.

79. S. sees an advantage to having just one child: if "something's broke, you know who did it." 
That's true. [pause] This is one thing I'm struck by, listening to you is that, you've got a lot of confidence about being a father and it sounds like you've had that for quite awhile, like, I know I can do this.

$/$ Yeah, it's just something that I've felt. just, I mean, I guess I'm like that. I mean it's not like, oh, geez, can I pull this off?

Yeah.

Am I going to be able to do this? I know that I can do it. /I guess part of it was just the raising that I had, um, both dad and mom worked during the week, they were home on the weekends, home for supper every night pretty much. occasionally one of them had to work late or had something going on. but we always had them back. sat down around the table and had dinner and....

So it felt pretty stable for you. You learned how to do it, it almost sounds like...

Yeah.

...being in your own family.

they might have had some influence. But as I got older, it was, I think I'd like to do this. You sure? Yeah. Okay.

\section{Right.}

/So. And I don't -- my sister and I were never spoiled, I mean we didn't come from a high six-figure household or, we didn't come from the slums either, I mean we, we had a comfortable life.

Right there in the middle class.
80. S. feels confident about his ability to be a father. He knows that he can handle it. He isn't feeling like "oh. geez. can I pull this off?"

81. S.'s confidence about his ability to be a parent comes in part from his experience with the regularity and stability of his own childhood family life. When he was growing up. family dinners were a regular. stable occurrence. 
/Yeah, there was, dad did his own little things at home, out in the shop which was the garage. So, he'd be-bop out there usually after dinner or something like that, I'd go out and watch him. And then as I got older I was able to help out more. That sort of stuff. Yeah, when I was home, usually if dad was tinkering on a project, I was right there.

\section{So that gave you a real model of how} to be, yourself.

/Yeah, it wasn't like, they never pushed me into anything. You know, it wasn't like, oh, why don't you go do this. It was. I'd go to them. I'd like to do this. You sure? Yeah. Okay. Whatever decision I made, it was my decision. It wasn't like, you know, when I was growing up. I mean when I was littler

Yeah. So....

So, yeah, not a whole lot of worries in terms of your parenting, in terms of that part of the decision. It sounds like that, the early part of it as you described it before that, sort of those first few years, they're not quite as clear to you. When you think about it, you think more ahead to camping and doing stuff.

/Um-hm. Just kind of -- I guess, to me that's when you can start getting out and doing stuff is when the kids can start enjoying it. Because before that it's like...why?

Right. If they're not appreciating it.

That's right.

I think the only thing that I'd like to go back to just a little bit, even though
83. S.'s parents never pushed him into anything. Rather. he would go to them and tell them what he wanted to do. It was always his decision.

84. S. and his sister weren't spoiled as children. They weren't rich, but they weren't poor either. They had a comfortable life.
85. S. looks forward to the time when he'll be able to get out and do things with his own children. 
I'm going to sound maybe a little bit like Alice, poking an prodding you here -

Okay.

-but that's my job as an interviewer is just kind of ask you one more time about that, the point of your saying, you know, when you said to yourself...okay, I'm ready. I guess I'm not clear whether there was such a point, and if not, sort of, how it happened.

I don't know if there was any point like. one day I woke up saying, okay. I'm ready. I don't think it was anything like that, /it was like... when we first started trying I guess it was like, well, if it happens... I've got nine months to get ready.

Hm. That's interesting.

Um....

So there was still a, it sounds like it wasn't like all the way "okay, we're going to do this," for you.

/It wasn't.

Okay.

It wasn't all the way okay. But... when we were trying, yeah, it was never. okay I'm, I'm ready. The day that it pretty much turned, turned definitely ready for it was Friday when I heard the heartbeat.

Right, right.

That was when it was just...wow. I'm ready for this. I mean there's, I wouldn't change this for the world.
86. In making the decision to have a child. there was never a point when S. "woke up saying. okay. I'm ready."

87. When S. and his wife started trying to conceive. he thought "if it happens... I've got nine months to get ready."

88. When $\mathrm{S}$. and his wife started trying to conceive. he still wasn't "all the way okay" with it -- "it was never, okay I'm, I'm ready."

89. The point at which S. felt "definitely ready" to have a child was when he heard the baby's heartbeat at the doctor's office. At that point he felt that he "wouldn't change this for the world." 
That's, yeah, that's making sense to me how that happened. I'd still like to know more if you can tell me about what it was like for you to start trying to have a baby when it was kind of a...you still kind of weren't all the way there, it sounds like.

/Um. I guess it was more...I was doing it more for her, when we were trying. [pause] Because I wasn't sure that this is the time. /I didn't think it was going to happen this fast.

\section{Right.}

Because I know if you put your whole heart into something, it's liable to happen a whole heck of a lot quicker. /Um...but it was, I guess it was kind of tough for me, because it was like...okay, I guess I'm kind of doing this to kind of keep peace in the household, and to be able to live with this other person that's sharing the same bed.

\section{Right.}

Um... and I guess knowing in the back of my head that yeah. I'm going to be a good father regardless when it happens.

\section{So you had that as an anchor.}

Yeah, I mean, because it was never, it was never a question of am I going to be a good father -- I am going to be a good father.

\section{Right.}

/But for me I guess, the feelings would be...scared...confused, just the normal thing. /Am I ready, am I not ready? Is this the time, isn't this the time? /Oh, god, what happens if it happens and a
90. Before he felt fully ready to have a child, S. was doing it more for his wife. He still "wasn't sure that this is the right time."

91. Because he wasn't putting his whole heart into having a child when they started trying to conceive. S. didn't think they were going to get pregnant as quickly as they did.

92. It was hard for $\mathrm{S}$. when he and his wife were first trying to conceive, because he was "kind of doing this to kind of keep peace in the household, and to be able to live with this other person that's sharing the same bed."

93. Even though he wasn't certain when they started trying to conceive that he was ready to have a child, $S$. knew that he would be a good father. He never had any doubt in his mind about that.

94. The feelings $\mathrm{S}$. experienced as he and his wife started trying to conceive were "scared...confused, just the normal thing."

95. As he and his wife started trying to conceive, S. wondered: "Am I ready, am I not ready? Is this the time, isn't this the time?"

96. S. wondered what he would do if his wife got pregnant and then a really good job came up. 
really good job comes up?

\section{Right.}

What do I do? $/$ had all of those things floating around in my head. So, half the time I'd say okay, yeah. that's good. Two minutes later, nope, nope, no. no, definitely not it.

What would that...

As far as, one minute is I'd go, yeah. I think I'm ready. The next minute, no.

Um-hm.

You're not ready.

So you were really back and forth.

Yeah, generally, you know. /And at work. at work I knew it was affecting me because it wasn't like I was doing a good day's work. Because I was constantly thinking about it. Am I ready, am I not ready? Is this really what I want to do? If it isn't then, what? /And...now, I wouldn't change it.

Yeah, right.

Not at all.

It's amazing how that works, isn't it.

It really is.

I really appreciate your talking about this ambivalence part of it, because I know that it's a hard thing to talk about. It's hard to hold that, that experience, I mean you have those doubts and everything and then afterwards, you come to the point where you are now, it's like why did I
97. As $\mathrm{S}$. and his wife were trying to conceive. he went back and forth in his feelings about whether or not he was ready: "half the time I'd say okay, yeah, that's good. Two minutes later, nope, nope. no, no, definitely not it."

98. S.'s struggle to know whether or not he was ready to have a child affected his performance at work. He was constantly thinking about it: "Am I ready, am I not ready? Is this really what I want to do? If it isn't then, what?"

99. Now that his wife is pregnant, $S$. wouldn't change it. 
ever have those? So, that kind of, fears and confusion is part of the decision. And I appreciate your identifying that.

No problem.

And so that was going on sort of while, as you were starting trying to get pregnant. So that sounds like that was a really stressful time.

/I think it was. Like I said, it did kind of take its toll at work for awhile.

Yeah, yeah. Having two such contradictory feelings inside.

/And then especially the fact that my friend had talked to this gal and said that he had talked to her. and that brought up those feelings I had had in high school for her and had them for. up until, well I guess it'd be about, maybe four or five months before Alice and I met. Because I mean that's how -- I had them in high school up to about four or five months.

And she was the person, when, you were thinking about her when you initially started forming your idea of having a family and what that would mean.

$/$ Yeah. I even talked to my mom about it, and she goes, well, it takes a long time to get over your first love. It takes a heck of a long time. I'm going... you're not kidding! [laughs]

Yeah, it just reaches out and grabs you, a long ways down the line.

/But she, we never went on a, in high school, we never went on a date. I
100. For S., the difficulty of deciding whether or not he was ready to have a child "did kind of take its toll at work for awhile."

101. The decision to have a child was made more difficult for $\mathrm{S}$. by the fact that a conversation with a friend had brought up old feelings for a girl he'd known in high school.
102. S. talked to his mother about his lingering feelings for the girl he'd loved in high school. His mother told him that "it takes a long time to get over your first love." S. agrees with that.

103. It drives S. crazy to think back on his relationship with the girl he 
mean, let alone, I never even kissed her until...a year after we graduated, when we were at home. It was just. see ya.

And now, I mean...it drives me crazy.

Yeah, that stuff is....

/Just...go away, will you, just go away! [laughs]

Yeah.

But, life is hard.

It is. These things are long-lasting. And the same thing with decisions like this.

They're very difficult.

Are there any other aspects of this that you feel ought to be in this, that are important to your decision, to your experience of making the decision?

I don't think so. loved in high school, to remember how they never even went on a date and how he never even kissed her until after they graduated.

104. S. wishes he could make his feelings about the girl he loved in high school "just go away." He finds these feelings very difficult to manage. 


\section{Evan - Level 3}

S. always knew that he wanted to have children. Although he didn't think much about getting married or having children until after high school. he knew what he wanted in a family. He wanted to have children. He didn't want a big family because it would be too many kids to "divide up." He would consider having only one child but he didn't want more than two. He was concerned that if he only had one child it would get spoiled. But he also saw an advantage: if "something's broke. you know who did it."

It wouldn't have bothered S. to marry someone who already had a child -- as long as she didn't have more than two children. He wouldn't have been bothered. for instance. if his wife already had a child when they met. He knew that he could handle coming into a "ready-made family," that he could be a good father to a child that wasn't biologically his, "even if dad was still in the picture." At the same time he knew that if he married someone who already had a child. he would want "one child that was ours." even if it was a third. He knew that he wanted at least one child of his own.

In general. S. feels confident about his ability to be a father. He knows that he can handle it. He isn't feeling like "oh. geez, can I pull this off?" In making the decision to have a child, he never had any question of "am I going to be a good father?" Even when he experienced doubts about whether or not he was ready to have a child. he never had any doubt in his mind about whether he would be a good father. This feeling has been confirmed by the pleasure he takes in playing with his neighbor's two young children. His wife pointed this out to him and got him thinking "I do do a good job, don't I?" Although he recognizes that it would be a few years before his own child was at the same age as his neighbor's children were, playing with them made him think "I can do this."

As with many of his ideas and feelings about becoming a parent. S.'s confidence that he will be a good father comes largely from his own positive childhood experience. His desire for a small family relates to the fact that no one on either side of his extended family has had large families. As a child, his family life was characterized by regularity and stability. His childhood family had a predictable schedule and routine which centered around family dinners together. After dinner his father would work in his shop and S. would watch or, when he was older, help him work. He says he was a "tinkerer" as a child. He liked to build things. He drove his parents nuts by taking everything apart. He was not a "sports person." But his parents never pushed him into anything. Rather, he would go to them and tell them what he wanted to do. It was always his decision. He and his sister weren't spoiled as children. They weren't rich, but they weren't poor either. They had a comfortable life.

When S. and his wife met they found that they "basically had the same ideas about family." They both want to have a boy and girl. They both want to have the boy first and the girl second. Because they want it this way, he suspects that they'll get the boy first instead. They have been discussing having a child for "quite awhile." But 
initially he was "always trying to avoid" discussing the question of children with his wife. He would try to avoid the issue whenever it came up. She would "poke and prod" him and try to get him to talk about it. But like his father. he is "a man of few words." His wife has to pull information out of him. He and his wife started "seriously contemplating it" earlier in this year but they decided that they would put off the decision until June and then see where they were in terms of S.'s employment situation and whether or not they were likely to be moving soon.

Because he "knew the issue was not going away." S. understood that he was "going to have to talk about it in one way. shape or another." So he did talk about it. But "she still had to pull." He could understand where his wife was coming from in terms of her desire to have a child because all she had ever wanted was to be a wife and a mother. She felt that it would be too long to wait if they waited until they had their bills paid off before having a child. Putting off the decision was difficult for his wife, because "she's been wanting kids since the day we got married." When June came, he and his wife discussed having children as they'd agreed. S. was still "a little unsure whether the time was right. He wanted to make sure he was ready before he had children. He had "a basic case of very cold feet."

Most of S.'s worries about deciding to have a child at this point in his life centered around his concems about his employment situation. In making the decision. he wondered "am I in the right situation to do this now?" He was not happy at his job and he didn't want to feel "trapped at a job" when he started a family. He didn't want to feel that he had to stay at his current job just to keep the insurance. even though he was unhappy there. He wanted to be happier and more stable in a job before having a child. He wanted to be "more stable in a job that I was enjoying." rather than just going to work in order to pay the bills.

Related to these concerns. S. worried about whether or not they would be moving. He wants to move out of state in order to be able "to provide a little better for the family." He wants to be able to get ahead and not just be surviving paycheck to paycheck the way he is now. But he's not sure how his wife will feel about moving. He wondered what he would do if his wife got pregnant and then a really good job came up. He knew that he wanted to have children. but he first "wanted to be more... a little more stable." Because he wasn't happy at his work, he wanted to put off having a child. He told his wife that he didn't want to feel trapped at his job and that if something better came along he was going to take it. He wasn't ready to "try for a family" yet because he wanted to be at a more stable job first. He says that his work situation was the excuse he used to delay making the decision to have children. But as he mulled over the idea of having a child, he realized that "even if we have a little one, it's not that tough to move." On the other hand, he would not consider moving if his wife was too far along in the pregnancy.

Another factor which has made the decision to have a child difficult for S. was a conversation with an old friend who reminded him of his feelings for a woman he was in love with when he was in high school. He hadn't talked to this woman in almost three years and it was upsetting to hear about her again. The relationship had ended abruptly 
because the girl's mother prevented them from seeing each other. S. found out some time later -- when he was in the service -- that she had become pregnant by another man. It had been his feelings about this woman and her child that made him star "thinking about family and stuff." It drives him crazy now to think back on his relationship with this woman, to remember how they never even went on a date and how he never even kissed her until after they graduated. He finds these feelings very difficult to manage. He has talked to his mother about this and his mother told him that "it takes a long time to get over your first love." He agrees and wishes he could make his feelings about this woman "just go away."

In picturing himself as a father, S. imagines "doing the stuff I did with my father and then trying to go a step above that." He says that he would like to resemble his own father "as far as being there," being involved in groups and "doing guy stuff together." When he imagined being a father, $S$. thought mostly about how it would be when the children were older. He didn't think much about what it would be like when they were very young. He looks forward to the time when he'll be able to get out and do things with them. He imagines doing the sorts of things with his children that he and his father did together. He imagines doing things like camping and playing ball.

But in addition to these sorts of activities, S. would also like to see if he "could change some of it, just as far as...trying to be more of a friend. also." He wants to "try to be more of a friend" to his children than his own parents were to him. As a child, he "kept a lot of stuff from" his parents. He didn't talk to them about some things. In high school he couldn't have imagined talking to his parents when something went wrong. He thinks that this is in part just what it's like to be a teenager. When he was in the service, he realized that he had missed something in his relationship with his parents when he was growing up. He now has an open relationship with his parents in which he "can talk to them and say, hey, this and this and this and this is going on." He sees other families where the children feel comfortable talking to their parents and he thinks "that's really neat." He would like to have a relationship with his children in which they can talk openly with him. He hopes that his children "would feel like they could come to me and talk to me about anything." He isn't sure how he can pull this off.

S. has heard people say that "you're never ready" to have children. For example, you're never ready financially. He believes that a person never feels financially ready to have a child and that there is no point waiting for that to happen. But while he knows that "everyone says, you're never ready," he also thinks "there's a point when you're not ready and when you're not not ready." There is a point when "you're just plain not ready" to have children, when you are truly financially unable to provide for a child. And there is a point at which you acknowledge that while your bills will never go away you start asking "where can we pinch from to have money to provide for this little one?" At that point you have the ability to do it by "pinching" - but you're not yet ready "to make the lifestyle change." He sees in the issue of readiness to have children a distinction between "a point where you're really really not ready and when you're just not ready." 
For S., making the decision to have a child came down to asking himself: "when do I want to start" trying to have a child? He asked himself "am I really ready" to have a child? The struggle to know whether or not he was ready to have a child took it's toll at work for awhile. He was constantly thinking about it: "Am I ready, am I not ready? Is this really what I want to do? If it isn't then, what?" The more he thought about it. he realized that "yeah, I am ready."

There was no one point in making the decision to have a child at which S. said "okay let's just go for the gusto, let's try." There was never a point when he "woke up saying, okay, I'm ready." As he mulled over the decision, he thought that "it isn't going to be that bad" to have a child. He figured "if it happens... I've got nine months to get ready." But his concerns about whether or not he was ready persisted even after he and his wife started trying to conceive a child. He continued wondering: "Am I ready. am I not ready? Is this the time, isn't this the time?" He went back and forth in his feelings about whether or not he was ready: "half the time I'd say okay, yeah. that's good. Two minutes later, nope, nope, no, no, definitely not it." He still wasn't "all the way okay" with it -- "it was never, okay I'm. I'm ready." The feelings he experienced were "scared...confused, just the normal thing." It was hard for him because he was "kind of doing this to kind of keep peace in the household. and to be able to live with this other person that's sharing the same bed." He was doing it more for his wife. She wanted a child "a hundred and twenty percent." But he "wasn't up there" at the level of enthusiasm. He still "wasn't sure that this is the right time.

From reading books and talking to other parents. S. and his wife had gotten the impression that it would take them a year or two to get pregnant. He had the feeling that "you're damn lucky if you get pregnant." When they didn't get pregnant after trying the first month, his wife was "crushed." He felt that there was no way his wife could handle a year and a half of unsuccessful attempts to get pregnant when she wanted it so much. He on the other hand was not so badly disappointed. He's the sort of person who doesn't get his hopes up too much. He never got his hopes up about his wife getting pregnant. He figured "if we try and it happens... great." Because he wasn't putting his whole heart into having a child when they started trying to conceive, he didn't think they were going to get pregnant as quickly as they did. In the end, it took them only two months to get pregnant.

The point at which S. felt "definitely ready" to have a child was when he heard the baby's heartbeat at the doctor's office. At that point he felt that he "wouldn't change this for the world." Now he wonders why he waited so long. He didn't fully understand how ready he was to have a child until his first doctor's appointment at which he saw an ultrasound of the baby and heard the heartbeat. At that point he "melted," thinking "there's no way I'd ever pass this up." He finds it hard to describe the feeling he got at the doctor's office when he was hearing that the baby "looks great" and seeing the ultrasound and hearing the heartbeat. He "just melted." He wondered "why did I put this off?" $\mathrm{He}$ thought he'd been stupid to do so and asked himself "why were you so put off about this when it makes you feel so good?" He thought that he didn't know anybody that would want to pass this up." Now that his wife is pregnant, he wouldn't change it. He feels like he and his wife made "a good choice starting when we did." 


\section{Evan - Level 4}

S.'s ideas about having children have been deeply influenced by his own childhood experience. He feels positively about the comfortable. middle class family in which he was raised. His childhood was characterized by a structured routine, within which his parents encouraged in him a sense of personal independence. The experience of being able to make decisions for himself within an atmosphere of safety has carried over into his adult life, translating into a sense of confidence about his own ability to be a good father. This confidence pervades his experience of making the decision to have a child. Whatever doubts and worries he has had about becoming a parent, he has never been concerned about his ability to be a good father.

S. has always known that he wanted to have a family of his own and he has specific ideas about the sort of family he wants. He wants a small family, like those of his own extended family. But he has also been confident about his ability to be a good father to a child that is not biologically his and he was open to marrying a woman who already had one or two children.

S. sees his own father as both a model and a point of comparison as he imagines becoming a father himself. He hopes to emulate what he admires in his father but also to transcend his father's limitations. He imagines engaging his children in the same sort of activities that he engaged in with his father. But at the same time he hopes that he can be more of a friend to his children than his own father was with him. He didn't experience his parents as people with whom he could communicate easily. As an adult he has come to feel this lack of communication as a loss. Although he is not sure that he can achieve this goal. he hopes to be the sort of parent with whom his children feel they can talk openly.

In this, as in other aspects of making the decision, S. has been influenced by watching and interacting with other families and other children. He admires families in which children feel comfortable talking openly with their parents. Another important influence in making the decision to have a child has been his experience playing with children in his neighborhood, which has reinforced his confidence about his parenting abilities by allowing him to demonstrate his competence at interacting with and taking care of children.

While S. has always known that he wanted to have children, he has been concerned about whether or not he was ready to have a child at this particular point in his life. These worries have centered mostly around his career. He was concerned about how he could balance his need to provide adequately for his family with his need for personal satisfaction in his employment. He worried that having a child would trap him in an unsatisfactory job. He feared losing his ability make advantageous career choices because of the need to support a child. Directly related to these concerns was his wish to move out of state to find better employment. He worried about the difficulty of moving with a young child and he wondered whether his wife will be willing to move at all. 
Another concern which significantly affected S.'s feelings about having a child with his wife was a resurgence of emotions for an old girlfriend. As he was in the process of making the decision. he was reminded of his unresolved feelings for this woman. It was she who had initially caused him to think concretely about having children and a family. He continues to feel the loss of this relationship keenly and he struggles to find away to come to grips with these feelings.

From the beginning of their relationship. S. and his wife have shared the same basic feelings about having a family together. Their discussions have focused not on whether they would have a child but on when they would do so. They differed greatly in their feelings on this subject. While S. was aware of the depth and intensity of his wife's desire for children, he didn't share her enthusiasm or urgency. Rather, he felt a reluctance to proceed which led him to put off making the decision. Because he knew the issue was not going to go away, he agreed with his wife that they would start talking seriously about it with her at a certain point in time. But even after making this agreement he remained reluctant. He avoided discussing the issue and his wife had to push at him to talk about it.

S. struggled for some time over the question of whether or not he was ready to have a child. This question occupied his mind and he went back and forth about it constantly. He describes the whole issue of readiness as a sort of unsolvable puzzle. On one hand he feels that there is never a time when a person feels truly ready to have a child. But on the other hand, there is a point at which a person is "not not ready" -- when the conditions which make having a child impossible are no longer present. At this point the decision comes down to whether or not a person is willing to make the sacrifices that having a child would involve. This distinction was central for $\mathrm{S}$. as he made the decision. For him. deciding to have a child meant moving forward without being able to know for certain that moving forward was the right thing to do. This change was not a realization which came to him in a single moment. Rather it was a gradual process in which he came to believe that he was capable of navigating whatever changes came with being a father.

Even after he had made the decision and agreed with his wife that they would start trying to conceive a child, S. continued to experience doubts. His heart wasn't fully in it and he wouldn't have been disappointed if it took a long time for his wife to get pregnant. He continued to experience some uneasiness about the decision, to worry about whether or not he was ready and to vacillate dramatically in his answer to that question. These feelings were made more difficult by the fact that he had made the decision to a degree in order to keep peace and get along with his wife. In spite of having agreed to have a child, he continued to feel scared and confused and uncertain that he was ready.

In the end, $\mathrm{S}$. was not able to reach a sense of certainty about his readiness to have a child until after the child had been conceived. His feeling about becoming a father then underwent a transformation. At the doctor's office, listening to the fetal heartbeat, he felt a rush of emotion which he finds difficult to describe. In this moment, he became aware 
that he was in fact completely ready to have a child. This realization made him question his previous doubts and hesitation. He couldn't comprehend his own reluctance to do something that made him feel so good. He has a great sense of certainty now that he has made the right choice. He feels no desire to change the way things are. 
Appendix F

Abe: Data Analysis

Levels $1-4$ 


\section{Abe: Levels 1-2}

So...I know you've recently decided to have your first child. And what I'd

like you to tell me about is the experience of making that decision.

/Okay. Uh...the most recent experience or the life change that decided to get us to think about children in the first place?

\section{Um...either of those sound appropriate, whatever...}

/Well, I got married at thirty...

\section{Okay.}

...believing I would never get married in my life. much less have children.

\section{Okay.}

/Um, when I got married, I got married to a girl who was ten years younger than me. So we always had it that if I decided to change my mind, of course I could be a lot older than she could at the time, you know, and I'd still conceive. So I said. well. we'll see what happens land she. at the time was. let's see. I think she was nineteen, twenty. And she was in no rush to have children, she wasn't even allowed to drink at that point. And she really wasn't concerned with having children and she really didn't think she ever wanted to /and that fit my lifestyle fine. I'm a pretty active hunter. fisher and so on, and didn't want to be tied down with kids. Marriage was new to me and my wife was kind of immature and I thought that was enough of a burden at the time. $/ \mathrm{Uh}$, and then about, let's see, a year and a half ago a couple of my friends had kids and my

3. S. married a woman who was ten years younger than he was. They knew that if he changed his mind about not wanting children that he could be much older than her and he could still conceive. His attitude was "we'll see what happens."

4. S.'s wife was nineteen or twenty when they got married. She wasn't in a rush to have children. She wasn't concerned with children and didn't think she ever wanted them.

5. S. was content with his wife's attitude about children because it fit with his active lifestyle. He "didn't want to be tied down with kids."

6. Because marriage was new to $S$. and he felt his wife was "kind of immature," he thought "that was enough of a burden."

7. About a year and a half ago, several of S.'s friends had children and his sister had her third child. 
sister had her third child. /And we went and visited and for whatever reason we felt the need to have children all of a sudden. decided to see about whether or not we could. /So we let it go about another six months just to each think about it in our own way. /Uh, I'd say about September of last year we decided to start getting physically checked to see if we could have children. I underwent a physical that said I couldn't have children...

\section{Say that again?}

I underwent a physical, and the result was that I had a varicose seal in my scrotum. which is basically a varicose vein in your scrotal sack but it raises the temperature to a point to where sperm are not motile.

\section{Right.}

So they felt that 1 . you know, wouldn't be able to have children without having surgery first. Uh, that happened in about October or November of last year. So then my wife went and got physically checked out just to see if it was worth the trouble. And the doctor said yeah. she was fine. That took till about December or January of last year, or this year. /And uh, so I went and sought about different surgeries and so on, um. the doctors all said that they could make things work. but why not try first. So we waited a little while longer and in May of last year I went to a last doctor at St. Pat's Hospital who said that he thought that there would be a pretty good possibility if I used ice and some other things, that I would be able to conceive. We did it once....the rest is history.
8. S. and his wife went to visit his sister who had just had a child "and for whatever reason we felt the need to have children all of a sudden." They decided to see about whether or not they could.

9. S. and his wife spent about six months thinking individually about the decision to have a child.

10. S. and his wife decided to start getting physically checked to see whether or not they could have children. S. Found that he had a physical condition which made it unlikely that he would be able to have a child without first undergoing surgery. S.'s wife went through a medical examination which determined that she was capable of conceiving a child.
11. S. looked into the surgeries he would need to have in order to conceive a child, but the doctors suggested that he first try to conceive without the surgery. One doctor suggested techniques that would enhance the likelihood of conception. They tried it once and it worked. 
Wow.

[laughs] /So...I don't know if we spent three thousand dollars for nothing, but....[laughs]

Yeah, that made it, it sounds like that made it really, you had to really consciously make an effort.

/Yeah, we, we fought pretty hard to have it happen.

Yeah.

Well. I don't know if we fought very hard. but we researched it.

Yeah, yeah. Huh. Wow, so that's a ton of your life, kind of condensed down into a nutshell there, that's great. Um, so I guess I'd like to kind of get you to take me through it in more detail. It sounds like you had a...a sort of agreement that you started out with that kind of changed in the relationship.

/Correct.

\section{Could you start with telling me more about that?}

Well, I, my childhood wasn't the best. You know, I grew up in Brooklyn, New York. I had two brothers who were killed. New York is that way. And uh. my mother really didn't handle it well and she got sick and was put away for seven years in a mental institution. My father couldn't handle it either, so he left and we were raised by different relatives. / In any case, I felt that childhood wasn't all it was cracked up to be.
12. Because they conceived a child so easily, S. wondered whether they had wasted the money they'd spent on medical examinations.

13. S. and his wife "fought pretty hard" to conceive their child -- or at least researched it.

14. S.'s childhood "wasn't the best." $\mathrm{He}$ grew up in Brooklyn and had two brothers who were killed. His mother spent seven years in a mental institution. His father left. $\mathrm{He}$ and his siblings were raised by different relatives.

15. S. felt that "childhood wasn't all it was cracked up to be." He decided that "it wasn't for me." 


\section{Right.}

And decided that it wasn't for me. /And. you know, my parents are pretty strong people and they weren't strong enough to handle it. So I figured. hey, you know. there's a lesson for me there.

Yeah.

Uh. so I was dead-set against it. /And my wife is -- or was, I should say -- a pretty selfish person. And she didn't feel she had the capability of caring for a baby twenty-four, seven. And she was pretty honest about it. She said look. you know. I lose interest in things and a child, you know, I don't have that maternal instinct. I've never held another baby -- she's never baby-sat for anyone in her life. The one time she was asked to watch a baby she didn't do a good job and was reprimanded for it. /And we pretty much had an understanding, it just wasn't going to be for us. /We thought we'd be the rich, indulgent uncles and aunts. And I had enough children in my family where I could do that. And hers. So, uh....

So you were really strong, you had a strong sense of this is not something I want to do.

/Right. Yes, yes. very strong.

\section{And that was based pretty much} entirely on...just your own childhood experience, is that accurate?

/Yeah. I had taken care of my new-born nephew, my sister had jaundice when she gave birth to the child and she couldn't come home from the hospital. So I quit my job and took care of him,
16. S. felt that even though his parents were "pretty strong people" they weren't strong enough to handle parenthood. He figured "there's a lesson for me there."

17. S. was "dead-set against" having children.

18. S. describes his wife as "a pretty selfish person" who was honest with him about feeling that she wasn't capable of caring full-time for a baby. She told $S$. that she lost interest in things quickly and that she didn't have a maternal instinct. When asked to watch a baby once, she didn't do a good job.

19. S. and his wife "pretty much had an understanding" that having a child "just wasn't going to be for us."

20. S. and his wife imagined themselves as "the rich, indulgent uncles and aunts." They had plenty of children in their life with whom they could play this role.

21. S. had a very strong sense of not wanting to have a child.

22. S. once had the experience of taking care of his sister's new-born infant for eight months. He never formed a "paternal bond" with that child. He took care of him but it was hard 
for about eight months. And I never formed a paternal bond with it. You know, I took care of him, but it was a job. It was hard work and I didn't have that sense of joy that everybody said a parent has.

Yeah.

Nm, now I'm hoping it's because...uh, I wasn't his father. So [laughing], I'm praying that's the case. /But. uh, at the time I felt that was my lesson, you know, that, it wasn't for me.

Yeah.

/And, uh, I just really didn't want anything to do with giving up the fishing, hiking, camping all summer.

Yeah, so there was a sense of what you would lose, as well...

Right. yeah.

...if you had a child.

Yeah. you betcha.

Okay.

/And I also, up until this job, and even at this job I was responsible for night calls. And uh. you know I felt that that was, you know, too draining to also take care of a child. And you know, I'd get woken up ten to fifteen times a night when I was working in the private sector. So I just didn't think it was part of my lifestyle.

Yeah. Huh, okay. So what happened then? work. He didn't have "that sense of joy that everybody said a parent has."
23. S. hopes that the lack of feeling that he had when he took care of his sister's child was because he wasn't the child's father. He's "praying that's the case."

24. The lack of feeling that S. had for his sister's child when he took care of it made him think "that was my lesson, you know, that. it wasn't for me."

25. S. didn't want to have to give up "fishing, hiking. camping all summer."
26. In his work. S. is responsible for night calls. Because of this. he didn't think that having a child fit with his lifestyle. 
/Well, like I said you know, we went and visited my sister, who had a newborn. And uh, I saw it in my wife first. I saw how she started holding the baby and. uh, she had a look in her eye, I can't describe what the look exactly was, but it was a look of just tenderness that I'd never seen her display toward a young child before.

Hm.

Basically the way she looked at me. And...[laughs]

\section{That's interesting.}

/And I said, well, hey, you know, that's a good sign. $/ \mathrm{mm}$, some of our friends here in town had been having children. And they were all just...like me. All the guys were just like me, didn't want kids. didn't have room in their active lifestyles for -- didn't have the money, didn't have the insurance, so on and so forth. And uh, they started having kids nonetheless /and we started visiting them and I started talking to them about their experiences and they were all positive. /And somewhere deep inside of me all of a sudden I could see myself with a child. I could see myself teaching a child what I know. and spending time with a child. you know just for the fun of it. /And uh, it got to be a growing need inside of me land I discussed it with my wife. and uh. she felt the same way. She was like. yeah, I can see myself with kids in a couple years. /And I said in a couple years and then a month later it became in a couple of months. Then, fortuitously I got this job at the University, which presented us with insurance for the first time in our married lives. And we said well, hey, that's the last obstacle right there.
27. When $S$. and his wife visited her sister and her new-born baby. S. saw a look in his wife's eyes as she held the baby. He can't describe it exactly. but it was a look of tenderness that he hadn't seen her show to a young child before. She looked at the baby the way she looked at him.

28. When $\mathrm{S}$. saw the way his wife looked at his sister's child. he said "well, hey, you know, that's a good sign."

29. Some of S.'s friends had been having children. These guys were "just like" him. They "didn't have room in their active lifestyles" for children. But they started having children anyway.

30. S. and his wife started visiting and talking with their friends about their experiences of having children, "and they were all positive."

31. As S. talked with his friends about their experience of having children. "somewhere deep inside of me all of a sudden I could see myself with a child." He could see himself teaching a child what he knew and spending time with a child. just for the fun of it."

32. The idea of having a child "got to be a growing need" inside of S.

33. S. discussed his feelings about having children with his wife and found that she was feeling the same way.

34. At first S. thought about having children in a couple of years. but soon "it became in a couple of months."

35. S. got a job which provided him and his wife with insurance. They felt "that's the last obstacle right there." 
Huh. So it sounds like as soon as you started...started thinking about it, you were kind of moving slowly but it really sped up very quickly.

Yeah. it did. It accelerated. uh, probably about a year and a half ago it accelerated to the point where we started thinking. okay, what should we do before we get pregnant and what we can wait until after.

Yeah, you started planning.

As, you know. we were thinking should we get a house, should we get this. should we get that. /And then everybody told us. you'll never have enough money. You'll never live in the right place. you'll never have anything you want to have. You just have to take the baby and grow with the baby. And you know, get your house and get everything... when you can.

Huh, so you're not going to be ready...

Never going to be ready...

\section{...financially or whatever.}

...never going to be ready. /Um. I mean I wish. I wish somebody granted us money. You know, have a kid, we'll give you a million bucks. But, it's not that way.

\section{You've got to have septuplets to have that happen.}

Exactly, exactly. We need Oprah. That's what we need. [laughing] And uh, Dateline and stuff. /So, we -- I'm a twin. And that was another consideration. We thought, well, do we
36. The process of deciding to have children accelerated rapidly for $\mathrm{S}$. to the point where he and his wife started planning "what should we do before we get pregnant and what we can wait until after." They thought about whether they should get a house or other things before having a child.

37. Others told $S$. and his wife that they'd never have enough money or live in the right place before having a child. They told him "you just have to take the baby and grow with the baby" because they were "never going to be ready."

38. S. wishes that someone would grant them a million dollars because they're having a child, but he knows "it's not that way."

39. Because $\mathrm{S}$. is a twin, one consideration for him in deciding to have a child was whether or not he 
want to have twins. You know, everybody said it skips a generation and we said well. you know, if we have twins we have them and if we don't. we don't.

\section{Right, right.}

/And it got to the point where we really felt that we needed children. /And the need came from the fact that we had part of our life that we wanted to share with somebody else. /My entire family's on the east coast. My wife's family isn't a very, uh, they're close but they don't. they're not really...I don't know how to say it but they don't touch, they're not a very loving family, they don't really take care of each other the way I'm used to and the way my family is.

\section{Okay.}

/When my wife saw how my family and I interact. you know, that thousands of miles don't keep us from talking to each other every day and joking and being a part of each other's lives, she felt that that was missing in her life. And so she wanted to extend our family. There was also the fact that I go away quite a bit. for either conventions or classes or hunting, again, and fishing. And when I did, my wife found herself...alone. And she said. you know, a child would keep me from nagging you about going away all the time.

\section{Hm. That's interesting, yeah.}

/I think she felt it was leverage. And I had no problem with having a kid, so I was like, sure.

Yeah, yeah. wanted to have twins. He and his wife decided that "if we have twins we have them and if we don't. we don't."

40. S. and his wife "got to the point where we really felt that we needed children."

41. The sense of needing children that S. and his wife had came from their desire to share part of their life with someone else.

42. S.'s family lives on the east coast. And his wife's family is "not a very loving family, they don't really take care of each other" in the way that $S$. is used to.

43. When S.'s wife saw how close and connected his family is in spite of being thousands of miles apart, "she felt that that was missing in her life" and she "wanted to extend our family."

44. Because $S$. is away from home quite a bit. his wife thought that having a child would make her less lonely and keep her from nagging him about going away.

45. S. thought that his wife perceived her desire to have a child so as not to nag him about leaving her alone as "leverage." But S. had no problem with having a child and liked the idea that doing so would let him go on his fishing trips. 
If it lets me go on my fishing trips [laughs], I won't argue.

It works out well for both of you.

Yeah.

The need is interesting, I'm trying to understand that, I think. That feeling of need that you had, if you could describe that for me.

/Well, you know. I feel pretty strongly about a lot of things, I think I'm a bit of a compulsive person. And rather than just having an idea, usually once I get an idea it'll either ferment into a bad idea or a need. And when I say need. I mean all of a sudden I can't think of myself without doing that thing. /And uh. in this case it went from gee, yeah, a kid would be nice, to. well who am I going to leave this to? And who am I going to pass this on to? And, yeah, and who's going to unconditionally love me and trust me? /And I don't have that in my life with the exception of my sisters, who live a long ways a way and don't routinely use that part of our relationship as they did when I was younger. $/ \mathrm{Um}$. I'm the youngest in my family as far as males go because my two older brothers were killed, and uh. my sisters all came to rely heavily on my income. um, to further their education. I put three sisters through college. I bought my three sisters their houses. When my mother got out of the hospital I bought her her house and sent her to her doctoral program. And uh, you know, I was heavily relied upon and I lived my life...through them.

46. S. sees himself as "a compulsive person." someone who feels "pretty strongly about a lot of things." When he gets an idea. it develops either into a bad idea or into something that he feels he needs to do, "all of a sudden I can't think of myself without doing that thing."

47. S. went from thinking "a kid would be nice" to wondering who he could pass things on to and "who's going to unconditionally love me and trust me?"

48. S. doesn't have the feeling of unconditional love and trust in his life except with his sisters. who are far away and who don't use that part of their relationship with him like they did when they were younger.

49. S. was the youngest male in his family, but because his older brothers were killed his sisters and his mother came to rely on him for financial support. He put them through school and bought them their houses. He was "heavily relied upon" and he lived his life "through them."

Yeah. 
/And then I moved here and claimed for a long time that I just needed to live for me. I went to college here for seven years and got my degree and came to work and so on and...people stopped depending on me. /And you know, even when I married my wife who is a lot younger than me, and I believe I married her also for her need and dependence on me -- she grew older, she started to get less and less dependent. And all of a sudden I found myself with no one to lean on me. /And whether or not that's psychologically sound, it's the way it is.

Yeah, yeah.

I needed something that needed me.

Yeah, right.

That really needed me. You know. for everything. /And guess what, you know, the cat didn't work. [laughs] The kitten needed me for about an hour and then said. "Who are you? The food's in the bowl, right? I'll see you later." [laughing] So, you know, people suggested a puppy, but again, you know. a puppy can't communicate in the ways that a child can. /So I started looking towards children.

Huh.

/And, you know, I think I have enough love and enough patience now where I can temper both and uh. do right by a child. /So it started to become, in me, something where I couldn't see myself without it. It was just a matter of when.

Yeah, it's interesting how that worked. I'm curious then what happened-- you started out this
50. When he moved to Montana. S. claimed for a long time that he wanted to live his life just for himself. As a result. people stopped depending on him.

51. S. believes that he married his wife for "her need and dependence" on him. But as she became more independent he found himself with no one to lean on him.

52. S. says that he "needed something that needed me." He doesn't know whether this is "psychologically sound" but he needs something that really needs him. for everything.

53. A cat didn't satisfy S.'s need for something that needed him. People suggested a puppy, but a puppy "can't communicate in the ways that a child can."

54. S. "started looking towards children" as a way to find something that would depend on him.

55. S. believes that he has "enough love and enough patience now where I can temper both and...do right by a child."

56. S. started to feel that a child was something he couldn't see himself without. "It was just a matter of when." 
process with a ton of doubts and really negative stuff about having a kid. What happened to that as you went through this process?

/Well. I realized that I wasn't -- I wasn't right in my assessment of what a child did to a marriage and to, to lifestyles. There's someone in this building. you might have spoke with. his wife was the other name, your wife got his name the same time as me.

Yeah, okay, right.

And they're a little older than we are and they're avid outdoor hikers and stuff, you know. And I asked him the same thing. I said well, when did it go from being an inconvenience to a possibility. And he kind of said exactly what I thought. He said. you know, I see people fly-fishing on the river down there with their babies in a backpack. I see people out camping all the time and they've got a little baby carrier with them. And you know, it' doesn't have to be the end of a lifestyle. It can enhance your lifestyle, you know. /A very close friend had a child who's two years old now and him and I were fishing buddies for years. And we've still been fishing. And I realized, hey this hasn't stopped him at all. And I got the pleasure of taking his boy with us a couple of times. you know. And it didn't cramp our style in any way, shape or form.

\section{Right.}

/You know, the days of doing things that you can't do around children are long gone for me. You know. I'm no longer a wild, drinking, crazy, smoking fool.

\section{Right.}

57. S. realized that he had had the wrong idea about "what a child did to a marriage and to...lifestyles."

58. S. knows another couple who is having a child and he asked the man when having a child went "from being an inconvenience to a possibility." The man described how he saw other men fly-fishing with a baby in their backpack. He said that "it doesn't have to be the end of a lifestyle. It can enhance your lifestyle."

59. S. has a very close friend who has a two year old child and he and this friend have continued to go fishing together. They have taken the child with them "and it didn't cramp our style."

60. S. no longer lives the sort of life where he does things "that you can't do around children." He didn't have to worry about bringing up the child in a bad atmosphere. 
So it wasn't a matter of geez, would I want to bring a child up in this atmosphere anymore.

\section{Right.}

Um. and I moved from New York to Missoula. Montana, which is quite a lifestyle change as far as what you would subject your child to once they go out into the world. /You know. I went through the New York City public school system. And it was a test. it really was. And I didn't want anything to have to live through what I lived through.

Huh. So that's how it worked with I'm trying to understand it all -- part of it was just getting evidence it sounds like, that contradicted what your expectation was.

That's correct, that's correct.

Then another aspect that you mentioned was just kind of the real tough childhood that you had growing up.

Right.

And you sort of got the idea that childhood wasn't so great.

Right.

And that, so you got over that or got through that by, by being here it sounds like.

By being here, mostly, yeah. /I was in a gang, you know, in Brooklyn, New York. We were pretty bad kids, you know, all the way around. And, uh, I didn't see much good in people.
61. Moving from New York to Montana was a big lifestyle change for $\mathrm{S}$. with regard to "what you would subject your child to once they go out into the world."

62. As a child, $S$. went through the New York City public school system. He wouldn't want his child to have to live through what he lived through.

63. By being in Montana, S. began to get past his idea that childhood wasn't so great.
64. As a child. $S$. was in a gang with some "pretty bad kids." He "didn't see much good in people." 
/And it took me a long time when I came to Missoula, Montana to believe that people were sincere. And that they weren't just putting on a front, /like. you know. in New York you can see people as nice as pie and then you drink with them that night and you find out what they're really about and it's a different motivation than they present. /And here it's not the same, here people actually have a community feeling, you know, they, you listen to my favorite radio station here in town and a kid is sick and the next thing you know there's twenty thousand dollars donated through the radio.

\section{Right.}

You know. and these are people who have nothing to gain by donating it. you know they're not going to write it off on their taxes this year. /And I started to think, geez. you know, this is a nice place. And you know the children here are happy. And I'm happy. And I don't have to hold onto that anger and that angst that I felt most of my life. you know. /And I started as the layers came away from me and I started to see the world for being good, you know, I started thinking I'd like to share it with somebody.

Yeah, so that is really interesting because it's a change in how you see the world itself. That it's not just the way you grew up, it's sort of different than what....

Y Yeah, right, you know and I think with everybody, your perceptions need to change. And that's part of growing. you know. /But if you can't see yourself in this world as a happy, functioning person, then I don't think you have any
65. It took S. a long time to believe that people in Montana were sincere and that they weren't just putting on a front.

66. S. found that while people in New York could act very nice, they might have different motivations than they were showing you.

67. S. believes that people in Missoula "actually have a community feeling." They give to others even when they have nothing to gain by it.

68. S. started to realize that Missoula was "a nice place." Children here were happy, and he was happy. He found that he didn't have to hold onto the anger that he'd felt for most of his life.

69. In Missoula. S. felt layers coming away from him. He "started to see the world for being good" and started thinking that he'd "like to share it with somebody."

70. S. believes that part of growing means that "your perceptions need to change."

71. S. believes that "if you can't see yourself in this world as a happy, functioning person," then you don't 
business bringing somebody else in. and subject it to that negative side, you know.

\section{Right.}

/So, and I felt that at many, many times in my life that it was only negative, you know, /and in the last six years I haven't been able to shake that... happy feeling [laughs]. So, I figured geez, it might be here for awhile.

\section{Yeah, that's a big change.}

It's a big change in my life, it's a big change in my marriage. My wife and I had a little bit of a rocky time in our marriage where I was a little too cynical, and she was a little too hard-boiled having been with me. /You know, she went from a sweet Montana girl to a semi-cynical New York wife. you know. She tried to keep up with my many many many attitudes and experiences. It's really difficult. but when you've been through and seen quite a bit and then you come to a place where somebody else you're sharing your life with hasn't been through or seen anything. you know. basically they have to take your word for it what's out there.

\section{Right.}

/And uh, what I felt was out there really wasn't any longer. I lived in a different world.

Hm.

/So I had to get rid of a lot of that baggage before I could change my attitude.

\section{Right.}

"have any business bringing somebody else in" and subjecting it to "that negative side."

72. S. had often felt about life that "it was only negative."

73. For the past six years, S. says he hasn't "been able to shake that... happy feeling." He thinks "it might be here for awhile."

74. Being able to see the world in a positive light has been a big change in S.'s life and in his marriage.

75. S. and his wife had "a bit of a rough time" in their marriage. where they were both too hard-headed and cynical.

76. Initially in their marriage. S.'s wife went from being "a sweet Montana girl to a semi-cynical New York wife." Because she had not had the range of experience that $S$. had. she had to take his word about "what's out there."

77. After living in Montana. S. found that "what I felt was out there wasn't any longer." He "lived in a different world."

78. S. had to get rid of a lot of baggage before he could change his attitude. 
/And when I did. my wife slowly changed her attitude. And both of us realized that it was a happy life. it was a good life. /And, uh, once you get to that point I think children come inevitably.

Right.

You know. it's a bundle of joy. [laughs]

Huh. So, I'd like to hear more about...that, going back to this point again where you're sort of looking at other people and talking to other guys. And kind of hearing in as much detail as you can tell me, kind of what, sort of how that change happened in you.

Um-hm. Um, well. again. my best friend and a good fishing buddy of mine, him and his wife I always felt were a little too competitive. I thought they were a little too independent to be a unit. to be married, much less be a family. I felt that they competed with each other in their careers and in their abilities and in their needs and wants. You know, geez. is it going to be my raft or is it going to be your sewing machine. And, you know. I felt that they were never really well matched. And then they got pregnant. And the change that came over my friend. um. was complete. And it was sincere. And for anyone who knew him it was easy to see. you know. It was no longer a matter of well, I got mine. did you get yours? It was, how are you and what can I do for you?

\section{Huh.}

To his pregnant wife. /And I saw that and I thought it was interesting. I noted it in my mind and said well, let's see what happens, you know. This is a man
79. When S. changed his attitude about life. his wife did too. They both realized "that it was a happy life. it was a good life."

80. S. feels that once you get to the point where you feel that life is happy and good. "children come inevitably."

81. S. had a good friend who had a child with his wife and the pregnancy changed him dramatically. Before the pregnancy $S$. felt that his friend and his wife were too competitive and independent to be married or to have children. But after the pregnancy his friend changed completely from being competitive and selfish to being concerned about the well-being of his wife. 
who never, ever spent time with his wife except after he was done doing what he wanted to do. And all of a sudden it was. I can't wait to get home from work and be with my child. Gee, I'm out of town. I miss my baby. Um, calling the home and saying put him on the phone, and the kid couldn't even gurgle much less speak. you know. and he would just go. can you hear me, it's daddy -- what's he doing? -- can you hear me it's daddy. And so I saw one person. I said, this is interesting --

\section{Yeah, what were you thinking about yourself as you were watching that, in terms of your own decision?}

/I was thinking that maybe I was wrong about whether or not I wanted children at that point.

\section{Okay.}

Not so much that I was wrong about my, my attitude as far as what I was giving up and what I was going to have to change in my life. But just whether or not I also wanted to be a father and wanted to have that love. that I felt magically appeared when the baby came out.

\section{Uh-huh, okay.}

Um. I'm starting to feel different about that as well now. I think the love comes... [coughs] excuse me, well before.

Well before...?

Well before the baby actually arrives. with his wife until after he'd done what he wanted to do. to a person who couldn't wait to get home to his child. S. thought that this change was interesting.
83. As he watched his friend go through a change with the birth of his child. S. thought "maybe I was wrong about whether or not I wanted children at that point." He wasn't thinking about his sense of what he would lose or have to change in his life, but rather "whether or not I also wanted to be a father and wanted to have that love that I felt magically appeared when the baby came out."

Oh.

84. S. is starting to feel that the love for a child comes "well before the baby actually arrives." 
$\Pi$ think that love comes when you decide to have a child, or even a little before that. and that's what makes that decision so possible. /I think you come to a point where the roads cross and you have to decide to become one, to give up that individuality, you know. My role as teacher and my wife's role as student all of a sudden became husband and wife. And equals. /And I don't know if it's a credit to her, or that l'm losing some of my ability to maintain power and control [laughs]. /But in any case. we shifted into a different relationship. where we were a lot more on equal footing. And she was no longer something that I had to devote a hundred percent of my time just to keep her happy, just to keep her doing what I thought I needed from her.

\section{Um-hm.}

/And all of a sudden, things just came naturally and it was no longer a job to be a husband. It was just a nice thing, to be a husband.

\section{That's nice.}

Yeah. And we reveled in that for awhile. but out of that sprung child. you know. /In ways you can't even describe. we felt that we could share this love with a child. /And, uh. I mean we bought little pets, we did. We had a little hedgehog first, we bought a kitten -- or adopted a kitten I guess you could say, and you know again it was kind of like a test.

\section{Uh-huh.}

Could we have this undevoted, nurturing love for something that can't even express love back to us in verbal ways?
85. S. believes that love for a child comes "when you decide to have a child or even a little before that. and that's what makes the decision so possible."

86. S. believes that "you come to the point where the roads cross" and you decide to become one. to "give up that individuality."

87. S. found that the roles of teacher and student that he and his wife had been in shifted and become equal. husband and wife.

88. S. doesn't know whether the change in roles in his marriage were a "credit" to his wife or whether he's losing his ability to maintain power and control.

89. The relationship between $\mathrm{S}$. and his wife shifted so that they were "a lot more on equal footing." He no longer had to spend all his time trying to keep her happy in order to keep her doing what he needed from her.

90. With the change in his marriage. $S$. found that "it was no longer a job to be a husband. It was just a nice thing." $\mathrm{He}$ and his wife "reveled in that for awhile."

91. Out of the change in his marriage. $S$. and his wife began to desire a child: "In ways you can't ever describe. we felt we could share this love with a child."

92. Before deciding to have a child. S. and his wife got pets. This was "kind of like a test" to see if they could show nurturance and love for something that couldn't express love back verbally. 
Yeah, right.

/And uh. you know. I saw it was true in my wife. And I guess I passed her test. /And we both started talking more and more about how neat it would be to have a kid. Nm, my other friends. uh. one of them had a child accidentally. Uh. and he was dead-set against it. for the first four months of their pregnancy was pretty much a jerk about it to his wife and saying, well, you know this is what you always wanted, well now you got it. And you trapped me. And I watched him conform, or reform. or whatever the word would be. into a doting and caring father-to-be. Uh. going to Lamaze classes and child CPR. child development. and learning all he could to be a better father. /And. uh, whether or not he ever became a better husband I really don't know, I don't live with them. But I see him with his child and I say to myself. well here's a guy who didn't want to have this kjd and for whatever reason he now is... really, really into having this child. And it hasn't changed his lifestyle at all. It hasn't affected his independence, it hasn't changed his, his willingness to go out and ride a motorcycle, you know. /We hear stories. you know, on the non-child side of, yeah. you know, I started riding motorcycles and then I had a baby and realized I couldn't ride a motorcycle anymore. Because I could die.

\section{Right.}

And you don't want to die because you have something to live for now. /You know, I never wanted to die. [laughs] I've always had something to live for. and felt well gee, I don't need anything more to live for than I already have. /And I realized with him that it
93. S. saw that his wife was capable of loving their pets. And he guesses that he "passed her test" as well.

94. S. and his wife "started talking more and more about how neat it would be to have a kid."

95. One of S.'s friends had a child accidentally. He was against having a child and was a "jerk" about it at first. But then S. saw this friend change into "a doting father-to-be."

96. S. can't say whether his friend who had the accidental pregnancy ever became a better husband. but he noticed how this man, who didn't want to have a child. was now "really in to having this child." It didn't change his lifestyle or his independence or his willingness to take risks.

97. S. hears stories about how the fear of dying after having a child keeps some people from doing things they liked to do. because "you don't want to die because you have something to live for now."

98. S. never wanted to die. He always felt that he had something to live for. He didn't need anything more to make him feel that. 
was definitely not a change for that bad.

\section{Um-hm.}

And I thought it really made him a better person. Then my father, who lost all his children....

[End of side one of tape. At this point the conversation continued for a period without the tape recorder running. As the recording resumes, we spend some time reviewing the discussion that had not been recorded.]

All right. So we're going to go back to...you were talking about your father, that's what it was, and kind of his....

Yeah, his experiences with life. Basically, my father helped me to decide that children were always there for you. My father told me on the phone one day that no matter how much other people in his life, his friends would get angry with him and didn't want to talk to him for long periods of time because of the type of person he was -- one day I told my father on the phone how I was never planning on having kids and how I was glad that I never did have kids with my wife because I thought maybe my wife and I wouldn't be together forever. And my father told me. uh. that one of the greatest things in his life is that he can always pick up the telephone, no matter who in his personal close circle of friends wasn't talking to him, he always had kids he could call and that would always be happy to talk to him on the telephone, whether they were glad to hear from him or not didn't really matter, it was just, we were always there for him and he could always be a part of our
99. S. realized that the change his friend went through after his accidental pregnancy was not for the bad and that "it really made him a better person."

100. S.'s father helped him decide "that children were always there for you."
101. When S. told his father that he wasn't planning on having children because he wasn't sure that he and his wife would stay together. his father told him that one of the greatest things in his life is that no matter how his friends were feeling about him. his children were always there for him. His children would always be a part of his life, just by virtue of his being their dad. 
lives. And we would always be a part of his lives, no matter how far away we were. just by the virtue of him being our dad. /And uh. you know. I got to realizing that there was something more to children than just people. They were part of you, they were an in-, un-. you can't disconnect that, you know. It's a part of you that will never ever cease to be a part of you. $/ \mathrm{Um}$. which, you know. to be honest with you, as I've gone through my different decades, I've lost a lot of parts of me.

Hm.

Permanently lost those parts. And some for the good and maybe some for the bad, you know. /And one of the things that appealed to me about having kids after thinking of it from my father's point of view, was that. you know. those kids that you have or that kid that you have. is never going to not be a part of you. it's never going to be a part of your life that you lose.

I see.

It's always. forever going to be a good thing about your life. you know. There are people I know with kids that have gone to jail, kids that have stolen from them and kids that have really made their lives miserable. But they love them unconditionally just the same. /And it appealed to me and it was something that I felt was positive and it was a good thing that I wanted in my life.

\section{It's like a continuity.}

Correct. Correct. /And you know, it's not really to extend the family line, it's not really to - although in my case my
102. Talking to his father. S. began to think differently about what children were. They were more "than just people." They were "a part of you" that you can't disconnect. "It's a part of you that will never cease to be a part of you."

103. As $\mathrm{S}$. has gone through his life he's "lost a lot of parts of me." some for the good and some for the bad.

104. It appealed to $S$. that when you have a child "that kid... is never going to not be a part of you. it's never going to be a part of your life that you lose." A child will always be "a good thing about your life."

105. S. knows parents whose children have gone to jail and have made their lives miserable -- but they still love their children unconditionally.

106. The idea of children always being something good in his life appealed to $\mathrm{S}$. He felt that it was positive and he wanted it in his life.

107. S. didn't want children in order to "extend the family line," although he believes his father will be 
two brothers were killed and I suppose my father was pretty happy that I decided to extend the family line.

\section{Right.}

/It's just more a matter of that connection with somebody. You know, that bond that nobody can break. /Like I feel with my sisters. And uh. my child hopefully won't move away as quickly as my sisters did. And uh, l'll have a little more closeness with it for awhile.

Right, okay. So then take me through sort of how the debate within yourself went as you were looking at other people, um, that you had a lot of doubts, then you started looking at other people. How did that work inside yourself?

/Yeah. I felt that the people that I knew, uh, and myself, were all in a set where we did not have time or room in our lives and our lifestyles for a child. For a dependent, needy being. /And uh, when I started to see some of my friends, my fishing partners and my hunting partners start to have kids. or their wives were pregnant or they just had kids. and I started to see them in their new lives as parents. or parents to be, enhancing their lifestyles instead of abandoning them. I started to realize that it wasn't necessarily a detriment to have a child, but it was more of an enhancement to your lifestyle, you know. /Like I said, my friend who was pretty much independent of his wife and vice versa, and pretty competitive with her in everything they did, um, all of a sudden I noticed that he wasn't any longer -- he didn't have a need to fulfill his own needs first. All of a sudden he became a happy that he's doing so. especially because his two brothers were killed.

108. The reason S. wants children is to have "that connection with somebody...that bond that nobody can break."

109. S. hopes to have the kind of connection with his child like he has with his sisters - except that it will be closer for longer.

110. Before deciding to have a child. S. felt that like other people he knew he didn't have room in his lifestyle for "a dependent. needy being."

111. As his friends started to have children. S. began to see that rather than a detriment. children were an enhancement to their lifestyle.

112. S.'s friend who was independent of and competitive with his wife suddenly became "a little bit more selfless, a little bit more doting and caring" than S. thought possible. He appreciated and enjoyed this change. 
little bit more selfless. a little bit more doting and caring than I thought him capable of.

Yeah.

And uh, you know, it got to the point where he was downright mushy. And he wasn't ashamed of it and he wasn't apologetic for it. It was just a natural transition.

\section{Right.}

And I really appreciated that and enjoyed that. /And another friend of mine who hadn't planned his pregnancy - excuse me -- and was dead-set against it for the longest time, um. I started to notice he really got into having it in his head that he was going to have a child. And he went to the classes and bought a camper instead of camping out of a tent, so that he could accommodate that lifestyle but he wouldn't have to give up his going outdoors. And he. uh. he made a baby's room in his house that had no room for him and his wife -- all of a sudden he found the means to build himself an addition. And you know, he started gearing his life toward having his child. /And I saw the transformation in him. And I thought it was wonderful, I thought it made him a better person. $\mathrm{Nm}$. then I started to realize that the things I was feeling inside of me, really weren't that contradictory toward my lifestyle. They really didn't have to change me and make me into a different person, but that they could make me into a better person.

\section{Okay.}

/You know, um, and it became more and more of a question inside of me of the
113. S.'s friend who had an unplanned pregnancy started to really get into having a child. He found ways to accommodate a child into his lifestyle. built an addition to his house and "started gearing his life toward having his child."
114. S. thought that the transformation in his friend who had had the accidental pregnancy was wonderful. He thought "it made him a better person."

115. S. started to realize that the feelings he was having about children "realiy weren't that contradictory toward my lifestyle." They might not make him into a different person but rather into a better person.

116. As S. thought about having a child, his focus shifted from "the 
dos and don'ts of having a child, more than the problems of having a child, it became, you know, answers of having a child and the problems they would solve. As opposed to the problems of having a child and the answers that might solve them.

\section{Could you go back and describe more what the debate was about.}

/Right. Again, inside of me there were, you know, three kind of areas that I had to address toward my lifestyle and how a child would be incorporated into those areas. The first was the fact that I'm kind of a, or was kind of a militaristic, inflexible. by the numbers, by the books type of guy. My training in the service and working for my dad growing up and working on Wall Street put me in a position where I would detach myself from my emotions when things came down to crunch. when pressure got high or crisis situations came about I would. I would just shut off the emotions and I would just go about taking care of the problems. /And I knew inside me that that was not, you know. conducive to having a child. um. that a child you have to temper everything with love and with understanding. And it can't just be well I don't have time for your tears now, this has got to be done. You know, it became, you know, a little bit more of give and take. And everything doesn't have to be signed, sealed and delivered, you know. And things can be left a little sloppy because you have better reasons now for what you're doing. /I used to be intimidating and overbearing. When I wanted to, to get things done my way, my response was to make people do it that way. And it was pretty easy for me to do, I'm a big guy and I'm pretty problems of having a child and the answers that might solve them" to the "answers of having a child and the problems they would solve." He focused more on "the dos and don'ts" of actually having a child than on the problems that would keep him from having a child.

117. S. had three areas of concern with regard to how a child would be incorporated into his lifestyle.

118. S.'s first area of concern with regard to having a child was that he was "a militaristic. inflexible, by the numbers. by the books kind of guy." His past experience had taught him to detach from his emotions when pressure got high and "just go about taking care of the problems."

119. S. knew inside that his militaristic attitude was not "conducive to having a child." that with a child his attitude would have to be tempered with love and understanding. He would have to be more flexible in his attitude and more accepting of a child's emotions.

120. S. used to be "intimidating and overbearing." Because he was "a big guy" he could be pretty intense and could make people do things his way. 
intense when I need to be. /And uh, you know I realized that in my marriage and in my dealing with other people, I had learned to soften that. And that it was no longer my way. /And I started to look at myself now -- as opposed to looking at myself in the past.

\section{Uh-huh.}

/And I started to see that even just by marriage, and by mellowing with age so to speak had already done a lot of that for me, had transformed me from being a "I'll get the job done, sir" to "well... how badly does the job need to be done?" And how well does the job need to be done to consider it done?

\section{Right.}

You know. I used to teach my wife how to clean my bathroom. You know, I would inspect my bathroom when my wife was done cleaning -- and that's a horrible thing for a child to have to grow up with. /I grew up with a friend whose dad -- he had two brothers and himself and their room was identical from bed to bed. dresser to dresser. bureau to bureau. closet to closet. Any mistakes they made they were punished by doing what we call "puta." which is military exercises. /And uh, you know I said this is not the kind of a parent I want to be. I don't want to be the disciplinarian-slashbreadwinner, you know, while my wife was the caregiver and you know, needs giver.

\section{Right.}

/And I started to realize that that wasn't the case anymore. That I was more of a caregiver and a need taker for my wife than I'd even given myself credit for. So
121. S. realized that in his marriage and in his dealings with other people. he had changed and softened his militaristic. inflexible style.

122. S. says that he "started to look at myself now -- as opposed to looking at myself in the past."

123. S. started to see that through marriage and "mellowing with age" he had been transformed from a person whose attitude was "I'll get the job done. sir" to someone who asked "how badly does the job need to be done?"

124. S. used to teach his wife how to clean his bathroom and to inspect her work when she was done. He thinks that this is "a horrible thing for a child to have to grow with."

125. S. grew up with a friend whose father forced his children to keep identical rooms and punished them with military exercises when they made mistakes.

126. S. doesn't want to be the sort of person who enforces rigid. militaristic rules on his children. He doesn't want to be the "disciplinarian-slash-breadwinner" while is wife is the caregiver.

127. S. started to realize that he had changed, that he was more of a caregiver for his wife than he'd given himself credit for. That has 
that kind of assuaged that fear.

Right.

/Another part of my life was my spirituality.

Okay.

Which at a certain point l'd come to a crossroads and realized that I wanted that to be in my life. /And being Jewish, my wife was not part of my religion. And this town was not part of my religion. /And I realized that my child, uh, or I had feared that my child would not be able to grow up with that heritage that I really wanted for a child. you know, that I thought a child needed. you know. in its early years to develop a sense of tradition and a sense of history and a sense of faith. IAnd you know, I felt that I couldn't do that for a child here. that I wasn't really living up to my end of the faith. And how could I ask a child to take unconditionally the word of God if I wasn't really living a better life? YYou know, I grew up. I grew up in a place that had a lot of dichotomies. Um. you know. I went to synagogue twice a week and then I was in a gang the rest of the week, robbing and hurting people. And uh. you know I felt my whole life was at, at ends, at odds.

Yeah.

/And I started to feel that melding together. And again I looked at myself now, at my capabilities and my beliefs and I realized that hey, you know, if I need a synagogue then I'll build a synagogue. You know. Or I'll have a synagogue brought here by calling people that I know from New York and from Florida and stuff. /And that. um, if "kind of assuaged that fear" about his militaristic personality.

128. Spirituality was another concern for $\mathrm{S}$. as he was deciding to have a child. He'd "come to a crossroads" and realized that he wanted spirituality to be in his life.

129. S. is Jewish. but his wife and the town he lives in did not share his religion.

130. S. feared that if he had a child it would not grow up with a sense of heritage. tradition. history and faith -- which he felt a child needed in its early years.

131. S. felt that he couldn't give a child a sense of its heritage where he lived and because of that he felt "I wasn't really living up to my end of the faith." He wondered "how could I ask a child to take unconditionally the word of God if I wasn't really living a better life?"

132. S. grew up "in a place that had a lot of dichotomies." He was in synagogue twice a week. but the rest of the time he was in a gang. He felt that his "whole life was....at odds."

133. S. started to feel the conflicting aspects of his spiritual life "melding together." He looked at his capabilities and beliefs in the present and thought that if he needed a synagogue here he could take steps to have one built or brought here and that he could travel if he needed to for occasions and holidays. 
I had to travel I would travel for certain occasions and holidays. And that my child could be immersed in that religion. And so I felt that, uh. that that was no longer a problem inside of me, you know.

\section{Right.}

/And uh. another part of me, besides the dominance and the overbearing and the spiritual aspect, was uh...I can't remember exactly what we said...but there was....

\section{I'm not sure.}

Geez, it had something to do with. uh. my ability to...I can't. I can't honestly remember. Oh -- l'm sorry. my wife's and I's lifestyle.

\section{Okay, yeah.}

/Um, you know, I was afraid of day care. In a big way. I really felt that day care wasn't what I wanted for my child until my child was three or four. And then I wanted some interaction with other children on a limited basis. /But I felt that our lifestyles were not able to support a baby at home with a wife and me taking care of everything. /My wife completed a training program that allowed her to run her own business. Which, all of a sudden now she can schedule her appointments around my work schedule. And we could both be with the child at different parts of the day -- or together -- and that the child wouldn't need day care or outside influences.

\section{Right.}

134. S. realized that his child could in fact be immersed in Judaism. And so he felt that this "was no longer a problem inside of me."

135. In addition to his concerns about spirituality and his overbearing personality. S. was worried about the effect a child would have on his and his wife's lifestyle.

136. S. was afraid of day care. He felt strongly that a child of his shouldn't be in day care until it was three or four. and that after that it should have "some interaction with other children on a limited basis."

137. S. felt that his and his wife's lifestyles "were not able to support a baby at home with a wife and me taking care of everything."

138. S.'s wife completed a program which allowed her to run her own business and to schedule appointments around his work schedule. so that they could each be with a child at different parts of the day and the child wouldn't need "day care or outside influences." 
/And I noticed my wife's self-sufficience emerging.

\section{Right.}

And I realized that her self confidence was rising. And her ability to deal with things was certainly far surpassed what I had given her credit for in our meeting and in our earlier relationship. /And uh, you know once I again looked at myself in the now as opposed to in the past -you know I'd al ways believed that I am what made me what I am. You know, and all my past is there. And I came to a different decision that I am no longer what I was that made me what I am now.

\section{Right.}

That I have grown past that. ['ve peeled those layers, so to speak, kind of like an onion.

\section{Yeah.}

/And that now I was at a point that I could support. lovingly and you know financially a child. you know. /And you know inside of me that fear that, that distant nagging that it just wouldn't work. you know that we would be on the cheese line, hiding our faces and my child would be having the same arguments I had with my parents about food stamps, you know and how "I don't want to go to the store" -- /and I realized that I wouldn't subject my child to that or hopefully I wouldn't subject my child to that. /And in my head it became less and less of a nagging doubt. And more and more of an affirmation that it wouldn't be that way. And that really made me feel a lot better about what $1 . .$. .
139. S. noticed his wife's selfsufficiency and self-confidence was rising. Her ability "to deal with things" surpassed what he had given her credit for.

140. S. looked at himself "now as opposed to in the past." He had always believed that "I am what made me what I am." that "all my past is there." But he came to the conclusion that had grown past that, that "I am no longer what I was that made me what I am now."
141. S. realized that he was at a point where he could support a child, "lovingly" and financially.

142. S. had had inside him a fear about having children. a "distant nagging that it just wouldn't work." $\mathrm{He}$ feared that he would re-create in his child his own childhood experiences of embarrassment at his family's lack of money.

143. S. realized that he wouldn't subject his child to the same embarrassment that he had been subjected to about his family's lack of money, "or hopefully I wouldn't subject my child to that."

144. S.'s worry that he would subject his child to being embarrassed about a lack of money "became less and 


\section{So, "hopefully" - the doubt doesn't go away altogether it sounds like.}

No. No. Anybody who says that they're not afraid is probably a little bit too rigid, you know, to open up and share with a child. /I mean. you know I think that the best lesson you could ever learn. and it took my father thirty years to tell me. was that you are afraid and that you are doubtful and that you aren't the Rock of Gibraltar. And that sometimes it is on a wing and a prayer. [laughs] You know?

\section{Yeah, so how do you manage that? What's the...}

/Well it's, you know, like I told you earlier it's self-confidence. I have an over-blown sense of self-confidence. I believe. honestly, that anything and everything that comes my way can be dealt with in a satisfactory solution. /It used to be that solution was satisfactory to me and me alone.

\section{Um-hm.}

And I really didn't care who else it was satisfactory to. And now I believe that it's different for me. I believe that uh, I believe I can handle these problems in a way that makes everybody happy. More of a diplomatic effort than I've ever made in my life.

\section{Right.}

Um. I was a late bloomer as far as getting a girlfriend, I was a late bloomer as far as getting a wife. I waited until I was thirty for that. And I was a late bloomer as far as becoming a father -- I was thirty-four before I got my wife pregnant. Or thirty-three and three- less of a nagging doubt. And more of an affirmation that it wouldn't be that way."

145. S. believes that anyone who claims not to be afraid when it comes to having a child "is probably a little bit too rigid. you know. to open up and share with a child."

146. S. believes that "the best lesson you could ever learn " is that "you are afraid and that you are doubtful and that you aren't the Rock of Gibraltar. And that sometimes it is on a wing and a prayer." It took S.'s own father thirty years to tell him this.

147. S. is able to manage his own doubts because of his "over-blown sense of self-confidence." $\mathrm{He}$ believes that he can deal satisfactorily with anything that comes his way.

148. S. used to be selfish in the solutions he came up with to his problems -- they only had to be satisfactory to him. Now he believes he is different. that he can handle problems in a diplomatic way that makes everybody happy.

149. S. considers himself to be a late bloomer as far as getting a girlfriend and getting married and having a child. 
thirds. /And uh, it became something inside of myself that just. it calmed me. it was soothing. I realized that anything I did would work out well.

\section{Yeah.}

/And my wife has an unconditional trust in me.

\section{Right.}

And now in herself.

\section{Right.}

/And knowing those things made me feel that there's nothing we couldn't do for a child or for ourselves. And uh. I was glad to meet that challenge and hopefully do well with it when it comes.

\section{Yeah. You mentioned faith before too.}

/Fantastic Adventures In Trusting Him.

\section{Right.}

Um, I believe strongly that we all have our revelations, we all have our callings. /I am not a model Jew. Or a model human being or Samaritan for that matter. I still have selfish needs. I understand that and accept it and I don't beat myself up for it. There are times I place other priorities higher than what the Bible says I should. $\mathrm{Um}$, but I also believe that I live my life in a way that is not harmful to anybody else. And that I don't make it my business to make other people feel badly or poorly about their abilities or about themselves. /And I've gone, overcome, or I've begun a transformation of positively affecting people's lives consciously.
150. S.'s sense of self-confidence was "something inside of myself that was just. it calmed me. it was soothing. I realized that anything I did would work out well."

151. S.'s wife has "an unconditional trust" in him. And "now in herself."

152. S.'s confidence in himself and his wife's trust in him make him feel that "there's nothing we couldn't do for a child and for ourselves." $\mathrm{He}$ "was glad to meet that challenge and hopefully do well with it when it comes."

153. S. refers to faith as "Fantastic Adventures In Trusting Him." He believes that "we all have our revelations. we all have our callings."

154. S. says that he is not a model Jew or a model human being. He has selfish needs and at times he places "other priorities higher than what the Bible says" he should. He understands and accepts this about himself and he doesn't beat himself up for it.

155. S. believes that he lives his life "in a way that is not harmful to anyone else." He doesn't make it his business to make other people feel badly about themselves.

156. S. has begun trying consciously to have a positive affect on other people's lives. He wants people to 
Hm.

Of people really walking away from conversations and walking away from interactions with me feeling better about that interaction. /And when I realized that that was happening, besides giving myself an enormous pat on the back. I felt an enormous release. /And I realized that it was through the greater power of God. you know. Or of even just my wife and mine love. That l'd become a better, kinder. gentler, maybe wiser person. /And uh. you know, that was something that I felt was good for a child. And good for me. And I wanted to share that with somebody. /I wanted to become a teacher all of a sudden. Um. and I didn't want to teach anybody but my child. thank goodness. But I wanted to all of a sudden become someone who took what he felt was a spiritual guidance and passed it on to people he felt needed it.

Hm.

/Amazingly enough, I get phone calls just about twice a day, three times a day from people we know. asking me questions about things I have no business knowing, for what reason my wife and I still ponder. We say, why does he call you for that? Why doesn't he call this or that? But maybe it's because of the way they interact with me now, you know, maybe it's because I have become a little bit more gentle and guiding as opposed to domineering and forceful. /And I realized that I have this ability to make people feel better. And that can't be bad, that's got to be a good thing, you know, for a kid. /So I thought in my head, I would talk to my wife about having a child. walk away from interactions with him "feeling better about that interaction.

157. S. felt "an enormous release" when he realized that he had changed into a person who was helping other people feel better about themselves.

158. S. believes that the change he has experienced -- that he has become "a better. kinder, gentler. maybe wiser person -- came about "through the greater power of God." or through the love he has with his wife.

159. The positive changes that $S$. experienced himself was something that he felt "was good for a child" and for himself. He "wanted to share that with somebody."

160. S. found that all of a sudden he "wanted to become a teacher" to a child. He wanted to pass on his spiritual guidance to someone who needed it.

161. S. gets several phone calls a day from people asking for personal advice. He and his wife don't know why people call him, but he wonders if maybe it's because he has become "more gentle and guiding as opposed to domineering and forceful."

162. S. realized that he had "the ability to make people feel better" and that this had to be a good thing for a kid.

163. S. decided in his mind that he would talk to his wife about having a child. 
Right. Yeah, so tell me about the conversation. Before the conversation you were thinking what, you weren't thinking "I really want to have a child," it was more of a question still?

/It was a question. It was, this is starting to feel right for me, in and of myself. /But I'm part of a unit now.

\section{Okay.}

And the unit has to be working properly

-- it again goes back to my military training. You know, it doesn't matter how good you steer, if the track is blown on the tank. You know, it's just the way it is. /So I started to think. this is something I would like to bounce off my wife and see how she felt about it. See if maybe she was thinking along the same lines as I was as far as children.

\section{Right.}

/We had both discussed previously that we didn't want children. we didn't think we were the right people to have children.

\section{Right, right.}

Maybe we didn't think we deserved children. I really can't say for sure if it got that far -- but it definitely felt that way.

\section{Yeah, yeah.}

/And uh, so I took my wife out for Valentine's Day. And uh, while we were sitting at Valentine's dinner um. I asked her, I brought it up. that I thought maybe it would be kind of something I wanted to discuss, having a child. /And
164. At the point when S. decided to discuss having a child with his wife. it was still a question for him. He felt that "this is starting to feel right for me. in and of myself."

165. S. recognized that he was "part of a unit" in the decision to have a child. He felt that "the unit has to be working properly" in order to make the decision.

166. S. felt that the idea of having a child was "something I would like to bounce off my wife." to see if she was having similar thoughts about it.

167. S. and his wife had previously discussed having children but they "didn't think we were the right people to have children."

168. S. wonders if he and his wife didn't think they "deserved" children. It felt that way to him.

169. At a Valentine's Day dinner, S. told his wife that he wanted to discuss the possibility of having a child. 
rather than her being surprised, or shocked or anything like that. she kind of had a sigh of relief. She smiled, her eyes smiled. And she started to tell me what she had been thinking about having children, um, and the way she thought a child would be incorporated into our lifestyle. And she wasn't trying to convince or present an argument. she was just telling me that she started feeling more and more that she thought it would be nice to have a child. that she felt that her love could be more channeled into a child than it could be into me. $/ \mathrm{Um}$. I have a tendency to feel that she's smothering me when she's so, so doting and forever "where are you. I need you, I just want to spend some time with you. this is our only weekend, we have forty-eight hours to make the best of it." you know...I had other things planned. [laughs]

\section{Um-hm.}

/And uh. you know she started to tell me how she was feeling and um, at that moment. definitely at that dinner, it went from "we're never going to have children" to "let's make this happen." 几m. yeah. I did not know I wanted kids for sure until I saw my wife's reaction.

Okay, so that was a moment when it just...

Correct.

...something clicked and you were like, okay, I can do this?

/Yes. We can do this.

Yeah, right.
170. S.'s wife was not surprised or shocked at his interest in having a child. Instead. she expressed "a sigh of relief." Her "eyes smiled" and she told him what she had been thinking about having a child, not as an argument for doing so but just to tell him that she had been thinking that it would be nice to have a child and that "her love could be more channeled into a child than into him."

171. When S.'s wife dotes on him and demands his time and attention. he tends to feel that she's "smothering" him.

172. When S.'s wife told him how she was feeling about having a child, "it went from 'we're never going to have children' to 'let's make this happen."

173. S. wasn't completely certain that he wanted to have children until he saw his wife's reaction to him when he brought up the subject to her.

174. Before discussing the idea of having children with his wife, $S$. knew that he could do it but he wasn't sure that they could to it together. 
I knew I could do it. At that point I knew I could do it. I wasn't sure we could do it. /And more important. I wanted to know if she could do it, without me. You know, because that's always a possibility. /I've... fortunately now I just passed my mark where I don't have to be called back to service. But until recently I was -- I mean, I get, I got called back for the Gulf. I got called back for the three stand-downs that came after it. And uh, I work in security here. um, unfortunately my wife doesn't understand that oftentimes the inherent risks that come with responding to a call at two o' clock in the moming.

\section{Right.}

You know, that I do understand. You know, drunk people react differently than sober people. And agitated people who are locking their spouses out of their houses at married student housing might always have a gun behind the door. I felt there were certain risks to my job, you know, that would present my wife as a single mom. /And I didn't know if that was something she could handle. And uh. after that Valentine's dinner I knew that it was something she could handle well.

Hm.

/So not that I really feared dying, but it was only a fair thing to assess, you know. before we ever got into it.

Right. Yeah, it's a sense of, it sounds like an awareness of your responsibility...
175. It was important to $S$. to know that his wife could raise a child without him. "because that's always a possibility."

176. Although he could no longer be called back for military service. S. has risks in his work that he feels his wife doesn't understand, risks "that would present my wife as a single mom."
177. S. hadn't known whether his wife could handle raising a child on her own. but after discussing it at their Valentine's Day dinner, he "knew that it was something she could handle well."

178. S. didn't fear dying. but he felt that "it was only a fair thing to assess" before making the decision to have a child.

Right. 
...in going into that and making the decision.

Right, right. /And like we said on the other side, while I don't feel that I ever wanted to die, and that I ever loved life less, I also don't feel that a child should make me give up what I loved before because now I have a kid and I can't make those risks and I can't take those chances. I'm always going to take chances, you know. I might be a bit of an adrenaline junky, it comes from jumping out of airplanes, you know. [laughs] /But I now know that if I should get stupid enough to where I'm dead, if I should fall through the ice at Georgetown Lake, you know, and never come back. that my child will be well cared for, that there is a support system there that is intact regardless of whether or not I'm there.

\section{Right.}

/It was kind of a big step for me to realize that I didn't run the show. you know.

\section{What do you mean?}

/Well. I felt that if I left the earth today my wife would be a pile of cinder within a week. She just wouldn't be able to handle it. /I felt that my sisters would all be without their guidance. without their support. /And my parents -- my mother's moving here next month to retire here in Montana so that we can keep a little bit of a closer watch on her. /And uh, you know my parents separated when I was a little kid and there was no real support system for them. But they were a great support system for us. /And I always thought that it was centered around me.
179. S. feels that he will always take chances. He's an "adrenaline junky." While he doesn't want to die. he doesn't feel that "a child should make me give up what I loved before."

180. S. now knows that "if I should get stupid enough to where I'm dead" that "my child will be well cared for, that there is a support system there that is intact regardless of whether or not I'm there."

181. It was a big step for $\mathrm{S}$. "to realize that I didn't run the show."

182. S. had felt that his wife "wouldn't be able to handle it" if he died, that she'd be "a pile of cinder within a week."

183. S. felt that if he died. his sisters "would all be without their guidance. without their support."

184. S.'s mother is moving to Montana "so that we can keep a little bit of a closer watch on her."

185. S.'s parents had "no real support systems" for themselves when they separated, but they were "a great support system" for him.

186. S. always thought that he was 


\section{Uh-huh.}

And now I'm realizing that people have their strengths, you know. And sometimes you have to nurture those strengths, sometimes they just, boom. pop right out on you. /But I realized that this world would run pretty smoothly without me. And uh...

Huh. So it sounds like you had a bigger sense of your own control than you'd actually needed to have?

/Correct. correct. yeah. I felt that I was pretty much in charge.

\section{Right.}

/And Pink Floyd has a neat little line in one of their songs, "it's too late to lose the weight you used to need to throw around." And it haunted me for years. Because I started thinking well. geez you know, maybe people don't need me to be this big daddy any longer. And it was, it started to feel bad. /And you know again that's part of the reason I'm having a kid is because I like that feeling.

\section{Huh.}

But in a different atmosphere, you know. /It was a pretty good release for me to know that I didn't. I wasn't responsible for the whole world.

Yeah, yeah.

You know? I guarantee you when the child comes I'll get a lot of that back. [laughs] You know, I'll feel responsible for the whole world again. responsible for supporting others. that "it was centered around me." But now he's realizing that other people have their strengths, which sometimes have to be nurtured and which other times emerge on their own.

187. S. realized that "this world would run pretty smoothly without me."

188. S. has often been haunted by the idea that people might not need him "to be this big daddy any longer." and this was starting to feel bad to him.

189. Part of the reason that $S$. is having a child is because he likes the feeling of having other people needing him for support -- "but in a different atmosphere."

190. S. found that it was a pretty good release" for him to know that he "wasn't responsible for the whole world."

191. S. feels certain that when his child is born that his old feelings will come back. that he'll feel responsible for the whole world again.

Yeah. 
/But it. it's neat because that's what a baby needs, you know.

\section{Right.}

/And hopefully, as in my marriage, when the child gets older and needs less of that. I'll learn to relinquish that control like I did with my wife.

\section{Yeah, right.}

You know, if that's possible then great. And if not, I hope my kid is like me and can stand up and say, "who the heck do you think you are. pop" you know? "I got this. You taught me. I can ride, you know. Take the training wheels off."

Well I guess one last area that I'd like to just hear a little bit about is kind of how things, how your feelings have changed, sort of, after making the decision?

/Well, um, again there was a lot of doubt whether or not we could conceive.

\section{Okay, right.}

And there was a lot of trepidation in that area. I was hesitant to have surgical procedures done on me.

\section{Sure.}

You know, with an iffy outcome. Um, I really didn't want to be that stereotypical, "honey, I'm ovulating, come home now," you know. I feared that. I feared, um, disappointments every month, you know. Geez. I'm bleeding. Geez. I'm bleeding. You know. And, and you hear an awful lot of that, fertility pills and so on and so forth.
192. S. likes the idea of feeling responsible for a child. "because that's what a baby needs."

$193 \mathrm{~S}$. hopes that as in his marriage. when his child gets older he'll "learn to relinquish that control." He hopes that if he doesn't do that his child will be like he was and will stand up and tell him to "take the training wheels off."

194. S. and his wife had a lot of doubt and fear about whether or not they could conceive a child. He was hesitant to have surgical procedures done on him. he feared having too much pressure placed on their efforts to conceive and he worried about having monthly disappointments. He had heard a lot of these sorts of stories from others. 
/And so that was a big burden and once we conceived, all of that melted away, obviously.

\section{Um-hm.}

And you know. we got to center on, wow, now we're going to have a kid.

Yeah.

/What should we do, you know, how is this going to affect us? We cheated. we took all the classes we could. Um, we went to Families First. we took their child development from zero to six months. And you know, we also took an outdoor recreation with baby class, you know. certain things that will help you with a child out in the woods.

Right.

You know, things you need to watch out for. $/ \mathrm{Um}$, we went for professional help. We went to counseling for six sessions with VRI, you know. to see about crisis management and to see about some of the issues that we thought we still had between us, /which turned out to be very, very minor.

Yeah.

Um. and once put in the right perspective we realized that we were being too persnickety and too worried about certain things just because we couldn't believe we were ready.

Yeah, right. So a lot of practical stuff and relationship stuff. How about in terms of your...that initial kind of debate that you went through, did that, has that been affected?
195. S.'s fears about their ability to conceive were "a big burden." but once they conceived all of that "melted away" and now they're focused on their amazement that they are going to have a child.

196. S. and his wife wonder what they should do to prepare for having a child. They wonder how it's going to affect them. They've taken all the parenting classes that they can.

197. After conceiving. S. and his wife went for counseling together "to see about crisis management and to see about some of the issues that we thought we still had between us."

198. S. and his wife found out that the problems between them were "very minor." He feels that he and his wife "were being too persnickety and too worried about certain things, just because we couldn't believe we were ready" to have a child. 
/Completely gone.

Completely gone, wow.

Completely gone. Honestly, I never ever question my ability to be a good father.

\section{Um-hm.}

Um. it's a wonderful thing. It takes so much of that gas and acid out of your stomach. /When you stop worrying about how am I going to take care of this baby and you start thinking about how well can I do for this child, you know. And it's become a constructive challenge instead of a debilitating, crippling fear.

\section{Yeah, yeah.}

/You know, I don't have any, any problems in my head that I had about what kind of a life I could give a child. They're gone. Now it's, it's what kind of a life can I build for my child. what kind of a life can I build with my child? /And how much money can he make as a football player? [laughs] /You know, I'm going to live vicariously through this kid. there's no doubt about it. I was a semi-pro football player...

\section{Oh, yeah?}

....and I had an injury in my back and I never did get to make it anywhere. I didn't go to college so I never got my shot at the pros. I was all-nation three years in a row in high school and, you know, so of course there's quite a bit of, of um, anticipation as far as what kind of a child is mine going to grow up to be. rou know, I mentioned earlier how I was afraid at first that my child might grow up to be a different kind of person...
199. The debate that $\mathrm{S}$. initially went through about having children is now "completely gone." He never questions his ability to be a good father. He's very happy to feeling this way and to have his worries gone.

200. S. has found that when he stopped worrying about how he would take care of the baby and started thinking about "how well can I do for this child." that it has become "a constructive challenge instead of a debilitating. crippling fear."

201. S. says he no longer has "any problems in my head that I had about what kind of a life I could give a child." Now he thinks about "what kind of a life can I build for my child, what kind of a life can I build with my child?"

202. S. jokingly wonders how much his child can make as a football player.

203. S. knows that he will "live vicariously through this kid." He was a semi-professionally football player and this makes him anticipate "what kind of a child is mine going to grow up to be."

204. S. has been afraid that his child "might grow up to be a different kind of person" than he was. He worried about how he would react 
Yeah, right.

...than I was or I am. You know, maybe my child won't stand up to everybody and every challenge. And how would I deal with that, would I call my child a pussy, would I call my child a baby, you know. And would I worry that my child wasn't manly enough, you know. /And that seems to have gone now. It seems that I feel that my child will grow up to be the best person it can be, by virtue of the fact that its parents were the best, most supportive people that my child could be.

Yeah, right.

/I have that trust in my wife now that I maybe didn't have before. I had doubts, now I have faith that my wife is going to be just as good to my child as I could ever hope she could be. $/ \mathrm{Um}$, so I don't worry too much about my wife and I being at odds on how to raise our child. Now I see it as being a team effort and you know, hopefully she sees it the same way. /You know, we don't have those kinds of conversations where geez. you know, if we get into this situation what would you do, and if we get into that situation -- we try to stay away from that. Um, again, she believes honestly that if I think it's right then she thinks it's right. And that might be chauvinistic. And it might be out-dated. But it's certainly worked for the last 5,634 years, you know of Jewish civilization. You know. So, we kind of stick to that. $/ \mathrm{Um}$, my wife has converted to Judaism.

Oh.

So my child will be born a Jew. And so that's made me feel a lot better. if his child didn't "stand up to everybody and every challenge." He worried that if his child wasn't "manly enough" that he might respond with ridicule.

205. S. has lost his fear that his child will grow up to be different than him. He feels that "my child will grow up to be the best person it can be. by virtue of the fact that its parents were the best. most supportive people" that they could be.

206. S. has a trust and a faith in his wife that he didn't have before, that she is "going to be just as good to my child as I could ever hope she could be."

207. S. doesn't worry about him and his wife "being able at odds on how to raise our child." He sees it as a team effort and he hopes she sees it the same way.

208. S. and his wife try to stay away from conversations about what each of them would do in particular situations. Instead, "she believes honestly that if I think it's right then she thinks it's right." $\mathrm{He}$ knows that this "might be chauvinistic" but he believes that it works.

209. S. feels good that his wife has converted Judaism, so that his child will be born a Jew. 
/I'm taking steps to bring Judaism to Missoula, Montana as opposed to having to leave Missoula to do that for my child. /And now it's just a matter of knocking pins down, as they stand up.

Yeah.

You know, it's uh. it's a wonderful process. It's made me grow in ways you know, that if this child is stillborn l've still learned so much from it.

\section{Uh-huh.}

You know, it'll have a place in my heart forever.

\section{Yeah.}

/Um. you know granted last week it had 136 beats a minute. so we're still going strong. /But whatever happens. it's going to be a good thing for us. And we firmly believe that we'll stick to that. /And so, you know the eighteenth birthday when it says, "I've been waiting twenty years to tell you this" [laughs] and gives us this big finger and walks out the door, you know, that'll be my wake-up call I guess and break the euphoria that I feel now. /We, uh. we are dead-set ready to be a family. And uh, we don't think, or I don't think personally inside of me, that's there's any reason why I shouldn't. /And I've learned an awful lot about loving in the last eight months and it's an amazing thing. /You know, all you see is a bump in the belly grow. You know, you don't see a baby until you look at the ultrasound. And even then, my wife is a bit of a hog, she keeps that baby to herself most often, you know. [laughs] All I get is the "ow, I'm hurting" and the "ow, I need this" and "ow, I need that."
210. S. is "taking steps to bring Judaism to Missoula" so that he won't have to leave Missoula to expose his child to his religion.

211. Currently S. feels that it's just a matter of knocking pins down as they stand up."

212. S. says that having a child is "a wonderful process" which "has made me grow in ways...that if this child is stillborn I've still learned so much from it." He says that "it'll have a place in my heart forever."

213. S.'s baby was healthy at their most recent doctor's visit.

214. S. believes that whatever happens with the pregnancy, "it's going to be a good thing for us."

215. S. believes that the euphoria he's currently feeling might not be broken until the day his child turns eighteen and "gives us this big finger and walks out the door."

216. S. says that he and his wife are "dead-set ready to be a family." He doesn't feel "that there's any reason why I shouldn't."

217. S. says that he's "learned an awful lot about loving in the last eight months," and that this is "an amazing thing."

218. All S. has seen of the baby before the ultrasound is "a bump in the belly." He says that his wife is "a bit of a hog." keeping the baby to herself while she complains to him about her pains. 
/But you know, the love that's growing is just amazing. I mean, it's so good for me, it makes me feel like a different person. Everyday. Everyday. Yeah. I enjoy it. I can't wait.
219. S. says that "the love that's growing is just amazing." that it makes him feel "like a different person." He can't wait to have a child. 


\section{Abe - Level 3}

S. says that his childhood "wasn't the best." He grew up in Brooklyn "in a place that had a lot of dichotomies." He felt that his "whole life was....at odds." He went to synagogue twice a week but the rest of the time he was in a gang with some "pretty bad kids." He "didn't see much good in people." He had two brothers who were killed. His father left home. His mother spent seven years in a mental institution. He and his siblings were raised by different relatives. He feels that even though his parents were "pretty strong people" they weren't strong enough to handle parenthood. They separated when he was young and had "no real support systems" for themselves. As an adult. S. thought "there's a lesson for me there." He wouldn't want a child of his own to have to live through what he lived through. He came to feel that "childhood wasn't all it was cracked up to be." He developed a very strong sense of not wanting to have a child. It wasn't for him. He was "dead-set against" having children.

S. considers himself to be a late bloomer as far as getting a girlfriend and getting married and having a child. He believed that he would never get married. much less have children. But he did get married at thirty, to a woman who was ten years younger than he was. She was nineteen or twenty when they got married and she wasn't in a rush to have children. She didn't think she ever wanted children. She lost interest in things quickly and didn't believe she had a maternal instinct. He describes her as "a pretty selfish person" who was honest with him about feeling that she wasn't capable of caring fulltime for a baby.

Because marriage was new to $\mathrm{S}$. and because he felt his wife was "kind of immature," he thought "that was enough of a burden." They discussed having children but they didn't think they were "the right people." He knew' that if he changed his mind about not wanting children that he could be much older than she and he could still conceive. His attitude was "we'll see what happens." It felt to him as if he and his wife didn't think they "deserved" children. They had "an understanding" that having a child "just wasn't going to be for us." Instead. they imagined themselves as "the rich. indulgent uncles and aunts." They had plenty of children in their life with whom they could play this role.

S. describes three primary areas of concern about having a child. His first concern was that he felt himself to be "a militaristic, inflexible. by the numbers, by the books kind of guy." Because he is "a big guy" he can be pretty intense and can make people do things his way. He can be "intimidating and overbearing." His past experience has taught him to detach from his emotions when pressure got high and "just go about taking care of the problems." He knew inside that this militaristic attitude was not "conducive to having a child." He describes how he used to teach his wife how to clean his bathroom and to inspect her work when she was done. He thinks that this is "a horrible thing for a child to have to grow with." He grew up with a friend whose fatiner forced his children to keep identical rooms and punished them with military exercises when they made mistakes. He doesn't want to be the sort of person who enforces such 
rigid, militaristic rules on his children. He doesn't want to be the "disciplinarian-slashbreadwinner" while is wife is the caregiver. He knew that with a child his attitude would have to be tempered with love and understanding. He would have to be more flexible in his attitude and more accepting of a child's emotions.

Spirituality was a second area of concern for $S$. when he thought about having a child. He'd "come to a crossroads" at which he'd realized that he wanted spirituality to be a part of his life. He was Jewish, but his wife and the town where he lives did not share his religion. He feared that if he had a child it would not grow up with a sense of heritage. tradition, history and faith which he felt a child needed in its early years. He felt that he couldn't give a child a sense of its heritage where he lived and because of that he felt "I wasn't really living up to my end of the faith." He wondered "how could I ask a child to take unconditionally the word of God if I wasn't really living a better life?"

A third area of concern for $S$. when he thought about having a child was the effect it would have on his lifestyle. In part this reflected his worries about the practicalities of raising a child. He felt that he and his wife "were not able to support a baby at home with a wife and me taking care of everything." He was afraid of day care and felt strongly that a child of his shouldn't be in day care until it was three or four. and that after that it should have "some interaction with other children on a limited basis." Beyond these practical concerns, he felt that he didn't have room in his lifestyle for "a dependent, needy being." He was content with his wife's negative attitude about children because it fit with his active lifestyle. He didn't want to have to give up "fishing. hiking, camping all summer." He "didn't want to be tied down with kids." He has heard stories about how the sense of responsibility that comes after having a child keeps some people from doing things they liked to do, because "you don't want to die because you have something to live for now." S. always felt that he had something to live for. He never wanted to die. He didn't need anything more to make him feel that. But he doesn't feel that "a child should make me give up what I loved before." He says that he is an "adrenaline junky" and that he will always take chances.

In making the decision to have a child. S. has been influenced by the experiences of family and friends. About a year and a half ago, several of his friends had children. These were men like him -- they "didn't have room in their active lifestyles" for children. But they started having children anyway. When he asked one friend when having a child went "from being an inconvenience to a possibility," the man described how he saw other men fly-fishing with a baby in their backpack. He said that "it doesn't have to be the end of a lifestyle. It can enhance your lifestyle." S. has a very close friend who has a two year old child and he and this friend have continued to go fishing together. They have taken the child with them "and it didn't cramp our style." He had another friend who was quite selfish, competitive with and independent of his wife. But with the pregnancy and the birth, this friend changed completely. He became "a little bit more selfless, a little bit more doting and caring" than S. thought possible. He changed from a person who never spent time with his wife until after he'd done what he wanted to do, to a person who couldn't wait to get home to his child. S. took note of this change. He thought it was interesting and he appreciated it. Another of his friends had an accidental pregnancy. 
This person was against having a child and was a "jerk" about it at first. But S. saw him change into "a doting father-to-be." He can't say whether this man ever became a better husband, but he started to really get into having a child. found ways to accommodate a child into his lifestyle, built an addition to his house and "started gearing his life toward having his child." It didn't change his lifestyle or his independence or his willingness to take risks. S. realized that the change his friend went through after his accidental pregnancy was not for the bad and that "it really made him a better person." He thought that the transformation was wonderful. As he and his wife started visiting and talking with their friends about their experiences of having children. "they were all positive." $\mathrm{S}$. began to believe that rather than a detriment. children could be an enhancement to their lifestyle.

S.'s experience with his sisters' children have also influenced him both positively and negatively. He once had the experience of taking care of his sister's new-born infant for eight months. He never formed a "paternal bond" with that child. He took care of him but it was hard work. He didn't have "that sense of joy that everybody said a parent has." The lack of feeling that S. had for his sister's child when he took care of it made him think "that was my lesson, you know. that, it wasn't for me." He hopes now that this lack of feeling was because he wasn't the child's father. He's "praying that's the case."

About the the same time that his friends were starting to have children. S.'s sister had her third child. He and his wife went to visit her with her new child. As his wife held the baby, he saw a look in her eyes that he can't describe exactly. It was a look of tenderness that he hadn't seen her show to a young child before. She looked at the baby the way she looked at him. When he saw the way his wife looked at his sister's child. he said "well, hey, you know, that's a good sign."

Another influence on S.'s decision to have a child was a conversation in which he told his father that he wasn't planning on having children because he wasn't sure that he and his wife would stay together. His father told him that one of the greatest things in his life is that no matter how his friends were feeling about him, his children were always there for him. His children would always be a part of his life, just by virtue of his being their father. His father helped him decide "that children were always there for you."

S. speaks of two aspects of his decision to have a child. He speaks of "the life change that decided to get us to think about children in the first place" and also of the process of the decision itself. He identifies several changes in his personality which were important in allowing him to make the decision to have a child. For one thing, he no longer lives the sort of life where he does things "that you can't do around children." He doesn't have to worry about bringing up the child in a bad atmosphere. He says that as he has gone through his life he's "lost a lot of parts" of himself, some for the good and some for the bad. He believes that part of growing means that "your perceptions need to change." He had to get rid of a lot of baggage before he could change his attitude. He used to feel about life that "it was only negative." He used to be selfish in the solutions he came up with to his problems - they only had to be satisfactory to him. 
S. realized that he had changed in his marriage and in his dealings with other people, he had softened his militaristic, inflexible style. He started to see that through marriage and "mellowing with age" he had been transformed from a person whose attitude was "I'll get the job done. sir" to someone who asked "how badly does the job need to be done?" He now believes he is different. that he can handle problems in a diplomatic way that makes everybody happy. He believes that he lives his life "in a way that is not harmful to anyone else." He doesn't make it his business to make other people feel badly about themselves. He has begun "trying consciously to have a positive affect on other people's lives. He wants people to walk away from interactions with him "feeling better about that interaction. He gets several phone calls a day from people asking for personal advice. He and his wife don't know why these people call him for advice, but he wonders if maybe it's because he has become "more gentle and guiding as opposed to domineering and forceful."

S. started to realize that he had changed. that he was more of a caregiver for his wife than he'd given himself credit for. That has "kind of assuaged that fear" about his militaristic personality. He realized that he had "the ability to make people feel better" and that this had to be a good thing for a child. He believes that he has "enough love and enough patience now where I can temper both and...do right by a child." He felt that these changes were "good for a child" and for himself. He "wanted to share that with somebody." He found that all of a sudden he "wanted to become a teacher" to a child. He wanted to pass on his spiritual guidance to someone who needed it.

When he realized that he had changed into a person who was helping other people feel better about themselves. S. felt "an enormous release." He believes that the change he has experienced -- that he has become "a better, kinder. gentler, maybe wiser person -came about "through the greater power of God," or through the love he has with his wife. Being able to see the world in a positive light has been a big change in his life and in his marriage. For the past six years, he says he hasn't "been able to shake that... happy feeling." He thinks "it might be here for awhile."

Changes were happening in S.'s marriage as well. Initially in their marriage his wife went from being "a sweet Montana girl to a semi-cynical New York wife." Because she had not had the range of experience that he had, she had to take his word about "what's out there." They had "a bit of a rough time" in their marriage. where they were both too hard-headed and cynical. S.'s family lives on the east coast. He says that his wife's family is "not a very loving family, they don't really take care of each other" in the way that he is used to. When his wife saw how close and connected his family is in spite of being thousands of miles apart, "she felt that that was missing in her life" and she "wanted to extend our family."

As S.'s attitude about life changed, so did his wife's. They both realized "that it was a happy life, it was a good life." He realized that he had had the wrong idea about "what a child did to a marriage and to... lifestyles." He started to realize that the feelings he was having about children "really weren't that contradictory toward my lifestyle." They might not make him into a different person but rather into a better person. In 
addition, he realized that having a child might actually benefit his marriage. When his wife dotes on him and demands his time and attention. he tends to feel that she's "smothering" him. Because he is away from home quite a bit. his wife thought that having a child would make her less lonely and keep her from nagging him about going away. He thought that his wife perceived this as "leverage." but in fact he liked the idea that having a child would let him go on his fishing trips.

S. recognized that in making the decision to have a child he was "part of a unit." He believes that "you come to the point where the roads cross" and you decide to become one, to "give up that individuality." He felt that "the unit has to be working properly" in order to make the decision. He and his wife had assumed the roles of teacher and student. but these roles shirted and became equal, husband and wife. They were "a lot more on equal footing." He no longer had to spend all his time trying to keep his wife happy in order to keep her doing what he needed from her. He doesn't know whether the change in roles in his marriage was a "credit" to his wife or whether he's losing his ability to maintain power and control. But he found that that with this change "it was no longer a job to be a husband. It was just a nice thing."

In addition, $\mathrm{S}$. noticed that his wife's self-sufficiency and self-confidence was rising. Her ability "to deal with things" surpassed what he had given her credit for. She completed a program which allowed her to run her own business and to schedule appointments around his work schedule, so it would be possible for each of them to be with a child at different parts of the day and the child wouldn't need "day care or outside influences." Because of her trust in herself, he came to trust her more. And he has a trust and a faith in his wife that he didn't have before. that she is "going to be just as good to my child as I could ever hope she could be." Out of the changes in his marriage. S. and his wife began to desire a child: "In ways you can't ever describe, we felt we could share this love with a child." They "got to the point where we really felt that we needed children." This sense of needing children came from their desire to share part of their life with someone else. He says that "for whatever reason we felt the need to have children all of a sudden."

S. says that he has "started to look at myself now -- as opposed to looking at myself in the past." He had always believed that "I am what made me what I am." that "all my past is there." But he came to the conclusion that had grown past that, that "I am no longer what I was that made me what I am now." One aspect of this change has been his perception of the place where he lives. After living in Montana, he found that "what I felt was out there wasn't any longer." He "lived in a different world." The move from New York to Montana was a big lifestyle change for him with regard to "what you would subject your child to once they go out into the world." He had found that while people in New York could act very nice, they might have different motivations than they were showing you. As a result, it took him a long time to believe that people in Montana were sincere and that they weren't just putting on a front. He believes that people in Missoula "actually have a community feeling." They give to others even when they have nothing to gain by it. He started to realize that Missoula was "a nice place." Children here were happy, and he was happy. He felt layers coming away from him. He "started to see the 
world for being good" and started thinking that he'd "like to share it with somebody." He found that he didn't have to hold onto the anger that he'd felt for most of his life. He began to get past his idea that childhood wasn't so great.

At the same time, S. started to feel the conflicting aspects of his spiritual life "melding together." He says that he is not a model Jew or a model human being. He has selfish needs and at times he places "other priorities higher than what the Bible says" he should. He understands and accepts this about himself and he doesn't beat himself up for it. But his religious beliefs are an important part of his life. He believes that "we all have our revelations, we all have our callings." He refers to faith as "Fantastic Adventures In Trusting Him." As he thought about his spiritual needs in relation to having a child. he looked at his capabilities and beliefs in the present and thought that if he needed a synagogue here he could take steps to have one built or brought here and that he could travel if he needed to for occasions and holidays. His wife has converted to Judaism so that his child will be bom a Jew. He is "taking steps to bring Judaism to Missoula" so that he won't have to leave Missoula to expose his child to his religion. When he realized that his child could in fact be immersed in Judaism, he felt that this "was no longer a problem."

$\mathrm{S}$. is accustomed to having other depend on him. He was the youngest male in his family, but because his older brothers were killed his sisters and his mother came to rely on him for financial support. He put them through school and bought them their houses. He was "heavily relied upon" and he lived his life "through them." When he moved to Montana, he claimed for a long time that he wanted to live his life just for himself. As a result, people stopped depending on him. He doesn't have that feeling of unconditional love and trust in his life except with his sisters, who are far away and who don't use that part of their relationship with him like they did when they were younger. Although he believes that he married his wife for "her need and dependence" on him. she became more independent and he found himself with no one to lean on him.

S. says that he "needed something that needed me." He doesn't know whether this is "psychologically sound" but he needs something that depends upon him for everything. A cat didn't satisfy this need. People suggested a puppy, but a puppy "can't communicate in the ways that a child can." He "started looking towards children" as a way to find something that would depend on him. He likes the feeling of having other people needing him for support -- "but in a different atmosphere" than he has experienced in the past. He likes the idea of feeling responsible for a child, "because that's what a baby needs." He feels certain that when his child is born his old feelings of having responsibility for the whole world will come back.

Another aspect of the decision arose from S.'s conversation with his father, which made him think differently about what children would mean in his life. They were more "than just people." They were "a part of you" that you can't disconnect. "It's a part of you that will never cease to be a part of you." It's not that he wants children in order to "extend the family line," although he believes his father will be happy that he's doing so, especially because his two brothers were killed. It appealed to him that when you have a 
child "that kid...is never going to not be a part of you. it's never going to be a part of your life that you lose." A child will always be "a good thing about your life." He knows parents whose children have gone to jail and have made their lives miserable -- but they still love their children unconditionally. He wants to have "that connection with somebody...that bond that nobody can break." He hopes to have the kind of connection with his child like he has with his sisters -- except that it will be closer for longer. The idea of children always being something good in his life appeals to $\mathrm{S}$. He feels that it would be a positive experience and he wanted it in his life.

As he watched and talked with his friends about their experience of having children, S. thought "maybe I was wrong about whether or not I wanted children at that point." He did not undertake the decision casually. He says that "somewhere deep inside of me all of a sudden I could see myself with a child." He could see himself teaching a child what he knew and spending time with a child. just for the fun of it." At first he thought about having children in a couple of years. but soon "it became in a couple of months." He went from thinking "a kid would be nice" to wondering who he could pass things on to and "who's going to unconditionally love me and trust me?" He describes himself as "a compulsive person," who feels "pretty strongly about a lot of things" and so when he gets an idea, it soon develops either into a bad idea or into something that he feels he needs to do: "all of a sudden I can't think of myself without doing that thing." In this way he started to feel that a child was something he couldn't see himself without. "It was just a matter of when." The idea of having a child "got to be a growing need" inside of him.

S. feels that once you get to the point where you feel that life is happy and good. "children come inevitably." By the same token, he believes that "if you can't see yourself in this world as a happy, functioning person." then you don't "have any business bringing somebody else in" and subjecting it to "that negative side." His focus as he thought about having a child began to shift from "the problems of having a child and the answers that might solve them" to the "answers of having a child and the problems they would solve." He wasn't thinking about his sense of what he would lose or have to change in his life. but rather "whether or not I also wanted to be a father and wanted to have that love that I felt magically appeared when the baby came out." He focused more on "the dos and don'ts" of actually having a child than on the problems that would keep him from having a child.

At this point. the debate that he initially went through about having children was "completely gone." He says that he no longer has "any problems in my head that I had about what kind of a life I could give a child." Now he thinks about "what kind of a life can I build for my child, what kind of a life can I build with my child?" He's very happy to be feeling this way and to have his worries gone. He never questions his ability to be a good father. He has found that when he stopped worrying about how he would take care of the baby and started thinking about "how well can I do for this child." that it has become "a constructive challenge instead of a debilitating, crippling fear." 
S. says that his ability to manage his earlier doubts about having children comes from his "over-blown sense of self-confidence." He believes that he can deal satisfactorily with anything that comes his way. He says that this sense of selfconfidence is "something inside of myself that was just. it calmed me. it was soothing. I realized that anything I did would work out well." At the same time. an important insight for him as he was making the decision to have a child was "to realize that I didn't run the show." He had always thought that he was responsible for supporting others. that "it was centered around me." He felt that if he died. his sisters "would all be without their guidance, without their support." Similarly. he had felt that his wife "wouldn't be able to handle it" if he died. that she'd be "a pile of cinder within a week." But now he realizes that other people have their strengths, which sometimes have to be nurtured and which other times emerge on their own. As a result. he has realized that "this world would run pretty smoothly without me." He has often been haunted by the idea that people might not need him "to be this big daddy any longer." and this was starting to feel bad to him. But in reality he has found that it was a pretty good release" for him to know that he "wasn't responsible for the whole world."

At the point when S. decided that he would talk to his wife about having a child. it was still a question for him. He felt that "this is starting to feel right for me. in and of myself." He felt that the idea of having a child was "something I would like to bounce off my wife," to see if she was having similar thoughts about it. At a Valentine's Day dinner, he told his wife that he wanted to discuss the possibility of having a child. His wife was not surprised or shocked at his interest in having a child. Instead. she expressed "a sigh of relief." She was feeling the same way. Her "eyes smiled" and she told him what she had been thinking about on the subject. She had been thinking that it would be nice to have a child and that "her love could be more channeled into a child than into him." Until he saw his wife's reaction to him when he brought up the subject to her, he wasn't completely certain that he wanted to have children. They spent about six months thinking individually about the decision to have a child. They "started talking more and more about how neat it would be to have a kid." They quickly went from "'we're never going to have children' to 'let's make this happen."'

Before discussing the idea of having children with his wife, S. had known that he could do it. but he wasn't sure that they could to it together. It was important to him to know that his wife could raise a child without him. "because that's always a possibility." S. has risks in his work that he feels his wife doesn't understand. risks "that would present my wife as a single mom." He didn't fear dying, but he felt that "it was only a fair thing to assess" before making the decision to have a child. Before the Valentine's Day conversation he hadn't known whether his wife could handle raising a child on her own, but afterwards he "knew that it was something she could handle well." He now knows that "if I should get stupid enough to where I'm dead" that "my child will be well cared for, that there is a support system there that is intact regardless of whether or not I'm there."

S. had had inside him a fear about having children, a "distant nagging that it just wouldn't work." He had feared that he would re-create in his child his own childhood 
experiences of embarrassment at his family's lack of money. This worry "became less and less of a nagging doubt. And more of an affirmation that it wouldn't be that way." He started to feel that "hopefully I wouldn't subject my child to that." He realized that he was at a point where he could support a child both "lovingly" and financially. He got a job which provided him and his wife with insurance. They felt "that's the last obstacle right there."

Before deciding to have a child, S. and his wife got pets. This was "kind of like a test" to see if they could nurture and love something that couldn't express love back verbally. He saw that his wife was capable of loving their pets. And he guesses that he "passed her test" as well. As the process of deciding to have children accelerated. they started planning "what should we do before we get pregnant and what we can wait until after." They thought about whether they should get a house or other things before having a child. He wishes that someone would grant them a million dollars because they're having a child, but he knows "it's not that way." Others have told them that they'd never have enough money or live in the right place before having a child. They told him "you just have to take the baby and grow with the baby" because they were "never going to be ready."

S. and his wife decided to start getting physically checked to see whether or not they could have children. They "fought pretty hard" to conceive their child -- or at least researched it. They had a lot of doubt and fear about whether or not they could conceive a child. One concern for $\mathrm{S}$. is that because he is a twin. he might have twins. He and his wife decided that "if we have twins we have them and if we don't, we don't." He found that he had a physical condition which made it unlikely that he would be able to have a child without first undergoing surgery. He was hesitant to have surgical procedures done on him. He also feared putting too much pressure on their efforts to conceive and he worried about continuing monthly disappointments. He had heard a lot of these sorts of stories from others. He looked into the surgeries he would need to have in order to conceive a child, but the doctors suggested that he first try to conceive without the surgery. One doctor suggested techniques that would enhance the likelihood of conception. They tried it once and it worked.

Although their fears about their ability to conceive were "a big burden." once S. and his wife conceived those fears "melted away." Now they're focused on their amazement that they are going to have a child. At the same time, some fears remain. He believes that anyone who claims not to be afraid when it comes to having a child "is probably a little bit too rigid. you know. to open up and share with a child." He believes that "the best lesson you could ever learn " is that "you are afraid and that you are doubtful and that you aren't the Rock of Gibraltar. And that sometimes it is on a wing and a prayer."

After conceiving. S. and his wife went for counseling together "to see about crisis management and to see about some of the issues that we thought we still had between us." They found out that the problems between them were "very minor." He feels that he and his wife "were being too persnickety and too worried about certain things, just 
because we couldn't believe we were ready" to have a child. They've taken all the parenting classes that they can. They wonder what more they should do to prepare for having a child. They wonder how it's going to affect them.

S. doesn't worry about being at odds with his wife "on how to raise our child." He sees it as a team effort and he hopes she sees it the same way. They try to stay away from conversations about what each of them would do in particular situations. He says that his wife has "an unconditional trust" in him. that "she believes honestly that if I think it's right then she thinks it's right." He knows that this "might be chauvinistic" but he believes that it works. His confidence in himself and his wife's trust in him make him feel that "there's nothing we couldn't do for a child and for ourselves." He is "glad to meet that challenge and hopefully do well with it when it comes."

S. has been afraid that his child "might grow up to be a different kind of person" than him. He has worried about how he would react if his child didn't "stand up to everybody and every challenge." He worried that if his child wasn't "manly enough" that he might respond with ridicule. He knows that he will "live vicariously through this kid." He jokingly wonders how much his child can make as a football player. He was a semiprofessionally football player and this makes him anticipate "what kind of a child is mine going to grow up to be." He has lost his fear that his child will grow up to be different than him. He feels that "my child will grow up to be the best person it can be. by virtue of the fact that its parents were the best, most supportive people" that they could be.

S. hopes that when his child gets older he will "learn to relinquish" the control that he will have over his child. He hopes that if he doesn't do this that his child will be like he was and will stand up and tell him to "take the training wheels off." He believes that the euphoria he's currently feeling might not be broken until the day his child turns eighteen and "gives us this big finger and walks out the door."

S. says that he and his wife are "dead-set ready to be a family." He doesn't feel "that there's any reason why I shouldn't." He says that he's "learned an awful lot about loving in the last eight months." He feels that the love for a child comes "well before the baby actually arrives." He believes that love for a child comes "when you decide to have a child or even a little before that. and that's what makes the decision so possible." All he has seen of the baby before the ultrasound is "a bump in the belly." But he says that "the love that's growing is just amazing," that it makes him feel "like a different person." $\mathrm{He}$ says that having a child is "a wonderful process" which "has made me grow in ways...that if this child is stillborn I've still learned so much from it." He says that "it'll have a place in my heart forever." Currently he feels that "it's just a matter of knocking pins down as they stand up." He believes that whatever happens with the pregnancy, "it's going to be a good thing for us." He can't wait to have a child. 


\section{Abe - Level 4}

S.'s feelings about having children have been strongly influenced by his own childhood experience, which was characterized by contradiction. conflict and violence. Both his brothers were killed when he was young and an awareness of death informs his life and this decision in many ways. The difficulty and pain that he experienced growing up made him feel strongly that he would never have children and he married a woman who shared this same feeling. He felt he did not "deserve" children and feared that if he had one he would subject it to the same negative experiences that he went through. In addition, in his adult interactions with children he had not seen in himself any paternal inclination. While his negative feelings about having children were quite strong however, there was a degree of ambivalence in his attitude. He knew that because he was much older than his wife. he had time to change his mind. He gave himself the opportunity to reconsider his decision.

S. had concrete reasons why it was impractical and unwise for him to have a child. He worried that a child would tie him down and keep him from doing the things that he loved. He worried about the possibility that he would raise a child who wouldn't be immersed in the heritage of his own religious tradition. And more importantly, he felt that he was too detached from his own emotions. too rigid and controlling to be able to raise a child compassionately. He perceived these qualities as more or less fixed personality characteristics and felt that unless he became more flexible, understanding and expressive, his role as a father would be limited to that of disciplinarian.

The process through which S. transcended his deeply-rooted negative attitudes about childhood occurred through a combination of social influences and personal growth. One crucial aspect of this process involved his observation of other men as they became fathers. He noticed how they adapted to and were changed by having children. how their lives and their personalities changed for the better, how they became less selfish and independent. more caring. concerned and accommodating.

At the same time, S. found himself going through an unexpected and fundamental shift in his view of the world: he stopped seeing himself in terms of his past and started looking at himself in the present. This transformation was spiritual in nature and it had a liberating effect. He saw that he was no longer the person he used to be and realized that major changes had already occurred in his personality, his relationships and his spiritual life. In some ways this transformation was simply a matter of his looking more realistically at the place he currently lived: the negative experiences he associated with childhood simply did not exist in his present environment. On a deeper level. this shift in perspective involved his recognizing that changes in his own personality had already occurred. Without fully realizing it, he had become more flexible, generous, expressive and wiser. These changes made him feel that he had something positive to pass on to a child.

S.'s shift in perspective also had significant implications on how he perceived his marriage and the potential effect that a child might have on his relationship with his wife. 
Again he recognized that this relationship had already changed. that he and his wife were functioning more as equals than he had previously acknowledged. His need for power and control over her and had been transformed into a faith and trust in her abilities. As he recognized this change, he became able to consider the possibility that both childhood and parenthood might be more positive than he had previously understood.

The transformation which led S. to decide to have a child thus involved not simply a change within himself at the point of the decision but also an acceptance and awareness of the changes in his life that had already taken place. His ability to embrace these changes was made possible by a deep sense of faith which gave him a feeling both of confidence in himself and trust in his wife. This faith co-exists alongside of an understated but continuing set of worries, doubts and fears. He has felt a "distant nagging" that his efforts to be a good parent will fail. He fears re-creating for his child of his own the same pain he experienced as a child. He expresses confidence that these fears will not become reality, but that confidence involves an invocation of forces beyond his own control. He "hopes" that he won't subject a child to the pain that he experienced. He "prays" that his previous lack of paternal feelings was simply the result of his not actually being a father. He acknowledges that this uncertainty exists alongside his selfconfidence, stating that fear and doubt are part of the process and that a person who claims not to feel these things is too rigid. He says that "you are afraid and that you are doubtful and that you aren't the Rock of Gibraltar." and that "sometimes it is on a wing and a prayer." Thus in making the decision to take on the responsibility of having a child, he has paradoxically had to relinquish responsibility and control. to accept that he is not the center of the world, to acknowledge that he "didn't run the show."

Although it was not a choice which he took lightly, there were moments of abrupt realization contained within S.'s decision to have a child. As he describes it, the decision had an almost magical quality. It began simply with an emotional opening to the idea -he let himself consider the possibility that he might have been wrong in his previous attitudes about children. Later he was profoundly affected by watching his wife holding a newborn child. He saw a look of tenderness and love in her eyes that moved him deeply, making conscious the dramatic transformation in his feelings about children. "Somewhere deep inside of me," he says, "all of a sudden I could see myself with a child." He thus began a process of imagining himself as a father. His earlier negative view of himself as disciplinarian who ridiculed his children for their failings began to change into an image of a father who supports his child in being the best person it can be. Instead of weighing the gains and losses of having a child, he asked himself whether or not he wanted the experience of having a child, whether he wanted to feel the love that it seemed "magically appeared" when a baby is born. Instead of thinking about the problems that a child would create, he began to consider the benefits that a child would bring.

With this internal shift, S. moved rapidly from considering the positive aspects of having a child to feeling a deep need for a child. This need arose out of his desire to have someone in his life who depenuad on him completely. In the past, his family members and his wife had been dependent on him but this was no longer the case. He says that he 
"needed something that needed me." He was strongly attracted to the idea that a child would be a permanent connection in his life. someone whom he would always love unconditionally and who would always be there for him.

Though he had undergone dramatic personal changes in his ideas about having children, S. still understood that the decision had to take place within his marriage. When he raised the subject with his wife it was a still a question in his mind. a question which had primarily to do with whether or not they were ready as a couple to have a child together. Part of his concern in this regard was his awareness of the possibility that he could die and his uncertainty about whether his wife would capable of raising a child on her own. Coming to trust his wife as they made the decision to have a child thus again had a paradoxical quality: in order to assume the responsibility of parenthood. he had first to acknowledge his lack of control, to reach the point at which he could accept the fact that "this world would run pretty smoothly without me."

S.'s wife's positive reaction when he brought up the subject of children made him feel with certainty that she was capable of raising a child on her own. It was her reaction which made him feel completely certain that he wanted to have a child.

The process of getting pregnant was somewhat stressful for $\mathrm{S}$. and his wife. But their fears and worries "melted away" when they got pregnant much more easily than they had expected. Now they have a sense of astonishment. amazement and even disbelief that they are going to have a child. The concerns which S. once saw as debilitating fears he now sees as a "constructive challenge." $\mathrm{He}$ is trying with his wife to prepare as much as possible. but he also accepts the fact that they will never be fully ready. that they cannot take care of everything they'd like to before the baby is born. $\mathrm{He}$ trusts his ability to be a good father and he believes that his wife has an unconditional trust in him. As he imagines being a father, he projects himself into the future, looking ahead with pleasure to both the positive aspects of parenthood and the conflicts that he knows will arise. He wonders how he will feel if his child turns out to be very different from him and whether as his child grows older he will be able to relinquish control appropriately. His child is already vividly alive in his mind and heart. He has felt a powerful love for that child from the point at which he made the decision to conceive. In fact. it was the love that he felt in making the decision to have a child which allowed him to be able to make that decision. That love has shown him that he is a different person than he used to be. But even now his optimism and hope and confident anticipation are informed by and co-exist with his awareness of death and his acceptance of the aspects of life that are beyond his control. He does not know what impact the child will have on his life after it is born. He knows that he cannot control what will happen in the course of the pregnancy. But he says that even if the child is stillborn it will have affected his life profoundly. 